\title{
Modelo sistémico para el manejo con SIG de indicadores de calidad de vida
}

Lic. Dante A. Barbero

Director de Tesis:

Dr. Elías Rosenfeld

Co-Directores de Tesis:

Dra. Silvia Gordillo

Dr. Gustavo Héctor Rossi

Tesis presentada para obtener el grado de Doctor en Ciencias Informáticas

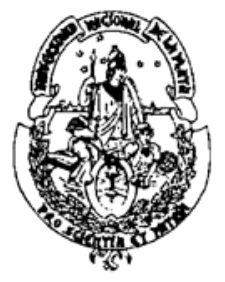

Facultad de Informática

Universidad Nacional de La Plata

La Plata, Argentina. Marzo de 2008. 


\section{Índice}

Agradecimientos $\quad 6$

$\begin{array}{ll}\text { Prólogo } & 7\end{array}$

Capítulo 1. Introducción 99

1.1 Introducción $\quad 8$

1.2 Marco teórico $\quad 8$

1.3 Problemas encontrados 9

1.4 Objetivos 9

$\begin{array}{ll}1.5 \text { Aportes originales } & 10\end{array}$

1.6 Metodología 11

1.7 Organización de la tesis $\quad 12$

Capítulo 2. Sistemas de información geográfica 14

2.1 Definición de Sistema de información geográfica (SIG) 14

2.2 Etapas de un proyecto que emplee SIG 14

2.2.1 Adquisición de datos $\quad 15$

2.2.2 Preprocesamiento 15

2.2.2.1 Conversión de formato 16

2.2.2.2 Reducción y generalización de datos 16

2.2.2.3 Detección y edición de errores 17

2.2.2.4 Mezclado (merging) 17

2.2.2.5 Matching de ejes 17

$\begin{array}{ll}\text { 2.2.2.6 Rectificación/registrado } & 17\end{array}$

2.2.2.7 Interpolación 18

2.2.2.8 Fotointerpretación 18

2.2.3 Manejo de datos $\quad 19$

2.2.4 Manipulación y análisis $\quad 20$

2.2.5 Generación del producto 24

2.3 El uso de SIG para evaluar modelos de calidad de vida 25

2.4 Estructuras de datos de los Sistemas de Información Geográfica 26

2.4.1 Características de los datos geográficos 26

2.4.2 Modelo integrado y modelo híbrido $\quad 27$

2.4.3 Formas de organización de la base de datos espacial 27

2.4.3.1 Formato raster 27

2.4.3.2 Formato vectorial 30

2.4.4 Cambio de formato $\quad 32$

2.4.4.1 Transformación de formato vectorial a formato raster 32

2.4.4.2 Transformación de formato raster a formato vectorial 33

2.4.5 Ventajas y desventajas de los formatos raster y vectorial 34 
3.1 Introducción 36

3.2 La lógica borrosa $\quad 36$

3.2.1 La lógica borrosa: Diferencias con la lógica clásica 36

$\begin{array}{ll}3.2 .2 \text { Funciones de pertenencia } & 37\end{array}$

3.2.3 Variables lingüísticas y valores lingüísticos 38

3.2.4 Definición de conjunto borroso 39

3.2.5 Operaciones con conjuntos borrosos 39

3.2.6 Operadores de T-norma y T-conorma 39

$\begin{array}{ll}3.2 .7 \text { Reglas } & 40\end{array}$

3.2.8 Sistemas de inferencia borrosos $\quad 41$

3.2.9 Etapas en la construcción de un sistema de inferencia borroso 41

3.2.9.1 Fuzificar las entradas $\quad 42$

3.2.9.2 Aplicar el operador borroso $\quad 42$

3.2.9.3 Aplicar el método de implicación 43

3.2.9.4 Agregación de las salidas $\quad 43$

3.2.9.5 Defuzificación 43

3.2.10 Ejemplo de sistema de inferencia borroso 45

3.2.11 Trabajos existentes $\quad 46$

3.3 Dinámica de sistemas $\quad 48$

3.3.1 Concepto de sistema 48

3.3.2 Concepto de sistema dinámico 48

3.3.3 Elementos del lenguaje sistémico $\quad 50$

3.3.4 Diagramas de Forrester 51

3.3.4.1 Variables de estado 51

3.3.4.2 Variables de flujo $\quad 52$

3.3.4.3 Variables auxiliares $\quad 52$

3.3.4.4 Otros símbolos 53

3.3.5 Modelado en dinámica de sistemas 53

3.3.5.1 Fase de contextualización $\quad 54$

3.3.5.2 Fase de formulación $\quad 54$

3.3.5.3 Fase de evaluación $\quad 55$

3.3.6 Arquetipos $\quad 55$

3.4 Optimización multicriterio $\quad 57$

3.4.1 Vector ideal 57

3.4.2 Optimalidad de Pareto 57

3.4.3 Dominancia de Pareto $\quad 57$

3.4.4 Frente de Pareto 58

3.4.5 No dominancia débil 58

3.4.6 No dominancia fuerte $\quad 59$

3.4.7 Trabajos relacionados $\quad 59$

Capítulo 4. Modelización de indicadores de calidad de vida $\quad 60$

4.1 Introducción $\quad 60$

$\begin{array}{ll}4.2 \text { Concepto de calidad de vida } & 60\end{array}$ 
4.3 Concepto de calidad de vida urbana $\quad 61$

4.4 Parámetros, índices e indicadores 61

4.5 Agregación de indicadores para formar índices $\quad 64$

4.6 Métodos de agregación 66

4.7 Formas de representación de los indicadores $\quad 68$

$\begin{array}{ll}4.8 \text { Clasificación de indicadores } & 70\end{array}$

4.8.1 Clasificación de indicadores según la Agencia Europea de Medio Ambiente(EEA) $\quad 70$

4.8.2 Clasificación de indicadores según el modelo Presión-Estado$\begin{array}{ll}\text { Respuesta(PER) de la OCDE } & 70\end{array}$

4.8.3 Clasificación de indicadores según el modelo Fuerza Conductora -Presión-Estado- Impacto-Respuesta(DPSIR) de la OCDE 72

4.9 Ejemplos de índices e indicadores y visualización mediante SIG 73

4.10 Otras formas de calcular el impacto de acciones antrópicas sobre una región 77

4.11 Definición de modelo de calidad de vida urbana 79

4.12 Modelos y ejemplos tendientes a evaluar la calidad de vida urbana $\quad 79$

4.12.1 Programa "Sistema municipal de indicadores de sostenibilidad" de $\begin{array}{lr}\text { la Diputación de Barcelona } & 80\end{array}$

4.12.2 Programa Ciudades Sostenibles (UNCHS-UNEP) 81

4.12.3 Auditoría urbana de la Comisión Europea $\quad 82$

4.12.4 Modelo de la dinámica urbana de Forrester 83

Capítulo 5. Frameworks para la representación de modelos de calidad de 85

5.1 Introducción $\quad 85$

5.2 Estimación de la calidad de vida a partir de índices e indicadores borrosos $\quad 88$

5.2.1 Modelos basados en sistemas de inferencia borrosos 89

5.2.1.1 Framework para el desarrollo de modelos basados en sistemas de inferencia borrosos 90

5.2.1.2 Ejemplo de uso del framework para el desarrollo de sistemas de inferencia borrosos 95

5.2.2 Modelos basados en operaciones de agregación de conjuntos borrosos 98

5.2.2.1 Framework para el desarrollo de modelos basados en operaciones de agregación de conjuntos borrosos $\quad 99$

5.2.2.2 Ejemplo de uso del framework para el desarrollo de modelos basados $\begin{array}{ll}\text { en operaciones de agregación de conjuntos borrosos } & 101\end{array}$

5.3 Estimación de la calidad de vida a partir de índices e indicadores tradicionales $\quad 102$

5.3.1 Framework para el desarrollo de modelos basados en el uso de índices e indicadores tradicionales

5.3.2 Ejemplo de uso del framework para el desarrollo de modelos basados en $\begin{array}{ll}\text { índices e indicadores tradicionales } & 110\end{array}$

Capítulo 6. Aportes del trabajo y conclusiones 112

6.1 Aportes del trabajo $\quad 112$

6.2 Conclusiones y trabajo futuro 114 
1. Framework para el desarrollo de modelos basados en sistemas de inferencia borrosos

1.1 Ejemplo de uso del framework para el desarrollo de modelos basados en sistemas de inferencia borrosos

1.2 Resultados obtenidos

2. Framework para el desarrollo de modelos basados en operaciones de agregación de conjuntos borrosos

2.1 Ejemplo de uso del framework para el desarrollo de modelos basados en operaciones de agregación de conjuntos borrrosos

3. Framework para el desarrollo de modelos basados en el uso de índices e indicadores tradicionales

3.1 Ejemplo de uso del framework para el desarrollo de modelos basados en el uso de índices e indicadores tradicionales

Referencias 


\section{Agradecimientos}

Quiero expresar mi agradecimiento al Dr. Elías Rosenfeld por haber podido formar parte de la unidad de investigación Nro. 2 del Instituto de Estudios del Hábitat (IDEHAB), donde además de conocer un grupo de profesionales de diversas disciplinas, he conocido a un gran grupo humano. El contacto con todos ellos me ha permitido crecer en todo sentido.

Quiero recordar aquí también al Dr. Gustavo H. Rossi quien fuera director de mi tesina de grado por renovar su confianza en mí y apoyarme nuevamente en esta oportunidad.

También le agradezco a la Dra. Silvia Gordillo por aceptar sin vacilaciones ser mi codirectora y por sus prácticas y precisas sugerencias que permitieron mejorar en gran medida el presente trabajo.

Al Dr. Juan Ale y a la Lic. Nélida Echebest por haber ofrecido su ayuda en caso de ser necesaria.

Este trabajo fue realizado gracias al apoyo económico de la Agencia Nacional de Promoción Científica y Tecnológica (ANPCyT), organismo que ha financiado mi beca.

Por último, a mis padres, por el apoyo que siempre me han brindado. 


\section{Prólogo}

Este trabajo aborda el tema de la calidad de vida, en adelante CV, la posibilidad de su estudio a través de conjuntos de índices e indicadores, y el uso de SIG como herramienta de análisis.

Según la Real Academia Española, la palabra indicador significa dar a entender o significar una cosa con indicios o señales. En la actualidad, muchas son las disciplinas que hacen uso de indicadores para arribar a conclusiones. Por ejemplo, en medicina, cuando un médico observa un análisis de sangre, lee un conjunto de indicadores que le permiten elaborar un diagnóstico sobre la salud del paciente.

En economía, por citar otro ejemplo, el riesgo país, el producto bruto interno (PBI) y el coeficiente de Gini no son más que simples indicadores.

Otros autores han sugerido que los indicadores ambientales pueden utilizarse como herramientas para el seguimiento del estado del medio en relación al desarrollo sostenible o a amenazas ambientales (OECD 1993).

Los índices, en cambio, combinan información proveniente de diversos indicadores en un resultado único, resultando ser un número de una magnitud generalmente adimensional que intenta sintetizar gran cantidad de información y dar una idea de la situación del objeto de estudio.

Ahora bien, habiendo definido previamente los conceptos de índice e indicador ¿qué relación tienen con la calidad de vida? y ¿cuál es el significado de ésta última?

En el marco de este trabajo se entenderá por $\mathrm{CV}$ el hecho de poder lograr consolidar un desarrollo social sin deteriorar la base de recursos: naturales, humanos, energéticos y ambientales.

Dado que si quisiéramos "capturar" la realidad el volumen de datos a analizar sería excesivo, en su lugar lo que se busca es tomar unas pocas pero significativas observaciones que nos permitan comprender de manera bastante aproximada la realidad. Es aquí donde intervienen entonces los indicadores.

Es evidente que la CV abarca diferentes dimensiones como la ética, social, ambiental, económica, entre otras, con distinto peso en el espacio y en el tiempo al igual que ocurre con los diversos problemas que deben afrontar las sociedades.

Como señala Leva (Leva 2005, pp.61) "la calidad de vida urbana no es estática en el tiempo ni en el espacio, por lo que se requerirán revisiones constantes para que los indicadores se adapten a los cambios de la ciudad y las exigencias de sus habitantes que, al mismo tiempo, varían en función de los cambios que aquellos mismos experimentan". Gómez Orea (Gómez Orea 2003) también pone de manifiesto el carácter dinámico de la CV en lo que respecta a sus dimensiones espacio-temporales al señalar que "en esquema la calidad de vida de un individuo está determinada por la integración de tres componentes: nivel de renta, condiciones de vida y trabajo y calidad ambiental, con distinto peso según momento y lugar. Siendo los problemas y aspiraciones de la sociedad cambiantes, en el tiempo y en el espacio, la importancia relativa de los citados aspectos, es también variable".

Por lo tanto, para el estudio de la CV será necesario contar con un conjunto de indicadores para describir cada una de las diferentes dimensiones que abarca el concepto de CV. Desde luego que este conjunto debe ser diseñado por un grupo 
multidisciplinario de expertos en el tema. Estos indicadores pueden clasificarse en objetivos y subjetivos, siendo los primeros los que intentan precisar lo que la gente realmente necesita y los últimos lo que la gente cree necesitar.

Puesto que distintos grupos sociales perciben las cosas de distintas maneras, un estudio que intente dar cuenta de la calidad de vida no puede tener un modelo aplicable a todos los lugares por igual. Un modelo de $\mathrm{CV}$ deberá tener en cuenta necesariamente las particularidades de la región bajo estudio.

Por ser la CV un tema que presenta cambios en el espacio y en el tiempo no es de extrañar que varios autores hayan usado SIG como herramienta para su análisis. Ocurre, sin embargo, que la modificación de tales indicadores no suele ser un hecho aislado y que, dada la naturaleza interdependiente de la realidad, el cambio en un indicador normalmente implica cambios en otros indicadores. Por este motivo, la actualización de aquellos indicadores modelizados mediante SIG se torna una tarea de difícil mantenimiento. No obstante, existen en la actualidad técnicas para tratar con el manejo complejo de dependencias. Una de ellas son los patrones de diseño, que representan el último eslabón en desarrollo de software bajo el paradigma de la programación orientada a objetos. Mediante esta técnica, se construirán 3 frameworks para abordar el tema de la calidad de vida.

Dada la importancia que tiene para cualquier individuo o grupo social, no sólo desde el punto de vista político, el poder lograr una mejor calidad de vida, el presente trabajo pretende contribuir al estudio y monitoreo de la CV de un lugar, con el objetivo de detectar problemas en forma temprana y servir como base para la toma de decisiones tendientes a mejorar la calidad de vida de los ciudadanos. 


\section{Capítulo 1}

\section{Introducción}

\subsection{Introducción}

En este capítulo se presenta el proyecto del que surge la presente tesis; los problemas encontrados durante su desarrollo que motivaron este trabajo; así como la metodología propuesta y los aportes esperados.

\subsection{Marco teórico}

La presente tesis se inscribe en el marco de los desarrollos planteados por el proyecto "URE-AM 2. Políticas de uso racional de la energía en áreas metropolitanas y sus efectos en la dimensión ambiental", financiado por la $\mathrm{ANPCyT}^{1}$, proyecto $\mathrm{N}^{\circ}$ 13-04116, llevado a cabo en la unidad de investigación $\mathrm{N}^{\circ} 2$ del Instituto de Estudios del Hábitat (IDEHAB) perteneciente a la Facultad de Arquitectura y Urbanismo (FAU) de la Universidad Nacional de La Plata (UNLP).

El proyecto proponía estudiar y conocer la dinámica energético-funcional de las redes de los sectores residencial y terciario y su interacción. Los objetivos generales fueron:

$>$ Establecer las bases para la formulación de políticas de mejoramiento de la gestión, conservación y nuevas fuentes de energía en las redes edilicias y de infraestructura de sectores residencial y terciario (educación y salud pública, comercio y administración) de grandes aglomeraciones urbanas argentinas en el marco de un uso eficiente de los recursos energéticos.

$>$ Proponer normas y cursos de acción posibles en función de escenarios, para posibilitar planes alternativos de uso racional y conservación de la energía.

$>$ Proponer tecnologías adecuadas para la administración del recurso energético y la gestión y el manejo de información en las redes de los sectores a estudiar.

Entre los objetivos más específicos se hallaba la construcción de un modelo con el cual estimar la calidad de vida urbana (CVU) tendiente a una gestión territorial eficiente en la que intervenían principalmente los aspectos energéticos y ambientales. Dicho modelo

\footnotetext{
${ }^{1}$ Agencia Nacional de Promoción Científica y Tecnológica.
} 
constaba de una serie de índices e indicadores que involucraban los aspectos antes mencionados.

La metodología utilizada incluyó auditorías, diagnósticos energéticos, estudios tipológicos, perfiles de consumo y la construcción de indicadores de los recursos energéticos en relación con los aspectos sociales, económicos y ambientales.

Los beneficios que se esperaban se centraron en la construcción de indicadores, pautas para políticas, determinación de tecnologías adecuadas que puedieran facilitar considerables ahorros de energía y elaboración de pautas orientadas a la conservación y el uso racional de la energía y el incremento de los niveles de habitabilidad.

\subsection{Problemas encontrados}

Se presentaron durante el desarrollo del proyecto problemas en el monitoreo dinámico de índices e indicadores usando sistemas de información geográfica (SIG). Dada la interdependencia existente entre los distintos índices e indicadores sumado a los rápidos cambios en los datos que se usan para calcularlos, se observó que la consistencia y actualización de los mismos resulta ser una tarea difícil de llevar a cabo.

Por otra parte, ciertos datos numéricos que son usados para el cálculo de índices o indicadores en el análisis de la calidad de vida son difíciles de obtener de manera precisa. Por este motivo, la lógica borrosa se ha utilizado en el marco de esta tesis como técnica para trabajar con datos que tienen asociado un grado de incertidumbre significativo.

\subsection{Objetivos}

En relación a los problemas antes enunciados se plantea como objetivos de este trabajo el desarrollo de frameworks que permitan representar modelos sistémicos de calidad de vida basados en índices (conjunto agregado de variables) e indicadores cuantitativos que permitan relacionar los aspectos técnicos, sociales, ambientales y económicos a los efectos de medir la interrelación entre distintas variables, permitir la evaluación de sus impactos y sugerir pautas aplicables al desarrollo de políticas y cursos de acción posibles planteado en términos de ahorro de energía, mejoramiento ambiental y habitabilidad.

Siguiendo la definición de Souza de que "un framework es un diseño genérico en un dominio, que puede ser adaptado a aplicaciones específicas, siendo útil como un molde para la construcción de aplicaciones" (Souza citado en Urciuolo 2003) se desarrollará un framework para cada uno de las clases posibles de modelos sistémicos de calidad de vida basados en índices e indicadores cuantitativos (enumerados en el inciso 1.5) con el fin de evaluar la calidad de vida de la región a estudiar.

Dado su inherente carácter genérico, cada framework podrá, además de permitir ser instanciado con diferentes modelos de calidad de vida, ser usado en otros dominios donde la evaluación mediante índices e indicadores cuantitativos sea una alternativa válida. 


\subsection{Aportes originales}

Desde el punto de vista de los datos sobre los que operan, los índices e indicadores suelen clasificarse en cuantitativos y cualitativos. Como puede apreciarse en la figura 1.1 los índices e indicadores cuantitativos, que serán los interés en este trabajo, pueden clasificarse en tradicionales (cuando no hay o es muy pequeña la incertidumbre respecto del valor señalado por el índice o indicador) y borrosos (cuando existe un grado de incertidumbre significativo acerca del valor señalado por el índice o indicador). A su vez, los índices e indicadores borrosos se subdividen en 2 clases: los modelizados mediante sistemas de inferencia borroso y los modelizados usando operaciones de agregación de conjuntos borrosos. Por lo tanto hay en total 3 maneras de representar índices e indicadores cuantitativos y, por ende, 3 formas de construir modelos sistémicos a partir de ellos:

> Modelos sistémicos basados en índices e indicadores tradicionales.

Modelos sistémicos basados en índices e indicadores representados mediante un sistema de inferencia borroso (SIB).

Modelos sistémicos basados en índices e indicadores representados mediante operaciones de agregación de conjuntos borrosos.

En relación a los problemas planteados en el inciso 1.3 y atendiendo a la clasificación anterior, puede decirse que el aporte principal de este trabajo será el desarrollo de 3 soluciones genéricas (frameworks), una para cada una de las clases de modelos sistémicos antes enumerados. Cada solución, dado su carácter general, servirá como molde para poder ser instanciada con diferentes modelos sistémicos. Estas soluciones genéricas podrán ser aplicadas incluso a otros dominios diferentes al de la calidad de vida en los cuales sea válido la evaluación a través de índices e indicadores cuantitativos.

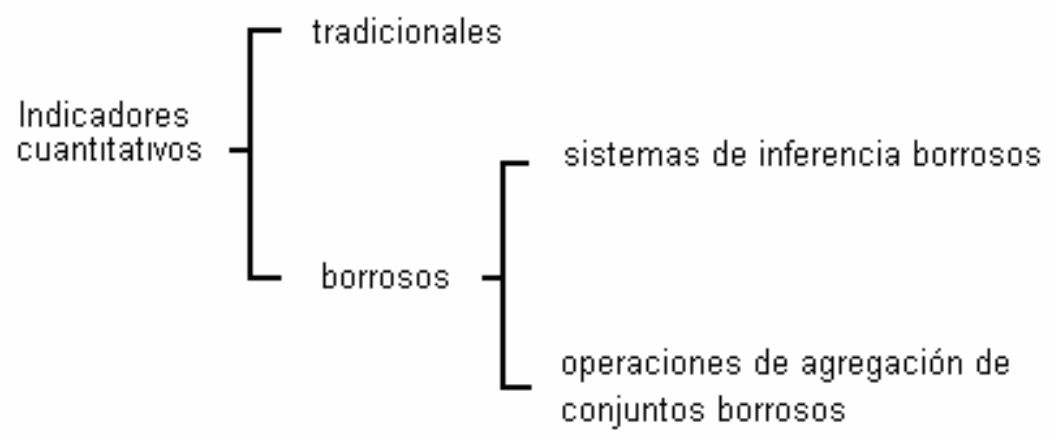

Figura 1.1. Clasificación de los indicadores cuantitativos. 
Otros aportes, ya de carácter más específico, son los relativos a las mejoras sustanciales que cada solución propuesta tendrá respecto de las soluciones existentes hoy en día.

En este sentido, el primer framework permitirá modelar las interacciones entre diferentes índices e indicadores tradicionales y tiene la ventaja de contar con un mecanismo que permite la actualización de los valores de los indicadores al mismo tiempo que mantiene la consistencia de los valores de aquellos índices relacionados con el índice o indicador que sufrió un cambio. Esto supondrá una notable mejora en términos del tiempo que se ahorra en comparación al requerido cuando la actualización y el cálculo se hacen de forma manual. El mecanismo de actualización permitirá mantener la consistencia en relaciones de interdependencia, incluso en aquellas de carácter cíclico.

El segundo framework permitirá la construcción de sistemas de inferencia borrosos (SIB). A diferencia de los sistemas borrosos conocidos hasta la fecha, la solución propuesta supondrá una significativa mejora en términos de flexibilidad ya que en un mismo sistema de inferencia borroso se podrá trabajar de manera simultánea con diferentes definiciones de operadores lógicos borrosos, diferentes métodos de implicación, diferentes métodos de agregación y diferentes métodos de defuzificación en caso de ser necesario. Estos aportes se traducirán en un mayor grado de flexibilidad a la hora construir un sistema de inferencia borroso.

Por último, el tercer framework, que también emplea la lógica borrosa, permitirá representar modelos basados en operaciones de agregación de conjuntos borrosos y contará con el agregado de un mecanismo de actualización automático. Este mecanismo es necesario dada la naturaleza sistémica de los modelos a tratar en este trabajo.

\subsection{Metodología}

Como se mencionó en el punto 1.4 los framewoks que se propondrán constituyen una solución genérica en un dominio que, en este caso, será el de los modelos de calidad de vida. Por este motivo se requiere de una metodología capaz de tratar de manera efectiva la genericidad propia de los modelos de calidad de vida sistémicos basados en índices e indicadores cuantitativos.

Los patrones de diseño permiten construir software con un alto grado de genericidad y rehusabilidad y ha sido la metodología adoptada en este trabajo para, a partir de ellos, diseñar y desarrollar el software correspondiente a cada uno de los frameworks propuestos.

Los patrones de diseño son soluciones exitosas a problemas que suelen aparecer una y otra vez durante el desarrollo de software y cuya solución ha sido documentada. Como señalan Stelting y Maasen "la idea que hay detrás de los patrones de diseño es desarrollar una forma estandarizada para representar soluciones generales de problemas que se encuentran comúnmente en el desarrollo de software” (Stelting et al. 2003). El uso de patrones de diseño tiene los siguientes beneficios (Stelting et al. 2003 op.cit): 
$>$ “Con el tiempo, podemos construir catálogos de patrones. Esto permite que los novatos en el desarrollo de software se beneficien mucho más de la experiencia obtenida durante los años.

> Hay una documentación formal sobre los compromisos adquiridos en el diseño de software: sobre los pros y contras de la elecciones en el desarrollo. La estandarización de los patrones facilita a todos los profesionales -tanto expertos como novatos- la comprensión de todos los efectos que pueden conllevar las decisiones.

$>$ Los patrones de diseño proporcionan un vocabulario común. Esto hace que la comunicación de las soluciones a los desarrolladores sea más sencilla. En vez de describir un diseño en detalle, podemos utilizar el nombre de un patrón para expresar nuestras ideas.

$>$ Podemos interrelacionar los patrones entre sí, por lo que un desarrollador puede ver fácilmente qué patrones pueden ser utilizados conjuntamente en un proyecto".

Urciuolo señala que "la tecnología de orientación a objetos; y en particular el uso de patrones, ha demostrado su efectividad para el desarrollo de software extensible y rehusable" (Urciuolo 2003).

Además, existen patrones de diseño que se pueden aplicar para el manejo complejo de relaciones de dependencias (Gamma et al. 1995, pp. 12) como el que presentan los modelos de calidad de vida.

Durante el transcurso de esta tesis se tiene previsto el desarrollo e implementación de 3 frameworks generales.

El primero de ellos servirá para representar modelos que consistan de conjuntos de índices e indicadores interrelacionados en los cuales el grado de incertidumbre de los valores tomados por los índices o indicadores no sea significativo.

Los otros 2 restantes se aplicarán a modelos en los cuales los valores de los índices e indicadores poseen un significativo grado de incertidumbre, en cuyo caso, la lógica borrosa será la técnica a utilizar junto con los patrones de diseño para abordar tal situación. La lógica borrosa ha sido utilizada como herramienta sistemática para tratar temas como la evaluación de la sustentabilidad (Phillis et al. 2001) y la calidad de vida. Esto se debe a su capacidad para tratar con datos con incertidumbre, a que permite emular ciertas habilidades humanas y manejar ambigüedades, en situaciones donde las matemáticas tradicionales no resultan ser efectivas (Andriantiatsaholiniaina et al. 2004, Phillis et al. 2001 op. cit).

\subsection{Organización de la tesis}

A continuación se detalla la organización de la parte restante de este trabajo. En el capítulo 2 se describen los sistemas de información geográfica (SIG), las etapas de un proyecto que 
involucre el uso de SIG, las principales características de los datos geográficos con los cuales trabaja un SIG, y la viabilidad de éstos como herramienta para evaluar índices e indicadores de calidad de vida (CV) y de calidad de vida urbana (CVU).

En el capítulo 3 se expone, desde el marco de la calidad de vida, el estado del arte de metodologías que han sido adoptadas para abordar el estudio de modelos sistémicos basados en índices e indicadores cuantitativos interrelacionados. Para cada metodología, se brinda una breve introducción, se comentan trabajos recientes desarrollados a partir de las mismas y/o trabajos que constituyen una referencia ineludible sobre el tema.

En el capítulo 4 comienza explicando lo que significa "calidad de vida" en el marco del presente trabajo para luego definir lo que son parámetros, índices e indicadores. Se describen también diferentes formas de clasificar a los índices e indicadores y se presentan modelos existentes que se basan en el uso de índices e indicadores para estimar la calidad de vida.

El capítulo 5 presenta los frameworks propuestos, para cada uno de ellos se explica su funcionamiento y se fundamentan las decisiones de diseño adoptadas. Luego de presentar y explicitar las decisiones de diseño adoptadas se muestra un ejemplo en cada caso para una mejor comprensión. Por motivos de claridad, el código fuente completo de cada framework y su ejemplo correspondiente fueron ubicados en el Apéndice I.

El capítulo 6 describe los aportes del trabajo como así también las conclusiones obtenidas y posibles trabajos futuros.

Por último, se incluyen en el Apéndice I el código fuente completo de los frameworks propuestos y sus ejemplos correspondientes presentados en el capítulo 5. 


\section{Capítulo 2}

\section{Sistemas de Información Geográfica}

\subsection{Definición de sistema de información geográfica (SIG)}

Un Sistema de Información es un proceso que consta de un conjunto de etapas que tiene como fin servir para la toma de decisiones. El proceso comienza con el planeamiento, la recolección de datos y el almacenamiento de los mismos, para luego ser analizados y usados. Estos datos son procesados y arrojan determinados resultados que el usuario obtiene para seguir determinadas acciones.

Según F. J. Moldes (Moldes 1995) un SIG es un “conjunto de programas y aplicaciones informáticas que permiten la gestión de datos organizados en base de datos, referenciados espacialmente y que pueden ser visualizados mediante mapas”.

Cabe aclarar que no se trata sólo de un sistema de software. En efecto, como señala la NCGIA, un SIG es "un sistema de hardware, software y procedimientos elaborados para facilitar la obtención, gestión, manipulación, análisis, modelado, representación y salida de datos espacialmente referenciados para resolver problemas complejos de planificación y gestión” (NCGIA 1990, vol. 1, p. 1-3).

Además de la capacidad propia de los SIG, técnicas ajenas a éstos han sido integradas a los mismos, por ejemplo las técnicas de evaluación multicriterio y multiobjetivo, para resolver ciertos problemas de índole espacial o territorial (Barredo Cano 2006).

\subsection{Etapas de un proyecto que emplee SIG}

Un proyecto que involucre el uso de SIG normalmente consta de 5 etapas (Star et al. 1990):

$>$ Adquisición de datos.

$>$ Preprocesamiento.

$>$ Manejo de datos.

$>$ Manipulación y análisis.

$>$ Generación del producto.

La etapa de adquisición de datos consiste en identificar y obtener los datos necesarios para la aplicación. Estos datos pueden provenir de distintas fuentes, por ejemplo: fotos, planos, mapas.

En la etapa de preprocesamiento los datos de la etapa anterior son convertidos o adaptados a los efectos de poder ser interpretados en un SIG. 
En la etapa de manejo de datos se realizan funciones para la creación y el acceso a las bases de datos de los SIG.

En la etapa de manipulación y análisis se realizan funciones que trabajan con los datos para obtener nueva información. Por ejemplo, podemos marcar una región y consultar la altura promedio en ese terreno o los puntos cuya pendiente supere los 45 grados.

La generación del producto es la fase que consta de los resultados finales de un SIG. Estos resultados pueden ser gráficos de barras, mapas marcando zonas con determinadas características requeridas por el usuario, un valor numérico que indique la altura media del terreno, etc..

A continuación se describen con más detalle cada una de estas etapas.

\subsubsection{Adquisición de datos}

Esta etapa consiste en reconocer y obtener los datos necesarios para nuestra aplicación. Los datos que se necesitan pueden ser de naturaleza muy variada: fotos, gráficos, tablas, mapas, texto, etc.. Estos pueden o no estar en formato digital. En el caso de que no lo estén, se requerirá un preprocesamiento previo para poder ingresarlos al SIG como veremos a continuación.

\subsubsection{Preprocesamiento}

Los datos obtenidos en la etapa anterior, a menudo, suelen requerir un proceso de transformación para poder ser ingresados al SIG. Este proceso incluye, por ejemplo, hacer que los datos sean compatibles con el tipo y formato de datos que maneja el sistema, compatibilizar el sistema de coordenadas, entre otras tareas.

La aplicación de las funciones de la etapa de preprocesamiento tienen como objetivo producir un mapa temático o layer.

Como se describe en (Star et al. 1990 op. cit), las tareas comunes en esta etapa son:

$>$ 2.2.2.1 Conversión de formato.

$>$ 2.2.2.2 Reducción y generalización de datos.

$>$ 2.2.2.3 Detección y edición de errores.

$>$ 2.2.2.4 Mezcla de puntos en líneas y de puntos y líneas en polígonos.

$>$ 2.2.2.5 Matching de ejes.

$>$ 2.2.2.6 Rectificación/registrado,

$>$ 2.2.2.7 Interpolación.

$>$ 2.2.2.8 Fotointerpretación. 


\subsubsection{Conversión de formato}

Star (Star et al. 1990 op.cit) destaca 2 tipos de conversiones de datos:

$>$ Conversión de estructuras de datos en formato digital.

$>$ Conversión entre diferentes medios de datos.

La primera se refiere a los cambios necesarios para trabajar con una misma estructura de datos. Esto puede involucrar cambiar el formato de los datos (por ejemplo, pasar de formato raster a vectorial) o cambiar la estructura de datos manteniendo el formato como sería el caso de pasar de la estructura arco-nodo a la estructura relacional, ambas pertenecientes al tipo de formato vectorial.

El tema de la conversión de formato se tratará con más detalle en la sección 2.4.4.

En cuanto a la conversión entre diferentes medios de datos a formato digital (ej: tablas, fotos a formato digital) pueden clasificarse en base al tipo de datos a ingresar en:

Ingreso de datos no espaciales (temáticos).

$>$ Ingreso de datos espaciales.

Los datos no espaciales se ingresan generalmente por teclado. Para ayudar en esta tarea se puede emplear una base de datos para que el DBMS(sistema manejador de bases de datos) chequee la validez de los datos que se ingresan. Otra posibilidad puede ser permitir seleccionar los datos de los campos a partir de listas previamente cargadas, lo que permitiría lograr reducir el número de errores de tipeo. Otro técnica viable, es el asignar valores por defecto a los campos y que el usuario sólo cargue los datos que difieran del valor de default.

A veces es posible usar lectores ópticos y técnicas de OCR para el reconocimiento de automático de caracteres para posteriormente ser almacenados en tablas o bases de datos.

En el caso de datos espaciales; para ingresar datos en formato raster lo común es usar técnicas de barrido de imágenes usando escáneres, videocámaras o cámaras fotográficas digitales.

En cambio, si los datos espaciales a ingresar van a estar en formato vectorial normalmente se cargan mediante tabletas digitalizadoras o sistemas de posicionamiento local o global (GPS).

\subsubsection{Reducción y generalización de datos}

El proceso de reducción y generalización de datos puede aplicarse tanto a datos espaciales como no espaciales (temáticos). Como veremos en breve, el formato de datos raster define un tamaño de celda a la que se asocian datos de interés. Tener un tamaño de celda más pequeño que el que se necesita para la aplicación implica un volumen mayor de datos a almacenar. Por ejemplo si se tiene un mapa raster con tamaño de celda de $50 \mathrm{mts}$. x $50 \mathrm{mts}$. y se desea pasar a una resolución de $100 \mathrm{mts}$. x $100 \mathrm{mts}$. promediando 4 celdas de $50 \mathrm{mts}$. 
de lado implica una reducción de 4 veces en tamaño de almacenamiento y probablemente una menor precisión del valor temático asociado debido al cálculo del promedio de las 4 celdas.

En el caso vectorial en ocasiones se reduce el número de puntos que forman una curva promediando las coordenadas de pares de puntos vecinos.

A veces los valores temáticos también se generalizan formando grupos de una granularidad más fina. Por ejemplo, se pueden agrupar las precipitaciones anuales, inicialmente expresadas en mm/año, en: escasa, normal o abundante.

\subsubsection{Detección y edición de errores}

Este punto tiene que ver con el proceso de digitalización. En el mismo es deseable que exista una rutina que testee que los polígonos que se crean sean efectivamente áreas cerradas, que no haya solapamiento de polígonos adyacentes y que no existan espacios entre polígonos que parecen ser vecinos entre sí.

\subsubsection{Mezclado (Merging)}

El proceso de merging se usa en SIGs vectoriales donde se trabaja con puntos, líneas y polígonos. En estos casos, a veces es posible transformar puntos alineados en líneas y líneas consecutivas en polígonos. En éste último caso, se define una tolerancia o radio de referencia de modo que si 2 vértices de líneas se encuentran a una distancia menor que dicho radio se asumirá que sólo uno de los vértices es el correcto y el polígono se cerrará.

\subsubsection{Matching de ejes}

Este proceso es necesario cuando 2 o más partes de un mismo mapa se digitalizan o se escanean separadamente. Es necesario entonces hacer coincidir las distintas partes y evitar discontinuidades en los bordes.

\subsubsection{Rectificación y registrado}

Estas operaciones modifican las relaciones geométricas de los objetos sin cambiar el contenido de los datos.

La diferencia entre rectificación y registrado es que el primero modifica la posición relativa de los objetos llevándolos a un sistema de coordenadas específico. El proceso de registrado, por su parte, cambia las relaciones geométricas para hacerla coincidir con otra sin importar el sistema de referencia que ésta última utilice.

Cuando se trabaja con SIG pasamos de una representación tridimensional de la superficie de la Tierra a una bidimensional que es el mapa. Este proceso de reducción de la 
dimensionalidad se lleva a cabo mediante proyecciones. La rectificación es empleada cuando se tienen mapas base en diferentes proyecciones y se quiere llevar los mapas a una única proyección. La función de un algoritmo de rectificación es cambiar la proyección de un mapa dado.

Rotaciones, traslaciones y cambios de escala también forman parte de este conjunto de operaciones matemáticas.

\subsubsection{Interpolación}

La interpolación se usa en SIG para asignar valores de atributo en lugares donde los mismos no han sido calculados usando información de zonas cercanas.

También podemos incluir aquí las técnicas geoestadísticas de simulación como el kriging de datos.

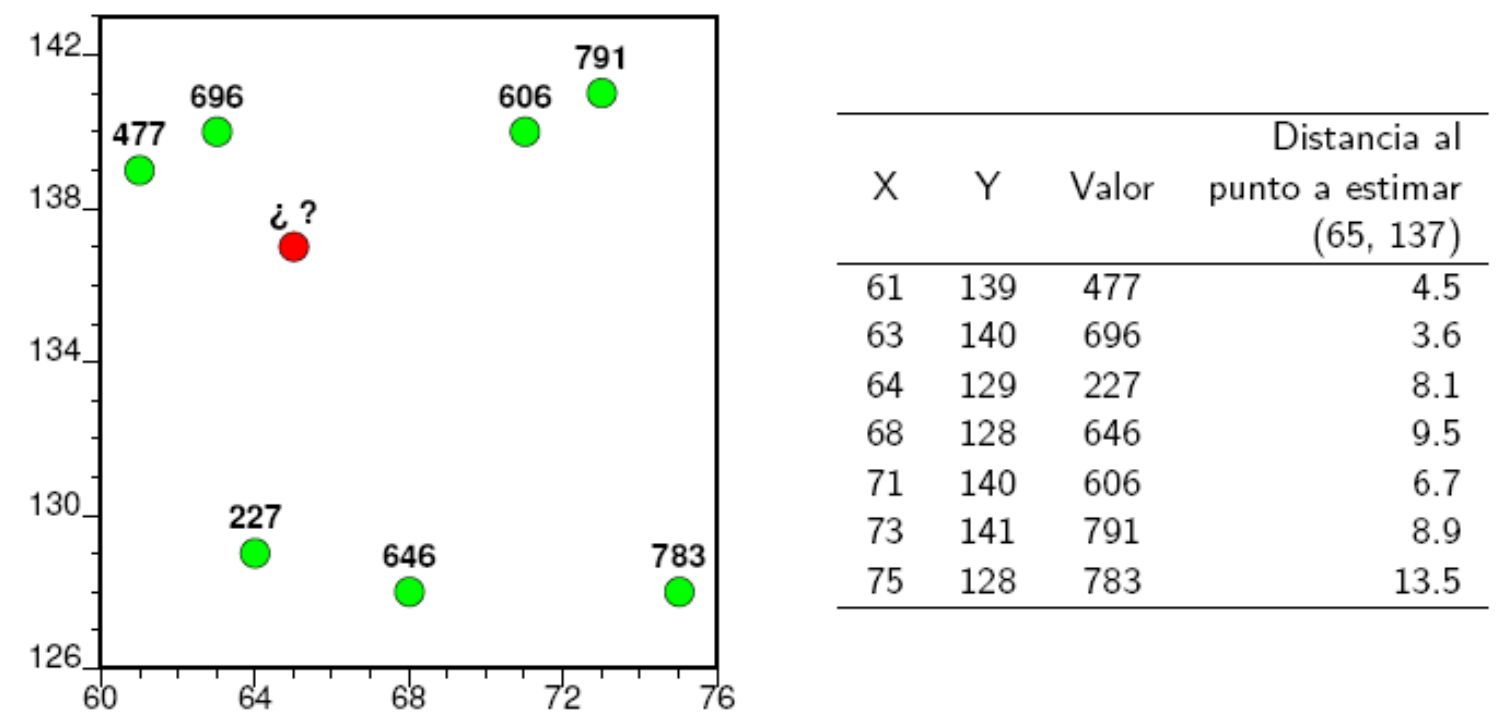

Figura 2.1. El uso de técnicas geoestadísticas como el kriging permite estimar valores en determinados lugares si se cuenta con cierta información de vecindad. Fuente: (Cassiraga 2002 op cit).

En la figura anterior se presenta un caso donde es posible aplicar métodos de kriging y, en particular, el método de krigeado ordinario. Este método intenta predecir el valor de un atributo en una posición dada a partir un conjunto conocido de pares (posición,valor) correspondientes a puntos vecinos.

\subsubsection{Fotointerpretación}

Es el proceso de extraer información útil a partir de imágenes. Las principales características que tienen en cuenta los expertos a la hora de analizar una imagen son (Star et al. 1990 op cit.): 
Tono o color: el color puede servir para determinar el tipo de suelo de una región.

$>$ Tamaño: Es posible estimar el tamaño de objetos de una imagen si se conoce el tamaño de la misma o estableciendo relaciones entre los distintos objetos.

Forma: en ocasiones es posible identificar objetos en una foto por su forma.

Textura: permite el reconocimiento de objetos basándose en cambios espaciales en el tono.

> Sombra: Las sombras en las imágenes dificultan la visualización de objetos que se encuentran en ella. Si se conoce el ángulo de inclinación del sol, la sombra puede servir para estimar la altura de los objetos.

$>$ Patrones: a veces las disposiciones espaciales de objetos sobre un terreno pueden ser de ayuda para determinar cada uno de los objetos en cuestión. Por ejemplo un sembrado consta de surcos y plantas sembradas a un distancia regular a lo largo de cada surco. Con estos datos una persona puede, en ocasiones, determinar el tipo de cultivo que se ha sembrado.

Lugar: la ubicación geográfica de una imagen puede ser de utilidad para reconocer especies autóctonas.

Asociación: el reconocimiento de determinados objetos en la imagen puede implicar la presencia de otros.

\subsubsection{Manejo de Datos}

El software de esta etapa debe permitir a un usuario crear una base de datos, insertar, modificar y eliminar datos de la base y realizar consultas acerca de los datos así como también setear permisos de acceso a los datos y operaciones permitidas sobre los mismos.

Los SIG suelen tener un sistema manejador de bases de datos mediante el cual el usuario puede especificar un requerimiento por medio de consultas (por ejemplo en SQL o QBE). Otro aspecto importante que deben proveer los DBMS es el chequeo de la integridad de los datos en las operaciones de altas, bajas o modificaciones a la base de datos (ej.: en una base de datos en formato arco-nodo no se debería permitir borrar un nodo si aún existen arcos que lo referencien).

Además, los DBMS deben proveer de un mecanismo de sincronización para evitar inconsistencias en los datos producto del acceso simultáneo de varios usuarios.

Al igual que un sistema operativo facilita el uso de una computadora, el DBMS debe facilitar al usuario el manejo de los datos de la base de datos. 


\subsubsection{Manipulación y análisis}

Tanto la etapa de manejo de datos como la de manipulación y análisis tienen objetivos similares, excepto que la última trata con los datos espaciales y la primera con los datos temáticos (no espaciales).

En esta etapa se trabaja con información espacial con la intención de responder algún requerimiento particular. Algunas de las operaciones que se realizan en esta etapa modifican la forma o estructura de un layer de un modo específico. Se pueden obtener nuevos layers de datos a partir de los ya existentes, los cuales pueden servir de datos de entrada para otros análisis.

Las operaciones más comunes en esta etapa son (Star et al. 1990 op cit):

a) Reclasificación y agregación.

b) Determinación del centroide.

c) Conversión de estructuras de datos.

d) Operaciones espaciales:

Conectividad y operaciones de vecindad.

e) Operaciones geométricas:

Rotación, traslación, escalado, rectificación y registrado.

f) Medidas:

Distancia y dirección.

g) Análisis estadístico:

Estadísticas descriptivas.

Regresión, correlación, y tabulación cruzada.

h) Modelado.

a) Reclasificacion y agregación:

La operación de reclasificación transforma los datos para poder trabajar con ellos de una manera más conveniente. Por ejemplo, si tenemos un mapa con un nivel de detalle superior al que necesitamos podemos transformar el mapa de modo que contenga un mayor grado de generalización.

Por otra parte, la operación de agregación aumenta el nivel de detalle de un mapa obteniendo un mapa con una resolución más fina.

b) Determinación del centroide

El centroide es una manera común de hallar una ubicación promedio de un polígono. Normalmente se asocia a cada polígono con su centroide en las bases de datos para luego ser usado como clave para la búsqueda de objetos cercanos a una ubicación dada.

c) Conversión de estructuras de datos 
Mediante estas operaciones se pueden transformar objetos geográficos de formato raster a vectorial o viceversa. También es posible convertir objetos, por ejemplo de formato arconodo a formato relacional, manteniendo el mismo tipo de representación (vectorial en este caso).

d) Operaciones espaciales

La clasificación mas común que se hace en relación a las operaciones espaciales distingue 3 grupos: las relacionadas con la conectividad, las que tienen que ver la cercanía o vecindad a un lugar y las que realizan superposiciones de coberturas.

$>$ Proximidad: Este tipo de operaciones se usa cuando se requiere localizar objetos geográficos a cierta distancia de un objeto o grupo de objetos. Las áreas de influencia constituyen un ejemplo típico de este caso. Pertenecen a esta clase aquellas operaciones que hagan uso del cálculo de la distancia entre objetos geográficos.

$>$ Vecindad: las operaciones de vecindad hacen uso de información topológica para averiguar relaciones entre objetos vecinos. Cuando se trabaja con formato vectorial ésta técnica permite responder consultas como por ejemplo: si una línea es adyacente a un polígono, si un polígono se encuentra a la izquierda de otro, etc..

$>$ Superposición de coberturas: las funciones de esta categoría permiten yuxtaponer diferentes layers y generar uno nuevo aplicando operaciones tales como uniones, intersecciones, etc..

Las superposiciones de polígonos en sistemas vectoriales da como resultado un nuevo layer de polígonos en tanto que, en sistemas raster, la operación equivalente sería aplicar operaciones aritméticas o lógicas entre diferentes mapas temáticos generando a partir de ellos un mapa nuevo.

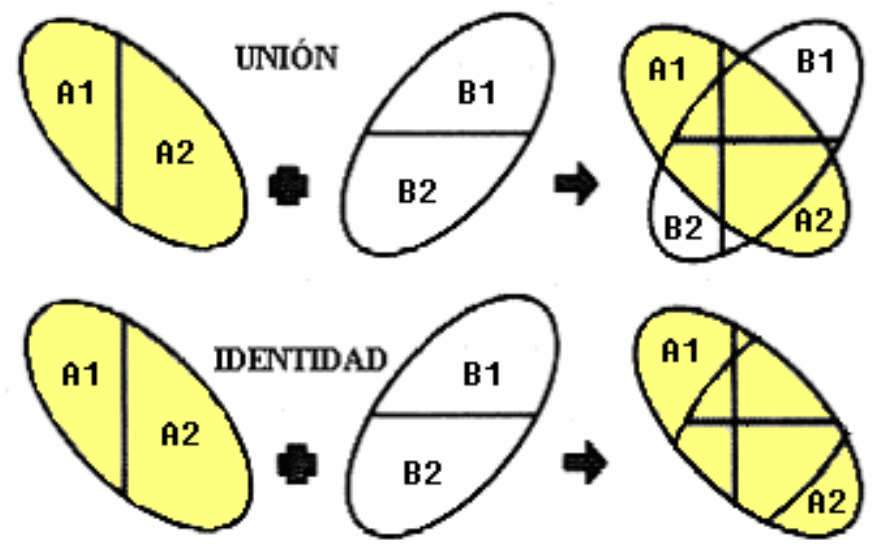



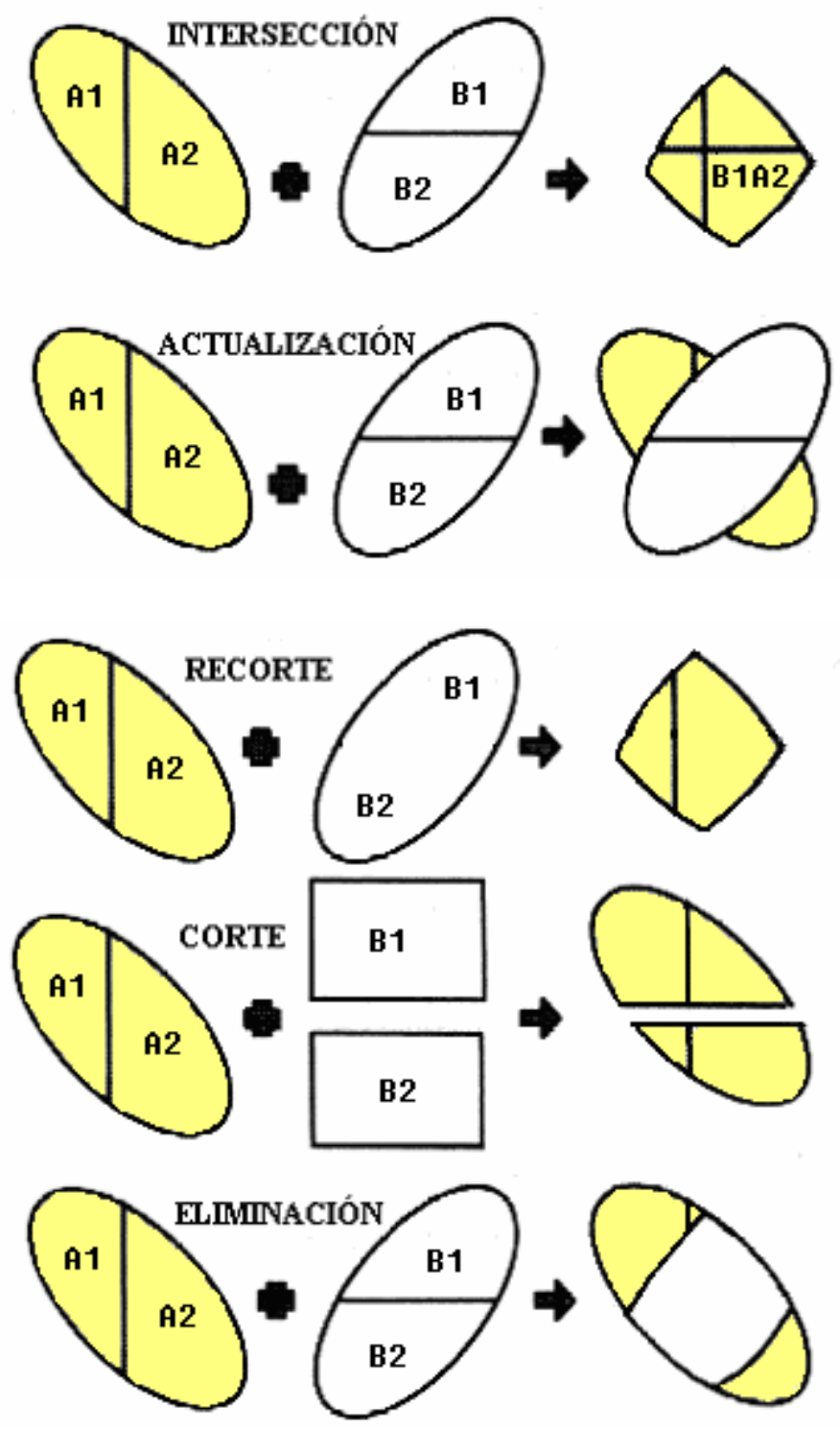

Figura 2.2. Distintas operaciones de superposición de polígonos. Fuente: Adaptado de Moldes 1995, op.cit. .

e) Operaciones geométricas

Este tipo de operaciones ya fue descripto en el inciso 2.2.2.6. También en esta etapa se aplican esta clase de operaciones.

f) Medidas

Los SIG incorporan funciones para el cálculo de áreas, perímetros y distancias entre objetos geográficos (puntos, líneas y polígonos). 
Si se usa la representación vectorial, el criterio para el cálculo de distancias puede ser el de distancia entre centroides o el de distancia mínima cuando uno de los objetos involucrados es un polígono.

Los que emplean la representación raster suelen calcular la distancia teniendo en cuenta los centroides de cada celda.

\section{g) Análisis estadístico}

Existen numerosas técnicas estadísticas de uso frecuente en SIG como el cálculo de la media, varianza, covarianza de una determinada región, histogramas y cálculos de coeficientes de correlación.
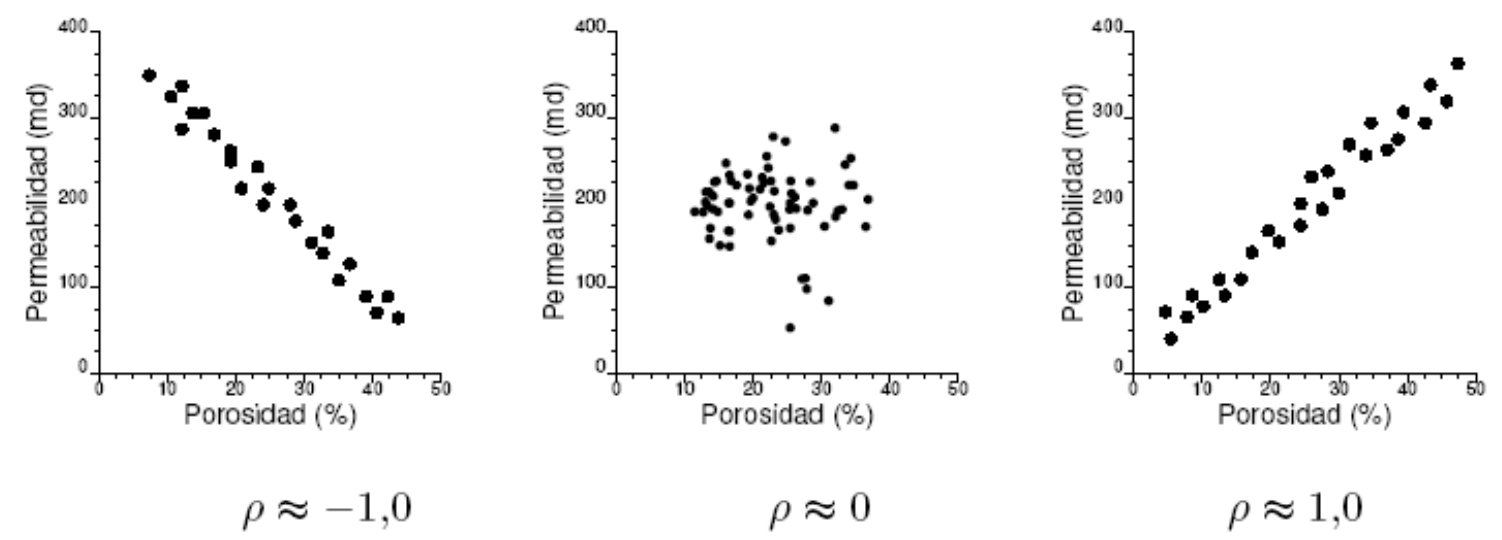

Figura 2.3. Diferentes coeficientes de correlación mostrando la relación existente entre pares de variables. Fuente: Cassiraga 2002 op cit.

Los distintos valores valores arrojados por el coeficiente de correlación en el gráfico anterior permiten observar relaciones entre pares de variables. El gráfico muestra aproximadamente: una relación inversamente proporcional entre las variables (izquierda), una relación directamente proporcional (derecha) o una situación sin relación aparente (centro).

\section{h) Modelado}

Además de las operaciones antes mencionadas, los SIG hoy en día permiten incorporar un número cada vez mayor de posibilidades de uso mediante la incorporación de extensiones que consisten en paquetes de software con rutinas para ciertas tareas de un área específica como por ejemplo el procesamiento digital de imágenes.

Algunos SIG permiten ejecutar scripts o rutinas donde el usuario programa la tarea que se desea llevar a cabo de manera automática. Actualmente, los lenguajes de programación de scripts que permiten desarrollar aplicaciones para SIG han evolucionado hacia lenguajes orientados a objetos. Esta característica es la que permite acoplar sistemas(por ejemplo, la implementación de un modelo de calidad de vida basado en alguno de los frameworks propuestos en este trabajo) y al mismo tiempo observar su localización geográfica. 


\subsubsection{Generación del producto}

En esta etapa se producen las diferentes salidas que pueden obtenerse mediante un SIG.

Entre las salidas más comunes podemos citar a los mapas, gráficos e información tabular. Dentro de la categoría de mapas, los más frecuentemente usados son:

Los mapas temáticos: muestran las variaciones espaciales de un atributo.

Los mapas choropleth sirven para mostrar espacialmente un mismo atributo continuo estratificado en rangos. Un ejemplo típico es mostrar las zonas cuya precipitación se encuentre en un determinado rango de mm/año.

$>$ Mapa de contorno: sirven para mostrar mediante líneas ubicaciones con igual valor de atributo. Ejemplos de este tipo son: isobaras, isotermas y curvas de nivel.

Mapa de puntos: muestra espacialmente puntos cuyo tamaño está relacionado con el valor de un atributo en esa ubicación.

Los gráficos y las tablas constituyen una alternativa viable para comunicar información de manera simple y sintética. Entre los más usados en los SIG se encuentran:

Gráfico de barras: sirve para observar diferencias entre categorías. La longitud de la barra indica el valor del atributo.

Gráfico de tortas: es útil para mostrar la proporción de un atributo respecto del total.

Scatter plots: permiten observar el comportamiento de un atributo contra otro.

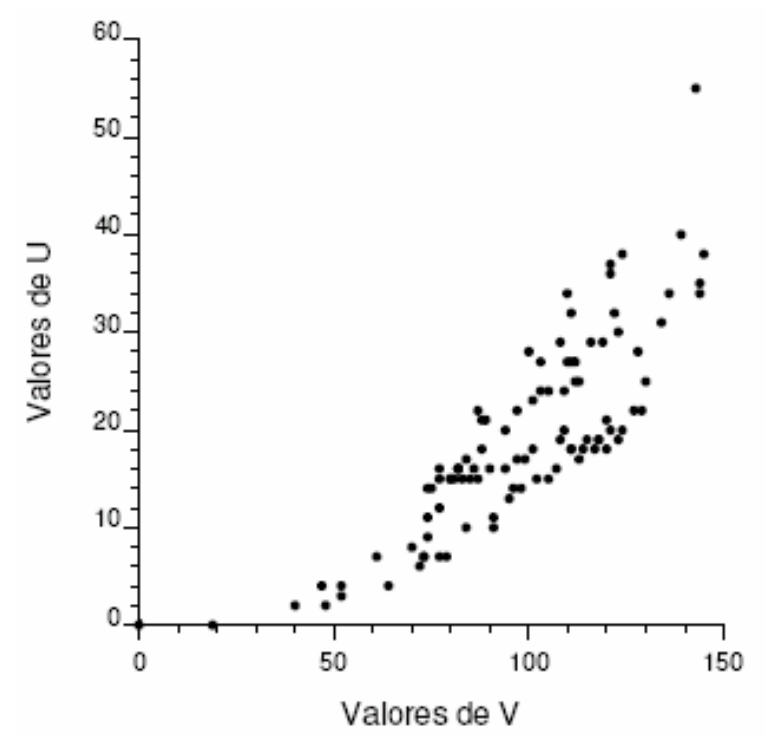

Figura 2.4. Scatter plot. Fuente: Cassiraga 2002 op cit. 
Histogramas: muestra la frecuencia de un atributo entre diferentes valores posibles.

Tablas de frecuencia e histogramas

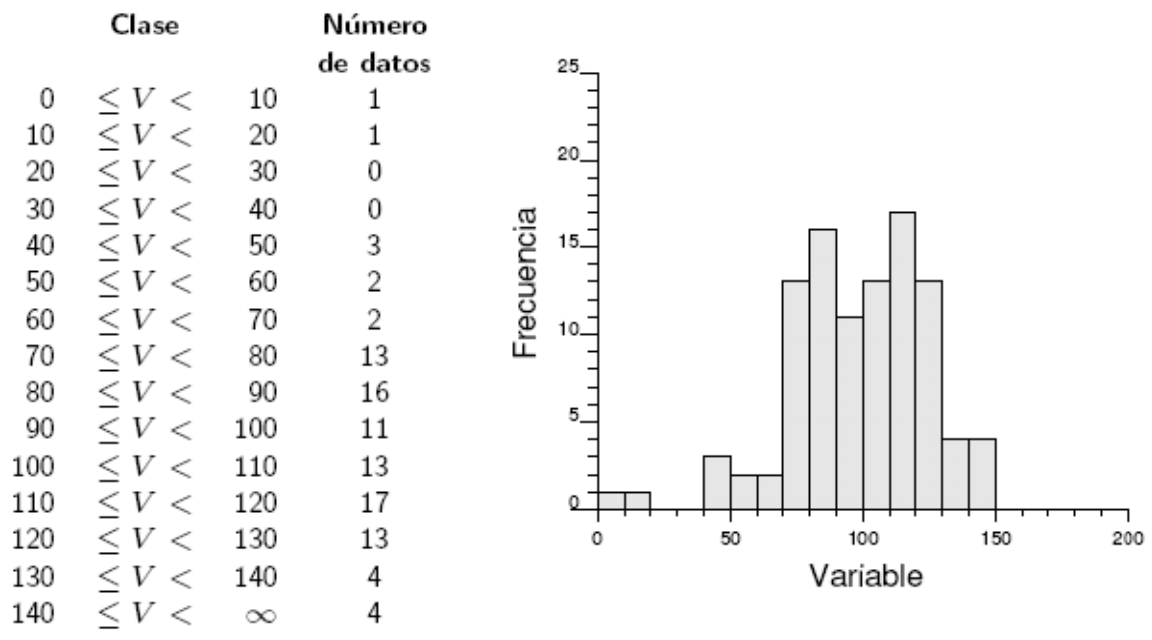

Figura 2.5. Histograma de una variable. Fuente: Cassiraga 2002 op cit.

\subsection{El uso de SIG para evaluar modelos de calidad de vida}

El uso de SIG como herramienta para la toma de decisiones puede verse como un ciclo cerrado. El mismo comienza con la obtención de datos tomados del mundo real. Estos datos se almacenan para luego, ser analizados y procesados, con el objeto de producir resultados que sirvan para tomar decisiones. Tales decisiones se aplicarán sobre el mundo real.

Algunas de las numerosas aplicaciones que se les ha dado a los SIG han sido la planificación urbana y regional y la gestión de los recursos naturales renovables. Dada su capacidad para operar con información espacial y temática de manera simultánea los SIG constituyen una herramienta de gran valor para la gestión de varios aspectos vinculados a los municipios. La gestión del catastro urbano, la planificación del transporte y usos del suelo son sólo algunas de las numerosas aplicaciones que se les ha dado a los SIG.

Dentro de la planificación urbana y regional diferentes municipios y organismos han desarrollado distintos modelos con el objeto de analizar la calidad de vida en las ciudades.

Estos modelos se componen generalmente de conjuntos de índices e indicadores, tema que será abordado en el capítulo 4. Cabe adelantar aquí que los índices son funciones agregadas de indicadores que pretenden dar cuenta de una situación sintetizando la información relevante.

Lo interesante de los modelos de calidad de vida(CV) es que muchos de sus índices e indicadores pueden visualizarse espacialmente mediante SIG pudiendo rápidamente advertir la situación de una región con un simple "golpe de vista".

Es importante destacar, en este punto, que los indicadores de calidad de vida no son independientes entre sí, en realidad, son interdependientes unos de otros. Por ejemplo, el 
aumento de la proporción habitantes/hectáreas normalmente trae aparejado un incremento en el nivel de ruido, lo cual puede a su vez puede producir efectos sobre la salud como alteraciones en el sueño...

Los puntos suspensivos anteriores denotan una secuencia de relaciones que ponen de manifiesto que la modificación de algún indicador suele ocasionar modificaciones en los valores de aquellos indicadores que dependan de manera directa o indirecta de aquel que sufrió un cambio. Es evidente entonces que existe una relación sistémica entre indicadores y que si deseamos modelizar la realidad debemos cambiar el enfoque analítico tradicional de la ciencia por un enfoque sistémico, dado que es éste último el que mejor se ajusta a la naturaleza interdependiente de la realidad.

En efecto, y tal como señala Jiménez Herrero "necesitamos una visión global integradora que persiga el conocimiento de las partes en relación al todo en evolución; en definitiva, un nuevo concepto de doctrina científica que abarque la compleja realidad que forman, la sociedad y la ecosfera. La ciencia, primero empírica después experimental, pasaría ahora a su tercer estadio como integradora o "evolucionista".

Interpretar los sistemas humanos interactuando con los sistemas ambientales y los procesos ecológicos y económicos (degradación ambiental y agotamiento de los recursos) en su plena dimensión, precisa de un tratamiento global e integrador. La teoría económica clásica ha mantenido una actitud demasiado "economicista", materialista y reduccionista. Esto, en parte, es una consecuencia lógica del auge de la visión parcelaria y el gran impulso dado al prestigioso "método analítico" de investigación científica que no contemplaba una visión más amplia de la realidad y que desconsideraba el principio de conservación de materia/energía y la ley de entropía. Una ciencia económica que no abarque y profundice en la realidad de los flujos materiales, energéticos y en las relaciones del mundo viviente, estará evidentemente limitada para responder a los problemas planteados fuera de la lógica cerrada del sistema de mercado, como son los que conciernen al cambio global ambiental y social'(Jiménez Herrero 1997).

\subsection{Estructuras de datos de los Sistemas de Información Geográfica}

\subsubsection{Características de los datos geográficos}

Un dato geográfico posee 2 aspectos (Bosque et al. 1994):

$>$ El aspecto espacial (geometría y topología).

$>$ El aspecto temático.

La geometría describe la posición absoluta de cada objeto respecto a unos ejes de coordenadas.

La topología describe relaciones entre los objetos (por ej. el punto A está dentro del polígono A).

El aspecto temático se compone de variables asociadas a cada objeto (por ejemplo: habitantes en cada lugar). 


\subsubsection{Modelo integrado y modelo híbrido}

Los aspectos espacial y el temático pueden almacenarse en bases de datos diferentes en cuyo caso se dice que el SIG tiene un modelo híbrido o puede almacenar ambos aspectos juntos en la misma base de datos dando lugar a un modelo integrado.

La base de datos temática puede ser representada de varias formas (relacional, red, jerárquica, orientada a objetos, etc.) dependiendo de la aplicación y teniendo en cuenta las ventajas y desventajas de cada modelo. Debe considerarse, además, si el SIG con el que vamos a trabajar soporta o no el modelo de base de datos que hayamos elegido.

\subsubsection{Formas de organización de la base de datos espacial}

Típicamente, la base de datos espacial puede organizarse de manera raster o vectorial.

\subsubsection{Formato raster}

En el formato raster el espacio geográfico es dividido en celdas de igual tamaño que se asocian a un dato temático.

En la figura 2.6 se muestra un mapa temático según tipos de suelo de una región. Para obtener un mapa raster a partir de un mapa base se define, en primer lugar, un tamaño de celda.

Luego se asocia a cada celda con un valor temático obteniendo como resultado una matriz que representa una abstracción del mapa base cuya precisión viene dada por el tamaño de la celda. Está claro que a menor tamaño de celda mayor precisión y mayor tamaño del archivo resultante.

No existe un tamaño de celda ideal, en realidad, depende del problema que se intenta modelizar.

Para reducir el tamaño del archivo de un mapa raster existen formatos comprimidos que permiten representar mapas usando menos espacio de almacenamiento. El más conocido es el formato raster run-length basado en el conocido método de compresión de datos. Éste método almacena pares de valores (parámetro de interés, cantidad). 


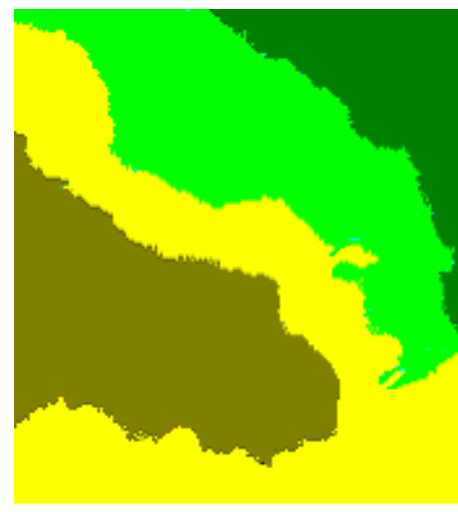

Mapa base.

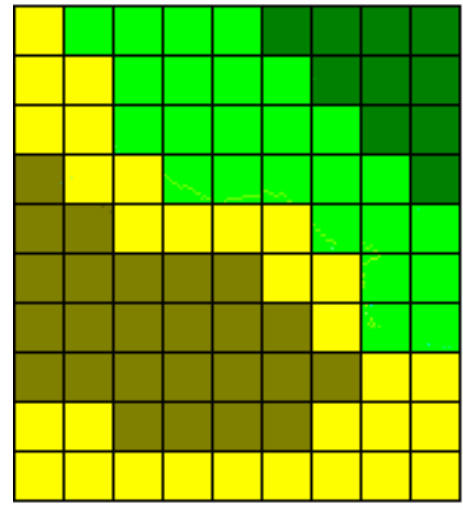

Asignación de valor único a cada celda.

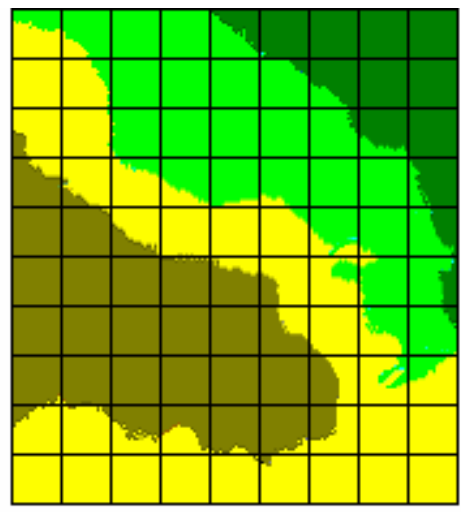

Especificación del tamaño de celda.

\begin{tabular}{|l|l|l|l|l|l|l|l|l|}
\hline 1 & 2 & 2 & 2 & 2 & 3 & 3 & 3 & 3 \\
\hline 1 & 1 & 2 & 2 & 2 & 2 & 3 & 3 & 3 \\
\hline 1 & 1 & 2 & 2 & 2 & 2 & 2 & 3 & 3 \\
\hline 4 & 1 & 1 & 2 & 2 & 2 & 2 & 2 & 3 \\
\hline 4 & 4 & 1 & 1 & 1 & 1 & 2 & 2 & 2 \\
\hline 4 & 4 & 4 & 4 & 4 & 1 & 1 & 2 & 2 \\
\hline 4 & 4 & 4 & 4 & 4 & 4 & 1 & 2 & 2 \\
\hline 4 & 4 & 4 & 4 & 4 & 4 & 4 & 1 & 1 \\
\hline 1 & 1 & 4 & 4 & 4 & 4 & 1 & 1 & 1 \\
\hline 1 & 1 & 1 & 1 & 1 & 1 & 1 & 1 & 1 \\
\hline
\end{tabular}

Formato raster resultante.

Figura 2.6. Creación de un mapa raster.

Entre las estructuras más usadas para representar datos en formato raster están:

Celdillas raster.

Raster run-length.

$>$ Árboles cuaternarios.

Las celdillas raster guardan para cada celda del mapa la descripción del parámetro de interés (por ej.: altura en metros). Esta representación es muy redundante puesto que generalmente existen conjuntos de puntos próximos con la misma característica.

El método raster run-length mejora este aspecto guardando pares (parámetro de interés, cantidad). Esto significa, suponiendo que el parámetro de interés sea la altura, que si aparece el par $(20,100)$, existen 100 puntos consecutivos que representan una altura de 20 metros. 


\begin{tabular}{|l|l|l|l|l|l|l|l|l|}
\hline 1 & 2 & 2 & 2 & 2 & 3 & 3 & 3 & 3 \\
\hline 1 & 1 & 2 & 2 & 2 & 2 & 3 & 3 & 3 \\
\hline 1 & 1 & 2 & 2 & 2 & 2 & 2 & 3 & 3 \\
\hline 4 & 1 & 1 & 2 & 2 & 2 & 2 & 2 & 3 \\
\hline 4 & 4 & 1 & 1 & 1 & 1 & 2 & 2 & 2 \\
\hline 4 & 4 & 4 & 4 & 4 & 1 & 1 & 2 & 2 \\
\hline 4 & 4 & 4 & 4 & 4 & 4 & 1 & 2 & 2 \\
\hline 4 & 4 & 4 & 4 & 4 & 4 & 4 & 1 & 1 \\
\hline 1 & 1 & 4 & 4 & 4 & 4 & 1 & 1 & 1 \\
\hline 1 & 1 & 1 & 1 & 1 & 1 & 1 & 1 & 1 \\
\hline
\end{tabular}

Formato raster

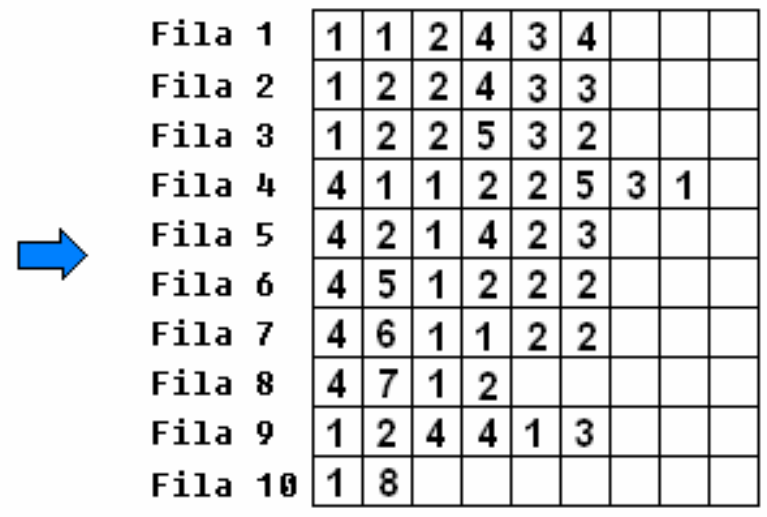

Formato raster run-length

Figura 2.7. Creación de un mapa en formato raster run-length.

Los árboles cuaternarios dividen el mapa en 4 partes, a su vez c/u de éstas partes se divide en 4 partes y así sucesivamente hasta alcanzar un nivel de detalle deseado. La idea es que a medida que se desciende del árbol se obtiene una descripción cada vez más exhaustiva, y recíprocamente, a medida que se asciende en el árbol se tiene una descripción más generalizada.

Por ejemplo, si contamos con un mapa de alturas de un terreno de 25 mts. x 25 mts. podemos construir otro mapa con las alturas del terreno anterior en unidades de $50 \mathrm{mts}$. $\mathrm{x}$ $50 \mathrm{mts}$. promediando cuatro celdas de $25 \mathrm{mts}$. x $25 \mathrm{mts}$.. Luego podemos hacer lo mismo para obtener una aproximación de 100 mts. x 100 mts.. Esta es la idea empleada en la representación de árboles cuaternarios. 


\section{Referencias}

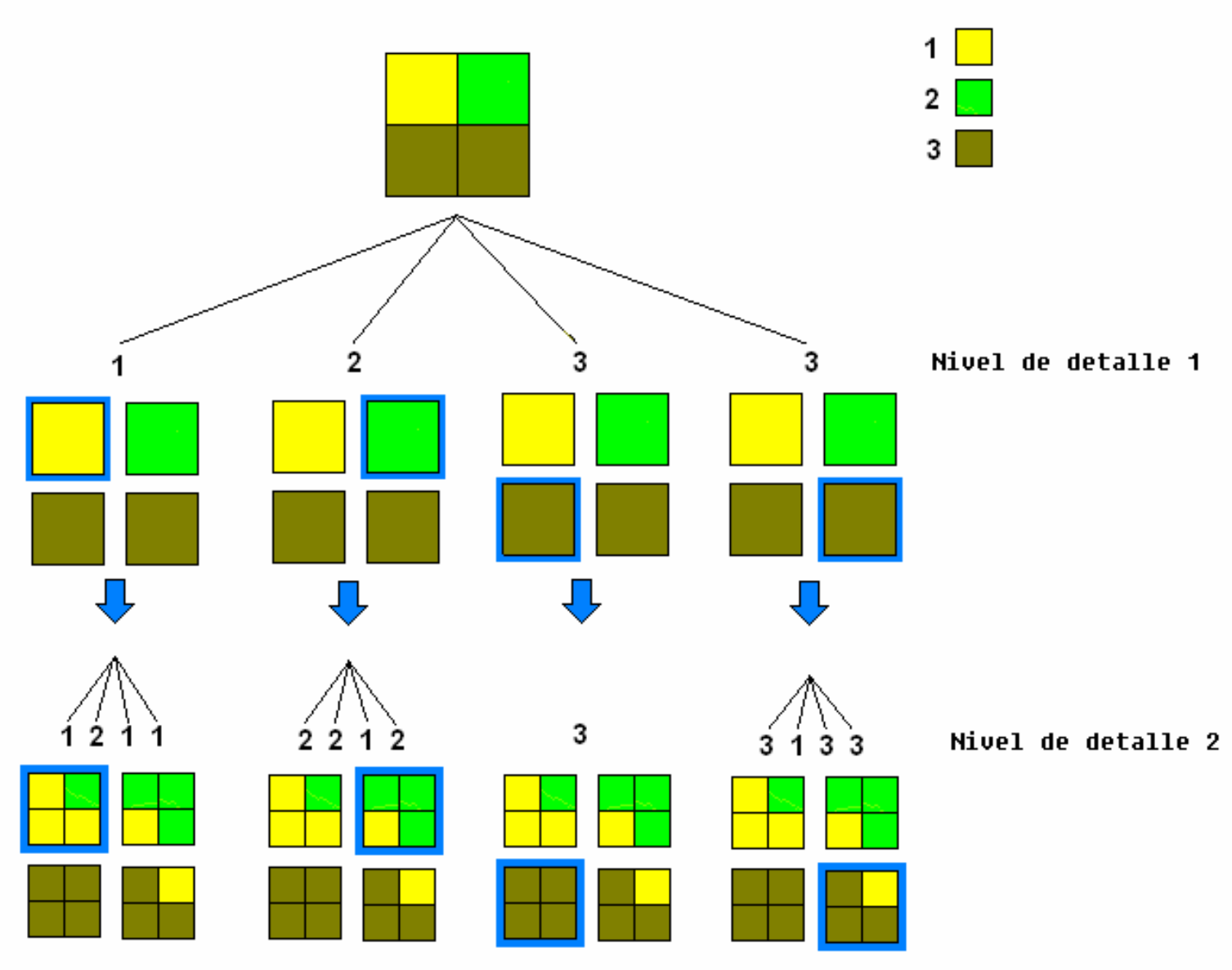

Figura 2.8. Representación usando árboles cuaternarios.

\subsubsection{Formato vectorial}

Este formato se centra en la descripción de las fronteras de cada objeto geográfico. Se suelen asociar los datos espaciales y temáticos mediante un identificador que aparezca en cada tabla.

Los SIG vectoriales manejan 3 tipos de elementos geográficos:

> Puntos: objetos espaciales sin área que tienen asociado un sistema de coordenadas de referencia (ej.: latitud y longitud).

$>$ Líneas: objeto espacial formado por una secuencia conectada de puntos.

> Polígonos: objeto espacial formado por un área cerrada.

Entre las estructuras más usadas para representar datos en formato vectorial están:

$>$ Lista de coordenadas.

$>$ Estructura arco-nodo. 


\section{Estructura relacional.}

Veamos un ejemplo de la primera estructura, la lista de coordenadas. En el siguiente dibujo se observan 3 parcelas A, B, y C junto con la línea D (rojo) y el punto E (verde) que se encuentra en la parcela $\mathrm{A}$.

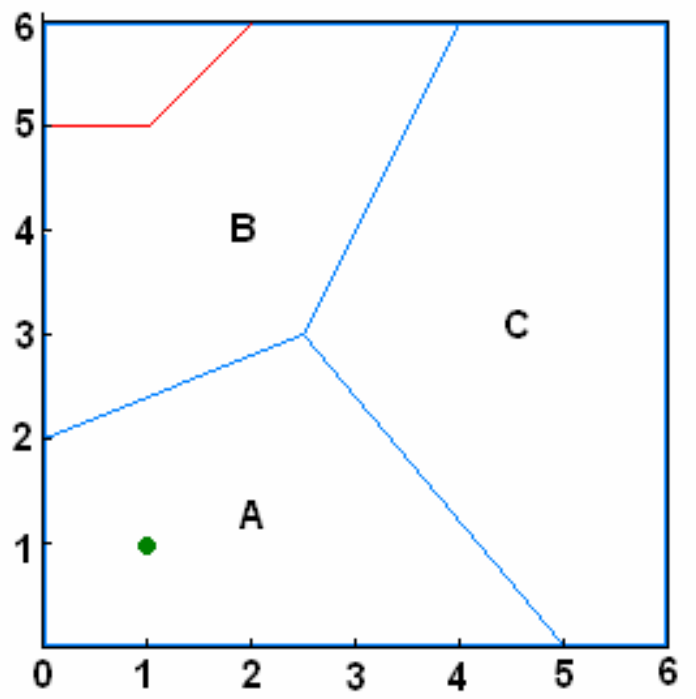

\section{Polígonos}

\begin{tabular}{|c|c|c|}
\hline 5 & $B, 5$ & 0.6 \\
\hline 0 & 2.53 & 2.53 \\
\hline 2.5 & & \\
\hline$E$ & 06 & \\
\hline 0 & 46 & 60 \\
\hline 0 & 2.53 & $\begin{array}{l}50 \\
253\end{array}$ \\
\hline
\end{tabular}

Líneas

Puntos

0,3

E,1

05

11

15

26

Figura 2.9. Representación vectorial mediante lista de coordenadas. Fuente: adaptado de Bosque et. al 1994 op cit.

Cada elemento geográfico posee un identificador: el número de vértices que posee y a continuación cada uno de ellos, por ejemplo: la parcela $A$ tiene 5 vértices $(0,2 ; 2.5,3 ; 5,0$; $0,0 ; 0,2)$.

En la estructura arco-nodo se almacenan objetos estructurados jerárquicamente. Los vértices (puntos) son los componentes básicos elementales. Se entiende por arco un conjunto de segmentos rectos orientados que tienen, todos ellos, los mismos polígonos a derecha y a izquierda. Se define como nodo a aquellos vértices que unen 3 o más líneas.

Los polígonos son conjuntos de arcos que forman un área cerrada.

A diferencia de la lista de coordenadas, en la estructura arco-nodo se almacenan también componentes topológicos, como se observa en la figura siguiente. Nótese que los arcos poseen información acerca de que polígono se encuentra a su derecha e izquierda. 

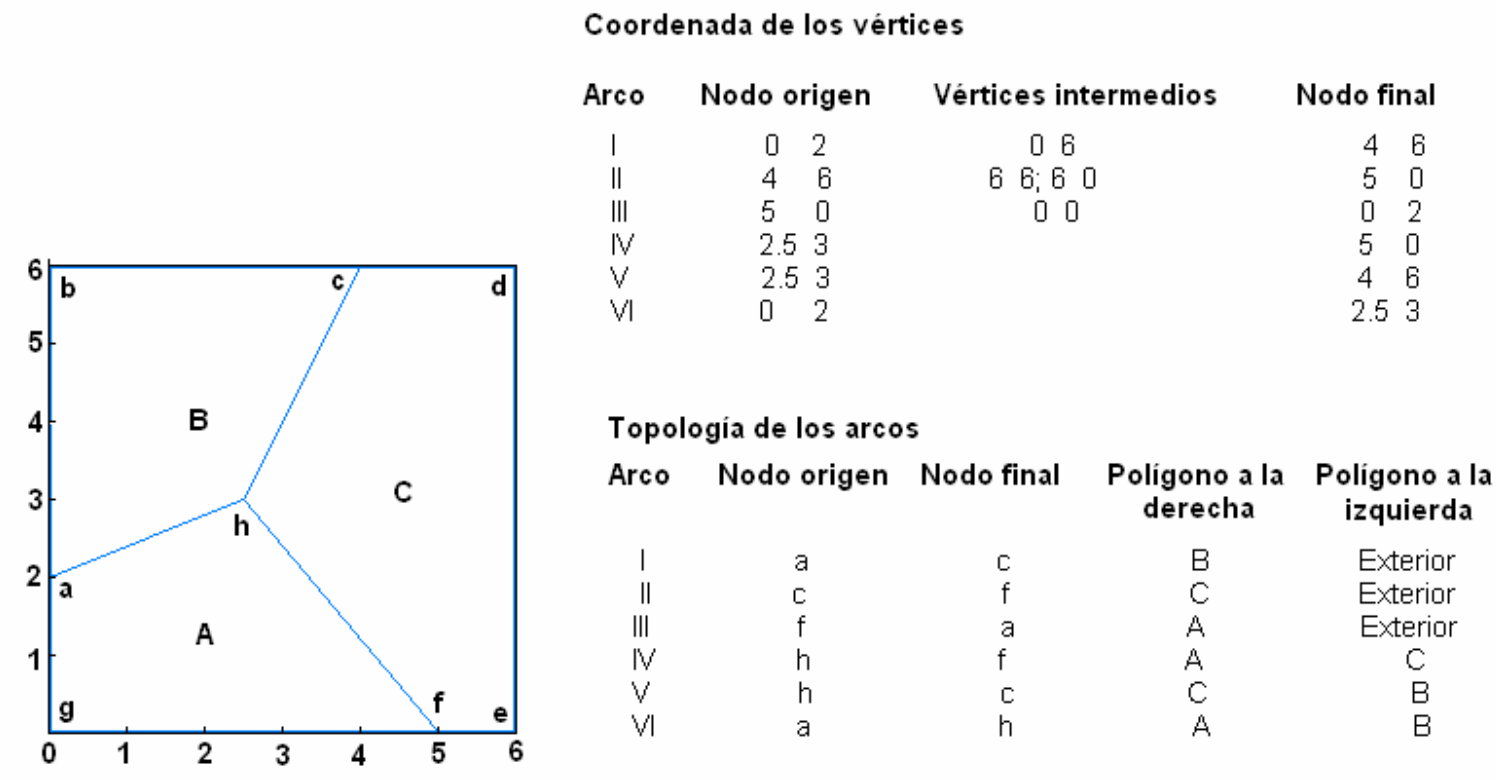

Topología de los polígonos

Polígono Arcos que lo delimitan

$\begin{array}{ll}\text { A } & \text { I, VyV } \\ B & \text { II, Vy Y V } \\ \text { C } & \text { V, IIV }\end{array}$

Figura 2.10. Representación vectorial empleando la estructura relacional. Fuente: adaptado de Bosque et. al 1994 op cit.

En la estructura arco-nodo tradicional es posible anexar datos temáticos. Así, el polígono A podría tener asociado, además de los arcos I-V-VI, datos como población, superficie en hectáreas, etcétera.

La estructura relacional es similar a la anterior, con la diferencia que la base de datos espacial se almacena en forma separada y es posible establecer relaciones por el hecho de compartir el mismo valor de identificador.

\subsubsection{Cambio de formato}

En ocasiones es necesario realizar operaciones entre 2 mapas en diferentes formatos o cambiar de formato para poder realizar una función determinada.

\subsubsection{Transformación de formato vectorial a formato raster}

Para pasar de un mapa vectorial a un mapa en formato raster se debe crear una matriz de celdas que cubra a los polígonos. Previamente se debe definir el tamaño de celda en función de la precisión requerida por la aplicación y la memoria disponible. Después de crear la 
grilla de celdas, se asocia cada cuadrícula a uno de los áreas cerradas formadas por los arcos vectoriales. "En la mayoría de los sistemas no es necesario que los arcos formen polígonos perfectamente cerrados, ya que los pasillos de menor ancho que una celda se consideran cerrados. Todas las celdas asociadas a un recinto se agrupan en un polígono y se le asocia a éste un registro en la base de datos. Los datos de éstos registros están, por lo tanto, asociados a todas las celdas que forman parte del recinto"(Moldes $1995 \mathrm{op}$ cit).

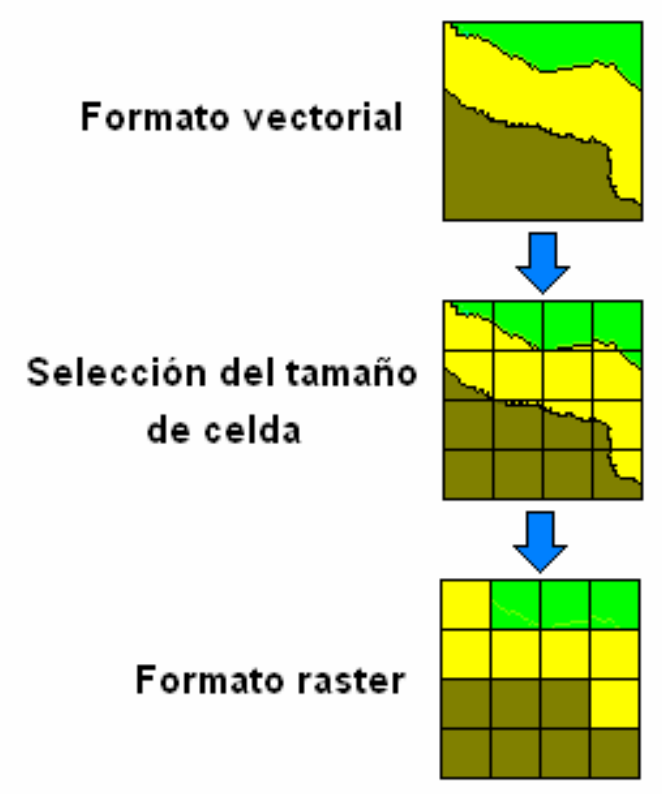

Figura 2.11. Conversión de formato vectorial a formato raster.

\subsubsection{Transformación de formato raster a formato vectorial}

Como señala Moldes (Moldes 1995 op cit) "para vectorizar un mapa raster, se generan las líneas que separan las diferentes categorías de celdillas con una línea quebrada en técnica vectorial y posteriormente se procede a la suavización de contornos, con lo que resulta un mapa vectorial.

Luego, deberá generarse la topología de este tema para que pueda ser integrado en el SIG como un mapa temático vectorial”. 


\section{Formato raster}

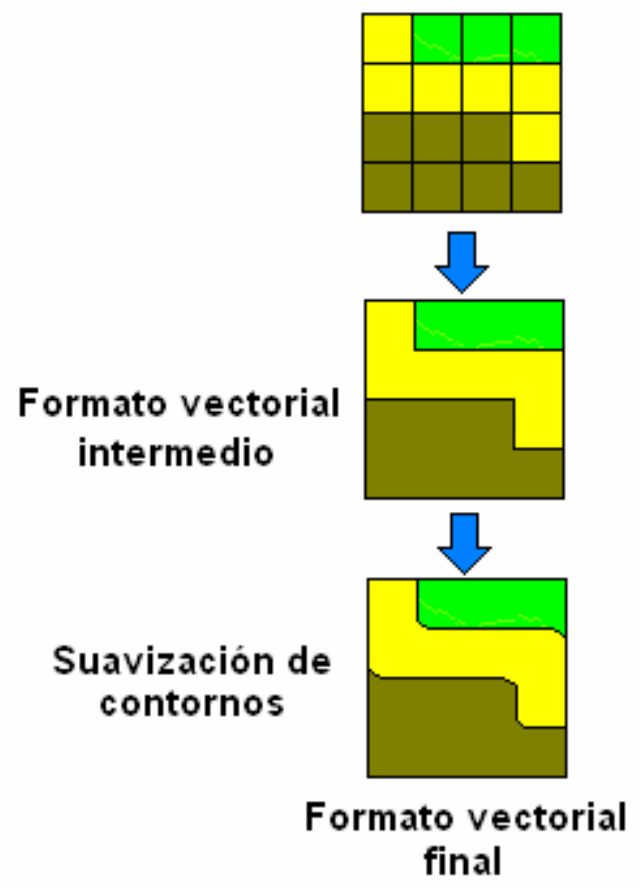

Figura 2.12. Conversión de formato raster a formato vectorial.

\subsubsection{Ventajas y desventajas de los formatos raster y vectorial}

A continuación se enumeran las ventajas y desventajas de ambos formatos (adaptado de Moldes 1995).

Entre las ventajas del formato raster podemos citar:

$>$ Es fácil introducir datos raster a partir de escáneres, cámaras fotográficas digitales o videocámaras, como hemos visto en el inciso 2.2.2.1.

$>$ La comparación o superposición de mapas temáticos es sencilla dado que se hace celda por celda operando con los datos asociados a la mismas.

$>$ Los algoritmos para trabajar con técnicas raster son, en general, más simples que los usados en las técnicas vectoriales.

Desventajas del formato raster:

$>$ Los mapas raster ocupan mucho espacio, por lo que es conveniente guardarlos en formatos comprimidos como el raster run-length para reducir su tamaño. 
Los mapas vectoriales representan mejor entidades lineales.

$>$ Las técnicas raster resuelven los cálculos de distancia y superficie con un grado de error que, según el tamaño de la celda, puede llegar a ser muy significativo. Por ejemplo, algunos sistemas calculan la distancia entre un par de celdas como la distancia entre sus centroides.

Ventajas del formato vectorial

$>$ Es más eficiente desde el punto de vista del espacio de almacenamiento. Dada su característica de dar importancia al contorno de los elementos geográficos, es más efectivo para representar entidades lineales y puntos.

$>$ El cálculo de superficies y distancias es más preciso que el sistema raster.

$>$ Es fácil modificar la escala de un mapa cuando se trabaja con esta representación.

$>$ Permite representar una gestión individualizada de las entidades geográficas; frente a la técnica raster, que identifica las clases; es decir, permite punteros precisos a la base de datos, al identificar a cada entidad individualmente; frente a los sistemas raster, que identifican la clase, por ejemplo a través de un atributo de color.

$>$ Es posible gestionar individualmente cada objeto geográfico.

Desventajas del formato vectorial

$>$ Demanda más tiempo ingresar datos en formato vectorial que en formato raster y su actualización, por ejemplo cuando se trabaja con aplicaciones catastrales, demanda gran esfuerzo y tiempo.

$>$ Las operaciones entre mapas temáticos demanda más tiempo que las mismas en formato raster.

> Para representaciones complejas como podrían ser paisajes y bosques la representación vectorial no es la adecuada. 


\section{Capítulo 3}

\section{Estado del arte}

\subsection{Introducción}

En este capítulo veremos las principales técnicas que han sido aplicadas para estimar la calidad de vida a partir de índices e indicadores.

\subsection{La lógica borrosa}

A veces los datos con los que trabajamos poseen cierto grado de incertidumbre. Según Rabinovich (Rabinovich 2005) "las incertidumbres, que se manifiestan como sorpresas pueden surgir de 3 fuentes distintas:

(i) del carácter estadístico (estocástico) de la naturaleza,

(ii) de nuestros errores en estimar parámetros biológicos, ecológicos, etc. $Y$

(iii) de nuestra ignorancia acerca de los componentes y relaciones claves entre las variables de los sistemas naturales.

Las de tipo (i) pueden minimizarse acumulando registros cada vez más largos de datos de los procesos naturales.

Las de tipo (ii) se pueden reducir con mejores equipos y métodos estadísticos (muestreo, monitoreo).

Las de tipo (iii) sólo se pueden reducir mejorando nuestro conocimiento sobre como funciona la naturaleza".

La lógica borrosa es capaz de representar datos con incertidumbre, emular habilidades humanas y manejar situaciones imprecisas donde la matemática tradicional no es efectiva (Phillis et al. 2001 op cit.).

Usando lógica borrosa es posible diseñar el funcionamiento de un sistema usando reglas escritas en lenguaje corriente en lugar de hacerlo especificando de manera precisa las reglas matemáticas que gobiernan el comportamiento del sistema.

\subsubsection{La lógica borrosa: Diferencias con la lógica clásica.}

La lógica borrosa entiende la realidad en términos de grados. A diferencia de la lógica binaria (lógica clásica) donde las cosas son o no son, en la lógica borrosa las cosas son 
y no son en cierto grado. Un ejemplo muy conocido plantea el tema de la altura de una persona. Si establecemos que 0 cms. es una altura baja y 200 cms. es una altura considerable, entonces debe existir, siguiendo los lineamientos de la lógica clásica, un punto en el intervalo [0,200] a partir del cual una persona pasa de ser baja a ser alta. Sea $x$ tal punto, ¿es cierto que si 2 personas, la primera supera por una milésima de milímetro la altura $x$ la otra no la alcanza por la misma diferencia pueden considerarse una alta y la otra baja? Estamos planteando que 2 personas son, una baja y la otra alta, aún cuando su diferencia en altura es de sólo 2 milésimas de milímetro, es decir, son casi iguales.

Es en éste tipo de casos en que el empleo de la lógica binaria no resulta ser muy adecuado. En cambio, la lógica borrosa entendería el problema como que las 2 personas del ejemplo anterior son altas; una (la primera) con un cierto grado mayor a la otra (segunda).

Teniendo en cuenta esto último tenemos las siguientes tablas de verdad en la lógica clásica:

\begin{tabular}{|c|c|c|}
\hline \multicolumn{3}{|c|}{ AND } \\
\hline $\mathrm{A}$ & $\mathrm{B}$ & $\mathrm{A}$ and $\mathrm{B}$ \\
\hline 0 & 0 & 0 \\
\hline 0 & 1 & 0 \\
\hline 1 & 0 & 0 \\
\hline 1 & 1 & 1 \\
\hline
\end{tabular}

\begin{tabular}{|c|c|c|}
\hline \multicolumn{3}{|c|}{ OR } \\
\hline $\mathrm{A}$ & $\mathrm{B}$ & $\mathrm{A}$ or $\mathrm{B}$ \\
\hline 0 & 0 & 0 \\
\hline 0 & 1 & 1 \\
\hline 1 & 0 & 1 \\
\hline 1 & 1 & 1 \\
\hline
\end{tabular}

\begin{tabular}{|c|c|}
\hline \multicolumn{2}{|c|}{ NOT } \\
\hline $\mathrm{A}$ & $\operatorname{not} \mathrm{A}$ \\
\hline 0 & 1 \\
\hline 1 & 0 \\
\hline
\end{tabular}

Figura 3.1. Tablas de verdad de los operadores y, o y negación en la lógica clásica.

Ahora bien, en la lógica borrosa tanto A como B pueden tomar valores en el intervalo [0..1]. ¿Qué valores tomará la conjunción, la disyunción y la negación cuando al menos un operando tome un valor distinto de 0 y 1 ? La respuesta es que el AND se asocia con la operación min y el OR con la operación max, en tanto que el NOT se asocia con la operación de complemento aditivo (dado un valor de $A$, su negación será 1-A). Volviendo a la lógica clásica y considerando sólo los valores 0 y 1 vemos que las operaciones supra citadas cumplen las propiedades de la lógica clásica y además permiten extender la misma para los restantes valores del intervalo [0..1].

\subsubsection{Funciones de pertenencia}

Las funciones de pertenencia se utilizan para especificar en qué grado un elemento pertenece a un conjunto. En el caso de la lógica binaria, se la define de la siguiente manera:

Sea A un conjunto. Se denomina función de pertenencia a la función $\mu_{\mathrm{A}}$ definida como:

$$
\begin{array}{r}
\mu_{A}: A \rightarrow\{0,1\} \text { tal que } \mu_{A}(x)=1 \text { si } x \in A . \\
\mu_{A}(x)=0 \text { si } x \notin A .
\end{array}
$$


En el caso de la lógica bivalente hay sólo 2 posibilidades: un elemento pertenece o no a un conjunto. En la lógica borrosa, en cambio, los valores de $\mu_{A}(x)$ pueden tomar cualquier valor en el intervalo [0,1] (donde 0 implica completamente falso y 1 absolutamente verdadero).

En la figura siguiente se observa el gráfico correspondiente a una función de pertenencia empleando lógica borrosa (izquierda) y lógica clásica (derecha).

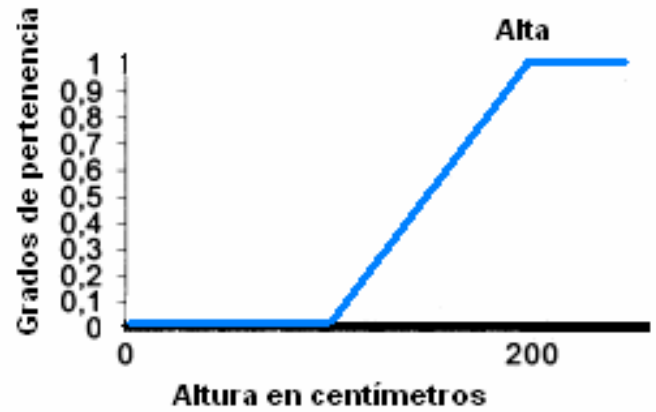

a) Lógica borrosa

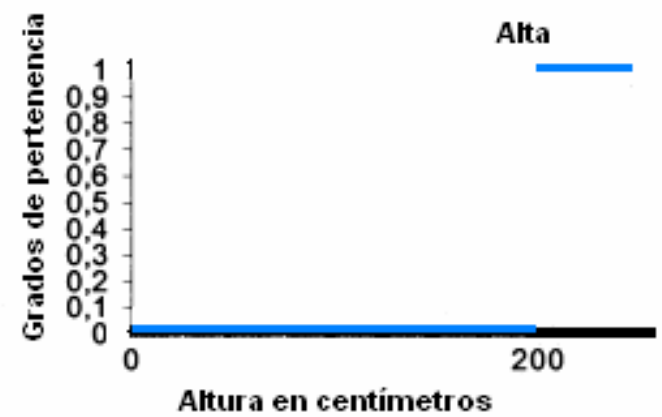

b) Lógica binaria (clásica)

Figura 3.2. Funciones de pertenencia en la lógica borrosa y en la lógica clásica.

Como se observa en los gráficos de arriba una función de pertenencia puede estar constituída por diferentes funciones definidas en diferentes intervalos.

La forma que adopte la función de pertenencia depende del fenómeno que se quiere representar. Entre las formas más usadas podemos citar las de forma triangular, trapezoidal y gaussiana.

\subsubsection{Variables lingüísticas y valores lingüísticos}

Una variable lingüística define una variable de interés en un sistema. Por su parte, los valores lingüísticos definen distintas categorías de una variable lingüística. Por ejemplo, una variable lingüística podría ser la altura de una persona. En este caso, los valores lingüísticos asociados podrían ser: alta, media y baja.

En la figura siguiente se muestran las funciones de pertenencia asociadas a los valores lingüísticos correspondientes a los 3 tipos de altura: baja, media y alta (arriba izquierda, arriba derecha y abajo izquierda respectivamente). En el gráfico de la parte inferior derecha se observa la superposición de las 3 funciones de pertenencia asociadas a los valores lingüísticos de la variable lingüística altura. 

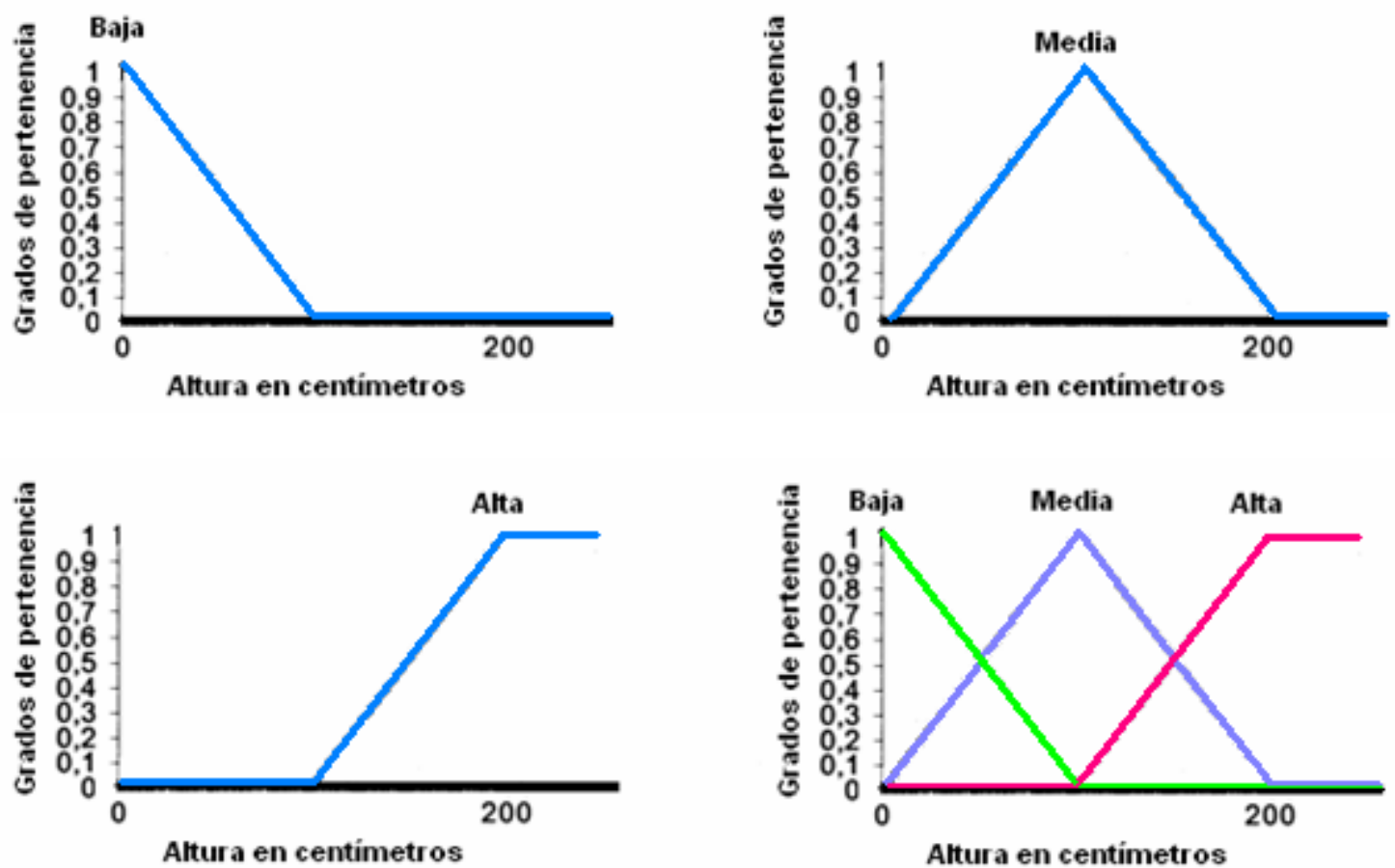

Figura 3.3. Funciones de pertenencia asociadas a los valores lingüísticos "baja", "media" y "alta" pertenecientes a la variable lingüística "altura".

\subsubsection{Definición de conjunto borroso}

Si $X$ es el universo de discurso y sus elementos se denotan por $x$, entonces un conjunto borroso $A$ en $X$ se define como un conjunto de pares ordenados

$A=\{x, \mu A(x) \mid x$ pertenece $a X\}$

En otras palabras, un conjunto borroso puede entenderse como un conjunto de pares que asocia a cada elemento $x$ con su grado de pertenencia.

\subsubsection{Operaciones con conjuntos borrosos}

Sean A y B dos conjuntos borrosos cuyas funciones de pertenencia son $\mu_{A}(x)$ y $\mu_{B}(x)$ respectivamente. Se definen las operaciones:

Complemento: $\quad \mu \bar{A}(\mathrm{x})=1-\mu_{\mathrm{A}}(\mathrm{x})$

Intersección: $\quad \mu A \cap B=\mu_{A}(x) \wedge \mu_{B}(x)=\min \left(\mu_{A}(x), \mu_{B}(x)\right)$

Unión: $\quad \mu A \cup B=\mu \mathrm{A}(\mathrm{x}) \vee \mu \mathrm{B}(\mathrm{x})=\max \left(\mu_{\mathrm{A}}(\mathrm{x}), \mu_{\mathrm{B}}(\mathrm{x})\right)$ 


\subsubsection{Operadores de T-norma y T-conorma}

Un operador $\mathrm{T}:[0,1] \mathrm{x}[0,1] \rightarrow[0,1]$ es llamado operador de $\mathrm{T}$-conorma si satisface las siguientes condiciones (Choi 1999):
a) $\mathrm{T}(\mathrm{a}, \mathrm{b})=\mathrm{T}(\mathrm{b}, \mathrm{a})$.
b) $T(a, T(b, c))=T(T(a, b), c)$.
c) $T(a, b)>=T(c, d)$ if $a>=c$ y $b>=d$.
d) $\mathrm{T}(\mathrm{a}, 1)=\mathrm{a}, \mathrm{T}(\mathrm{a}, 0)=0$.

Un operador $\mathrm{S}:[0,1] \mathrm{x}[0,1] \rightarrow[0,1]$ es llamado operador de $\mathrm{T}$-conorma si satisface las siguientes condiciones(Choi 1999 op cit):
a) $\mathrm{S}(\mathrm{a}, \mathrm{b})=\mathrm{S}(\mathrm{b}, \mathrm{a})$.
b) $S(a, S(b, c))=S(S(a, b), c)$.
c) $S(a, b)>=S(c, d)$ if $a>c$ y $b>d$.
d) $\mathrm{S}(\mathrm{a}, 1)=1, \mathrm{~S}(\mathrm{a}, 0)=\mathrm{a}$.

Se deduce de las leyes anteriores que el operador lógico "y" asociado generalmente con el operador "min" es un operador de T-norma en tanto que el operador lógico "o" asociado generalmente con el operador "max" es un operador de T-conorma.

\subsubsection{Reglas}

Las reglas son sentencias que sirven para relacionar variables de entrada con variables de salida en un sistema. Su estructura tiene la forma:

If $x$ es A entonces y es $B$

En la regla anterior se denomina antecedente a "x es A" y consecuente a "y es B". El consecuente especifica uno o más conjuntos borrosos a ser asignados a la salida.

En la regla anterior $\mathrm{x}$ e y son variables lingüísticas y $\mathrm{A}$ y $\mathrm{B}$ son valores lingüísticos asociados a $\mathrm{x}$ e $\mathrm{y}$ respectivamente.

En el desarrollo de programas, donde se aplica la lógica clásica, la regla anterior se lee como "si el antecedente es verdadero entonces el consecuente también lo es". No obstante, en la lógica borrosa el antecedente puede tomar valores distintos al verdadero (1) y falso (0) en el caso de sentencias parcialmente verdaderas (o parcialmente falsas respectivamente). En estos casos, si el antecedente es verdadero en cierto grado, el consecuente también será verdadero con el mismo grado.

En el caso de que la regla tenga un antecedente compuesto se emplean los operadores borrosos citados anteriormente obteniendo como resultado un único número (en el intervalo [0..1]) que representa el grado con que se satisface el antecedente. 
Si el consecuente es compuesto, cada término es afectado con el mismo grado (el grado indicado por el antecedente).

En el caso de que un conjunto borroso aparezca en más de un consecuente le corresponderá el mayor grado con que se satisfizo el antecedente de alguna regla en la que el citado conjunto aparezca en el consecuente. Por ejemplo (tomado de Hilera et al. 1995):

$$
\begin{aligned}
& \text { Regla i: Si ... Entonces }\left(y_{1} \text { será } C\right) \text { y }\left(y_{2} \text { será } D\right) \\
& \text { Regla j: Si ... Entonces }\left(y_{1} \text { será } C\right) \text { y }\left(y_{2} \text { será } E\right) \\
& \qquad \begin{aligned}
\mu_{C}\left(y_{1}\right)= & \max (\text { Peso regla } i, \text { Peso regla } j) \\
& \mu_{D}\left(y_{2}\right)=\text { Peso regla } i \\
& \mu_{E}\left(y_{2}\right)=\text { Peso regla } j
\end{aligned}
\end{aligned}
$$

\subsubsection{Sistemas de inferencia borrosos}

Los sistemas de inferencia borrosos mapean un conjunto de valores de variables de entrada en otro conjunto de valores de variables de salida. Por ejemplo, en el trabajo de Phillis y Andriantiatsaholiniaina (Phillis et al. 2001) se diseñó un sistema de inferencia borroso cuyas variables de entrada eran indicadores que intentaban describir las distintas dimensiones de la sustentabilidad y cuya única salida era el nivel de "sustentabilidad" alcanzado. Para transformar el conjunto de valores de entrada en un conjunto de valores de salida se define un conjunto de reglas que relacionan variables de entrada con variables de salida siguiendo los pasos (etapas) que se enuncian en el inciso siguiente.

El sistema de inferencia borroso de tipo Mamdani (Mamdani 1975) es el más usado en la práctica para aplicaciones relacionadas con la calidad de vida y el que se asumirá de aquí en adelante cuando se hable de sistema de inferencia borroso.

\subsubsection{Etapas en la construcción de un sistema de inferencia borroso:}

Normalmente, el diseño de un sistema de inferencia borroso consiste de los siguientes pasos:

$>$ En primer lugar se seleccionan las variables de interés del sistema que se pretende modelar. Una vez seleccionadas las variables relevantes, se procede a definir los valores lingüísticos (cada uno con su función de pertenencia asociada) asociados a cada una de ellas.

$>$ Definir las reglas que relacionen las variables del sistema. 
Una vez definido explícitamente el sistema de inferencia borroso, el modo en que procede para arribar a los resultados que se obtendrán en las variables de salida sigue un proceso de 5 etapas:

1. Fuzificar las entradas.

2. Aplicar el operador borroso.

3. Aplicar el método de implicación.

4. Agregación de las salidas.

5. Defuzificación.

Este proceso ha sido detallado en numerosos trabajos (Cornelissen et al. 2001, The MathWorks 2007, Ferraro 2005, Hilera et al. 1995 op cit.). A continuación se comentan cada una de las etapas:

\subsubsection{Fuzificar las entradas}

El primer paso consiste en calcular para cada valor de las variables de entrada con qué grado pertenecen a cada uno de los valores lingüísticos que tienen asociados usando las correspondientes funciones de pertenencia. Las variables de entrada toman valores comprendidos en su universo de discurso (ej.: altura entre 0 y $200 \mathrm{~cm}$.) y la fuzificación asigna valores en el rango [0..1] a los valores lingüísticos asociados a la variable lingüística (por ejemplo: un individuo cuya altura es de $180 \mathrm{cms}$. podría interpretarse como que tiene altura baja con grado 0 , media con grado $0.2, y$ alta con grado 0.8 ).

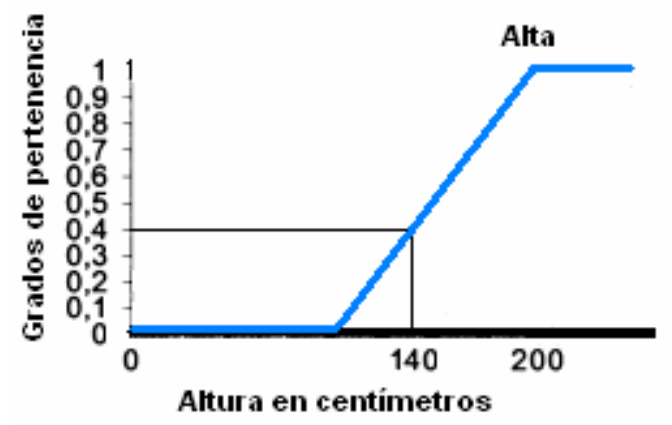

Figura 3.4. Proceso de fuzificación.

En la figura anterior se observa que si una persona tiene una altura de $140 \mathrm{cms}$. es alta con grado 0.4 .

\subsubsection{Aplicar el operador borroso}


Una vez concluído el paso anterior se sabe con que grado se satisfizo cada parte del antecedente de una regla. En el caso de que la regla involucre el uso de operadores se emplean los operadores borrosos que correspondan a los efectos de obtener un único número que represente el resultado del antecedente de la regla.

Este paso toma como entrada un vector de números (donde cada posición del vector es un número entre 0 y 1) y devuelve como resultado un único número que representa el grado con se satisface el antecedente de la regla.

\subsubsection{Aplicar el método de implicación}

Ciertos programas como el Fuzzy Logic Toolbox de MATLAB ${ }^{2}$ (The MathWorks 2007 op cit.) implementan un sistema de prioridades entre las distintas reglas; esto significa asociar un peso a cada regla el cual se aplica al valor con que se satisfizo el antecedente (una vez que se han fuzificados todas sus entradas y aplicado los operadores correspondientes en caso de ser necesario) antes de aplicar el método de implicación. Este peso normalmente es un número entre 0 y 1 . Asignando un 1 como peso a cada regla se obtiene entonces un sistema en el que todas las reglas tienen igual prioridad, es decir, no tendrá ningún efecto sobre el método de implicación que se aplicará.

Una vez concluído el paso anterior que establece las prioridades de las distintas reglas se proceda a aplicar un método de implicación para cada regla.

Para cada una de las reglas, el método de implicación toma el número obtenido al evaluar el antecedente de la regla en el paso anterior y modifica a cada conjunto borroso de salida en función de dicho valor.

Entre los distintos métodos de implicación existentes, el método min es probablemente el más usado. Para un conjunto borroso asociado a un valor lingüístico de salida, el método de implicación min produce como salida un nuevo conjunto borroso cuya función de pertenencia asocia a cada punto $x$ del universo de discurso, el mínimo entre el valor obtenido al evaluar el antecedente y el valor de evaluar el conjunto borroso original en ese punto.

Resumiendo, un método de implicación recibe 2 parámetros: un número entre 0 y 1 y un conjunto borroso de salida, y produce como resultado un nuevo conjunto borroso.

\subsubsection{Agregación de las salidas}

\footnotetext{
2 MATLAB ® 1995-2007 The MathWorks, Inc. URL: www.mathworks.com.
} 
Para cada variable lingǘstica de salida, los conjuntos borrosos parciales (obtenidos luego de aplicar el método de implicación correspondiente a cada regla) correspondientes a los valores lingüísticos asociados a dicha variable lingüística son combinados para obtener un único conjunto borroso final.

De esta manera, se obtendrá un conjunto borroso final para cada variable de salida del sistema. Para realizar esta operación existen diferentes métodos (por ej.: suma de los conjuntos de salida de las reglas, máximo, or probabilístico).

En síntesis, un método de agregación recibe un conjunto de conjuntos borrosos (parciales) y retorna un conjunto borroso (final) agregado.

\subsubsection{Defuzificación.}

La etapa de defuzificación toma como entrada un conjunto borroso (el producido en el paso anterior) y produce como salida un número. Este proceso se realiza para cada una de las variables lingüísticas de salida.

Existen distintos métodos para obtener ese número siendo quizás el más conocido el método del centroide; el cual retorna la coordenada $x$ del centro del área del conjunto borroso. Su fórmula para el caso continuo es:

$$
x=\frac{\int x \mu(x) d x}{\int \mu(x) d x}
$$

En tanto que para el caso discreto se tiene:

$$
x=\frac{\sum_{k=1}^{n} x_{k}^{*} \mu\left(x_{k}\right)}{\sum_{k=1}^{n} \mu\left(x_{k}\right)}
$$

El método de defuzificación recibe un conjunto borroso (que es una agregación de conjuntos borrosos) y retorna un número en el rango de valores de la variable de salida en cuestión.

Otros métodos de defuzificación menos usados son: el más grande de los máximos (conocido como LOM), el más pequeño de los máximos(SOM) y bisector. Este último es la coordenada $x$ que divide al área en 2 subáreas de igual tamaño(en el caso de la figura siguiente el valor que resultaría al aplicar el método bisector sería 9.25). A continuación se ilustran algunos de los métodos de defuzificación citados. 


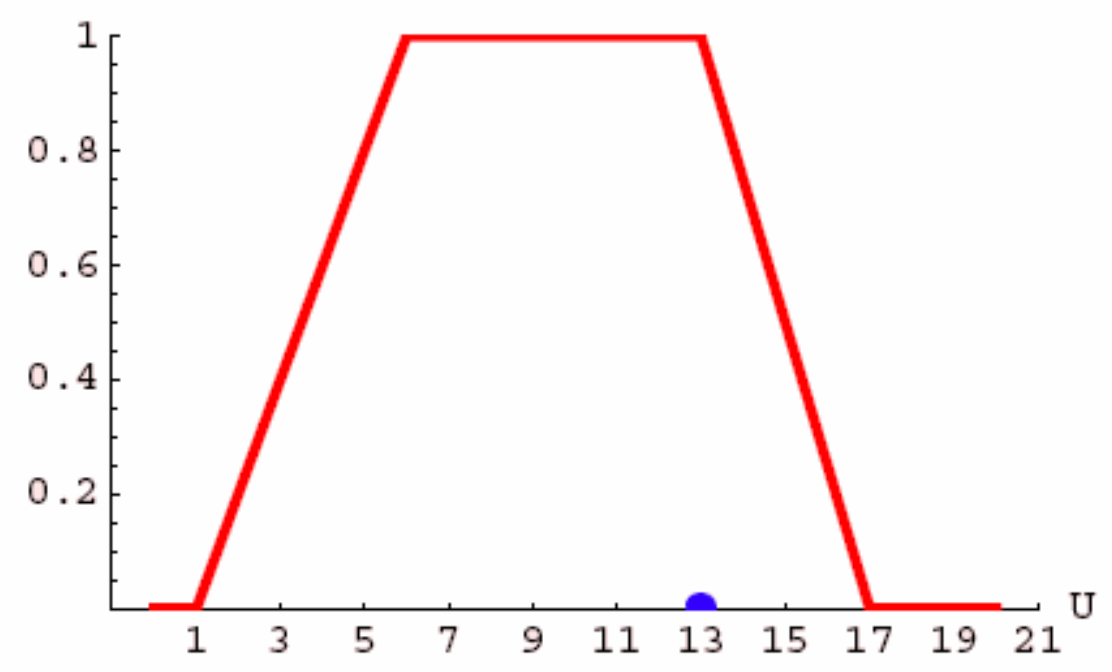

Figura 3.5. Método de defuzificación: El más grande de los máximos. Fuente: http://www.addlink.es/pdf/AGDWeb205.pdf Accedido: 23-8-2007.

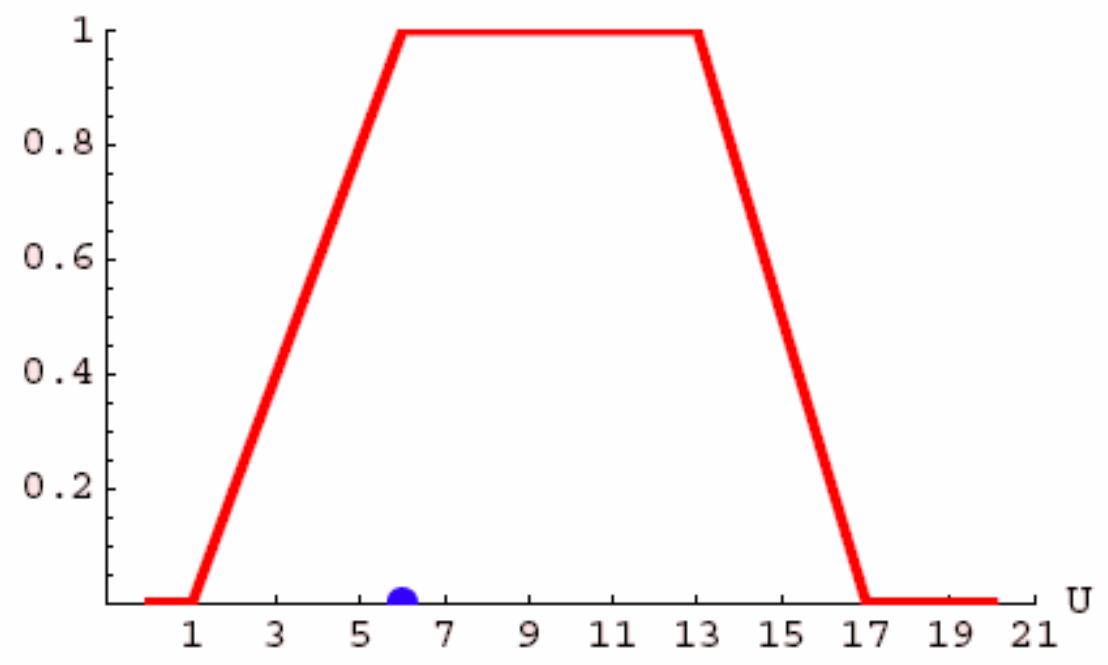

Figura 3.6. Método de defuzificación: El más pequeño de los máximos. Fuente: http://www.addlink.es/pdf/AGDWeb205.pdf Accedido: 23-8-2007.

Obsérvese que la figura anterior no es simétrica ya que desciende de manera más pronunciada de lo que asciende, ya que alcanza el grado uno después de recorrer 5 unidades ( 1 al 6 ) en el eje $x$. El descenso a 0 se produce a lo largo de 4 unidades (13 al 17) en el eje $x$. Por tal motivo, si se aplica el método del centroide el resultado será aproximadamente 9.2 .

3.2.10. Ejemplo de sistema de inferencia borroso 
Un sistema de inferencia borroso requiere de una serie de valores de entrada $\left(\mathrm{x}_{1}, \mathrm{x}_{2}, \mathrm{x}_{3}\right.$ en el caso de la figura 3.7). Una vez ingresados al sistema, el mismo procede a fuzificar cada uno de los valores lingüíticos de cada regla. Por ejemplo, en la regla uno se obtienen los valores $(0.2,0.3,0.9)$, en la regla $2(0.2,0.3,0.1)$, en la regla $3(0.2,0.7,0.1)$ y en la regla $4(0.8$, $0.7,0.1)$ concluyendo así la etapa correspondiente a la fuzificación de los valores de entrada.

Luego, a los vectores asociados a las reglas, resultantes de la etapa anterior, se le aplican los operadores lógicos borrosos necesarios (and en el ejemplo). Ya vimos que el and se asocia con el mínimo, por lo tanto los grados de satisfacción de los antecedentes de cada regla quedan de la siguiente manera.

Grado de satisfacción del antecedente

$\begin{array}{ll}\text { Regla 1: } & 0.2 \\ \text { Regla 2: } & 0.1 \\ \text { Regla 3: } & 0.1 \\ \text { Regla 4: } & 0.1\end{array}$

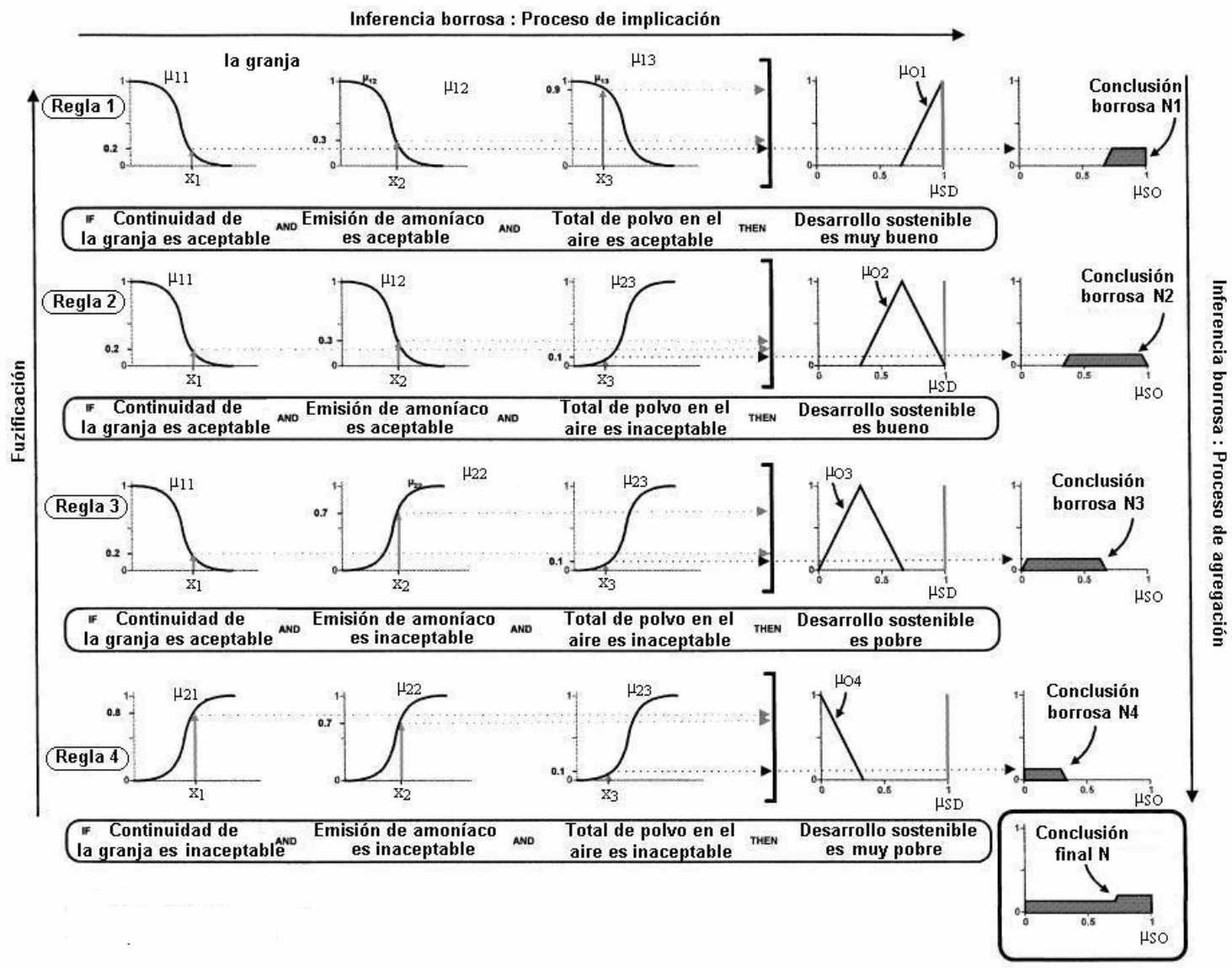

Figura 3.7. Fuente: Traducido de Cornelissen et al., 2001 op.cit.

La tercer etapa toma los grados con que se satisfacen los antecedentes de cada regla y modifica el conjunto borroso asociado al valor lingüístico de salida (correspondiente a la 
variable lingüística "Desarrollo sostenible") en función de dicho valor dando como resultado los conjuntos borrosos N1, N2, N3 y N4.

La etapa de agregación toma los conjuntos $\mathrm{N} 1, \mathrm{~N} 2, \mathrm{~N} 3$ y $\mathrm{N} 4$ y forma con ellos un único conjunto borroso agregado final; $\mathrm{N}$.

Se infiere de la forma del conjunto $\mathrm{N}$ que se ha usado el método de agregación max.

Finalmente se aplicará al conjunto borroso final $\mathrm{N}$ un método de defuzificación para arribar a un resultado final que retornará un número asociado al "nivel de sustentabilidad" alcanzado para el conjunto de valores de entrada $\left(\mathrm{x}_{1}, \mathrm{x}_{2}, \mathrm{x}_{3}\right)$.

\subsubsection{Trabajos existentes}

De los trabajos realizados hasta la fecha analizados, los trabajos de Phillis y Andriantiatsaholiniaina (Phillis et al. 2001 op cit., Andriantiatsaholiniaina et al. 2004a y 2004b) son los que proponen una metodología cuyo universo posible de análisis es el más amplio. En tales trabajos se presenta un modelo, llamado SAFE, para estimar la "sustentabilidad" de la región bajo estudio usando lógica borrosa. Para ello se combinan indicadores de factores ecológicos (tierra, agua, aire y biodiversidad) y humanos (económicos, sociales, educativos, políticos) y se trata de derivar a partir de ellos un valor único que represente el "grado de sustentabilidad" de una región. Según sus propios autores "el modelo es flexible en el sentido que los usuarios pueden elegir el conjunto de indicadores y ajustar las reglas base de la base de conocimiento de acuerdo a sus necesidades y a las características del sistema socio-ambiental a evaluar (Phillis 2001 et al. op.cit)".

Otro trabajo relacionado es el de Lemmi (Lemmi et al. 2006), en el cual se proponen técnicas para la evaluación multidimensional de la pobreza usando lógica borrosa.

\subsection{Dinámica de sistemas}

\subsubsection{Concepto de sistema}

Draper Kaufman sostiene que "un sistema es una colección de partes que interactúan con cada una de las otras para funcionar como un todo" (Kaufman citado en Vergara et al. 2002).

Bajo esta definición encontramos 2 acepciones del término sistema. Una de ellas se refiere al objeto $\mathrm{S}$ del mundo real que se quiere estudiar y otra a su representación mediante un modelo matemático adecuado; en adelante, M. Es importante en este punto destacar que normalmente el modelo $\mathrm{M}$ no puede cubrir todos los aspectos de la realidad que representa y que además está influenciado por el modelo mental que el modelador haya concluído que más se acerca al fenómeno real $\mathrm{S}$.

Este modelo $\mathrm{M}$ puede verse como una dupla $(\mathrm{C}, \mathrm{R})$ donde $\mathrm{C}$ es el conjunto de las partes que componen el sistema y $\mathrm{R}$ es el conjunto de relaciones entre las mismas. 
Es posible, a partir del par $(\mathrm{C}, \mathrm{R})$ derivar un grafo donde los nodos son los elementos $\mathrm{C}$ y las aristas los elementos de $\mathrm{R}$ como se muestra en la figura 3.8.

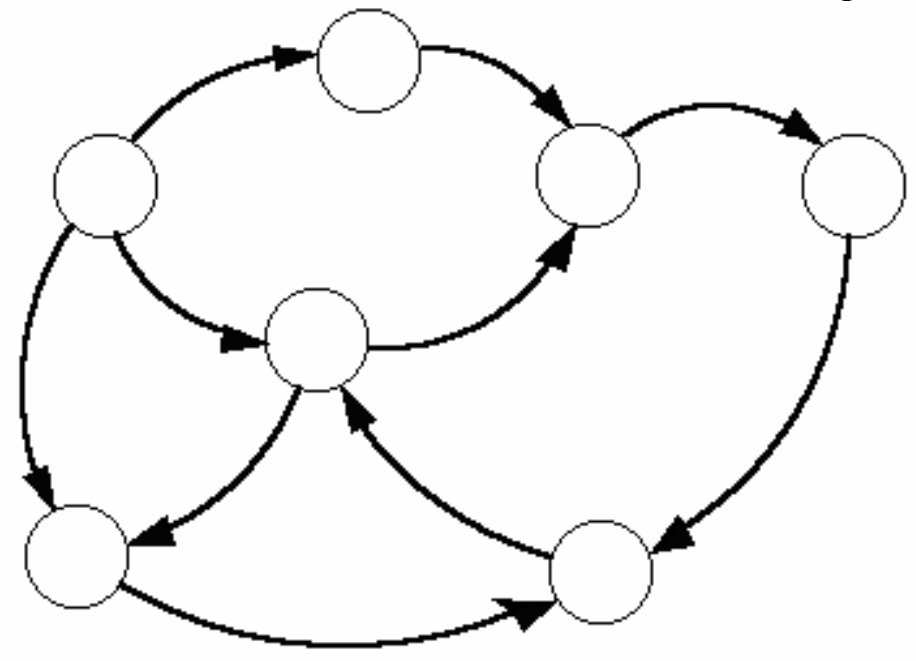

Figura 3.8. Grafo que representa un sistema.

Dado que el grafo ilustra la relación entre las distintas partes que componen el sistema, se dice que el mismo representa la estructura del sistema y se lo conoce con el nombre de diagrama causal o diagrama de influencias.

\subsubsection{Concepto de sistema dinámico}

A los valores que toma la unidad o magnitud de una variable del sistema a largo plazo se le conoce como trayectoria y el conjunto de trayectorias asociadas a las variables relevantes se dice que es el comportamiento del sistema.

Se entiende por sistema dinámico al estudio del comportamiento de sistemas mediante un modelo que ponga de manifiesto las relaciones entre la estructura del sistema y su comportamiento.

El paso siguiente a dar, una vez obtenido el grafo $(C, R)$ es pasar a un grafo $(C, R)$ signado.

Las aristas de éste último son dirigidas e indican la influencia de una parte del sistema sobre otra. Cuando la relación entre 2 partes del sistema es tal que si aumenta la magnitud de la primera también aumenta la segunda o si disminuye la primera implica un decremento de la segunda se dice que existe una relación positiva entre las 2 variables y se denota con un signo + . Caso contrario, cuando al aumentar la magnitud de la primera ocurre una disminución en la segunda o cuando al disminuir la primera aumenta la segunda entonces la relación es negativa y se denota con un signo - encima de la arista.

El grafo signado describe la estructura de realimentación del sistema.

Otro concepto relevante en la terminología de dinámica de sistemas es el de trayectoria. El mismo se usa para denotar el comportamiento de una parte del sistema a lo largo del tiempo. Asimismo el conjunto de todas las trayectorias asociadas a cada una de las partes o variables de interés del sistema se denomina comportamiento del sistema. 
Una ventaja importante de analizar la dinámica de un sistema mediante computadora es que facilita el trazado de trayectorias permitiendo mostrar el comportamiento mediante interfases gráficas.

En síntesis, podemos concluir que el conjunto de relaciones entre las variables del sistema forma la estructura del sistema, y su comportamiento propiamente dicho es el que describen las trayectorias de las variables relevantes.

La dinámica de sistemas es una herramienta para tratar con la complejidad, para expandir nuestra concepción del mundo y para comprender cómo son las estructuras las que producen determinados comportamientos, de los cuales sólo somos conscientes de los hechos que se nos hacen evidentes.

La técnica de dinámica de sistema fue aplicada por primera vez a problemas urbanos en 1969 (Forrester 1969). En el libro de Forrester se proponía un modelo de ciudad compuesto por diferentes sectores (ej.: uso de la tierra, trabajo, entre otros), los cuales, estaban interrelacionados entre sí. De esta manera podía observarse, por ejemplo, que efectos tenía sobre el uso de la tierra un incremento en la cantidad de habitantes o como aumentaba la demanda de infraestructura como consecuencia de una población cada vez mayor. En la figura 3.9 se observa la modelización del sector uso de la tierra, que es uno de los 15 sectores que componían el modelo completo.

Esta metodología ha sido empleada también para modelizar sistemas más amplios que el sistema urbano. Por ejemplo, el trabajo de Meadows y colaboradores (Meadows et. al 1992) en el que se contruyó un modelo mundial, World 3, en el que se analizaba de manera conjunta y bajo diferentes escenarios, el comportamiento de 5 (variables principales) de las variables del modelo: recursos, población, producción industrial, alimimentos y contaminación. El citado trabajo es una actualización del célebre informe publicado por el Club de Roma años atrás. 


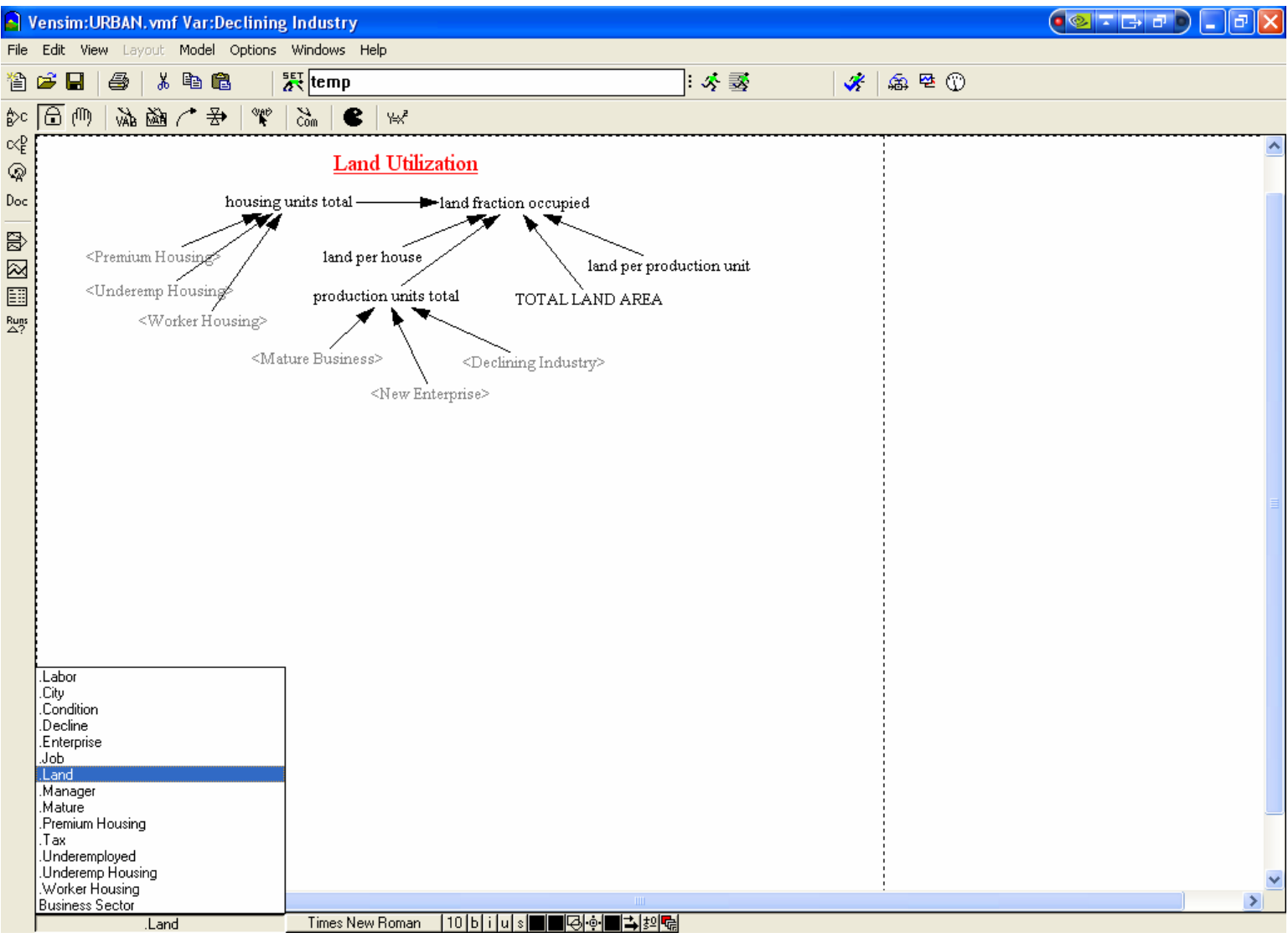

Figura 3.9. Modelización del sector uso del suelo del modelo de dinámica urbana de Forrester.

El modelo puede descargarse de Internet desde la página de modelos de dinámica de sistemas de Tom Fiddaman (www.metasd.com/models/Library/Misc/UrbanDynamics) para ser probado con el software Vensim ${ }^{3}$.

\subsubsection{Elementos del lenguaje sistémico}

Como sostienen Aracil y Gordillo (Aracil y Gordillo 1997) "La ciencia clásica ha sido fundamentalmente reduccionista, en el sentido de asumir como axioma metodológico básico el que para estudiar un objeto lo que había que hacer era reducirlo a sus partes y estudiarlas aisladamente. Una vez conocidas las propiedades de las partes, las propiedades del sistema se desprenden por sí solas. Se trataba, por tanto, de reducir el estudio de un sistema a su análisis, su disección. Este principio analítico ha sido enormemente fecundo, en particular en física. Sin embargo, desde las disciplinas que se ocupan del estudio de objetos de una cierta complejidad pronto se empezó a presentir su insuficiencia. Tan importante como la disección y el análisis es la integración y síntesis”.

${ }^{3}$ Vensim ${ }^{\circledR}$ (The Ventana Simulation Environment). Copyright Ventana Systems, Inc. URL: www.vensim.com 
La dinámica de sistemas es una disciplina que intenta ver el todo sin perder noción de las partes y al mismo tiempo ver las partes sin perder de vista el todo.

Veamos a continuación algunos temas que trata esta metodología.

\subsubsection{Diagramas de Forrester}

Los diagramas de Forrester permiten asociar un sistema dinámico a un grafo $(C, R)$ signado. Para ello se recurre a diferentes símbolos como se muestra en la figura 3.10.

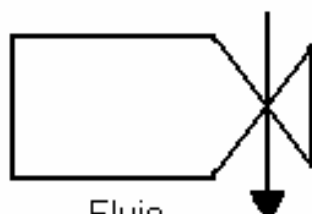

Flujo

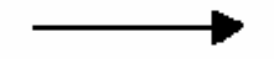

Canal de material

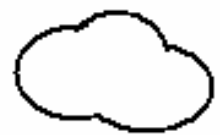

Fuente / Sumidero

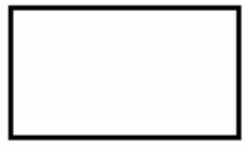

Estado

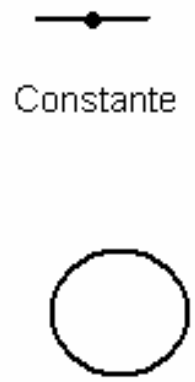

Variable auxiliar

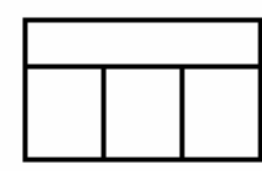

Retraso

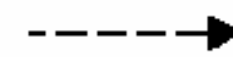

Canal de información

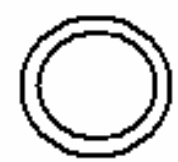

Variable exógena

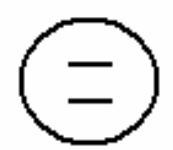

Variable auxiliar (Función no lineal)

Figura 3.10. Elementos de un modelo de dinámica de sistemas.

A continuación veremos con detalle cada uno de los elementos que componen un diagrama de Forrester, al cual se lo conoce también con el nombre de diagrama de stock y flujo.

\subsubsection{Variables de estado}

Las variables de estado, llamadas también niveles o stocks, son aquellas cuya evolución en el tiempo es importante para el estudio del sistema. Estas variables acumulan resultados de eventos que han ido ocurriendo a lo largo del tiempo.

Por ejemplo, un pluviómetro usado para medir la lluvia caída podría ser representado con una variable de estado pues, en un momento dado, el mismo indicará la cantidad de lluvia acumulada hasta ese momento, en tanto que la lluvia caída en los distintos instantes de tiempo podrían representarse como variables de flujo, como veremos acto seguido. 
En los diagramas de Forrester, las variables de estado se representan por medio de rectángulos.

\subsubsection{Variables de flujo}

Un flujo vendría a representar la razón de cambio de un stock. Por ejemplo, si representamos un modelo de crecimiento demográfico, los nacimientos serían variables de flujo mientras que la cantidad de habitantes sería una variable de estado. En otras palabras, las variables de flujo son las que producen los cambios en los estados del sistema.

Las ecuaciones que se asocian a una variable de flujo se les conoce con el nombre de ecuaciones de flujo o funciones de decisión debido a que representan a las acciones que se toman en el sistema y que se van acumulando en las variables de estado.

Cuando se construye un diagrama de Forrester no es válido conectar 2 variables de flujo entre sí. Las variables de flujo pueden tener como entradas a variables de estado o variables auxiliares, pero nunca otra variable de flujo. La salida de un flujo es la entrada a una variable de estado.

Las variables de flujo tendrán como unidad de medida asociada la misma que la del estado al que deriva su salida, dividida por la unidad de tiempo. Así, en el ejemplo del crecimiento demográfico, el stock sería la población (cuya unidad es habitantes) y la variable de flujo serían los nacimientos (cuya unidad sería por ej. habitantes/año).

Las variables de flujo se representan en los diagramas de Forrester con un símbolo que representa a una válvula.

\subsubsection{Variables auxiliares}

Las variables auxiliares pueden usarse para representar expresiones a partir de una serie de variables de entrada o también para representar funciones que arrojen un valor de salida a partir de un valor de entrada. En este último caso, la función se suele cargar mediante una interfaz gráfica en la que el usuario dibuja la función o bien carga pares de puntos $(\mathrm{x}, \mathrm{y})$. La idea es que la función retorne el valor y correspondiente al valor de entrada $\mathrm{x}$. Para ello, si la función fue construída a partir de pares de valores $(\mathrm{x}, \mathrm{y})$ lo que se hace es buscar el valor y correspondiente al valor de entrada de la función. Si ninguno de los pares ingresados tiene como componente $\mathrm{x}$ a ese valor, entonces se realiza una interpolación para obtener el valor de y correspondiente.

En ocasiones, se las utiliza para representar pasos intermedios en un cálculo que es la entrada de un flujo o de otra variable auxiliar.

A diferencia de lo que ocurre con las variables de estado o las variables de flujo, las variables auxiliares pueden enviar o recibir valores procedentes de otras variables auxiliares.

Las variables auxiliares se representan simbólicamente con un círculo. 


\subsubsection{Otros símbolos}

Los canales sirven para conectar elementos dentro de un diagrama de Forrester. Los hay de 2 tipos diferentes:

$>$ Los canales de material transmiten magnitudes físicas que se conservan.

$>$ Los canales de información transmiten, como su nombre lo indica, información que no es necesario que se conserve.

Otros elementos que pueden encontrarse son las fuentes y los pozos (sumideros) que se representan con una nube y pueden interpretarse como si fuesen niveles sin interés e inagotables. No tienen ecuaciones asociadas y se asume que tienen una capacidad infinita para generar o absorver magnitudes físicas que se transmiten por los canales de materiales. Las variables exógenas son variables independientes del sistema. Se las usa para representar acciones del medio sobre el sistema. Asocian valores a los distintos instantes del intervalo de tiempo que se está simulando. Un ejemplo sería representar la temperatura media diaria del mes de agosto.

Otro elemento importante de los diagramas de dinámica de sistemas lo constituyen los retrasos. Estos elementos sirven para modelizar el hecho de que el valor que fluye entre 2 variables puede darse recién al cabo de cierto tiempo. Dependiendo del tipo de canal (de información o de material) que lo una a una variable, el retraso puede ser de información o de material.

\subsubsection{Modelado en dinámica de sistemas}

Aracil y Gordillo (Aracil et al. 1997 op.cit) sostienen que el proceso de modelado de sistemas dinámicos puede dividirse en 3 etapas o fases:

$>$ Fase de conceptualización.

$>$ Fase de formulación.

$>$ Fase de evaluación.

El desarrollo de un sistema dinámico no es un proceso lineal, por lo que el desarrollador se encontrará en las etapas citadas anteriormente en más de una oportunidad a lo largo del proceso constructivo. A continuación veremos en que consisten cada una de estas etapas o fases. Al mismo tiempo, se irá desarrollando un ejemplo sencillo para dar una mejor idea de hasta donde llega cada etapa.

El ejemplo consiste en observar el crecimiento demográfico de una población a lo largo de un período de tiempo. Se ha supuesto una población inicial de 1000 habitantes, una tasa de natalidad del $2 \%$ anual y una tasa de mortalidad del $1 \%$ anual. Como es de esperar, al ser superior la tasa de natalidad a la de mortalidad, la población crecerá a medida que pasa el tiempo. Por motivo obvios, si se aumenta la tasa de natalidad a un $2.5 \%$ se podrá observar que la curva de crecimiento de la población tendrá una pendiente mayor a la que tenía en principio. 


\subsubsection{Fase de conceptualización}

En esta fase se trata de familiarizar con el problema que se pretende resolver recurriendo para ello a consulta a expertos, bibliografía, etc. para luego precisar los aspectos a resolver del problema de manera detallada.

En esta etapa se identifican los componentes relevantes de un sistema y como interactúan entre sí. Culmina esta etapa con la elaboración del diagrama de influencias.

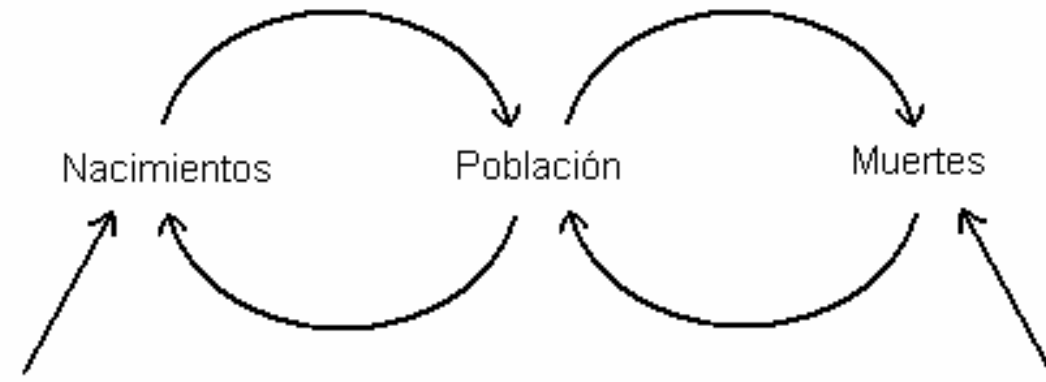

Tasa de natalidad

Tasa de mortalidad

Figura 3.11. Diagrama de influencias.

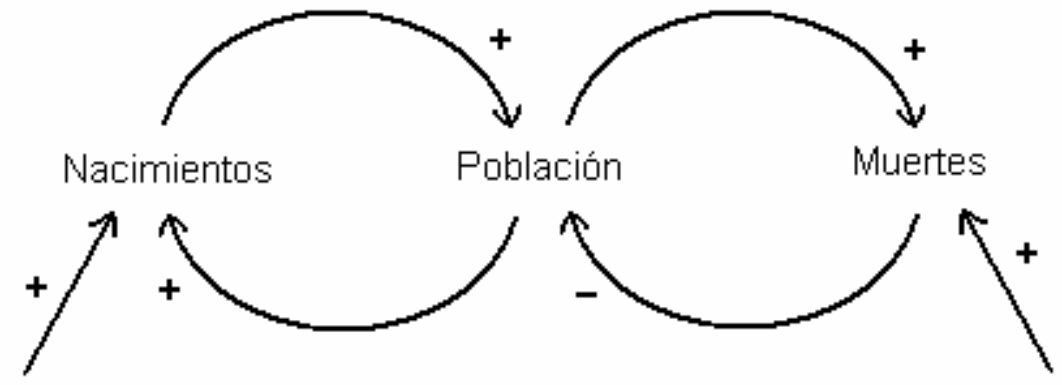

Tasa de natalidad

Tasa de mortalidad

Figura 3.12. Grafo signado explicitando las relaciones de influencia.

\subsubsection{Fase de formulación}

En la fase de formulación se construye el diagrama de Forrester a partir del diagrama de influencias y se procede a precisar las ecuaciones y valores de parámetros que necesita el sistema. Esto implica asignar un valor a las constantes, definir una expresión o construir una función para cada variable auxiliar, describir como se comportará en función del tiempo cada variable exógena y definir las ecuaciones que definirán los flujos y los niveles 
del sistema. De modo que los resultados finales dependerán en gran medida de los datos cargados en esta fase.

Es decir, en esta etapa se diseña el diagrama de Forrester y se especifica la formulación matemática necesaria para poder simular el sistema.

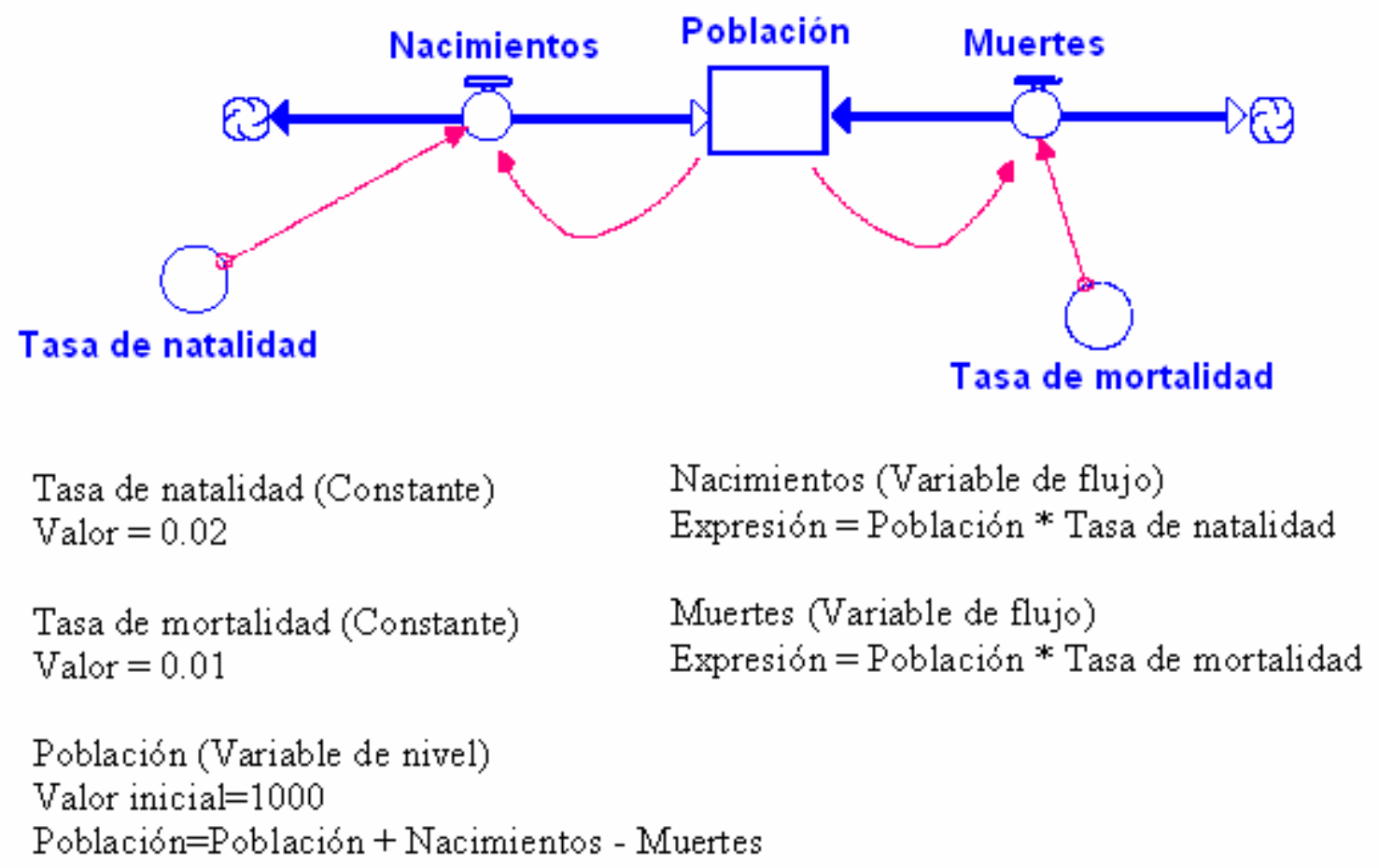

Figura 3.13. Diagrama de Forrester y las fórmulas asociadas a los símbolos.

\subsubsection{Fase de evaluación}

Una vez concluída la fase de formulación se procede a probar a través de diversas corridas (simulaciones) las hipótesis y la consistencia entre ellas. Una herramienta muy útil en esta etapa es el análisis de sensibilidad, la cual permite observar como responde el sistema ante cambio en alguna de las variables.

Una vez que se ha revisado la consistencia de las hipótesis y realizado un análisis de sensibilidad, y que ambos se ajusten bien a la realidad, se evalúa como responde el modelo ante distintos escenarios (políticas) posibles con objeto de servir a la toma de decisiones sobre las acciones a tomar sobre el sistema real.

\subsubsection{Arquetipos}

Los arquetipos son modelos de comportamiento típicos de sistemas. Es posible encontrar sistemas de naturaleza muy diferente que responden de manera análoga. Si esto sucede 
podemos describir esos sistemas con el mismo modelo, y consecuentemente experimentar con el modelo, en lugar de hacerlo con los sistemas reales (Vergara et al. 2002 op.cit).

Peter Senge describió una docena de arquetipos en su libro "La quinta disciplina" (Senge 2004).

\subsection{Optimización multicriterio}

Se presenta a continuación una breve introducción a los conceptos básicos de optimización multicriterio con el objeto de describir los trabajos que han intentado estimar la calidad de vida con esta técnica. El lector interesado en un análisis más profundo sobre optimización multicriterio puede consultar el trabajo de Yu (Yu 1985).

Según Osyczka (Osyczka 1985, citado en Coello Coello 2003) "el problema de la optimización multicriterio puede definirse como el problema de encontrar un vector de variables de decisión que satisfagan un cierto conjunto de restricciones y optimice un conjunto de funciones objetivos. Estas funciones forman una descripción matemática de los criterios de desempeño que suelen estar en conflicto unos con otros y que se suelen medir en unidades diferentes. El término "optimizar" en este caso toma pues un significado diferente al del caso de problemas mono-objetivo".

En los problemas con múltiples objetivos se puede querer:

$>$ Minimizar todas las funciones objetivo.

$>$ Maximizar todas las funciones objetivo.

$>$ Minimizar algunas y maximizar otras funciones objetivo.

Por lo general, se suele llevar el problema a alguno de los primeros 2 casos anteriores usando la priopiedad:

$\max \mathrm{f}_{\mathrm{i}}\left(\mathrm{x}^{*}\right)=\min \left(-\mathrm{f}_{\mathrm{i}}\left(\mathrm{x}^{*}\right)\right)$

\subsubsection{Vector ideal}

Es el vector de variables de decisión correspondiente a los óptimos considerando a cada una de las funciones objetivo del problema como aisladas.

\subsubsection{Optimalidad de Pareto}

Un vector de variables de decisión $\mathrm{x}^{*} \varepsilon \Omega$ es un óptimo de Pareto si no existe otro $\mathrm{x} \varepsilon \Omega$ tal que $\mathrm{f}_{\mathrm{i}}(\mathrm{x}) \leq \mathrm{f}_{\mathrm{i}}\left(\mathrm{x}^{*}\right)$ para toda $\mathrm{i}=1, \ldots, \mathrm{k}$ y $\mathrm{f}_{\mathrm{j}}(\mathrm{x})<\mathrm{f}_{\mathrm{j}}\left(\mathrm{x}^{*}\right)$ para al menos una $\mathrm{j}$.

\subsubsection{Dominancia de Pareto}


Un vector $\mathrm{u}=\left(\mathrm{u}_{1}, \mathrm{u}_{2}, \ldots, \mathrm{u}_{\mathrm{k}}\right)$ domina a otro $\mathrm{v}=\left(\mathrm{v}_{1}, \mathrm{v}_{2}, \ldots, \mathrm{v}_{\mathrm{k}}\right)($ denotado $\mathrm{u} \leq \mathrm{v})$ si y sólo si $\mathrm{u}$ es parcialmente menor que $\mathrm{v}$, es decir:

Para todo i $\varepsilon\{1, \ldots, \mathrm{k}\}, \mathrm{u}_{\mathrm{i}} \leq \mathrm{v}_{\mathrm{i}}$ y existe i $\varepsilon\{1, \ldots, \mathrm{k}\}$ tal que $\mathrm{u}_{\mathrm{i}}<\mathrm{v}_{\mathrm{i}}$.

Ejemplo:

Sean los vectores $a=(6,8), b=(4,10), c=(5,9)$ y $d=(7,8)$. Supongamos que se desea minimizar los 2 criterios.

Se tiene que $\mathrm{a} \leq \mathrm{d}$ (a domina a $\mathrm{d}$ ), sin embargo a no domina al vector $\mathrm{b}$ ni al $\mathrm{c}$.

Los vectores $\mathrm{b}$ y $\mathrm{c}$ no dominan a ningún otro. Por lo tanto los vectores $\mathrm{a}, \mathrm{b}$ y $\mathrm{c}$ son soluciones no dominadas. Obsérvese que el vector $c=(5,9)$ tiene asociados valores que no son mínimos en sus respectivas dimensiones, sin embargo no existen otros vectores que superen (sean menores en este caso) al vector c en cada una de las dimensiones.

En este ejemplo el vector ideal es $\mathrm{i}=(4,8)$.

Cotidianamente resolvemos problemas de este tipo. Por ejemplo, si salimos de casa y queremos ir al trabajo podemos optar por: ir a pie o ir en auto. Supongamos que nos interesan sólo 2 criterios: costo en $\$$ y tiempo que tardo en llegar al trabajo. Es evidente que la primera opción es más barata pero tardaremos más y la segunda cuesta más pero llegaremos en menos tiempo. En definitiva, como ninguna alternativa minimiza los 2 criterios simultáneamente (ninguna de las opciones domina a la otra, en el sentido de dominancia de Pareto), se termina privilegiando algún criterio por sobre otro (lo que equivaldría a una asignación de pesos a los distintos criterios) para arribar a una decisión final. Es decir, el que toma las decisiones necesita saber cual de las soluciones del conjunto de Pareto tomar. Este problema se conoce con el nombre de toma de decisiones multicriterio y existen diversas técnicas para tratarlo(ej.: outranking, teoría de utilidad multiatributo).

Ya tendremos ocasión de repensar el concepto de dominancia de Pareto cuando veamos la definición de "desarrollo sostenible" en el capítulo 4, la cual involucra varios criterios como el económico, social, ambiental y también cuando abordemos el concepto de "calidad de vida" el cual comprende también otros tantos aspectos o dimensiones.

\subsubsection{Frente de Pareto}

Los vectores $\mathrm{x}^{*}$ correspondientes a las soluciones no dominadas incluídas en el conjunto de óptimos de Pareto son llamados no dominados. La gráfica de las funciones objetivo cuyos vectores no dominados se encuentran en el conjunto de óptimos de Pareto se denomina frente de Pareto.

\subsubsection{No dominancia débil}


Un punto $\mathrm{x}^{*} \varepsilon \Omega$ es una solución débilmente no dominada si no hay otro $\mathrm{x} \varepsilon \Omega$ tal que $\mathrm{f}_{\mathrm{i}}(\mathrm{x})<\mathrm{f}_{\mathrm{i}}\left(\mathrm{x}^{*}\right)$ para $\mathrm{i}=1, \ldots, \mathrm{k}$.

\subsubsection{No dominancia fuerte}

Un punto $\mathrm{x}^{*} \varepsilon \Omega$ es una solución fuertemente no dominada si no hay x $\varepsilon \Omega$ tal que $\mathrm{f}_{\mathrm{i}}(\mathrm{x})$ $\leq \mathrm{f}_{\mathrm{i}}\left(\mathrm{x}^{*}\right)$ para $\mathrm{i}=1, \ldots, \mathrm{k}$ y para al menos un valor $\mathrm{i}, \mathrm{f}_{\mathrm{i}}(\mathrm{x})<\mathrm{f}_{\mathrm{i}}\left(\mathrm{x}^{*}\right)$.

\subsubsection{Trabajos relacionados}

Quaddus y Siddique (Quaddus et al. 2001) propusieron un modelo multicriterio para la planificación del desarrollo sostenible de Bangladesh. En el mismo se podía analizar cual criterio acercaba más hacia un desarrollo sostenible y dentro de cada criterio cuales proyectos contribuían más para satisfacer el criterio al que pertenecían.

El trabajo de Mendoza y Prabhu (Mendoza y Prabhu 2000) han utilizado la evaluación multicriterio para evaluar pautas de manejo forestal sustentable.

En el trabajo de Liu (Liu 2007) el autor combina valores de calidad del aire, calidad y disponibilidad del agua, uso del suelo, recursos naturales y biodiversidad para calcular lo que denomina "índice de sustentabilidad ambiental". El trabajo combina el uso de evaluación multicriterio con lógica borrosa. 


\section{Capítulo 4}

\section{Calidad de vida}

\subsection{Introducción}

Este capítulo comienza explicando lo que significa "calidad de vida" en el marco del presente trabajo, luego trata el tema de parámetros, índices e indicadores como herramientas para estimar la calidad de vida y se muestra un ejemplo empleando SIG para visualizar el valor de un indicador. Se verá, asimismo, como por medio de índices e indicadores se pueden advertir rápidamente problemas, permitiendo de este modo tomar las decisiones correspondientes para revertirlos. Posteriormente se exponen diferentes frameworks que han surgido para intentar estimar la calidad de vida urbana y se analiza la posibilidad de representarlos mediante frameworks basados en patrones de diseño.

\subsection{Concepto de calidad de vida.}

El concepto de calidad de vida (CV) ha sido motivo de debate durante años por parte de filósofos, sociólogos, economistas y profesionales de diversas disciplinas. Como se advierte en el trabajo de Nussbaum y Sen (Nussbaum et al. 1996), no existe un concenso generalizado acerca de su significado. Por tal motivo, en el contexto de este trabajo, se entenderá por "calidad de vida" a poder consolidar un desarrollo social sin deteriorar la base de recursos: naturales, humanos, energéticos y ambientales.

La definición anterior tiene estrecha relación con el término "desarrollo sustentable" dado por la WCED (World Commission on Environmental and Development) en 1987 que sostiene que (WCED 1987): "Desarrollo sustentable es aquel que satisface las necesidades de las generaciones presentes sin comprometer la capacidad de futuras generaciones para satisfacer sus propias necesidades".

El economista Herman Daly (Daly 1990, Daly 1991) postuló 3 principios para tal fin:

$>$ "Las tasas de utilización de recursos no deben exceder de las tasas de regeneración del ambiente, es decir, no se debe extraer -o gastar- más de lo que la naturaleza pueda regenerar. $O$, si se quiere, no se debe destrozar la capacidad de feedback generativo del ambiente.

> Las tasas de utilización de recursos no renovables no deben exceder de las tasas a cuyo nivel los sustitutos renovables se desarrollan. Es decir, no debe peligrar el equilibrio entre producción natural y producción tecnohumana. 
- Las tasas de emisión de agentes contaminantes no deben exceder de la capacidad de asimilación del ambiente”.

Estas condiciones, aunque deseables, no son suficientes, dado que por ejemplo nada dicen respecto a la temática social. En este sentido, otros autores han ido más allá proponiendo además algunas pautas sociales (Castelar-Busó 1997, Meadows et al. 1992, Fundación Bariloche 1977).

\subsection{Concepto de calidad de vida urbana}

Como es de esperar, el término calidad de vida urbana, en adelante CVU, se refiere al estudio de la calidad de vida en el sentido antes expuesto, aplicado al ámbito urbano. Esto NO significa que cuando se habla de CVU debe entenderse como el estudio de la CV de una ciudad como si la misma fuese una entidad aislada del resto. Por el contrario, piénsese por ejemplo el caso de las grandes ciudades las cuales poseen todo su territorio urbanizado. Para cubrir sus necesidad de alimentos, por citar un ejemplo, recurren a la importación de los mismos. En otras palabras, la necesidad de recursos de diversa índole (energéticos, materiales, etc.) de una ciudad requiere de lugares que están más allá de sus propias fronteras.

Como veremos a continuación, con la colaboración de índices e indicadores, es posible advertir de manera temprana si las acciones, principalmente antrópicas, van de acuerdo con nuestras expectativas de calidad de vida para, en caso de que no sea así, tomar las decisiones necesarias para revertir la situación. Un ejemplo en este sentido es el trabajo de de Paz (de Paz 2006), quien combina el uso de SIG e indicadores ambientales para estimar la degradación del suelo y sugerir políticas de acción posibles para mejorar la situación.

\subsection{Parámetros, índices e indicadores}

La OECD (OECD 1993 op cit.) define los términos: indicador, índice y parámetro de la siguiente manera:

Indicador: un parámetro, o un valor derivado de parámetros que señala acerca de, proporciona información sobre, y describe el estado de un fenómeno/ambiente/área, con una significación que se extiende más allá de la que está directamente asociada con el valor de un parámetro.

Indice: un conjunto “agregado” o ponderado de parámetros o “indicadores”.

Parámetro: una propiedad que es medida u observada.

Los indicadores reducen la cantidad de mediciones y parámetros necesarios que serían requeridos para obtener una representación "exacta” de una situación (OECD 1993 op.cit). 
Los indicadores facilitan la tarea de comunicar los resultados de mediciones a los usuarios resignando requisitos necesarios desde el punto de vista científico para demostrar cadenas causales. Los indicadores deberían ser vistos como una expresión del "mejor conocimiento disponible" (OECD 1993 op.cit).

Los índices tratan de condensar información de diferentes indicadores bajo una única expresión numérica. Al hacer esto, se pierde cierta información debido a que se aumenta el grado de generalidad. Algo similar vimos que ocurre en la representación de árboles cuaternarios (ver 2.4.3.1): a medida que cambiamos de nivel de detalle ocurre que, a mayor grado de detalle, menos generalidad (aumenta la especificidad) y viceversa.

Los índices son magnitudes adimensionales generalmente, pues resultan de la adición ponderada, según el procedimiento que se elija, de diversas unidades de medida(Rueda 1999).

El objetivo que persigue la construcción de índices es obtener una síntesis de la información relevante que pueda ser usada como base para la toma de decisiones.

A continuación se presenta una síntesis de los criterios de selección para indicadores de sostenibilidad (Vera Rebollo 2004):

\section{Obtención de la información}

Disponibilidad. Los indicadores deben construirse con información existente o disponible dentro de una relación coste-beneficio razonable.

Representatividad. Determinados indicadores requieren la existencia de series estadísticas comprensivas de un período temporal suficientemente representativo.

Actualización. De acuerdo con las características del indicador, la información debe actualizarse periódicamente.

Equlibrio entre los indicadores científico-técnicos y los obtenidos a través de procesos de participación social. La combinación de ambos tipos de indicadores suele ser necesaria y conveniente, con lógicas variaciones según los objetivos cada sistema de indicadores.

\section{Consistencia metodológica y validez científica}

Rigor científico. Los indicadores deben estar basados en fundamentos científicos sólidos. Fiabilidad. Los datos utilizados no deben contener dudas acerca de su fiabilidad.

Consenso. Es deseable el mayor consenso científico en la aplicación de los indicadores de sostenibilidad al turismo.

Comparabilidad. Facilitada por el consenso, amplía los elementos de referencia, consolida la aplicación de metodologías de obtención, generaliza el uso y, en suma, facilita la mejora continua de los sistemas de indicadores.

Representatividad. Cada indicador debe medir un aspecto significativo de la sostenibilidad.

Sensibilidad a cambios. Los indicadores deben reflejar fielmente las modificaciones producidas en los distintos componentes de la sostenibilidad (ambiental, económica o sociocultural).

Integración. Deben estar fácilmente conectados con otros instrumentos científicos y técnicos (modelos econométricos o Sistemas de Información Geográfica, por ejemplo). 
Adaptación. No existen indicadores universalmente válidos, luego deben adaptarse a la especificidad de cada área de estudio.

\section{Aplicación y comunicación}

Comprensión. Los indicadores deben ser claros y sencillos de interpretar, tanto para facilitar su integración en los procesos de toma de decisiones de las políticas públicas como para su difusión social.

Simplificación. Un menor número de indicadores, rigurosamente seleccionado, facilita su mejor comprensión y aumenta las posibilidades de aplicación.

Resonancia. Capacidad de despertar el interés de los agentes implicados, en el caso del turismo, Administraciones Públicas, empresas, turistas y sociedad local.

Valores de referencia. Cada indicador debe relacionarse con valores de referencia, o umbrales de sostenibilidad, con los que comparar su situación actual.

Expresión de tendencias. Los indicadores deben señalar la evolución de los distintos componentes de la sostenibilidad en relación con los valores de referencia.

Integración. Los indicadores deben integrarse en los procesos de planificación y gestión.

Por su parte, para la parte específica de indicadores ambientales, la OECD definió las propiedades deseables de un "buen" indicador. La OCDE (OECD 1993 op.cit) ha adoptado 3 criterios rectores para la selección de indicadores:

$>$ Los relacionados a su relevancia política y a la utilidad para los usuarios.

> Los relacionados a su solidez analítica.

$>$ Los relacionados a la mensurabilidad.

Con respecto a la relevancia política y la utilidad para los usuarios la OECD establece que deberían:

$>$ Proporcionar un cuadro representativo de las condiciones ambientales, las presiones sobre el ambiente o las respuestas de la sociedad.

$>$ Ser simple, fácil de interpretar y capaz para mostrar tendencias en el tiempo.

$>$ Ser sensible a los cambios en el ambiente y a las actividades humanas relacionadas.

$>$ Proveer una base para comparaciones internacionales.

$>$ Ser de alcance tanto nacional como a escalas regionales pero de importancia nacional.

$>$ Tener un umbral o valor de referencia contra el cual compararlo de modo que permita a los usuarios evaluar la signifacancia de los valores asociados a éste.

Con respecto a la solidez analítica un indicador ambiental deberían:

$>$ Tener bases teóricamente sólidas, tanto en términos técnicos como científicos.

$>$ Estar basado en normas internacionales así como en consensos internacionales sobre su validez. 
$>$ Prestarse a ser vinculado a modelos económicos, proyecciones y sistemas de información.

Con respecto a la mensurabilidad, los datos necesarios para apoyar un indicador deben ser:

Fácilmente disponibles o accesibles a una razonable relación costo/beneficio.

$>$ Adecuadamente documentados y de calidad conocida.

$>$ Actualizados a intervalos regulares de acuerdo con procedimientos confiables.

En síntesis, se puede decir que las principales funciones de los indicadores son las siguientes (Rabinovich 2005 op cit.):

$>$ Evaluar condiciones actuales.

$>$ Comparar entre lugares y situaciones.

$>$ Evaluar condiciones y tendencias en relación a objetivos y metas.

$>$ Proveer de información temprana para alertas.

$>$ Anticipar futuras condiciones y tendencias.

En ocasiones, cuando por algún motivo no puede medirse el valor de un indicador se suele usar los proxies.

Los proxies constituyen una representación indirecta de algún indicador o combinación de indicadores y se los utiliza cuando (Rabinovich 2005 op. cit):

$>$ Hay variables que están fuertemente correlacionadas con otras variables.

$>$ Cuando la variable de interés no se puede medir (porque es imposible, o por razones de tipo ético o de costos).

En general, en sentido estricto, se suele reservar el término "indicador" a lo que representa una única variable -que representa un atributo-, mientras que un "índice" se deriva de un conjunto de variables (Rabinovich 2005 op. cit).

Un conjunto de variables que se presentan simultáneamente para informar acerca de una situación/ambiente no es un índice sino un perfil. Es decir, un perfil puede verse como un vector de indicadores.

El índice, en cambio, combina de alguna manera diferentes indicadores para obtener como resultado final un número, y no un vector de números como es el caso del perfil.

\subsection{Agregación de indicadores para formar índices}

Según Rabinovich (Rabinovich 2005 op.cit) “el proceso de amalgamar “indicadores” en índices es una necesidad tanto para los que toman decisiones sobre políticas como para el público en general.

Esa necesidad se manifiesta en una demanda por información confiable y bien sintetizada sobre el ambiente (sin "perderse" en los detalles). Por ello el creciente interés en un 
número reducido de indicadores ambientales que hayan sido seleccionados a partir de conjuntos mayores pre-existentes. También existe una creciente demanda por índices integrados de orden más alto.

Pero por otro lado satisfacer esta demanda tiene una consecuencia importante que lo hace riesgoso. Durante el proceso de aglomeración se suele perder la relación entre los valores del índice resultante los valores de las variables que lo componen. $Y$ son justamente estas últimas las que nos sugieren los posibles cursos de acción en función de la decisión tomada en base al índice".

Existen varias técnicas para formar índices de calidad de vida a partir de indicadores. La forma definitiva de la función que calculará el índice depende por lo general de la importancia que se le asigne a cada dimensión y, además, de la importancia relativa que se le dé a los indicadores pertenecientes a una misma dimensión.

Para la construcción de un índice de calidad de vida urbana, el primer paso consiste en seleccionar las dimensiones a considerar que, por lo general, suelen ser: ambiental, social y económica. Luego, para cada una de las dimensiones elegidas, debe confeccionarse una lista de indicadores que la represente lo mejor posible, como lo señala la figura 4.1.

Leva (Leva 2005 op cit.) destaca la importancia de contar además con una dimensión subjetiva afirmando que "no basta con proveer a la sociedad con suficientes satisfactores (en cantidad y calidad) sino que las personas los deben percibir así".

"Para conocer la experiencia de calidad de vida de un grupo social determinado o de un individuo, es necesario preguntar al individuo o los individuos de sus intereses y necesidades, aceptando que la distinción entre lo objetivo y lo subjetivo tiene cierta similitud con la distinción filosófica entre necesidades y deseos" (Chacón 2004, citado en Leva 2005 op.cit.).

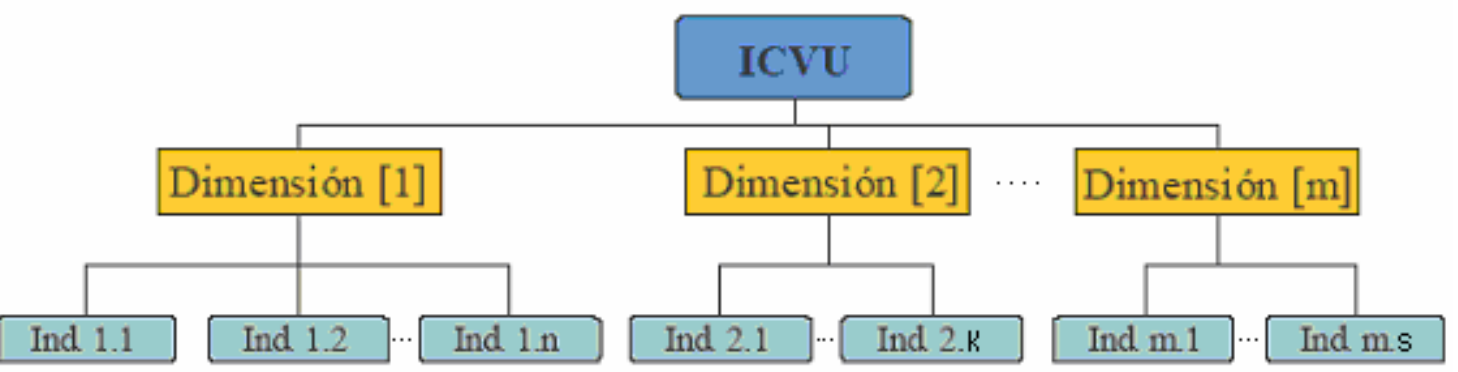

Figura 4.1. Estructura de un índice de calidad de vida. Fuente: Adaptado de Leva 2005 op.cit.

Como se observa en el gráfico anterior, un índice de calidad de vida urbana (ICVU) se caracteriza por tener múltiples dimensiones.

Cada dimensión está compuesta por un conjunto de indicadores que describen distintos aspectos de la dimensión a la cual pertenecen.

Así, por ejemplo, se podría tener una dimensión "Medio ambiente" dentro de la cual existan indicadores como "Concentración de monóxido de carbono en ppm (partículas por millón)".

Cuando se construye un ICVU es posible asignar mayor importancia a una dimensión que a otra y lo mismo acontece con los indicadores que pertenecen a una misma dimensión; unos pueden tener más relevancia que otros. 
Esto permite reflejar la importancia relativa que se le da a los problemas dentro de una determinada comunidad. Cabe resaltar aquí, que no existe un conjunto de indicadores que pueda ser aplicados a todas las ciudades y que permitan informar objetivamente del estado de una ciudad en relación con otra. En el trabajo de la European Communities (European Communities 2000 op.cit) se pone de manifiesto este hecho al intentar comparar la calidad de vida de 58 ciudades europeas. En ese trabajo el criterio utilizado para evaluar los "espacios verdes al cual el público tiene acceso", por citar un ejemplo, no era el mismo para todas las ciudades que formaron parte del proyecto.

\subsection{Métodos de agregación}

Se define como método de agregación al proceso de generar un índice a partir de la combinación de un conjunto de indicadores por medio de una función matemética.

Estas combinaciones pretenden sintetizar la información proveniente de varios indicadores de modo que puedan servir como base para la toma de decisiones.

Previo al proceso de agregación de índices, se procede a normalizar los indicadores para que todos queden en la misma escala, normalmente, el intervalo [0..1].

En adelante, se supondrá que a mayor valor de indicador significará una situación mejor.

El proceso de normalización transforma valores de un cierto rango al intervalo [0..1]. Su fórmula es bien conocida:

(x-MIN) / (MAX-MIN)

y permite "mapear" el mínimo valor de un cierto rango a 0 y el máximo valor a 1 . La ventaja que proporciona la normalización es poder comparar relativamente magnitudes diferentes.

No obstante, hay situaciónes en las que un alto valor de un indicador puede reflejar una situación desfavorable, como por ejemplo un indicador que mida la "concentración de partículas por millón de un contaminante". Ante una situación así se emplea la fórmula:

$(\mathbf{M A X}-\mathbf{x}) /(\mathbf{M A X}-\mathrm{MIN})$

Mediante las fórmulas precedentes es posible entonces convertir un conjunto de indicadores, posiblemente heterogéneos en cuanto a su unidad de medida y magnitud, en indicadores cuyos valores estarán en el rango [0..1] de manera que cuando su valor sea próximo a 1 reflejará una situación favorable. Una vez hecho este procedimiento es posible aplicar diferentes criterios para la elaboración de un índice, como veremos a continuación.

Leva (Leva 2005 op.cit) describe 3 métodos que utilizan indicadores normalizados para elaborar un índice.

Construcción lineal.

$>$ Construcción ponderada simple.

$>$ Construcción ponderada múltiple.

En el primero de ellos, el índice es simplemente la suma de los indicadores. 


$$
\sum_{i=1}^{n} \text { indicador }_{i} \quad \text { donde: } \quad n=\text { Cantidad de indicadores }
$$

En la construcción ponderada simple hay 2 caminos posibles. En ambos casos, el cálculo de una dimensión se efectúa como sigue:

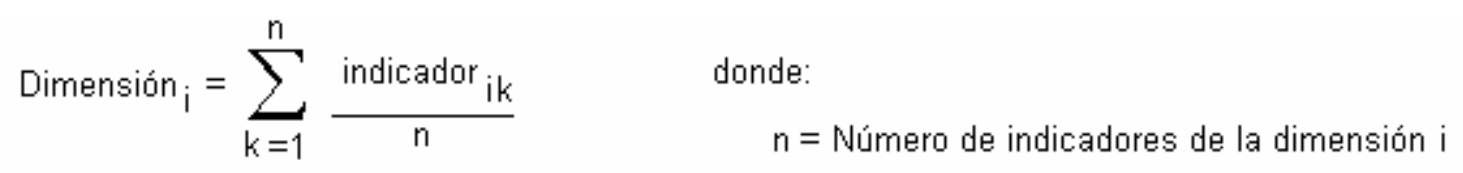

Pero para el cálculo del índice la fórmulas puede ser cualquiera de las 2 siguientes:

$$
\sum_{i=1}^{m} \frac{D_{i}}{m} \quad \text { donde: }
$$

o bien

$$
\begin{aligned}
\sum_{i=1}^{m} D_{i} * \text { PesoDeLaDimensión }_{i} \quad \text { donde: } & \\
& m=\text { Número de dimensiones } \\
& \sum_{i=1}^{m} \text { PesoDeLaDimensión }_{i}=1 \\
& 0<=\text { PesoDeLaDimensión }_{i}<=1 \quad \forall i
\end{aligned}
$$

La fórmula que utiliza ponderación permite dar distinto peso a las diferentes dimensiones. Por último, la construcción ponderada múltiple, se calcula de manera parecida a la anterior con la diferencia de que no sólo asigna pesos a las dimensiones sino que también lo hace con los indicadores dentro de cada dimensión.

$$
\begin{aligned}
& \sum_{i=1}^{m} D_{i} * \text { PesoDeLaDimensión } i \\
& \text { donde: } \\
& m=\text { Número de dimensiones } \\
& \sum_{i=1}^{m} \text { PesoDeLaDimensión }_{i}=1 \\
& 0<=\text { PesoDeLaDimensión }_{\mathrm{i}}<=1 \quad \forall \mathrm{i}
\end{aligned}
$$




$$
\begin{aligned}
& \mathrm{D}_{\mathrm{i}}=\sum_{\mathrm{j}=1}^{\mathrm{n}} \text { Indicador }_{\mathrm{ij}}{ }^{*}{ }^{\text {PesoDelndicador }} \mathrm{j}_{\mathrm{j}} \quad \text { Indicador }_{\mathrm{i} j}=\mathrm{j} \text {-ésimo indicador de la i-ésima dimensión } \\
& \mathrm{D}_{\mathrm{i}}=\text { Dimensión i-ésima } \\
& \mathrm{n}=\text { Número de indicadores de la dimensión } \mathrm{i} \text { (puede variar de una dimensión a otra) } \\
& \sum_{\mathrm{i}=1}^{\mathrm{n}} \text { PesoDelndicador }_{\mathrm{j}}=1 \\
& 0<=\text { PesoDelndicador }_{\mathrm{j}}<=1 \quad \forall \mathrm{j}
\end{aligned}
$$

Además de los ya citados, podemos encontrar otros índices como el promedio ponderado, la media geométrica, la media geométrica ponderada, raíz de los cuadrados medios, entre otros.

\subsection{Formas de representación de los indicadores}

Normalmente se requiere de varios indicadores para tener una idea respecto de alguna dimensión de la calidad de vida como podría ser la dimensión ambiental o la económica. Existen métodos que permiten mostrar de manera simultánea varios indicadores y que, no obstante ello, son fáciles de interpretar y permiten rápidamente dar una idea acerca de la situación que se quiere observar.

Dos de éstos métodos son:

El diagrama de Bugnicourt.

$>$ El sistema ameba.

El diagrama de Bugnicourt representa en forma de 5 anillos concéntricos los valores de diferentes variables (desde 1 "sin problemas" hasta 5 "problema serio").

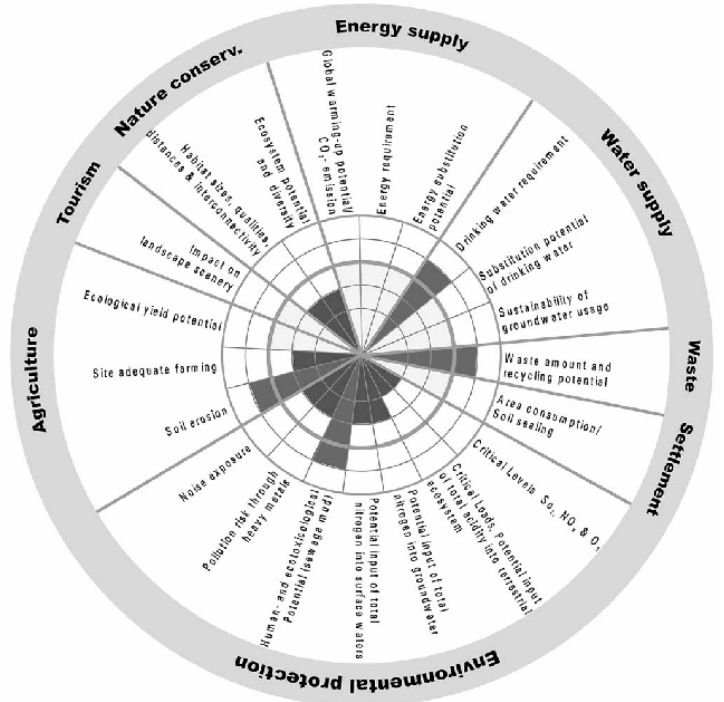


Figura 4.2. Diagrama de Bugnicourt. Fuente: Lenz 2003.

Una variante, similar a la anterior es el sistema "AMEBA" el cual, no cuenta con anillos concéntricos, pero los valores de los indicadores pueden superar su valor de referencia.

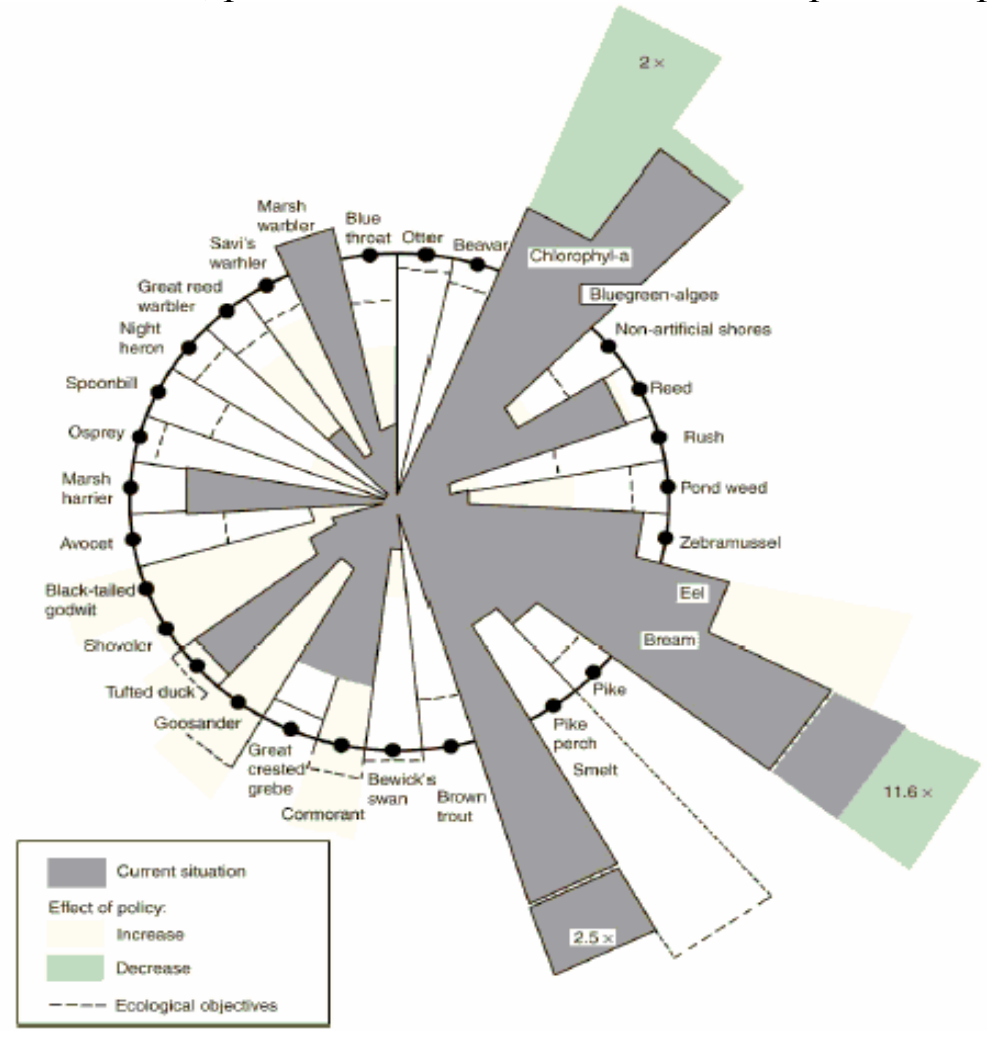

Figura 4.3. Representación en forma de ameba. Fuente: Sutter II, 2001.

\subsection{Clasificación de indicadores}

Los indicadores pueden clasificarse de distintas maneras en función de la problemática que pretenden describir. A continuación veremos las clasificaciones más comunes que se usan actualmente en la marco de la calidad de vida urbana.

4.8.1 Clasificación de indicadores según la Agencia Europea de Medio Ambiente (EEA)

La EEA distingue 3 tipos de indicadores: de modelo, indicadores de flujo e indicadores de calidad (Diputación de Barcelona 2000).

> Modelo: Los indicadores de modelo municipal describen procesos o fenómenos en los que influyen muchos factores y se relacionan directamente con el modelo municipal básico. 
$>$ Flujo: Los indicadores de flujo municipales abordan los ciclos de materia y de energía desde el punto de vista de su producción, distribución, tratamiento y reutilización.

> Calidad: Los indicadores de calidad ambiental municipal son aquellos que se refieren a las condiciones finales del medio municipal.

El trabajo de la Diputación de Barcelona (Diputación de Barcelona 2000 op.cit) se desarrolló en base a esta clasificación.

4.8.2 Clasificación de indicadores según el modelo Presión-Estado-Respuesta (PER) de la OCDE

El modelo de la OCDE divide los indicadores ambientales en 3 grupos: presión, estado y respuesta.

El modelo PER intentar modelizar el hecho de que las actividades humanas ejercen presiones sobre el ambiente, las cuales afectan la cantidad y calidad de los recursos naturales y el medio ambiente ( $\underline{\text { estado }})$. Esta información provoca que se adopten políticas e implementen proyectos (respuestas) para prevenir o reducir los impactos negativos sobre el medio ambiente. Las respuestas generarán nuevas presiones formando nuevamente un ciclo.

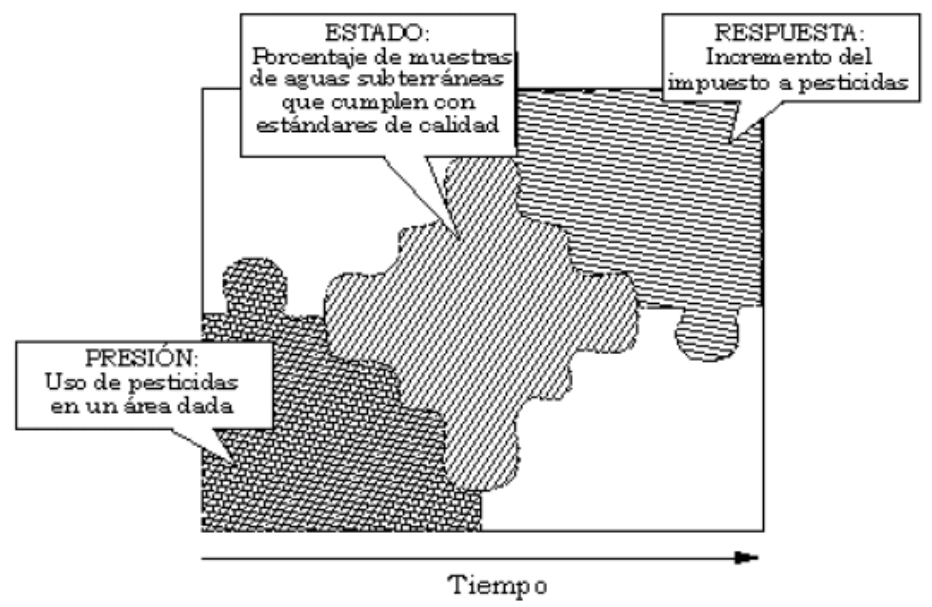

Figura 4.4. Ejemplo del modelo presión-estado-respuesta. Fuente: Hardi et al. 1995.

En el modelo PER se definen 3 tipos de indicadores en base a los criterios siguientes:

> Presión: Los indicadores de presión son aquellos que describen los impactos que provocan las actividades humanas sobre el medio ambiente, ya sea de forma directa (ej.: emisiones de gases de efecto invernadero o consumo de recursos naturales) o indirecta (ej.: presiones sobre la biodiversidad ejercidas por la construcción de 
carreteras). Sirven para describir como ciertas acciones antrópicas afectan la calidad y cantidad de recursos naturales.

Estado: Los indicadores de estado muestran la calidad del medio ambiente y de los recursos naturales (flora, fauna, suelo, aire y agua). Estos indicadores tienen que dar una visión global de la situación del medio ambiente y de su evolución, pero no de la presión que se ejerce sobre él.

Respuesta: Los indicadores de respuesta expresan en qué medida la sociedad (instituciones, administraciones, colectivos, sectores económicos, etc.) responde a los cambios ambientales y su preocupación por ellos. Entendemos por respuesta de la sociedad las acciones individuales o colectivas que tienen como propósito evitar, atenuar o corregir las repercusiones negativas para el medio ambiente como consecuencia de la actividad humana.

Framework Presión - Estado - Respuesta

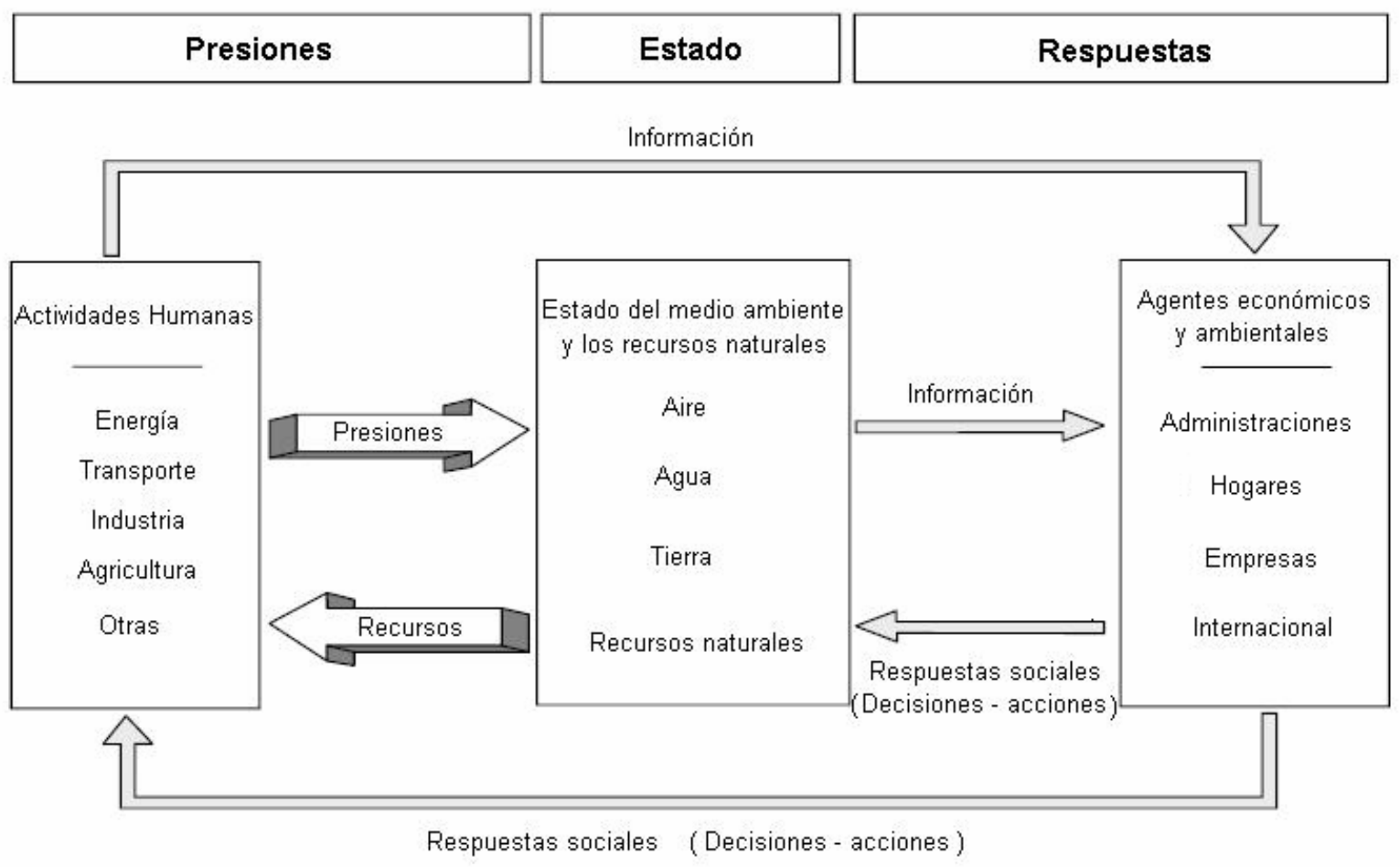

Figura 4.5. Framework presión-estado-respuesta. Fuente: OECD 1993 op.cit.

4.8.3 Clasificación de indicadores según el modelo Fuerza conductora-Presión-EstadoImpacto-Respuesta (DPSIR) de la OCDE

Este framework, sucesor del anterior, proporciona una metodología para el análisis de problemas medioambientales. 
Clasifica los indicadores en 5 tipos diferentes:

$>$ Fuerzas conductoras: Actividades antrópicas y procesos que causan presiones sobre el ambiente. Ej.: producción agrícola, producción industrial, transporte.

$>$ Presiones: cargas directas sobre el ambiente producto de acciones antrópicas. Ej.: emisiones de contaminantes al aire proveniente del uso de medios de transporte.

> Impactos: efectos sobre las personas debido a cambios en el estado del medio ambiente. Por ejemplo: consecuencias negativas para la salud, pérdidas económicas.

$>$ Estado: los indicadores de estado describen la situación y tendencias del medio ambiente (local y global) en un momento dado.

$>$ Respuestas: actividades de la sociedad para reducir, compensar o evitar los impactos negativos.

Una descripción del DPSIR y su comparación con otros frameworks puede encontrarse en un trabajo de la OECD (OECD 2005).

En la figura 4.6 se expone un ejemplo de la aplicación del framework DPSIR a la actividad turística.

\section{MODELO DPSIR APLICADO A LA ACTIVIDAD TURÍSTICA}

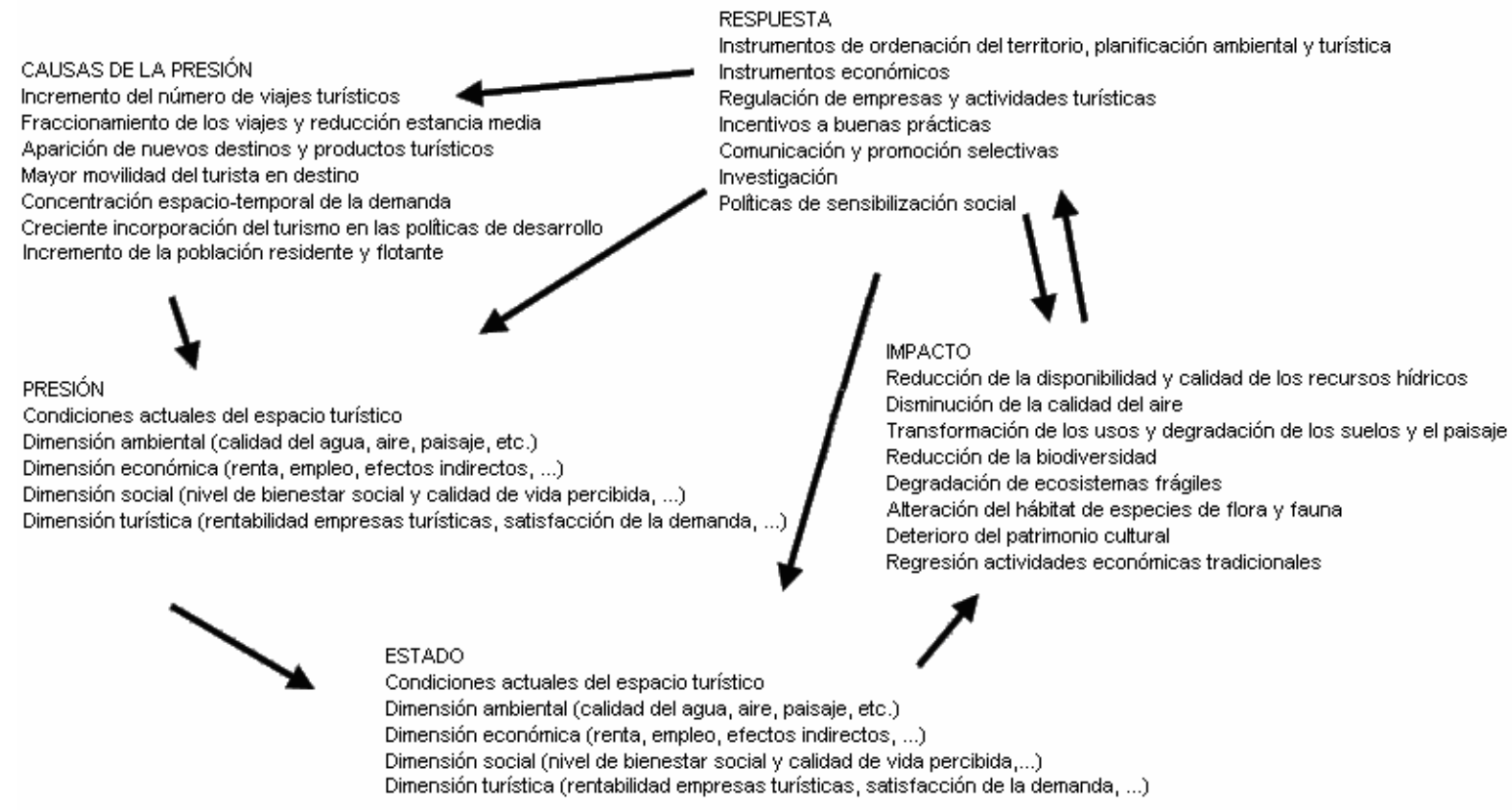

Figura 4.6. Framework DPSIR aplicado a la actividad turística. Fuente: Vera Rebollo et al. 2004 op cit. 


\subsection{Ejemplos de índices e indicadores y visualización mediante SIG.}

Veamos ahora como ejemplo, un índice del trabajo de la Diputación de Barcelona (Diputación de Barcelona 2000 op.cit.). Este trabajo detalla para cada indicador:

$>\mathrm{Su}$ fórmula,

$>$ la unidad en que se mide,

$>$ la periodicidad con la cual debe calcularse,

$>$ las fuentes de donde obtener la información necesaria,

$>$ una representación gráfica en función del tiempo y

$>$ la tendencia deseada sugerida.

Dado que el trabajo se basó en la clasificación de la EEA, los índices se hallan clasificados en 3 categorías: modelo, calidad y flujo. A continuación se muestra el índice "Proximidad a servicios urbanos básicos", que es un índice de modelo. El mismo tiene en cuenta los siguientes tipos de equipamientos y servicios básicos:

$>$ Equipamientos educativos públicos y concertados (escuela infantil, primaria y secundaria obligatoria ).

$>$ Espacios verdes y otros espacios de uso público al aire libre (jardines, parques, plazas).

$>$ Centros de salud (centros de atención primaria y hospitales )

$>$ Abastecimiento alimentario.

$>$ Transporte público (incluye el urbano y el interurbano ).

$>$ Dotaciones públicas culturales y de ocio (teatros, cines, centros cívicos, bibliotecas, polideportivos, etc.)

Índice: "Proximidad a servicios urbanos básicos”

Fórmula: ( Población con densidad entre 75 y 550 habitantes/hectárea que dispone de 6 servicios básicos a menos de 500 metros / Población total ) x 100

Unidad: \%.

Fuente: Ayuntamiento.

Representación gráfica: 


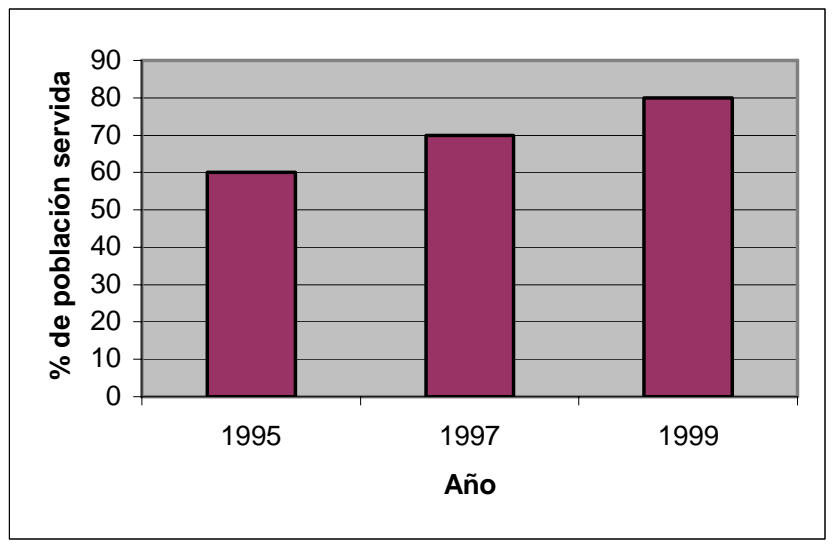

Figura 4.7. Representación gráfica del indicador "Proximidad a servicios urbanos básicos". Fuente: Diputación de Barcelona 2000 op cit.. Elaboración propia.

Periodicidad: cada 2 años.

Tendencia deseada: aumento.

La figura 4.8 considera la proximidad de servicios de salud, educación y espacios verdes a menos de 500 metros en el casco urbano de la ciudad de La Plata, Argentina. Se muestran las manzanas de la ciudad en una graduación de colores. Aquellas con el color más oscuro significa que tienen los 3 servicios (salud, educación y espacios verdes a menos de 500 metros). Por el contrario, las que tienen el color más claro no tienen ningún servicio en un radio de 500 metros.

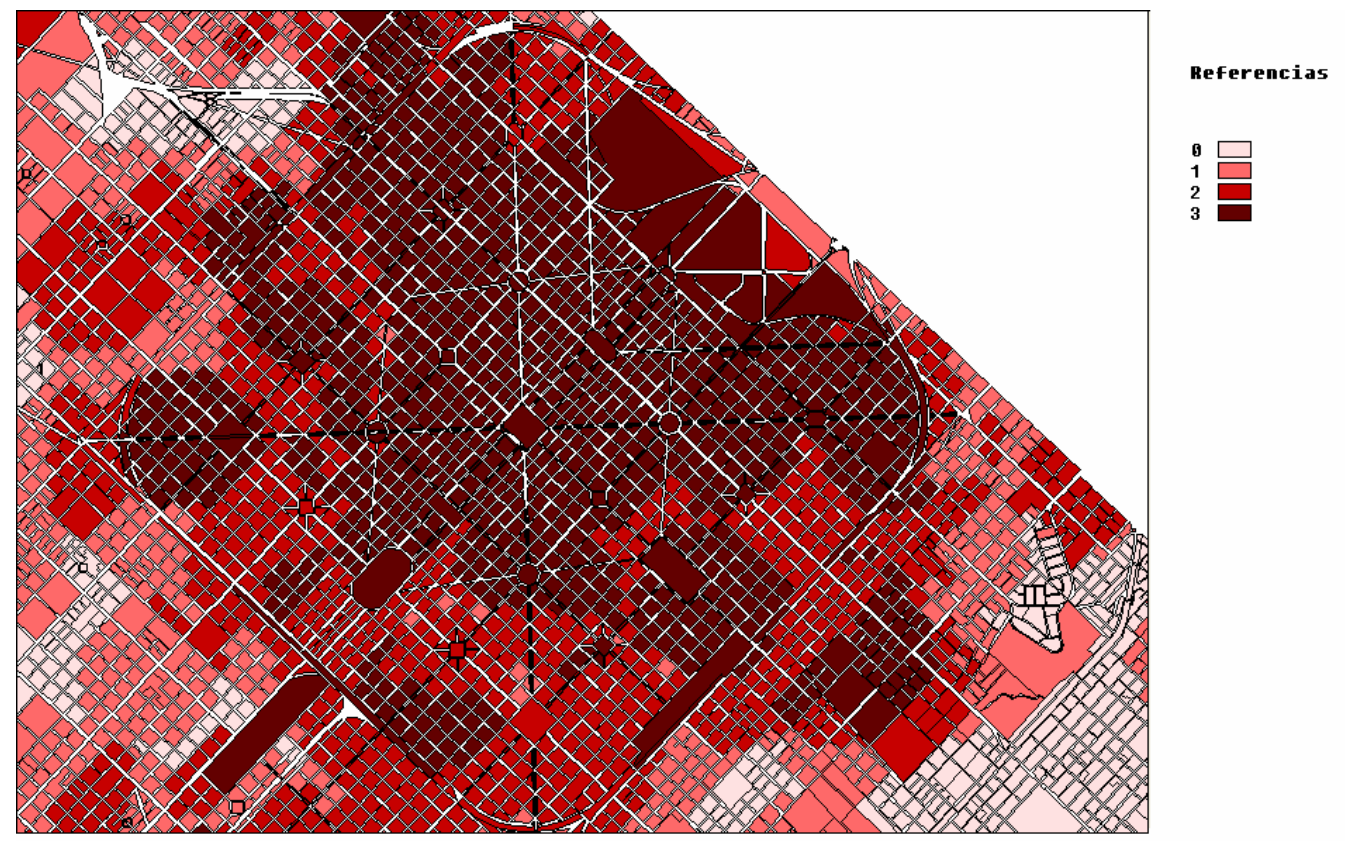

Figura 4.8. Visualización de un índice mediante SIG. 
Algunos índices de CVU pueden visualizarse espacialmente mediante SIG, como en el ejemplo de la figura 4.8. Otra forma posible de visualizarlos es mediante los diagramas de Bugnicourt y el sistema ameba (inciso 4.7). También es posible obtener una salida gráfica que permita observar la ponderación asignada a cada dimensión así como también la asignada a cada uno de los indicadores dentro de una misma dimensión. A continuación se observan los resultados obtenidos en el estudio de CVU hecho en la ciudad de Quilmes por Leva (Leva 2005 op cit.). En el mismo se ha puesto énfasis en la dimensión subjetiva (opinión de las personas) por sobre las dimensiones relacionadas al hábitat, lo social y lo económico. Esto se refleja en la relación que ocupa dentro del círculo cada dimensión.

Rápidamente se advierte la criticidad de la situación social puesta de manifiesto por el color rojo y viendo que la mayoría de los indicadores de esta categoría están asimismo de color rojo.

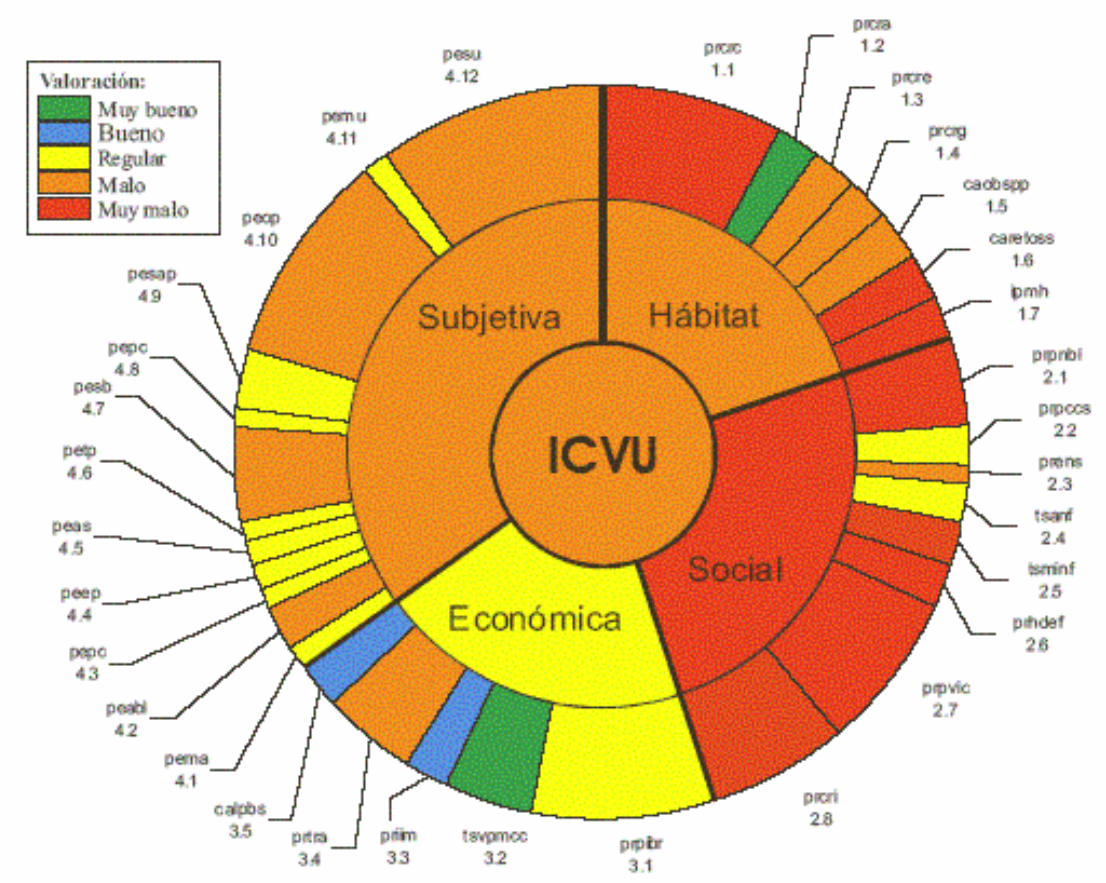

Figura 4.9. Resultados obtenidos por el índice de CVU en la ciudad de Quilmes. Fuente: Leva 2005 op.cit.

Otro ejemplo de índice es el ICA (índice de calidad del agua o Water Quality Index, WQI en inglés) que fue desarrollado en 1970 por la Fundación de Sanidad Nacional de los Estados Unidos. El mismo usa 9 indicadores como se observa en la tabla 4.1 con sus respectivos pesos. Cada indicador puede tomar valores en el rango 0 a 100. El valor de cada indicador se multiplica por el peso que tiene asociado y luego se suman todos estos productos.

La característica del agua viene entonces dada por la puntuación obtenida luego de realizar la suma anterior, según se describe en la tabla 4.2. 


\begin{tabular}{|l|r|} 
Oxígeno disuelto & 0,17 \\
\hline Coliformes fecales & 0,15 \\
\hline PH & 0,12 \\
\hline DBO & 0,1 \\
\hline Nitratos & 0,1 \\
\hline Fosfatos & 0,1 \\
\hline Desviación del la temperatura & 0,1 \\
\hline Turbidez & 0,08 \\
\hline Sólidos totales & 0,08 \\
\hline
\end{tabular}

Tabla 4.1. Indicadores usados para la obtención del índice ICA y sus pesos respectivos.

\begin{tabular}{|l|l|}
\hline Característica del agua & Valor numérico \\
\hline Muy mala & $0-25$ \\
\hline Mala & $26-50$ \\
\hline Media & $51-70$ \\
\hline Buena & $71-90$ \\
\hline Excelente & $91-100$ \\
\hline
\end{tabular}

Tabla 4.2. Determinación de la calidad del agua a partir del valor obtenido del índice.

Se observa que el ICA usa el método de la suma ponderada para arribar a un número que da una idea de la calidad del agua a partir del conocimiento del valor obtenido por los 9 indicadores citados.

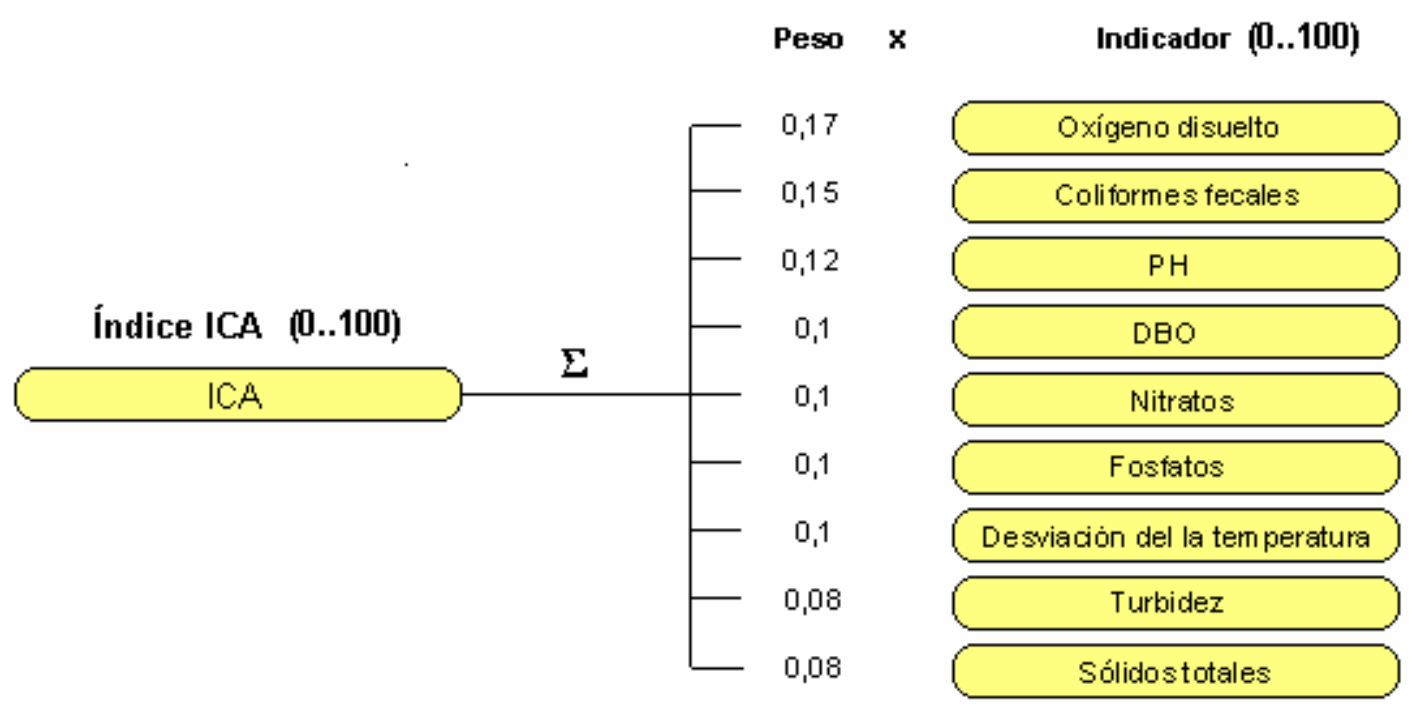

Figura 4.10. Obtención del índice ICA a partir de indicadores.

Dado que el índice depende del valor de los 9 indicadores de la tabla 4.1, cualquier cambio en alguno de ellos implicará un cambio en el valor del índice. 


\subsection{Otras formas de calcular el impacto de las acciones antrópicas sobre una región}

Además de las metodologías citadas previamente existen otras relacionadas que de alguna manera miden el impacto sobre el medio ambiente producto de las acciones antrópicas. Entre las más conocidas podemos mencionar los conceptos de: capacidad de carga y huella ecológica.

Por capacidad de carga se entiende a la población máxima de una especie que puede mantenerse sustentablemente en un territorio sin deteriorar su base de recursos(Rueda 1999).

Se define como huella ecológica a la superficie de suelo productivo necesaria para mantener una población determinada, independientemente de donde sea que se encuentre dicho suelo (Rees 1996, Wackernagel y Rees 1996, Venetoulis y Talberth 2005).

El área de suelo/agua requerida para mantener los flujos de materiales, energía y sus degradados requeridos por una determinada población es la denominada "huella ecológica" de la población en cuestión (Rueda et al. 1999 op.cit). Su cálculo nos permite tener una medida aproximada de las necesidades de capital natural de cualquier población, en comparación al suministro disponible (Rees 1996 op cit.).

Otro tema que tiene relación con el impacto que tienen las acciones antrópicas sobre una región es el cambio de uso del suelo. Briassoulis (Briassoulis 2000) describe exhaustivamente en su trabajo los distintos tipos de modelos de cambio de uso del suelo brindando un estado del arte al respecto.

Otro enfoque que tiene relación con la calidad de vida urbana es la organización territorial de una ciudad. Existen 2 modelos de organización antagónicos: ciudad compacta y ciudad difusa aunque es difícil que una ciudad encuadre perfectamente en alguno de los 2 anteriores criterios. Puede afirmarse que toda ciudad es compacta en cierto grado y también difusa en cierto grado.

Se presenta a continuación una comparación de ambos enfoques. 


\begin{tabular}{|c|c|c|c|c|c|}
\hline \multirow{2}{*}{\multicolumn{2}{|c|}{$\begin{array}{l}\text { presión sobre los sistemas } \\
\text { de soporte por explotación }\end{array}$}} & \multicolumn{2}{|r|}{ MODELO DE CIUDAD DIFUSA } & \multicolumn{2}{|r|}{ MODELO DE CIUDAD COMPACTA } \\
\hline & & nivel & causa & nivel & causa \\
\hline $\begin{array}{l}\text { consumo de } \\
\text { materiales } \\
\text { consumo de } \\
\text { energia } \\
\text { consumo de } \\
\text { energía } \\
\text { consumo de } \\
\text { energía } \\
\text { consumo } \\
\text { de agua }\end{array}$ & $\begin{array}{l}\text { para la producción y el } \\
\text { mantenimiento del mo- } \\
\text { delo urbano } \\
\text { en relación al modelo } \\
\text { de movilidad } \\
\text { en relación a las tipolo- } \\
\text { glas edificatoria } \\
\text { en relación a los servi- } \\
\text { cios } \\
\text { en relación a las tipolo- } \\
\text { gias edificatorias }\end{array}$ & $\begin{array}{l}> \\
>\end{array}$ & $\begin{array}{l}\text { la dispersión de la edificación y las } \\
\text { infraestructuras. La superficie edifi- } \\
\text { cada por habitante es mayor. Tipo- } \\
\text { logia edificatoria con mayor mante- } \\
\text { nimiento } \\
\text { el modelo de movilidad descansa en } \\
\text { el vehiculo privado } \\
\text { se consume más energia en las } \\
\text { tipologias edificatorias unifamiliares } \\
\text { dispersión de las redes } \\
\text { consumo en jardin, piscina, etc. }\end{array}$ & $\begin{array}{l}< \\
<\end{array}$ & $\begin{array}{l}\text { la proximidad entre usos y funcio- } \\
\text { nes supone un menor consumo de } \\
\text { materiales. La suprficie edificada } \\
\text { habitante es menor. Tipologia edifi- } \\
\text { catoria con menor mantenimiento } \\
\text { la mayoria de viajes se pueden rea- } \\
\text { lizar a pie, bicicleta o en transporte } \\
\text { pubblico } \\
\text { las demandas energéticas en blo- } \\
\text { ques de apartamentos es menor } \\
\text { por proximidad de las redes } \\
\text { en edificación plurifamiliar es menor }\end{array}$ \\
\hline \multicolumn{2}{|c|}{$\begin{array}{l}\text { presión sobre los sistemas } \\
\text { de soporte por impacto }\end{array}$} & nivel & causa & nivel & causa \\
\hline & $\begin{array}{l}\text { consumo de suelo y } \\
\text { pérdida de suelo llano } \\
\text { y fértil } \\
\text { pérdida de biodiversi- } \\
\text { dad } \\
\text { perdida de la capacidad } \\
\text { de infiltración del agua. } \\
\text { Aumento de la veloci- } \\
\text { dad del agua de lluvia } \\
\text { caída hasta llegar al mar } \\
\text { emisión de gases de } \\
\text { efecto invernadero } \\
\text { emisión de contamina- } \\
\text { ción atmosférica }\end{array}$ & $>$ & $\begin{array}{l}\text { explosión urbana del modelo sin } \\
\text { crecimiento demográfico } \\
\text { insularización de los sistemas agri- } \\
\text { colas y naturales por la expansión } \\
\text { de las redes de movilidad } \\
\text { impermeabilización de las areas de } \\
\text { infiltración y otras y canalización de } \\
\text { cauces } \\
\text { por un mayor consumo energético } \\
\text { por el modelo de movilidad y el } \\
\text { modelo energético }\end{array}$ & $<$ & $\begin{array}{l}\text { consumo restringido, supeditado al } \\
\text { crecimiento de la población } \\
\text { conservación de los sistemas agri- } \\
\text { colas y naturales. Conservación del } \\
\text { mosaico agricola, forestal, pastos y } \\
\text { setos, tipico de la Europa templada } \\
\text { conservación de las areas de infil- } \\
\text { tración y los márgenes del cauce. }\end{array}$ \\
\hline
\end{tabular}




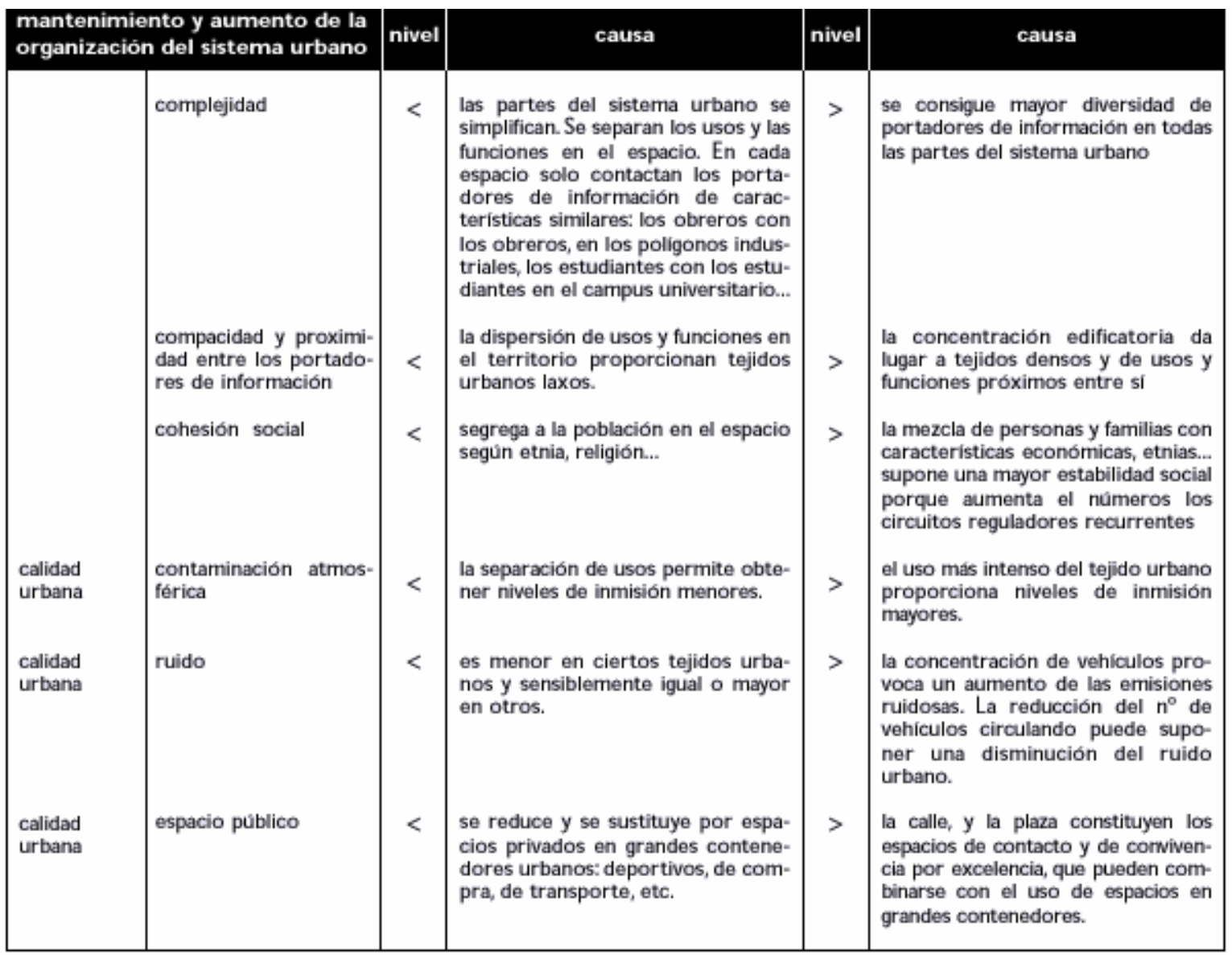

Figura 4.11. Cuadro comparativo de la características principales de los modelos de ciudad compacta y difusa. Fuente: Rueda 1999 op cit..

\subsection{Definición de modelo de calidad de vida urbana}

En adelante se asumirá como modelo de calidad de vida urbana a aquellos modelos que pretendar describir la calidad de vida de una ciudad según la definición dada en 4.2.

\subsection{Modelos y ejemplos tendientes a evaluar la calidad de vida urbana}

"Los comienzos de la planificación urbana se remontan al año 1860 aproximadamente cuando Cerdá en España y Geddes en Inglaterra introdujeron de manera teórica y práctica la planificación urbana y regional” (Ravella 2001).

Desde entonces a la fecha ha habido numerosos esfuerzos por hacer de las ciudades un lugar mejor para vivir (ej.: Forrester 1969 op.cit, United Nations Centre for Human Settlements - UNCHS- 1999, European Commision 1998, Rueda 1999 op.cit, Rueda 2002, Diputación de Barcelona 2000 op.cit, European Communities 2000 op cit., son sólo algunos de los tantos proyectos que se hicieron en este sentido). 
Una enumeración de programas y proyectos sobre la ciudad sostenible que prevén el uso de indicadores puede encontrarse en el libro de ecología urbana de Bettini (Bettini 1998). Veremos a continuación algunos de ellos.

4.12.1 Programa Sistema municipal de indicadores de sostenibilidad (Diputación de Barcelona)

Este programa emplea la clasificación dada por la Agencia Europea de Medio Ambiente (EEA) (ver 4.6.1). Se seleccionaron 30 indicadores que fueron agrupados en 3 categorías como establece la EEA: indicadores de flujo (13), de calidad (12) y de modelo (5). A continuación se detallan los indicadores incluídos en las distintas categorías.

Los 13 indicadores de modelo elegidos fueron (Diputación de Barcelona 2000 op.cit):

$>$ Mosaico territorial.

$>$ Intensidad de urbanización de la economía local.

$>$ Estructura urbana: ocupación urbana del suelo.

$>$ Estructura urbana: proximidad a servicios urbanos básicos.

$>$ Estructura urbana: desplazamiento y movilidad de la población.

$>$ Estructura urbana: calles de prioridad para peatones.

$>$ Adecuación del planeamiento a la singularidad ecológica del territorio.

$>$ Protección de espacios de interés natural.

$>$ Prevención de riesgos ambientales.

$>$ Participación ciudadana en procesos de sostenibilidad.

$>$ Asociacionismo ambiental del municipio.

$>$ Utilización de los puntos limpios municipales.

$>$ Gasto municipal en medio ambiente.

Indicadores de flujo:

$>$ Consumo final de energía.

$>$ Intensidad energética local.

$>$ Producción local de energías renovables.

$>$ Recuperación de residuos municipales.

$>$ Recuperación de resiuduos industriales.

$>$ Íntensidad de la producción de residuos de la economía local.

$>$ Abastecimiento de agua municipal.

$>$ Intensidad de consumo de agua de la economía local.

$>$ Gestión de las aguas residuales.

$>$ Utilización de las agua depuradas.

$>$ Emisión de contaminantes atmosféricos.

$>$ Emisión de gases que contribuyen al efecto invernadero.

Indicadores de calidad:

$>$ Concentración ambiental de contaminantes atmosféricos.

$>$ Personas expuestas a niveles sonoros significativos.

$>$ Evolución de la calidad del agua de los acuíferos.

$>$ Estado ecológico de los ríos. 
$>$ Superficie forestal quemada.

El indicador de modelo "Estructura urbana: proximidad a servicios urbanos básicos" fue explicado en detalle en el punto 4.7 .

La descripción de cada uno de los 30 indicadores sigue ese mismo patrón, a saber:

$>$ su fórmula.

$>$ la unidad en que se mide.

$>$ la periodicidad con la cual debe calcularse.

$>$ las fuentes de donde obtener la información necesaria.

$>$ una representación gráfica en función del tiempo.

$>$ la tendencia deseada sugerida.

Los principios rectores de este proyecto apuntaban hacia lograr una utilización eficiente de los recursos ecológicos, contribuir a la sostenibilidad global, valorar y proteger la biodiversidad, no superar la capacidad de carga del medio, utilizar recursos propios, implicar a la sociedad en el proceso de sostenibilidad y lograr diversidad funcional en la ciudad.

La aplicación del proyecto tuvo 3 etapas: primero se recolectaron los datos para el cálculo de los indicadores, luego se homogeneizaron los datos y el cálculo de los indicadores y por último se consultaron y validaron los resultados obtenidos con la comisión municipal.

Se intentó que el conjunto de indicadores elegidos fuese lo más universal posible y, al mismo tiempo, que permitiera incorporar características particulares específicas de un municipio.

4.12.2 Programa Ciudades Sostenibles (The United Nations Centre for Human Settlements-UNCHS y United Nations Environment Program-UNEP 1999)

El programa ciudades sustentables (SCP) ha sido puesto en práctica desde principios de la década del 90 en diferentes lugares del mundo. Las valiosas experiencias han permitido la elaboración de manuales que pueden ser usados para informar, dar apoyo y guiar el proceso de planeamiento ambiental de ciudades (UNCHS 1999 op cit.). Las herramientas contienen guías útiles para todos los actores involucrados en la gestión y manejo ambiental de ciudades.

Estas herramientas consisten en 9 volúmenes (ver figura 4.12) divididos en 3 categorías:

$>$ Herramientas específicas del proceso (Vol. 1, 2, 3, 4 y 5).

$>$ Herramientas complementarias a las específicas del proceso (Vol. 4, 7 y 9).

$>$ Herramientas para evaluar la calidad del aire urbano (Vol. 6) 


\begin{tabular}{|c|c|c|}
\hline Process Specific Tools & crosscutting & Issue Specific Tools \\
\hline $\begin{array}{l}\text { Preparing the SCP Environmental Profile } \\
\text { The SCP Source Book Series (Vol.1) }\end{array}$ & $\begin{array}{l}\text { Weasuring Progress in Environmental } \\
\text { Planning and Management, } \\
\text { The SCP Source Book Series (Vol. 9) }\end{array}$ & $\begin{array}{l}\text { Urban Air Quality Managerment, } \\
\text { Handbook (Parts A and B) } \\
\text { and Toolkit (Part C), } \\
\text { The SCP Source Book Series } \\
\text { (Vol. 6) }\end{array}$ \\
\hline $\begin{array}{l}\text { Organising, Conducting and Reporting } \\
\text { an SCP City Consultation, } \\
\text { The SCP Source Book Series (Vol. 2) }\end{array}$ & $\begin{array}{l}\text { Euilding an Environmental Management } \\
\text { Information System (EMIS), } \\
\text { The SCP Source Book Series (Vol. 7) }\end{array}$ & \\
\hline $\begin{array}{l}\text { Establishing and Supporting a Working } \\
\text { Group Process, } \\
\text { The SCP Source Book Series (Vol. 3) }\end{array}$ & $\begin{array}{l}\text { Integrating Gender Responsiveness in } \\
\text { Environmental Planning and Management, } \\
\text { EPM Series (Vol.4) }\end{array}$ & \\
\hline \multicolumn{3}{|l|}{$\begin{array}{l}\text { Formulating Issue Specific Strategies } \\
\text { and Action Plans, } \\
\text { The SCP Source Book Series (Vol. 4) }\end{array}$} \\
\hline $\begin{array}{l}\text { Institutionalising the Environmental } \\
\text { Planning and Wanagement Process, } \\
\text { The SCP Source Book Series (Vol. 5) }\end{array}$ & & \\
\hline
\end{tabular}

Figura 4.12. Herramientas del programa ciudades sustentables. Fuente: UNCHS 1999 op cit.

Las herramientas están escritas y diseñadas de manera amigable, con un estilo no técnico y numerosos ejemplos e ilustraciones.

\subsubsection{La Auditoría urbana de la Comisión Europea}

La Comisión Europea elaboró una auditoría urbana (European Communities 2000) con el objeto de medir la calidad de vida en ciudades a partir de una serie de indicadores y una metodología común que permitiera comparar cuantitativa y cualitativamente 2 ciudades.

Estos indicadores serían periódicamente actualizados para poder predecir el impacto de políticas en el desarrollo de áreas urbanas. Para el estudio se eligieron indicadores relacionados con la calidad de vida de acuerdo con la opinión de los residentes y trató, en la medida de lo posible, de que tales indicadores pudieran calcularse y sirvieran para comparar ciudades (Vol. I, pag. 76).

La auditoría incluía una serie de indicadores comprendidos dentro de 21 dominios relacionados con la calidad de vida. Cada dominio contaba con varios indicadores que trataban de aclarar ciertos aspectos mas particulares del dominio en cuestión. Los dominios quedaron definidos de la siguiente manera:

1) Población

2) Nacionalidad

3) Estructura de la vivienda

4) Mercado laboral y desempleo

5) Ingresos, distribución y pobreza

6) Vivienda

7) Salud 
8) Crímenes

9) Empleo

10) Actividad económica

11) Participación cívica

12) Proveer educación y capacitación

13) Nivel educativo

14) Calidad del aire y ruido

15) Agua

16) Manejo de la basura

17) Uso de la tierra

18) Patrones de viajes

19) Uso de la energía

20) Clima y geografía

21) Recreación y cultura

La auditoría urbana se interesó no sólo en la calidad de vida a nivel ciudad sino también observar las variaciones de calidad de vida entre sectores de una misma ciudad.

Durante la fase piloto de la auditoría urbana se desarrolló una metodología que permitó comparar ciudades.

El hecho de generar indicadores que permita comparar ciudades de distintos países requiere un considerable esfuerzo. Para ilustrar este punto consideremos por ejemplo que los métodos para registrar empleos varía de un país a otro. Este y otros problemas similares fueron descubiertos y analizados. En el (Vol. I, pag. 82-83) se detallan los problemas y soluciones adoptadas en indicadores correspondientes a 19 de los 21 dominios antes citados. Esto fue necesario para poder establecer un marco comparativo que permitiese analizar ciudades.

\subsubsection{Modelo de la dinámica urbana de Forrester}

Según Jay W. Forrester, éste modelo es una teoría de la estructura urbana y sus relaciones internas (Forrester 1969 op cit.). Fue un modelo desarrollado usando dinámica de sistemas como herramienta para mostrar las interrelaciones relevantes en una ciudad. Como se vió en el capítulo 3, mediante esta técnica es posible observar el comportamiento simultáneo de variables en el tiempo así como también el efecto que produce la modificación de una variable en el resto del sistema.

En el gráfico 4.13 se observa una parte del modelo: el sector empleo, que es una de las 15 partes que componen el sistema. A su vez, cada parte contiene variables interrelacionadas y pueden existir referencias a variables de otro sector.

Los botones con números encima pueden desplazarse a izquierda y derecha para decrementar o aumentar su valor respectivamente. Si se mueve cualquiera de estos botones hará que las gráficas asociadas al resto de las variables se redibujen mostrando el efecto que produciría dicho cambio. 


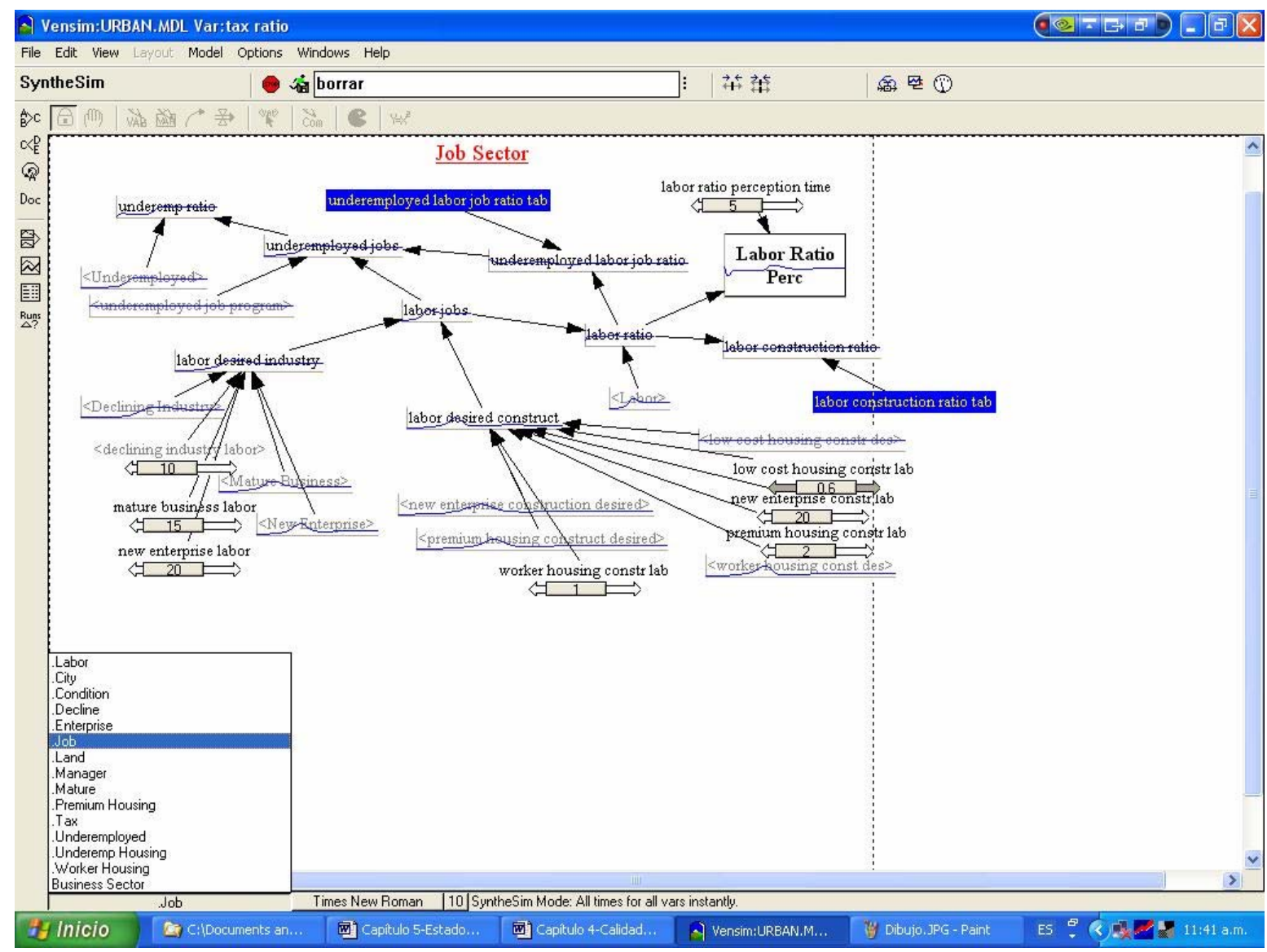

Figura 4.13. Modelo de la dinámica urbana de Forrester. 


\section{Capítulo 5}

\section{Frameworks para la representación de modelos de calidad de vida}

\subsection{Introducción}

Como hemos visto en el capítulo anterior, los modelos de calidad de vida basados en indicadores cuantitativos suelen diferir unos a otros en aspectos tales como: cantidad de indicadores, importancia relativa de cada indicador (peso asociado), dimensiones que tienen en cuenta al analizar el tema de la calidad de vida, etc.. Se pretende que los frameworks presentados en este trabajo sirvan no sólo para el análisis de modelos de calidad de vida sino también que puedan ser aplicadas en otros dominios en los que la modelización mediante índices e indicadores cuantitativos sea una alternativa válida. Es necesario entonces que la solución a adoptar cuente con un importante de grado de genericidad y rehusabilidad. Por este motivo, en el presente trabajo, los patrones de diseño se han convertido en la metodología a tener en cuenta para a la hora del diseño y desarrollo de software para construir a partir de ellos diferentes frameworks que permitan representar los diferentes tipos de modelos de calidad de vida.

Según la definición de Stelting y Maasen (Stelting y Maasen 2003 op cit.) los patrones de diseño "son soluciones documentadas que los expertos aplican para solucionar nuevos problemas porque han sido utilizadas con éxito en el pasado. Los expertos identifican partes de un problema que son similares a otros problemas que han encontrado anteriormente. Después, recuerdan la solución aplicada y la generalizan. Finalmente, adaptan la solución general al contexto de su problema actual.

La idea que hay detrás de los patrones de diseño es desarrollar una forma estandarizada para representar soluciones generales de problemas que se encuentran comúnmente en el desarrollo de software. Al hacer esto se obtienen algunos beneficios:

$>$ Con el tiempo, podemos construir catálogos de patrones. Esto permite que los novatos en el desarrollo de software se beneficien mucho más de la experiencia obtenida durante los años.

> Hay una documentación formal sobre los compromisos adquiridos en el diseño de software: sobre los pros y contras de la elecciones en el desarrollo. La estandarización de los patrones facilita a todos los profesionales -tanto expertos como novatos- la comprensión de todos los efectos que pueden conllevar las decisiones. 
$>$ Los patrones de diseño proporcionan un vocabulario común. Esto hace que la comunicación de las soluciones a los desarrolladores sea más sencilla. En vez de describir un diseño en detalle, podemos utilizar el nombre de un patrón para expresar nuestras ideas.

$>$ Podemos interrelacionar los patrones entre sí, por lo que un desarrollador puede ver fácilmente qué patrones pueden ser utilizados conjuntamente en un proyecto".

Existen plantillas para representar los patrones, que se suelen denominar formulario o formato. Básicamente, un patrón consta de 4 partes esenciales (Gamma et al. 1995 op cit.):

$>$ Nombre.

$>$ Descripción del problema.

$>$ Solución.

$>$ Consecuencias.

El nombre, normalmente de unas pocas palabras, intenta precisar el problema de diseño que resuelve el patrón .

La descripción del problema describe el problema y el contexto general junto con una serie de precondiciones que deben satisfacerse para poder aplicar el patrón.

La solución explicita los elementos participantes, sus relaciones, responsabilidades y colaboraciones necesarias para resolver el problema.

Las consecuencias describen las ventajas e inconvenientes que supone la aplicación del patrón y posibles relaciones con otros patrones relacionados.

Como se observa en la tabla 5.1 los patrones de diseño constituyen solución a problemas con un alto grado de rehusabilidad y genericidad.

Según Stelting y Maasen (Stelting y Maasen 2003 op. cit) "El concepto de clase como base para los objetos proporciona una ventaja principal al combinar dos de los mecanismos anteriores:abstracción funcional y abstracción de datos. Al empaquetar la estructura (los datos) de la entidad con las funciones (comportamiento) que se aplican con los datos, obtenemos una forma de reutilizar de forma efectiva un elemento de software.

Mas allá del concepto principal de clase, los lenguajes orientados a objetos nos ofrecen varias formas de estructurar el código en niveles. Los conceptos de subclase e interfaz, por ejemplo, abren nuevas posibilidades para la reutilización en el desarrollo de software. Finalmente, los grupos de clases se pueden asociar entre sí y ser tratados como un único componente lógico, proporcionando un modelo muy potente para la reutilización a nivel de sistema.

La siguiente tabla compara las diferentes aproximaciones a la reutilización del código y la abstracción”.

\begin{tabular}{|l|l|l|l|}
\hline $\begin{array}{l}\text { Tipo de } \\
\text { reutilización }\end{array}$ & Reusabilidad & Abstracción & Genericidad \\
\hline Fragmento de código & Muy pobre & Nada & Muy pobre \\
\hline Estructura de datos & Buena & Tipo de datos & Moderada-buena \\
\hline Funcional & Buena & Método & Moderada-buena \\
\hline Plantilla & Buena & Operación para tipo & Buena \\
\hline Algoritmo & Buena & Fórmula & Buena \\
\hline
\end{tabular}




\begin{tabular}{|l|l|l|l|}
\hline Clase & Buena & Dates + métodos & Buena \\
\hline \multicolumn{1}{|c|}{ Interfaz } & & & \\
\hline Polimorfismo & & & \\
\hline Clase abstracta & & & \\
\hline Biblioteca de código & Buena & Funciones & Buena-muy buena \\
\hline API & Buena & Clases útiles & Buena-muy buena \\
\hline Componente & Buena & Grupo de clases & Buena-muy buena \\
\hline Patrón de diseño & Excelente & Solución a problema & Muy buena \\
\hline
\end{tabular}

Tabla 5.1. Fuente: Stelting y Maassen 2003 op cit.

Dado que los indicadores que componen un modelo de calidad de vida pueden estar interrelacionados entre sí, es necesario analizar el posible uso de patrones para el manejo de las interrelaciones o bien, de que manera pueden combinarse distintos patrones para tratar la interdependencia.

En el trabajo de Gamma y colaboradores (Gamma et al. 1995 op.cit, pp.12) los autores proponen 2 patrones para el manejo de dependencias complejo: los patrones Observer y Mediator.

El patrón Observer pertenece a la clase de patrones de comportamiento, es decir, tiene que ver con el flujo de control en un sistema. El propósito del patrón Observer es definir una dependencia de " 1 a muchos" entre objetos para que cuando un objeto cambia de estado, todos sus dependientes sean notificados y actualizados automáticamente (Gamma et al. 1995 op.cit).

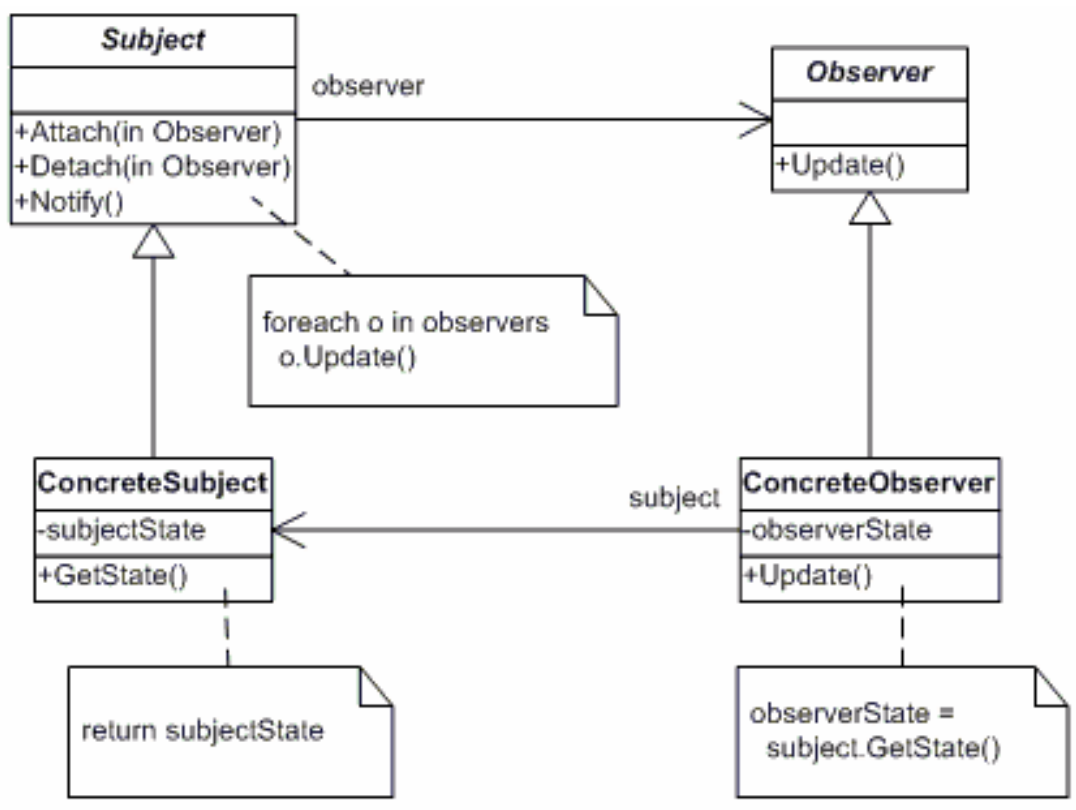

Figura 5.1. Diagrama de clases del patrón Observer. Fuente: http://www.dofactory.com/Patterns/PatternObserver.aspx .

En este capítulo se usará el patrón Observer en uno de los frameworks propuestos. 
El patrón Mediator también pertenece a la clase de patrones de comportamiento y tiene por objetivo simplificar la comunicación entre los objetos de un sistema introduciendo un único objeto que gestiona la distribución de mensaje entre los otros (Stelting y Maassen 2003 op cit.).

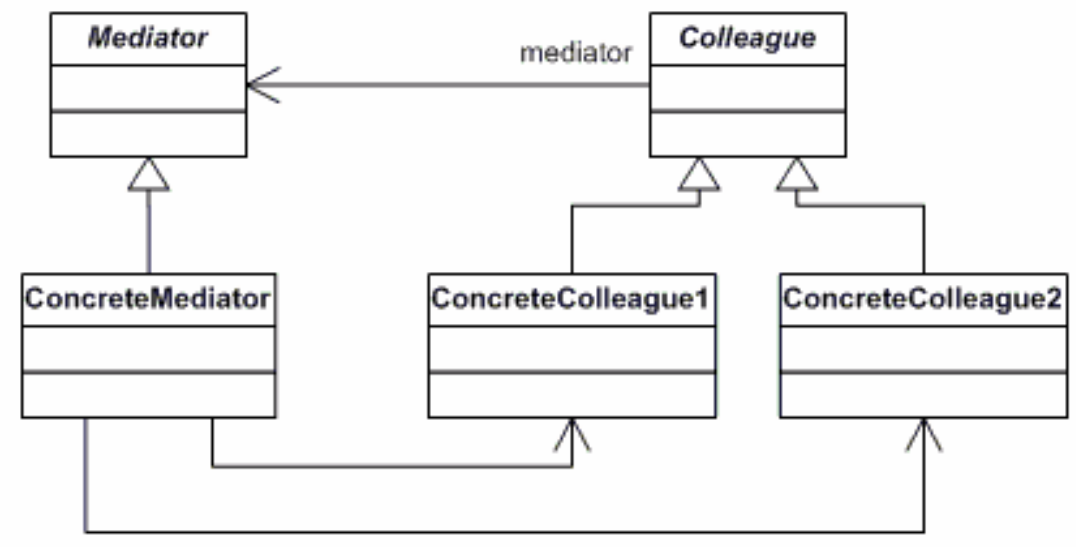

Figura 5.2. Diagrama de clases del patrón Mediator. Fuente: http://www.dofactory.com/Patterns/PatternMediator.aspx .

Hemos visto en el capítulo 1, inciso 1.5, que los índices e indicadores cuantitativos, que son los de interés en este trabajo, pueden clasificarse en tradicionales (cuando no hay o es muy pequeña la incertidumbre respecto del valor señalado por el índice o indicador) y borrosos (cuando existe un grado de incertidumbre significativo sobre el valor señalado por el índice o indicador). A su vez, los índices e indicadores borrosos se subdividen en 2 clases: los modelizados mediante sistemas de inferencia borroso y los modelizados usando operaciones de agregación de conjuntos borrosos. Por lo tanto hay en total 3 maneras de representar índices e indicadores cuantitativos y, por ende, 3 formas de construir modelos sistémicos a partir de ellos:

Modelos sistémicos basados en índices e indicadores tradicionales.

Modelos sistémicos basados en índices e indicadores representados mediante un sistema de inferencia borroso (SIB).

Modelos sistémicos basados en índices e indicadores representados mediante operaciones de agregación de conjuntos borrosos.

En lo que resta del capítulo se presentará un framework para cada uno de los 3 tipos de modelos sistémicos antes mencionados.

\subsection{Estimación de la calidad de vida a partir de índices e indicadores borrosos}


La lógica borrosa ha sido utilizada como herramienta sistemática para tratar temas como la evaluación de la sustentabilidad (Phillis et al. 2001 op cit) y la calidad de vida. Esto se debe a su capacidad para tratar con datos con incertidumbre, a que permite emular ciertas habilidades humanas y manejar ambigüedades, en situaciones donde las matemáticas tradicionales no resultan ser efectivas (Andriantiatsaholiniaina et al. 2004 op cit, Phillis et al. 2001 op. cit).

Según el trabajo de Cornelissen y colaboradores (Cornelissen et al. 2001 op cit) existen 2 formas de estimar la contribución al desarrollo sostenible usando lógica borrosa:

Mediante el desarrollo de modelos basados en sistemas de inferencia borrosos.

Mediante el desarrollo de modelos basados en la agregación de conjuntos borrosos.

Veremos a continuación algunas limitaciones que presentan los desarrollos de software comerciales más usados en el ámbito científico para el desarrollo de sistemas que hagan uso de la lógica borrosa y se propondrán soluciones que permitan superar dichas limitaciones.

\subsubsection{Modelos basados en sistemas de inferencia borrosos}

El programa comercial más utilizado para el diseño de sistemas de inferencia borrosos es probablemente el Fuzzy Logic Toolbox del software MATLAB ${ }^{4}$. Este software permite diseñar sistemas de inferencia borrosos de manera fácil y rápida. Posee un conjunto de interfases gráficas que ayudan al usuario en las distintas etapas de la construcción de un sistema de inferencia borroso (The MathWorks 2007 op cit.).

Presenta, no obstante, algunas limitaciones:

$>$ El software permite definir reglas que usen distintos conectivos lógicos (and, or y not) y exige establecer que método asociar a cada operador (por ej.: el operador and se puede interpretar con la operación min, prod o una definida por el usuario). Luego, en todas las reglas en que aparezca el mencionado operador, el programa lo interpretará con la misma operación. Es decir, no es posible usar distintas interpretaciones del operador en un mismo sistema de inferencia borroso.

> Otra limitación tiene que ver con el método de implicación. El programa permite seleccionar diferentes métodos de implicación: min, prod o uno definido por el usuario, que es el que se aplicará a cada una de las reglas. En otras palabras, no es posible elegir el método de implicación para una regla en particular sino que el método que se elija será el que se aplique a todas las reglas.

$>$ De manera similar, el citado software permite elegir diferentes métodos de agregación. El método que se elija se aplicará a todas las variables de salida. Esto

\footnotetext{
${ }^{4}$ MATLAB ${ }^{\circledR}$ es un producto de The MathWorks. URL: www.mathworks.com
} 
impide que cada variable de salida pueda tener asociado un método en particular puesto que el método seleccionado será el que se aplicará a todas las variables de salida.

Análogamente, el programa permite seleccionar diferentes métodos de defuzificación. El método que seleccione el usuario será el que se aplicará a cada una de las variables lingüísticas de salida. Es decir, no es posible asignar distintos métodos a las distintas variables de salida.

Vistas las limitaciones antes citadas y dado que los sistemas de inferencia han sido utilizados para la modelización de índices e indicadores relacionados con temas como la sustentabilidad o la calida de vida, se presentará a continuación un framework que contemple la posibilidad de construir un sistema de inferencia borroso que no tenga las limitaciones enumeradas anteriormente.

\subsubsection{Framework para el desarrollo de modelos basados en sistemas de inferencia borrosos}

A continuación se presenta un framework que tiene un mayor grado de flexibilidad que los programas comerciales usados habitualmente en la temática que nos ocupa dado que permite el uso de distintos tipos de operadores lógicos, métodos de implicación, métodos de agregación y de defuzificación en un mismo sistema de inferencia borroso.

El framework fue desarrollado usando el paradigma de la programación orientada a objetos. Ya han sido expuestas las ventajas que esto supone, y en este caso particular la combinación de múltiples patrones de diseño con el objeto de formar un framework general proporciona una mayor rehusabilidad, un mayor grado de abstracción y alcanza una muy buena generidad como vimos en la tabla 5.1.

Se han empleado en múltiples ocasiones los patrones Strategy e Interpreter y se han aprovechado las ventajas de la herencia de objetos para aumentar la rehusabilidad y, al mismo tiempo, distinguir entre objetos similares pero no idénticos.

El patrón Strategy ha sido empleado en 4 oportunidades:

$>$ En el diseño de los distintos tipos de funciones de pertenencia.

$>$ En el diseño de los distintos tipos de métodos de implicación.

$>$ En el diseño de los distintos tipos de métodos de agregación.

$>$ En el diseño de los distintos tipos de métodos de defuzificación.

Esto supone las siguientes ventajas: 
En el caso de las funciones de pertenencia, las cuales se asocian a conjuntos borrosos (más precisamente a valores lingüísticos), se emplea el patrón Strategy para que se pueda optar por cualquiera de los tipos (predefinidos o definidos por el usuario) en función de su mayor semejanza al fenómeno que se quiere representar.

Cada regla que compone un sistema de inferencia borroso puede tener un método de implicación que sea diferente al de otras reglas. Se observa el uso del patrón Strategy para modelizar este aspecto en la figura 5.3.

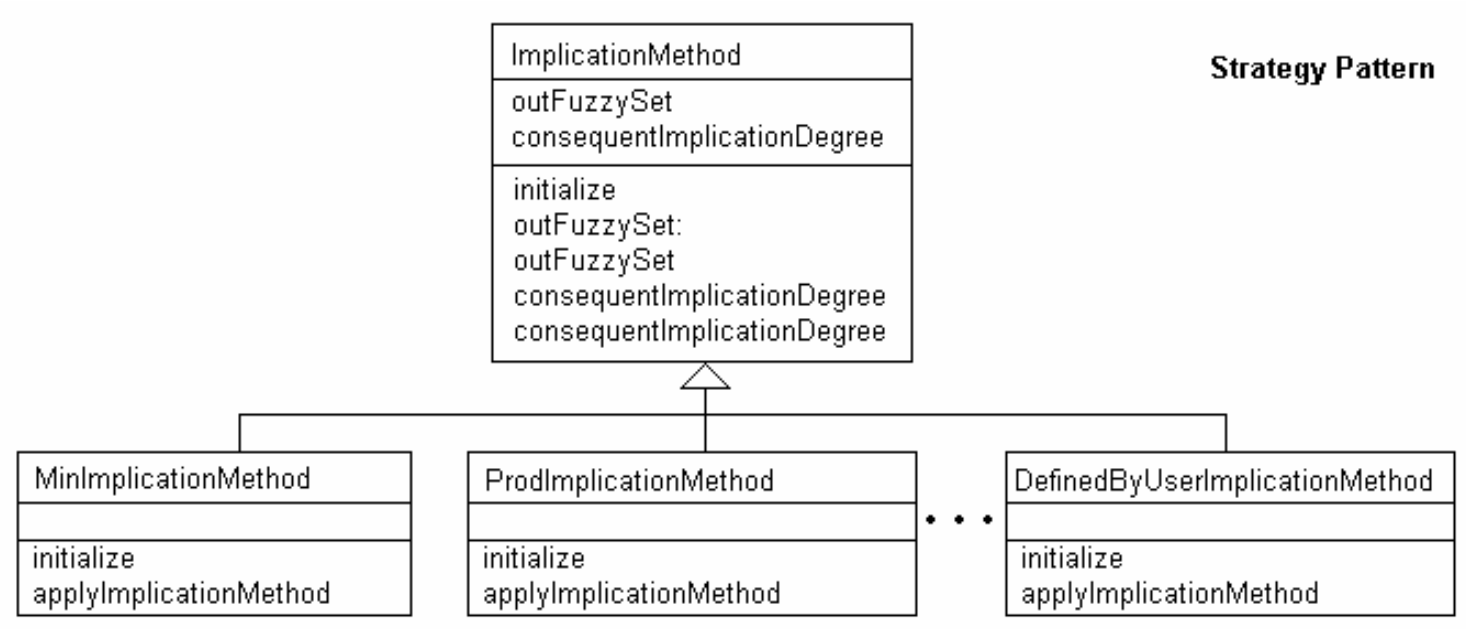

Figura 5.3. Implementación de los distintos métodos de implicación usando el patrón Strategy.

> Cada variable lingüística de salida puede tener un método de agregación (figura 5.4) diferente al de otras variables lingüísticas de salida.

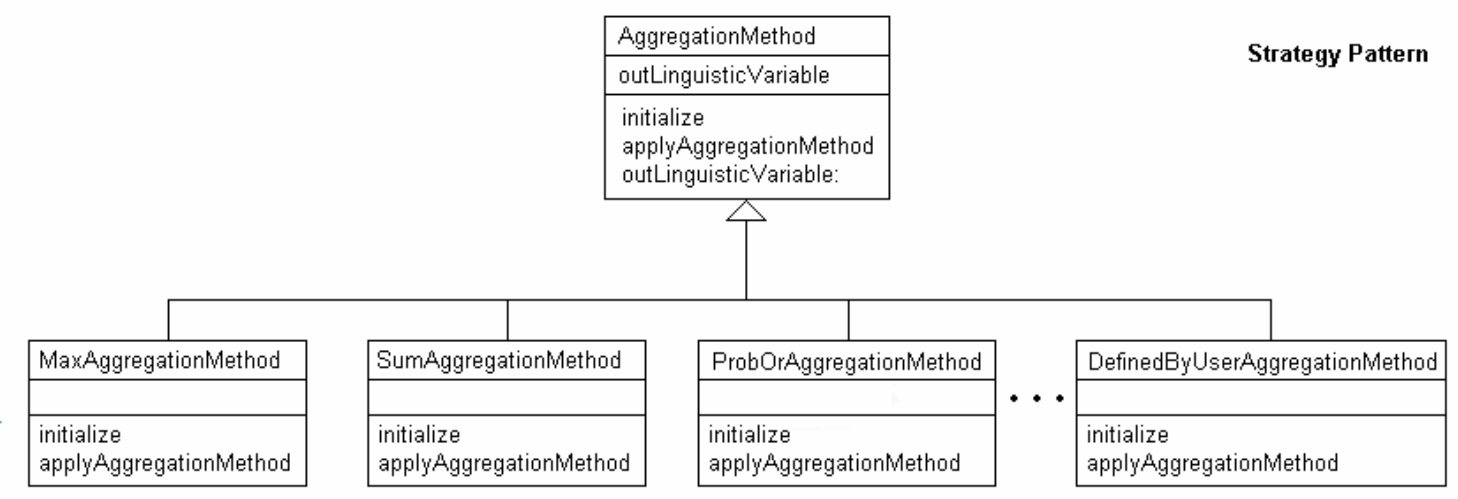


Figura 5.4. Implementación de los distintos métodos de agregación usando el patrón Strategy.

$>$ Cada variable lingüística de salida puede tener un método de defuzificación diferente al de otras variables lingüísticas de salida. Se observa en la figura 5.5 la jerarquía de clases asociada a los métodos de defuzificación.

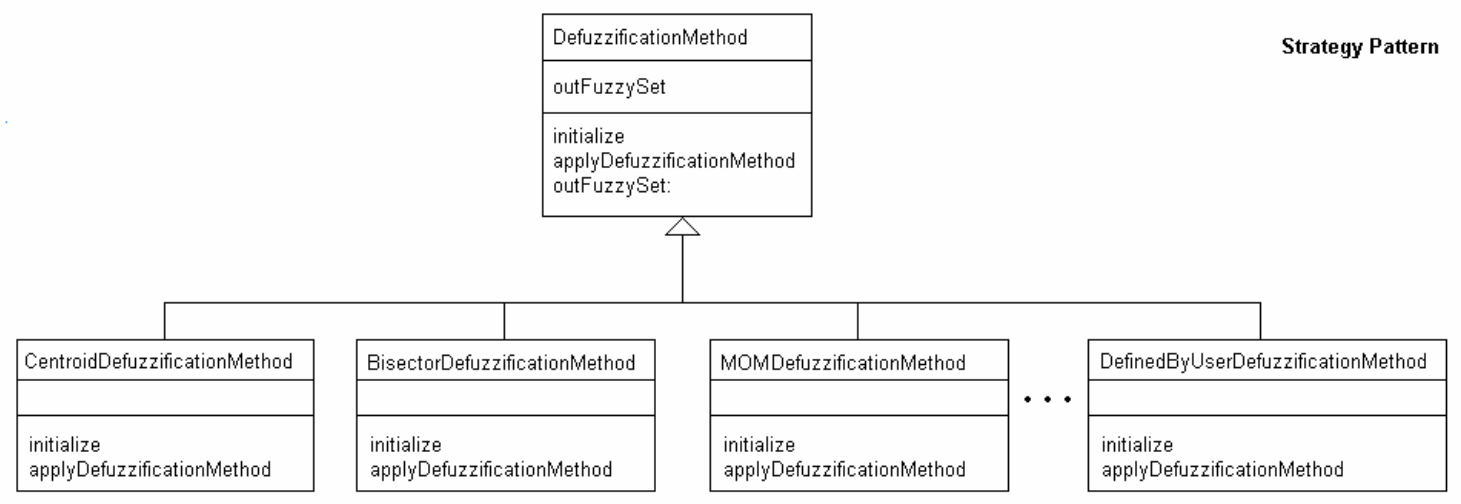

Figura 5.5. Implementación de los distintos métodos de defuzificación usando el patrón Strategy.

El patrón Interpreter, por su parte, ha sido utilizado en 2 ocasiones:

$>$ Para evaluar el grado en que se satisface el antecedente de una regla. Dado que cada regla posee un antecedente que es una expresión lógica, el patrón Interpreter es ideal para ser utilizado en tal situación (figura 5.6). En el caso de querer crear un nuevo operador; esto simplemente significará agregar una clase más (subclase de AntecedentFuzzyLogicBasedExpression) a las ya existentes con su correspondiente método interpret.

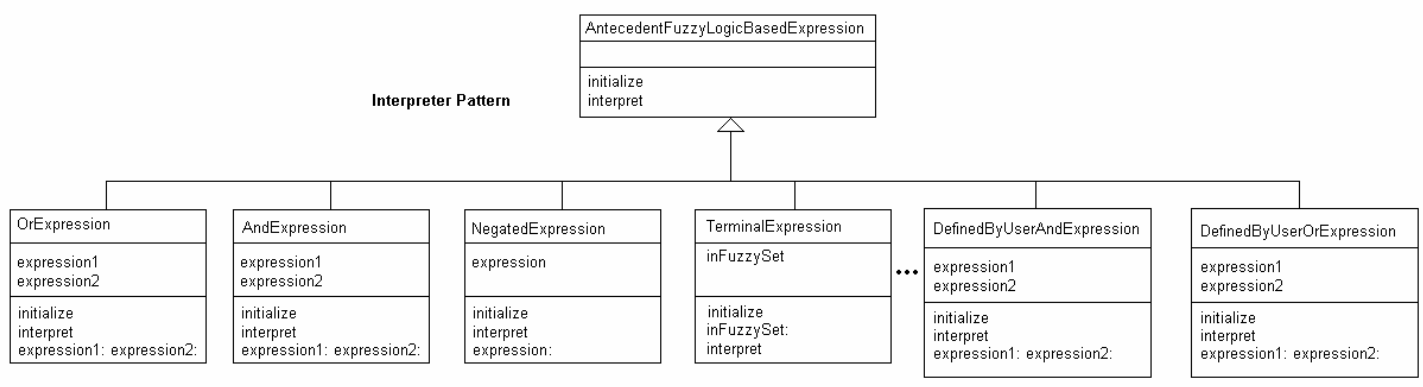

Figura 5.6. Implementación de los distintos operadores lógicos borrosos usando el patrón Strategy.

Al igual que ocurre con el antecedente de una regla, el consecuente es también una expresión lógica y por lo tanto también se empleó el partrón Interpreter para, en este 
caso, setear el grado de implicación en el consecuente de una regla (figura 5.7). Es decir, si por ejemplo, al evaluar el antecedente da como resultado un valor de 0.6, éste será el grado en que se afecte a los distintos valores lingüísticos presentes en el consecuente.

ConsequentOrExpression

expression1

expression2

initialize

setImplicationDegre

expression1: expression2
ConsequentFuzzyLogicBasedExpression

antecedentSatisfactionDegree

implicationMethod

initialize

antecedentSatisfactionDegree

antecedentSatisfactionDegree

implicationMethod:

implicationMethod

Figura 5.7. Implementación de los distintos operadores lógicos a ser aplicados en el consecuente usando el patrón Strategy.

La herencia se ha utilizado para aprovechar variables de instancia y métodos comunes de objetos parecidos. Este mecanismo se empleó en 3 ocasiones:

En la clase LinguisticVariables y sus subclases.

$>$ En la clase FuzzySet y sus subclases.

$>$ En la clase SystemVariable y sus subclases.

En el primer caso, atributos comunes como son los valores lingüísticos, el nombre y el rango de una variable lingüística se definen en la clase LinguisticVariable. Luego, dado que las operaciones que se aplican a las variables lingüísticas de entrada difieren a las operaciones propias de las variables lingüísticas de salida se ha definido una clase para cada tipo de variable. Así, la clase correspondiente a una variable lingüística de entrada implementa, por ej., el método que fuzifica las entradas en tanto que una variable lingüística de salida tiene asociados métodos para realizar los procesos de implicación, agregación y defuzificación.

De manera análoga, la clase FuzzySet provee las variables de instancia y métodos propios de los conjuntos borrosos (asignar una función de pertenencia, un rango de valores de entrada posibles para la función y el nombre correspondiente del valor lingüístico en cuestión). Luego, las operaciones y variables de instancia exclusivas de los conjuntos borrosos de entrada y salida se implementan en 2 clases separadas.

La clase OutFuzzySet merece una atención especial. En la misma se encuentra definida una variable de instancia "consequentsImplicationDegree" que contendrá una colección de 
objetos de la clase ImplicationMethod. El motivo de la misma obedece a que un mismo conjunto borroso puede aparecer en el consecuente de 2 o más reglas diferentes (las cuales, a su vez, pueden tener asociados métodos de implicación diferentes) en cuyo caso se toma como valor de entrada para el método de implicación el mayor grado con que se satisfizo el antecedente de alguna regla en la que el citado conjunto aparezca en el consecuente

Se muestra en la figura 5.8 el diagrama de clases del framework propuesto, en tanto que el código fuente completo se encuentra en el Apéndice I, inciso 1.

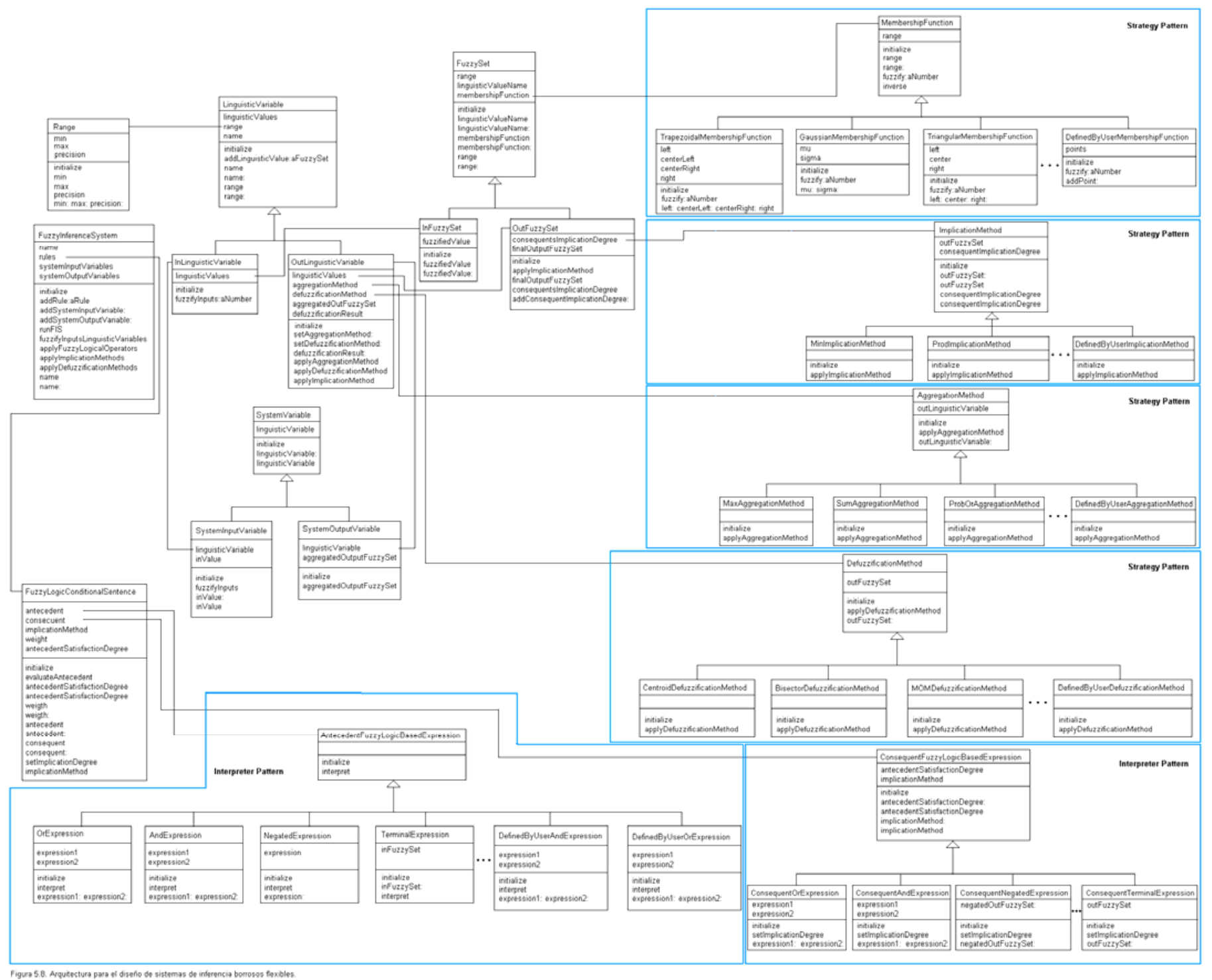

La clase SystemVariable tiene asociado una variable lingüística, en tanto que el resto de las variables de instancia y métodos propios de las variables del sistema de entrada y de salida se implementan en clases separadas. Así, por ejemplo, las variables del sistema de entrada 
tienen asociado un valor de entrada que es el que se usa para fuzificar los distintos valores lingüísticos asociados a una variable lingüística de entrada.

Se presenta en el Apéndice I, inciso 1, el código fuente completo del framework, lo que muestra que es posible su implementación mediante un lenguaje basado en el paradigma de la programación orientada a objetos. Así, resulta de esperar el hecho de que aquellos SIG que cuenten con lenguajes orientados a objetos para el desarrollo de aplicaciones puedan asimismo incorporar estas soluciones que, sumada a la capacidad de manejo de datos georreferenciados de los SIG puedan complementarse para estimar la calidad de vida del sector bajo estudio al mismo tiempo que se visualiza su estado en la interfase gráfica del SIG. Esto permitiría observar los valores de índices, indicadores y sus dimensiones y tomar nota para iniciar acciones para revertir tempranamente los problemas que se encuentren.

\subsubsection{Ejemplo de uso del framework para el desarrollo de sistemas de inferencia borrosos}

El ejemplo que sigue tiene como objetivo mostrar como es posible estimar la calidad de vida a partir de una serie de indicadores usando un sistema de inferencia borroso. El mismo es una adaptación del expuesto a modo de ejemplo en la tesis doctoral de Ferraro (Ferraro 2005 op cit.). La elección de este ejemplo tiene 2 motivos principales:

> Sirve para ilustrar de manera sencilla el proceso de inferencia borroso.

Como tiene 2 variables de entradas (salud y dinero) y 1 de salida (calidad de vida), es posible mostrar gráficamente las salidas en función de las 2 entradas.

Las funciones de pertenencia asociadas a los valores lingüísticos "Mucho" y "Poco" asociados a la variable lingüística "Dinero" se muestran en la figura 5.9. Las 2 han sido definidas como de tipo triangular con parámetros $\left[\begin{array}{lll}0 & 0 & 5000\end{array}\right]$ y $\left[\begin{array}{lll}0 & 5000 & 5000\end{array}\right]$ respectivamente.

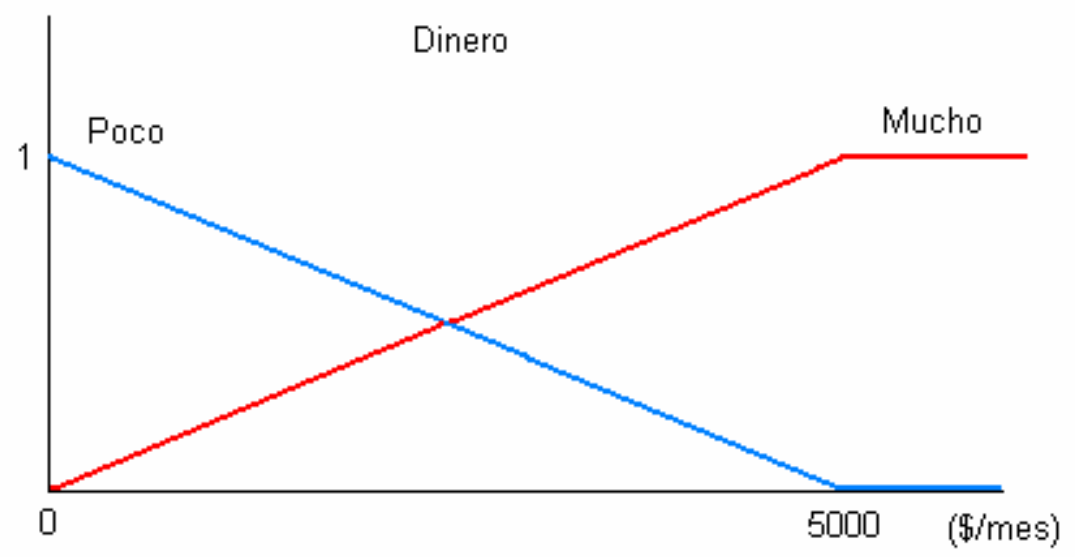




\section{Figura 5.9. Funciones de pertenencia de los valores lingüísticos "Mucho" y "Poco" asociados a la variable lingüística "Dinero".}

Las funciones de pertenencia asociadas a los valores lingüísticos "Buena" y "Mala" asociados a la variable lingüística "Salud" se muestran en la figura 5.10. Ambas pueden definirse como de tipo triangular con parámetros [ $\left[\begin{array}{lll}0 & 0 & 300\end{array}\right]$ y [ $\left[\begin{array}{llll}0 & 300 & 300\end{array}\right]$ respectivamente.

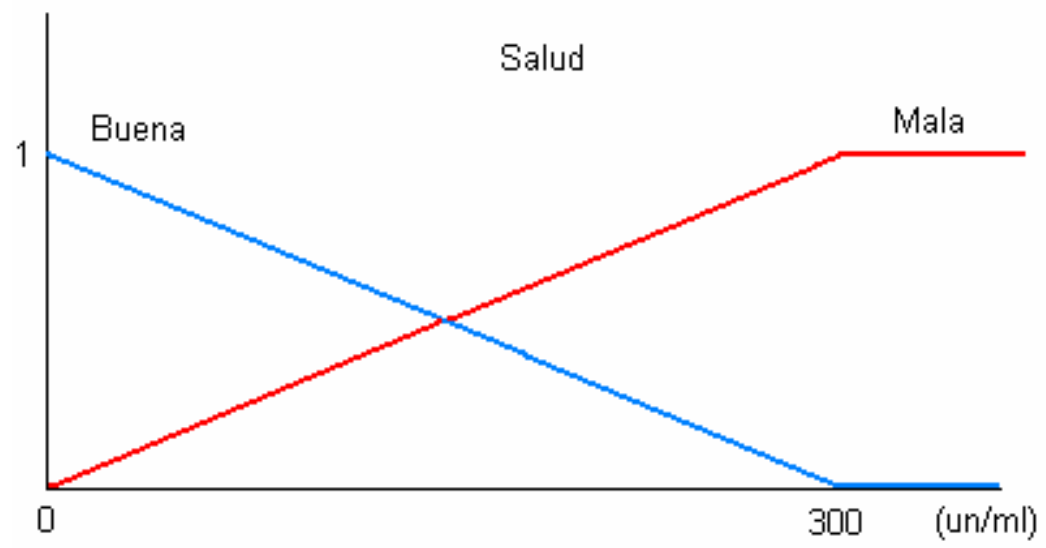

Figura 5.10. Funciones de pertenencia de los valores lingüísticos "Buena" y "Mala" asociados a la variable lingüística "Salud".

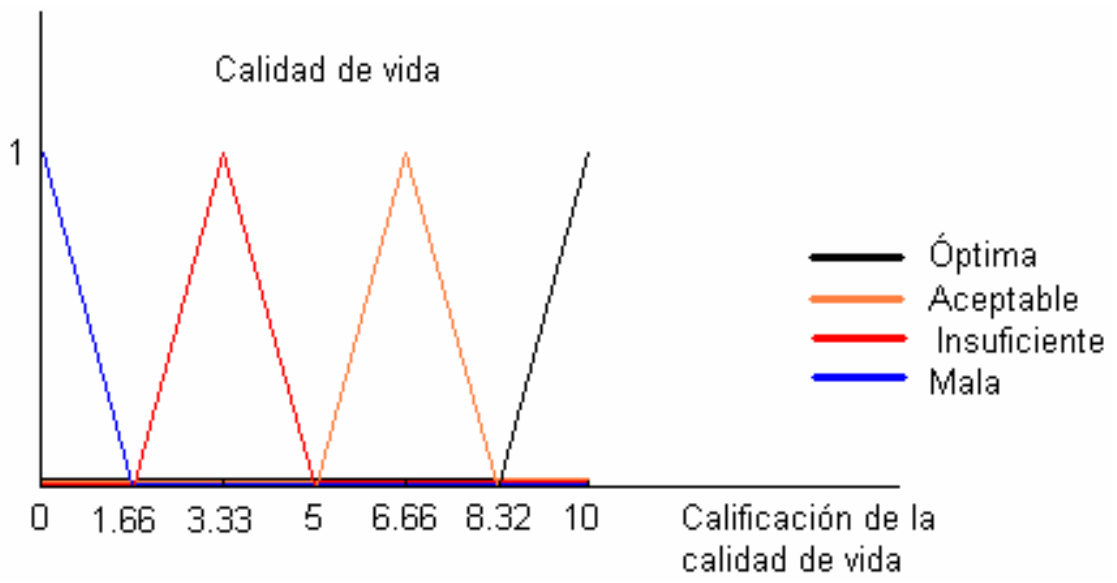

Figura 5.11. Funciones de pertenencia de los valores lingüísticos "Óptima”, "Aceptable”, "Insuficiente" y "Mala" asociados a la variable lingüística "Calidad de vida".

La variable lingüística "Calidad de vida" tiene asociados 4 valores lingüísticos: "Mala", "Insuficiente", "Aceptable" y "Óptima". Estos últimos se representan con funciones de pertenencia de tipo triangular con parámetros [ [ $\left.\begin{array}{lll}0 & 1.16\end{array}\right],\left[\begin{array}{lll}1.66 & 3.33 & 5\end{array}\right]$, [ $\left.\begin{array}{lll}5 & 6.66 & 8.32\end{array}\right]$ y [8.32 10 10] respectivamente (figura 5.11).

Se definieron las 4 reglas siguientes, todas con peso asociado igual a 1:

Si dinero=mucho y salud=buena entonces calidad de vida=óptima . 
Si dinero=poco y salud=buena entonces calidad de vida=aceptable.

Si dinero $=$ mucho y salud $=$ mala entonces calidad de vida $=$ insuficiente.

Si dinero $=$ poco y salud $=$ mala entonces calidad de $\operatorname{vida}=$ mala .

El operador "y" fue el "min" y el método de implicación fue "min" para todas las reglas. Como método de agregación se usó el "max" y como método de defuzificación se utilizó el "MOM".

Puede consultarse el código fuente completo de este ejemplo, desarrollado usando el framework propuesto para el desarrollo de sistemas de inferencia borrosos flexibles, en el Apéndice I, inciso 1.1.

Se muestran en el Apéndice I, inciso 1.2, los valores de calidad de vida obtenidos en función de las 2 variables de entrada: dinero y salud. La variable dinero se ha dividido en intervalos de longitud 500 en tanto que la variable salud se ha dividido en intervalos de longitud 30. La precisión numérica asociada para realizar los cálculos fue de 0.01.

Se observa de los resultados obtenidos que el máximo nivel de calidad de vida se halla cuando la variable salud alcanza su mínimo valor ( 0 un/ml, el cual expresa una salud inmejorable) y dinero toma el valor máximo posible (5000 \$/mes). En éste caso, el valor de calidad de vida obtenido usando el método MOM es de 10, como era de esperar. Sin embargo, el valor obtenido para el mismo par de valores usando el método del centroide es de 9.44. Este hecho no se trata de un error. Por el contrario, si observamos la figura que tiene la función de pertenencia asociada al valor lingüístico "Óptima" asociado a la variable lingüística "Calidad de vida" vemos que la misma tiene forma de triángulo en cuya base, en el sector derecho, el ángulo interior es de 90 grados. Por lo tanto, el centroide de ésta área, tiene una coordenada $x$ que nunca llegará a ser 10 , dado que los puntos del área en cuestión que estén a la izquierda de 10 harán desplazar el valor del centroide hacia la izquierda.

Por el mismo motivo se tiene que el sistema devuelve el valor 0 para la combinación $(0$, 300) usando el método MOM de defuzificación; en tanto que para los mismos valores de entrada el método del centroide da como resultado 0.55 (el centroide se desplaza hacia la derecha en este caso). 
5.2.2 Modelos basados en operaciones de agregación de conjuntos borrosos

Según Cornelissen y colaboradores (Cornelissen et al. 2001 op.cit), la construcción de un modelo basado en operaciones de agregación de conjuntos borrosos para estimar el "desarrollo sustentable" es un proceso de 5 etapas como lo resume la figura 5.12.

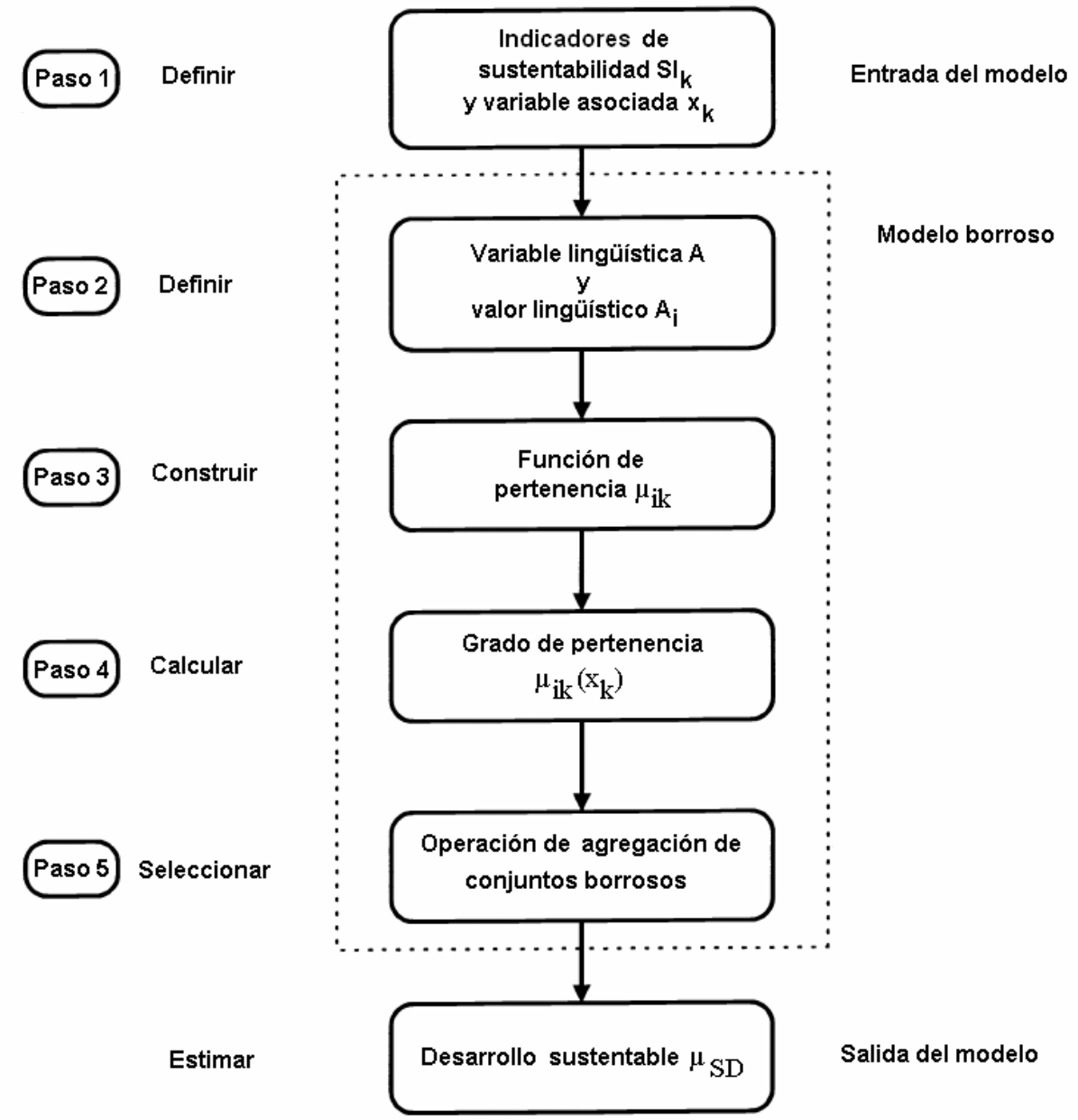


Figura 5.12. Etapas en la construcción de un modelo basado en la agregación de conjuntos borrosos. Fuente: Traducido de Cornelissen et al. 2001 op cit.

La idea básica consiste en estimar el estado de las diferentes dimensiones que conforman la noción de sostenibilidad (economía, ecología, sociedad, etc.) a partir de una serie de indicadores para luego formar con ellos un índice que informe acerca del nivel de sostenibilidad alcanzado.

\section{Si se utiliza el operador max como índice, ello implicará que si alguna de las funciones de pertenencia devuelve el valor 1 al ser evaluada, el índice tomará también el valor 1 como medida que estima el nivel de SD.}

Dubois y Prade (Dubois y Prade 1985, Dubois y Prade 1988) sostienen que el operador min representa una actitud conservadora hacia el desarrollo sostenible, en tanto que el operador max representa una actitud más liberal.

Además, como señala Silvert (Silvert 2000), la forma en la cual se combinan las funciones de pertenencia parciales depende de la aplicación. Un caso similar ocurre con la forma que adoptan las funciones de pertenencia, las cuales dependen obviamente del comportamiento del fenómeno que intentan representar.

\subsubsection{Framework para el desarrollo de modelos basados en operaciones de agregación de conjuntos borrosos}

La figura 5.12 representa en realidad una estructura jerárquica de tipo árbol cuyo nodo raíz sería el valor de entrada (nivel 1) de una variable lingüística que representa a un indicador. Con este valor se procede a fuzificar los valores lingüísticos (nivel 2) asociados a dicha variable lingüística. Estos valores lingüísticos forman estructuras de mayor complejidad, índices (nivel 3) usando operadores de agregación.

Dada la estructura detallada en el párrafo anterior, es necesario volver a calcular el valor de los valores lingüísticos de una variable lingüística cuando ésta última cambia de valor. Del mismo modo, es necesario actualizar el valor obtenido por la operación de agregación si alguno de los valores obtenidos al evaluar las funciones de pertenencia se modifica.

En términos del paradigma de desarrollo de software orientado a objetos, el caso anterior es un claro ejemplo para aplicar el patrón Observer. Este patrón, conocido en la jerga de los desarrolladores de software orientado a objetos plantea, ante una situación así, considerar los objetos que componen esa relación de dependencia como pertenecientes a 2 categorías distintas: objetos observadores y observados.

El rol que cumple cada uno es bien claro, los objetos observados deberán informar cuando su estado cambia para que los observadores puedan percibir ese cambio y actualizarse ellos mismos convenientemente.

El patrón Strategy permite en este caso seleccionar las distintas funciones de pertenencia posibles, como se observa en la figura 5.13. 


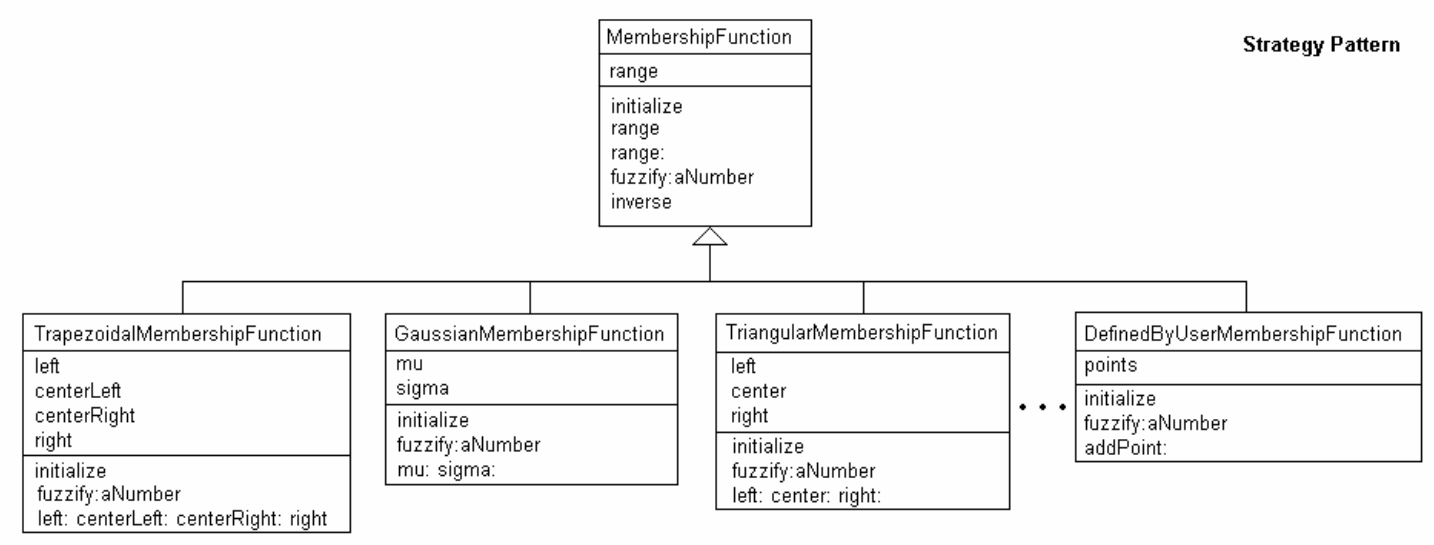

Figura 5.13. Implementación de las distintas funciones de pertenencia usando el patrón Strategy.

El framework completo se presenta en la figura 5.14 y propone la implementación de un modelo basado en la agregación de conjuntos borrosos que fue desarrollado usando, entre otras técnicas para el desarrollo de software, los patrones Observer y Strategy. 


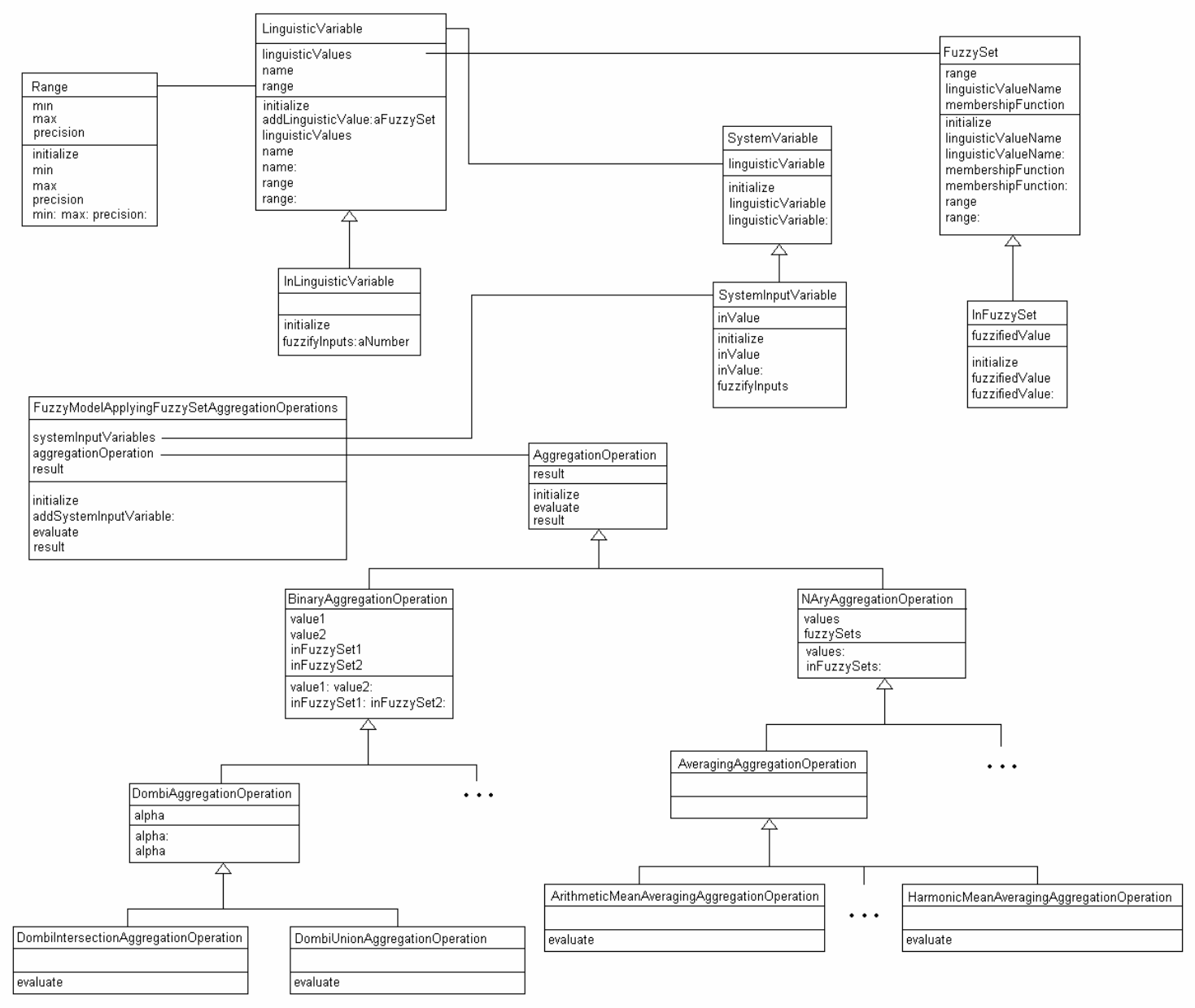

\section{Figura 5.14. Framework para el desarrollo de modelos basados en agregación de conjuntos borrosos.}

Aprovechando la rehusabilidad que permiten los desarrollos de software orientados a objetos basados en patrones de diseño, se utilizaron las clases definidas para el framework anterior, en su mayoría, sin modificaciones. Aquellas clases que sufrieron cambios, fueron sólo los necesarios para implementar el mecanismo de notificación-suscripción para implementar el patrón Observer. Se muestra el código fuente completo del framework de la figura 5.14 en el apéndice al final del trabajo.

Otra ventaja que posee el framework, además su mecanismo de actualización automática, es el uso en múltiples ocasiones de la herencia de objetos.

Son bien conocidas las ventajas de usar el mecanismo de herencia, por ejemplo, en términos de ahorro de líneas de código. Esto es evidente ya que las clases que heredan atributos y métodos de otra clase sólo deberán escribir los métodos y atributos que la diferencien de las superclases.

Para esta aplicación particular se ha contemplado también el uso del polimorfismo como técnica para invocar métodos que implementan la misma operación en clases diferentes.

Se observa que los autores que han creado métodos de agregación, lo hacen redefiniendo las 2 operaciones estandar existentes: unión ( $\min )$ e intersección (max). 
Por motivos de espacio y claridad, no se encuentran en la figura 5.14 todas las clases implementadas que heredan de la clase AggregationOperation. En su lugar, donde aparecen puntos suspensivos debe interpretarse como que las clases que irían allí y que no se muestran siguen los lineamientos de la clase que se encuentra a la izquierda de los puntos suspensivos. No obstante, se presenta en el anexo la jerarquía completa donde se puede apreciar las relaciones clase/subclase.

Puede consultarse el listado de las fórmulas propuestas por los diferentes autores en el trabajo desarrollado por Wolfram Research (Wolfram Research 2007).

5.2.2.2 Ejemplo de uso del framework para el desarrollo de modelos basados en operaciones de agregación de conjuntos borrosos.

Un ejemplo de uso de un modelo basado en la agregación de conjuntos borrosos es el presentado en el trabajo de Cornelissen (Cornelissen 2000 et al. op cit.). En dicho trabajo los autores seleccionaron 3 indicadores ("continuidad de la granja" expresada en \$/ave, “emisión de amoníaco" expresada en $\mathrm{Kg} \mathrm{NH}_{3}$ /ave y "polvo en el aire" expresado en mg/m³ para estimar el nivel de "sustentabilidad" de una granja que se dedica a la crianza de aves de corral.

En el citado ejemplo los autores adoptaron una actitud conservadora hacia el desarrollo sostenible (Dubois y Prade 1985 op cit., Dubois y Prade 1988 op cit,) la cual se ve reflejada en el uso del operador min (intersección estandar). Este operador se aplica a los grados de pertenencia obtenidos a partir de la fuzificación de los valores de entrada.

Se presenta en el Apéndice I, inciso 2.1, el código fuente completo de este ejemplo usando el framework propuesto. 
5.3 Estimación de la calidad de vida a partir de índices e indicadores tradicionales

\section{Consideremos, por un momento, un modelo sistémico de indicadores de CVU. Básicamente, para el cálculo del valor de cada índice o indicador en un momento dado, se requiere normalmente de:}

$>$ Datos provenientes de archivos o bases de datos.

$>$ Datos externos, por ejemplo provenientes de estaciones de medición.

$>$ En el caso de índices es probable que se necesite del valor de indicadores u otros índices previamente calculados.

En el trabajo de Papajorgji (Papajorgji 2005) se expone una solución basada en patrones de diseño para la adquisición de datos. La misma usa el patrón Strategy (figura 5.15) para tratar uniformemente los datos sin importar su procedencia (archivo, estación de medición o una base de datos).

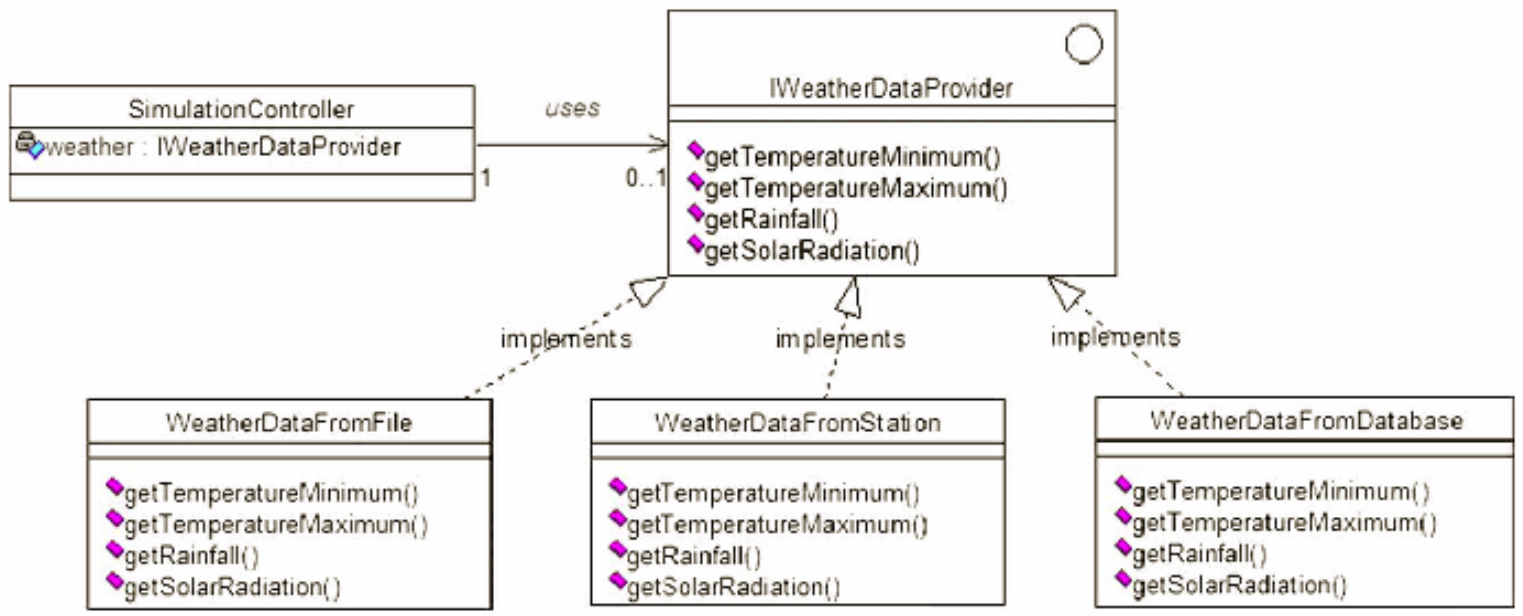

Figura 5.15. Diagrama de clases del patrón Strategy aplicado a un problema de adquisición de datos. Fuente: Papajorgi 2005 op.cit.

El tema de la actualización de índices e indicadores modelizados en SIG es una tarea que requiere una labor considerable. En general, el cambio o actualización de un dato normalmente requiere volver a calcular otros datos que guardaban cierta relación con el dato que sufrió el cambio. Este problema es muy evidente en aplicaciones catastrales.

Es posible expresar un modelo de calidad de vida basado en índices e indicadores interrelacionados por medio de grafos dirigidos que expresen las relaciones entre ellos como muestra la figura 5.16. 


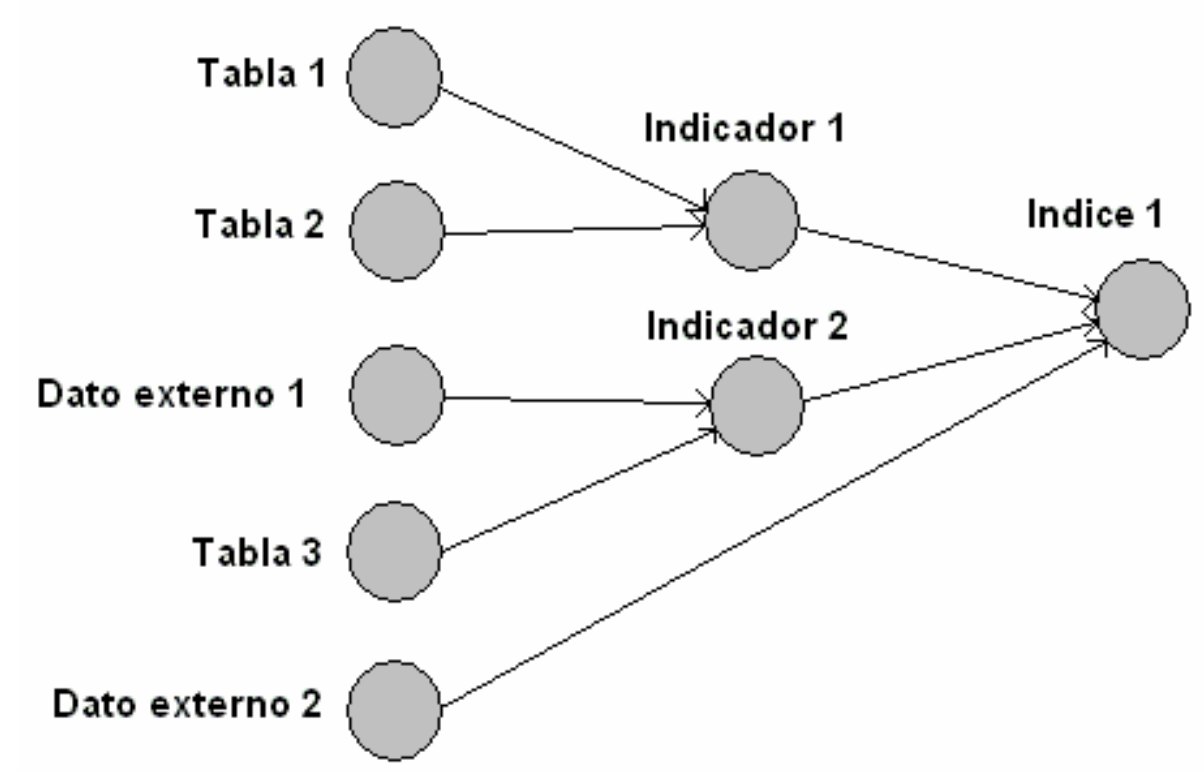

Figura 5.16. Ejemplo de relaciones entre datos de diferente procedencia, indicadores e índices.

En el dibujo se observa que el indicador 1 depende de los datos de la tablas 1 y 2 , por lo tanto cualquier modificación que sufran cualquiera de estas 2 tablas afectará al indicador 1 . El indicador 2, por su parte, depende de un dato externo y de la tabla 3 de modo que si se modificara cualquiera de éstos, el indicador 2 debería enterarse para actualizarse convenientemente. Por último el índice 1, depende de 2 indicadores que deben calcularse previamente, los indicadores 1 y 2 , y del dato externo 2 .

De este modo puede observarse fácilmente que, por ejemplo, un cambio del dato externo 1 no tiene incidencia sobre el indicador 1 , pero sí lo tiene para el indicador $2 \mathrm{y}$, en consecuencia, también con el índice 1.

El patrón Observer permite solucionar este tipo de problemas puesto que lo que hace es trabajar con objetos observadores y observados. Los objetos observados deben informar a sus observadores cada vez que se produce un cambio. Previamente, los observadores deben suscribirse a un objeto observado, lo que implica que éste último le avise cada vez que cambie.

En el ejemplo de la Figura 5.16 el indicador 1 debería suscribirse a la Tabla 1 y a la Tabla 2. Las tablas 1 y 2, por su parte, deberían notificar cuando sufran alguna modificación al Indicador 1. Este mismo proceso debería continuar hasta completar el árbol entero, si el mismo fuese más grande.

El resultado que se obtiene es un modelo sistémico, que ante la modificación de cualquiera de sus elementos, el resto del sistema se modifica de manera consistente, una vez que el o los objetos modificados informen al resto del sistema que cambiaron.

A continuación se muestra un ejemplo donde se tienen 2 layers o capas en un SIG: una capa corresponde a las manzanas de una ciudad y la otra a escuelas. Supongamos que existe un indicador que calcula el porcentaje de manzanas que se encuentran a una distancia de 300 metros o menos de una escuela cuya visualización puede observarse en la figura 5.17 en el mapa de la izquierda. Si se agregara una nueva escuela (figura 5.17 a la derecha) la cantidad de manzanas que tienen una escuela a 300 metros o menos sería mayor. 

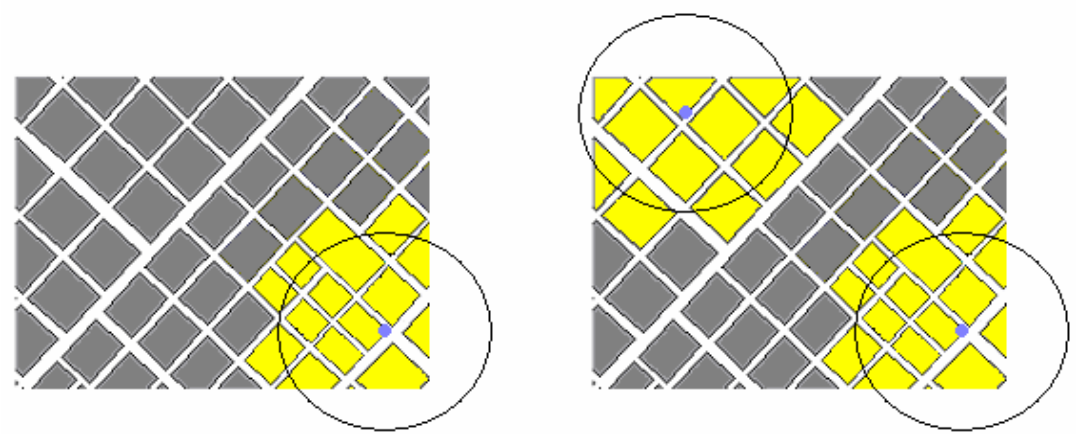

Referencias

Manzanas que están a más de 300 metros de una escuela

Manzanas que están a 300 metros o menos de una escuela

- Escuela

Figura 5.17. Actualización del área de influencia de escuelas a partir de la incorporación de una nueva escuela.

El ejemplo 5.17 se corresponde con el modelo de la figura 5.18. Para calcular un área de influencia, como en el presente caso, los SIG trabajan con 2 archivos o layers. En un primer paso se seleccionan del layer de escuelas, aquellas cuyo radio de influencia nos interesa calcular para luego consultar que objetos del layer manzanas se encuentran a menos de cierta distancia de las escuelas que fueron previamente seleccionadas. El hecho de agregar una nueva escuela hace que aumente el número de manzanas que tienen una escuela a 300 metros o menos.

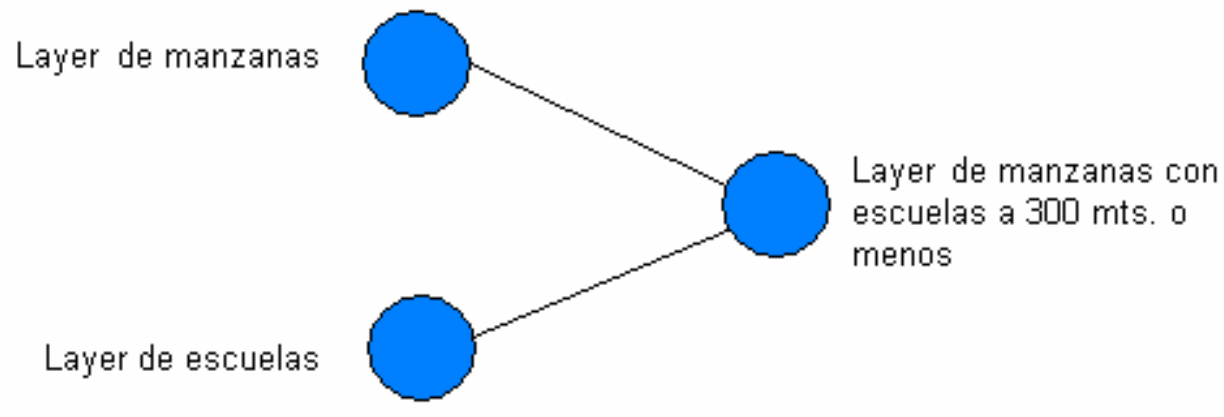

Figura 5.18. Relaciones entre los distintos layers involucrados.

Es evidente que el patrón Observer podría utilizarse de la manera tradicional en este caso, pero no siempre es así. Veamos el ejemplo que se presenta en la figura 5.19: 


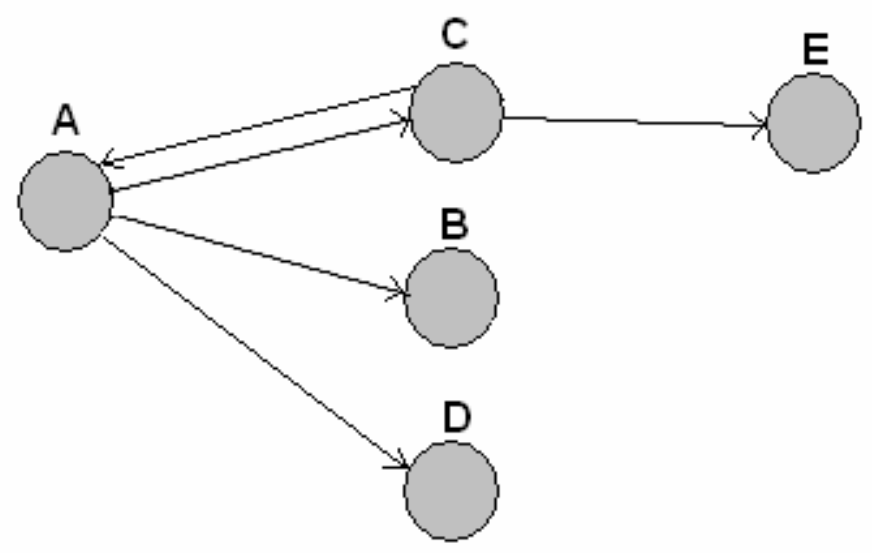

Figura 5.19. Ejemplo de posibles relaciones entre elementos de un modelo sistémico.

Aquí se observa que si el objeto A sufre un cambio, deberá notificar de ello a C, B y D. Por su parte, si se modifica el objeto C, se debe notificar a A y a E. Se tiene entonces la relación entre objetos y sus dependientes que se muestra en la figura 5.20.

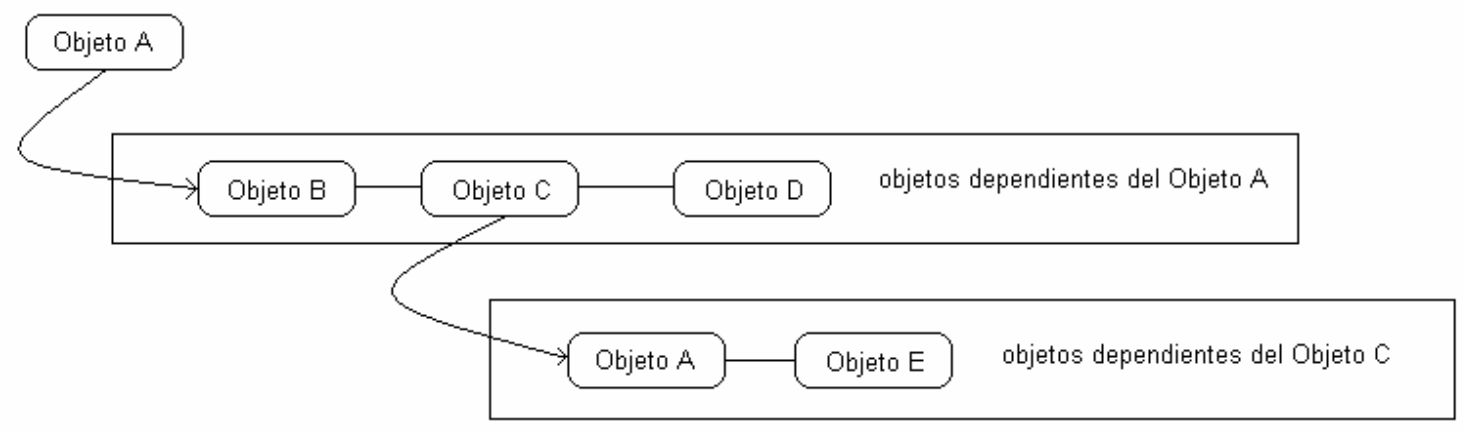

Figura 5.20. Dependencias de los distintos objetos de la figura 5.19.

Supóngase que se produce un cambio en el objeto A. Esto produce que se notifique al objeto B y luego a los objetos C y D. Ahora bien, si el método update de C desencadena un notify a sus dependientes, entonces se vuelve a la situación inicial formando un ciclo. Además, téngase en cuenta que los objetos D y E no fueron notificados. Esto constituye un grave problema dado que existen gran cantidad de ejemplos en los que la relación entre diferentes indicadores puede generar un grafo dirigido con ciclos. Por ejemplo, los ciclos biogeoquímicos que ocurren en la naturaleza cumplirían esta propiedad.

Es por tanto necesario adoptar otra estrategia que permita trabajar con indicadores interrelacionados de cualquier complejidad sin importar si entre ellos existe alguna referencia circular.

A continuación se presenta un framework para el manejo complejo de las dependencias que permite subsanar este inconveniente. 


\subsubsection{Framework para el desarrollo de modelos basados en el uso de índices e indicadores tradicionales}

En esta solución, los indicadores deberán agregar a los índices que afectan como objetos dependientes para que éstos últimos puedan actualizarse cuando algún indicador cambia. En principio, es fácil advertir cierta similitud de este comportamiento con el patrón Observer, sin embargo no ha sido usado en este framework debido a que los índices no siempre responden a una estructura arborescente, sino que pueden formar incluso grafos con ciclos. Si éste fuera el caso, el sistema quedaría en un loop infinito.

En su lugar, el patrón Composite es usado para especificar índices e indicadores, siendo los primeros una combinación de indicadores con una magnitud asociada (adimensional generalmente).

Es importante observar que las variables de instancia de los indicadores que aparecen en el framework propuesto son quizás las más evidentes ya que el número de variables de interés varía en función del problema a analizar. Por ejemplo, el día y la hora en que se efectúa la observación del valor de un indicador bien podrían ser parte del conjunto inicial de variables de instancia propuestas. No obstante, y tal como se observa en la figura 5.21 sólo se han tenido en cuenta las que se citan a continuación: Name, Buffer, Value, MinValue, MaxValue, Threshold, Units, NormalizationMethod, Description.

Threshold indica el valor umbral admisible para el indicador en cuestión. Superado éste valor máximo admisible, las consecuencias serán negativas. Superar, en este contexto, significa cualquier valor menor al threshold si el indicador representa mejores situaciones con valores más altos. Por el contrario, si el indicador representa peores situaciones a valores más altos (por ejemplo: partículas de algún contaminante por millón), el término superar significará la obtención de valores superiores al máximo admisible. Se ha usado el patrón Strategy para poder setear el método de normalización que corresponda (recordemos que existen 2 fórmulas posibles, que han sido presentadas en el inciso 4.6).

En otras palabras, depende como se modelice el indicador, el valor threshold deberá interpretarse de manera consecuente. Lo más lógico sería normalizar los indicadores de manera que todos ellos reflejen, por ejemplo, a mayor valor, una mejor situación (usando las fórmulas del inciso 4.6).

El mecanismo de manejo de las dependencias y actualización es de vital importancia; ya que de él depende el funcionamiento del modelo sistémico. La idea es que cada vez que ocurre un cambio en un indicador, se verifica quienes están relacionados de manera directa o indirecta (exceptuando el que sufrió el cambio) y se los actualiza convenientemente. Este proceso se realiza en 2 pasos con la ayuda de las variables value y buffer :

1) Para cada objeto relacionado directamente o indirectamente con el que acaba de sufrir un cambio (excepto el que cambió) se calcula el nuevo valor que debería tomar y se almacena en la variable buffer. 
2) Una vez que todos los objetos relacionados anteriores han terminado el paso 1) se actualiza el valor de la variable value con el que se encuentra almacenado en la variable buffer.

Este método es una adaptación del método stepSynchronously: presentado en el framework CORMAS $^{5}$ del trabajo desarrollado por el CIRAD (CIRAD 2003, pp. 7).

Como se observa en la figura 5.21, el patrón Composite define una estructura común para manejar de manera uniforme las operaciones en una jerarquía. Dado que en el caso particular de la modelización de índices e indicadores se tiene que los índices están compuestos por conjuntos de indicadores (eventualmente pueden haber también otros índices) la relación existente entre ambos tipos de descriptores puede verse como una estructura contenedor-contenido.

El hecho de que tanto los índices como los indicadores compartan la misma estructura básica, permite el uso del polimorfismo para tratarlos de manera uniforme.

${ }^{5}$ Desarrollado por el CIRAD (Centre de coopération internationale en recherche agronomique pour le développement). URL: http://cormas.cirad.fr/indexeng.htm 


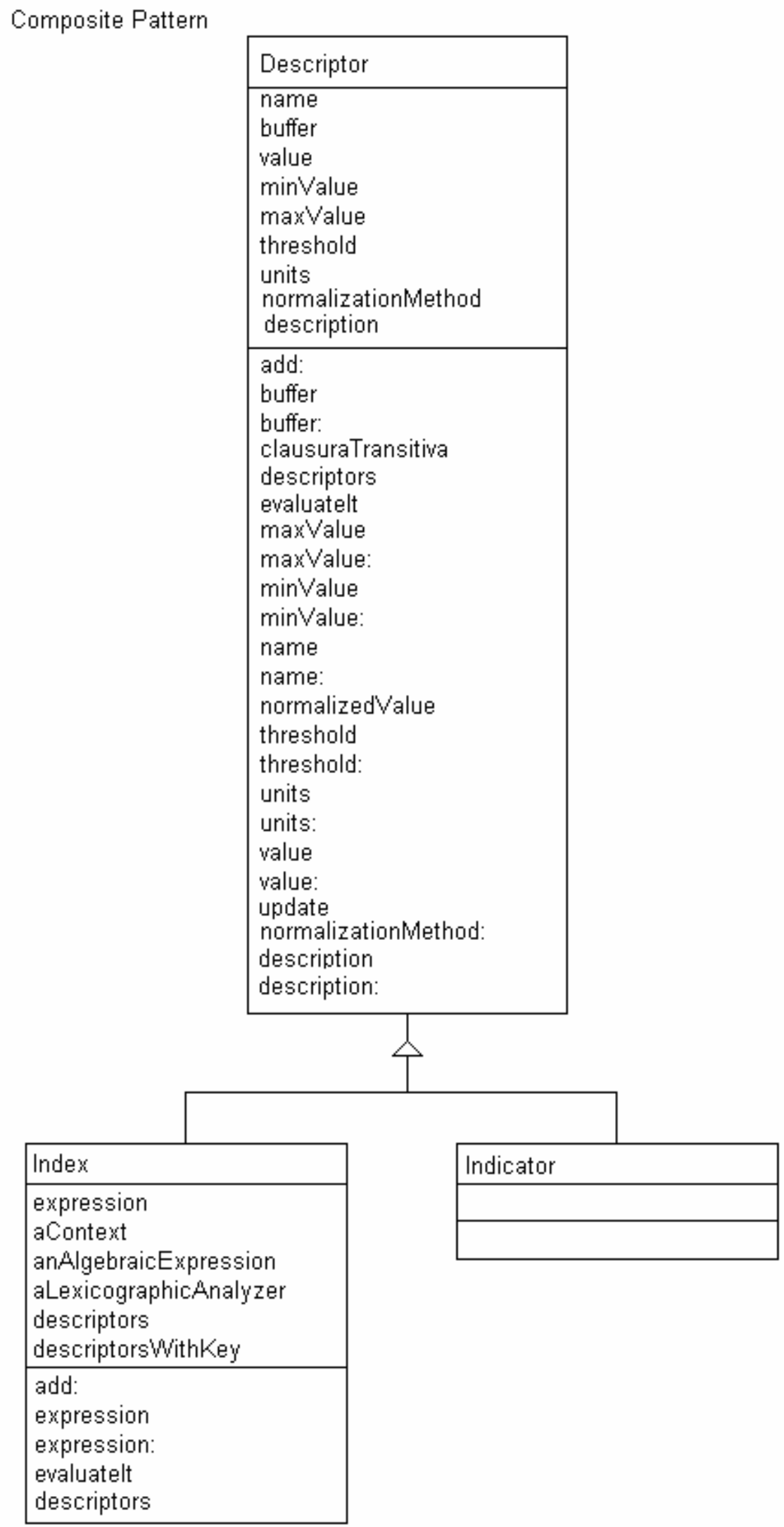


Figura 5.21. Patrón Composite para la modelización de índices e indicadores.

\section{El framework contempla también el uso del patrón Interpreter para el reconocimiento de expresiones algebraicas válidas en las fórmulas de los índices.}

La gramática que el patrón reconoce está basada en una definición dada por Aho (Aho et al. 1990, pp.766) aunque con ligeras modificaciones. La misma se muestra a continuación en formato BNF:

Expresión_simple :: Término | Signo Término |

Expresión_simple Opsuma Expresión_simple

Término :: Factor | Término Opmult Factor

Factor :: número | (Expresión_Simple) |Operación_Unaria

Signo $::+\mid-$

Opsuma $::+\mid-$

Opmult :: $*|/| \operatorname{div} \mid \bmod$

Operación_Unaria :: Nombre_de_la_operación(Expresión_Simple)

Nombre_de_la_operación $:: \sin |\cos | \tan \mid$ abs

El patrón Interpreter es usado para implementar la gramática que se necesita para reconocer expresiones algebraicas. La idea de este patrón es bien conocida por los desarrolladores de software orientado a objetos. En este caso se divide la expresión en partes más simples hasta llegar a valores concretos para luego ir recombinándose las diferentes partes para dar como resultado el valor correspondiente a la expresión completa. Esto implica declarar una clase por cada componente que se desee reconocer, exceptuando posiblemente aquellos componentes primitivos.

Interpreter Pattern
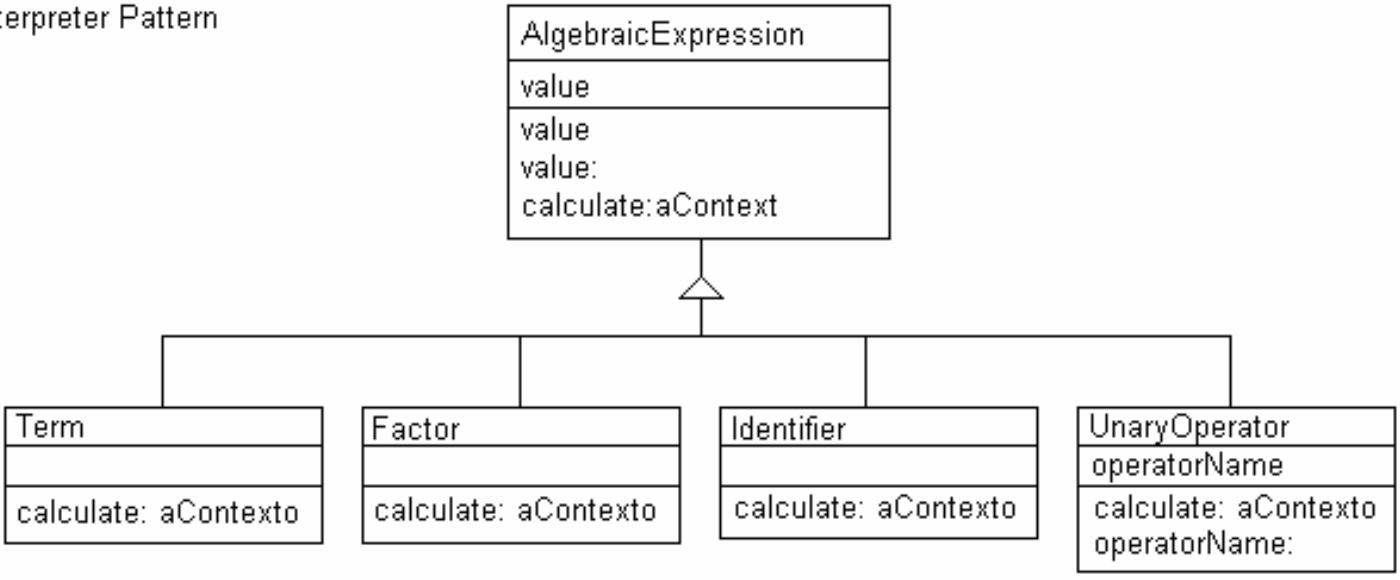

Figura 5.22. Patrón Interpreter para la representación de expresiones algebraicas.

Así, la gramática cuenta con una clase AlgebraicExpression y 4 subclases: Term, Factor, Identifier y UnaryOperator (ver Apéndice I para más detalles acerca de la implementación). 
El método para calcular el valor de una expresión se encuentra distribuido en las diferentes clases (figura 5.22).

Con el uso de este patrón es fácil realizar los cambios correspondientes en el caso de que la gramática cambie. Además, agregar una nueva regla a la gramática existente sólo implicará agregar una nueva clase que implemente dicha regla.

El framework queda entonces como aparece en la figura 5.23.

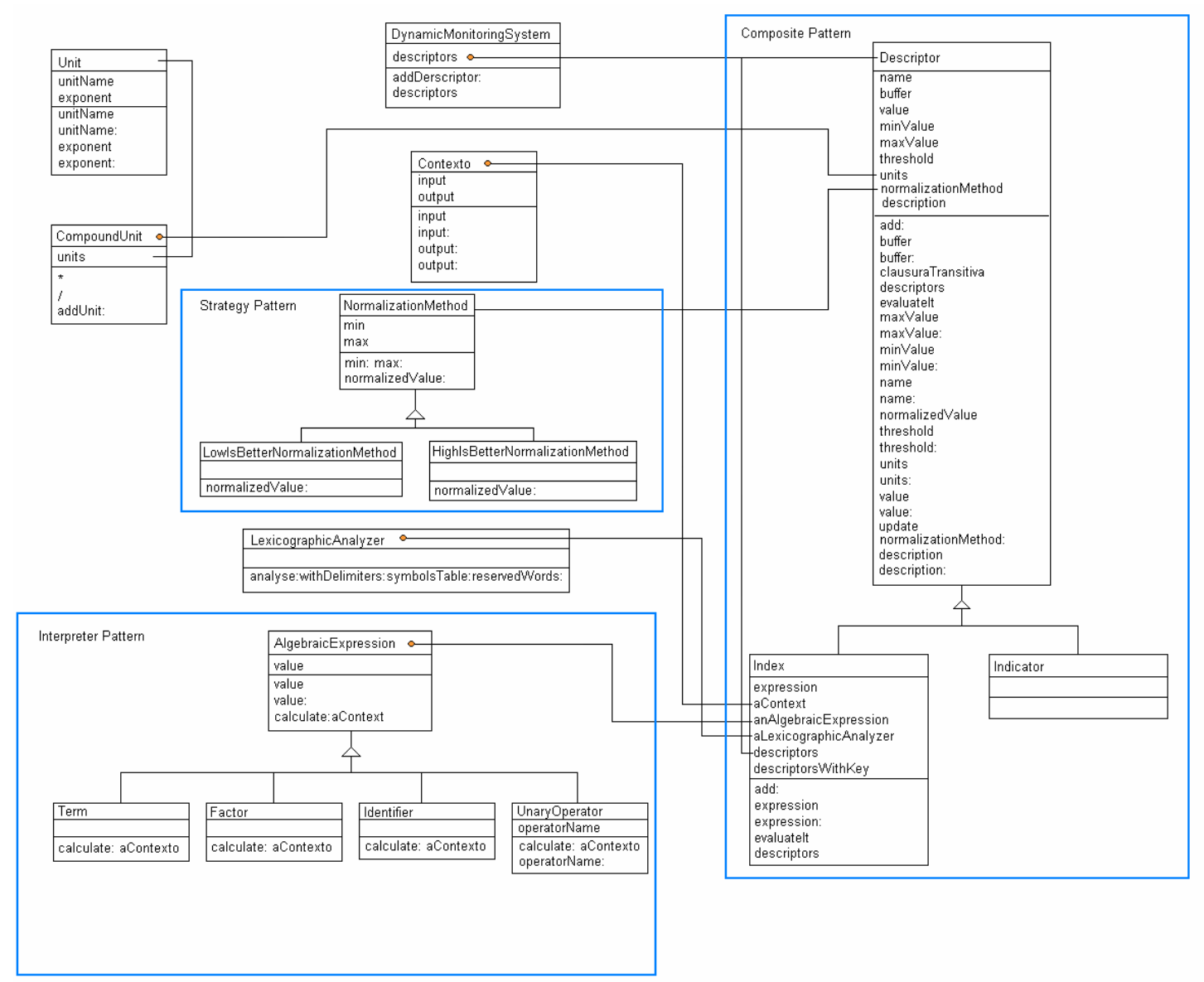

Figura 5.23. Framework para el desarrollo de modelos sistémicos de calidad de vida basados en ínidices e indicadores cuantitativos tradicionales.

La clase LexicographicAnalyzer implementa el método:

analyse: withDelimiters: symbolsTable: reservedWords

el cual recibe como parámetro los caracteres delimitadores, la tabla de símbolos y las palabras reservadas. De esta forma se aumenta la rehusabilidad en relación a la que se obtendría si alguno de los parámetros se inicializaran dentro del método ya que, de esta manera, esta misma clase podría servir como analizador lexicográfico para, por ejemplo, diferentes lenguajes de programación, instanciando el método cada vez con los diferentes parámetros 
propios de cada lenguaje. Además, en el caso de que se produjesen cambios en las palabras reservadas derivados de una actualización del lenguaje; esto sólo implicaría un cambio en el parámetro reservedWords, mientras que el código del método se mantendría intacto.

\subsubsection{Ejemplo de uso del framework para el desarrollo de modelos basados en índices e indicadores tradicionales}

Se expondrá como ejemplo para el framework desarrollado para el manejo complejo de dependencias el trabajo de Leva (Leva 2005 op cit.) desarrollado para la ciudad de Quilmes. En este trabajo el autor plantea un índice de calidad de vida urbana (ICVU) compuesto por un conjunto de indicadores. Cada uno de los indicadores pertenecen a una de las 4 dimensiones siguientes: hábitat, social, económica y subjetiva. Las dimensiones tienen un peso asociado de $0.2,0.25,0.2$ y 0.35 respectivamente. 


\begin{tabular}{|c|c|c|c|}
\hline Nombre del indicador & Dimensión & Porcentaje & Descripción del indicador \\
\hline prerc & Hábitat & 0,08 & $\%$ cobertura red de cloacas \\
\hline prera & Hábitat & 0,02 & $\%$ cobertura red de agua \\
\hline prore & Hábitat & 0,02 & $\%$ cobertura red de electricidad \\
\hline prerg & Hábitat & 0,02 & $\%$ cobertura red de gas \\
\hline caobspp & Hábitat & 0,02 & Obstáculos promedio al peatón \\
\hline caretoss & Hábitat & 0,02 & Reclamos ingresados en ETOSS \\
\hline ipmh & Hábitat & 0,02 & Índice de privación material de hogares \\
\hline prpnbi & Social & 0,04 & $\%$ población $\mathrm{NBI}$ \\
\hline prpccs & Social & 0,015 & $\%$ polación con cobertura social \\
\hline prens & Social & 0,01 & $\%$ población $18-29$ en nivel superior de educación \\
\hline $\operatorname{tsanf}$ & Social & 0,015 & Tasa de analfabetismo \\
\hline tsminf & Social & 0,02 & Tasa de mortalidad infantil cada 1000 habitantes \\
\hline prhdef & Social & 0,02 & $\%$ de hogares deficitarios \\
\hline prpvic & Social & 0,07 & $\%$ población victimizada \\
\hline preri & Social & 0,06 & $\%$ crímenes de zona sur \\
\hline prpilbr & Económica & 0,08 & $\%$ PIB regional bienes y servicios \\
\hline tsupmcc & Económica & 0,04 & Tasa de variación del precio del metro cuadrado construído \\
\hline priim & Económica & 0,02 & $\%$ importancia de la industria manufacturera \\
\hline prtra & Económica & 0,04 & $\%$ transferencias de provincia \\
\hline calbps & Económica & 0,02 & Cantidad de locales productores de bienes y servicios \\
\hline pema & Subjetiva & 0,02 & Percepción sobre el medio ambiente \\
\hline peabl & Subjetiva & 0,01 & Percepción sobre ABL \\
\hline pepc & Subjetiva & 0,01 & Percepción sobre la participación ciudadana \\
\hline peep & Subjetiva & 0,01 & Percepción sobre el estado de los espacios públicos \\
\hline peas & Subjetiva & 0,01 & Percepción sobre la asistencia social \\
\hline petp & Subjetiva & 0,01 & Percepción sobre la eficiencia del transporte público \\
\hline pesb & Subjetiva & 0,04 & Percepción sobre las soluciones al barrio \\
\hline pepc & Subjetiva & 0,01 & Percepción sobre la política cultural \\
\hline pesap & Subjetiva & 0,025 & Percepción sobre la salud pública \\
\hline peop & Subjetiva & 0,095 & Percepción sobre la obra pública \\
\hline pemu & Subjetiva & 0,01 & Percepción sobre la movilidad urbana \\
\hline pesu & Subjetiva & 0,1 & Percepción sobre la seguridad urbana \\
\hline
\end{tabular}

Tabla 5.2. Indicadores de calidad de vida y su ponderación. Fuente: Leva 2005 op cit.

A su vez, los indicadores que forman parte de una misma dimensión tienen un peso asociado, el cual es una fracción del asignado a la dimensión. Puede observarse el peso de cada uno en la tabla 5.2.

En base a la tabla anterior el autor calculó y normalizó los indicadores para llegar a obtener el índice de calidad de vida de la ciudad de Quilmes. Puede observarse en el gráfico de la figura 5.24 el peso relativo de cada dimensión, el peso relativo de los indicadores dentro de cada dimensión y el estado de cada uno de ellos. 


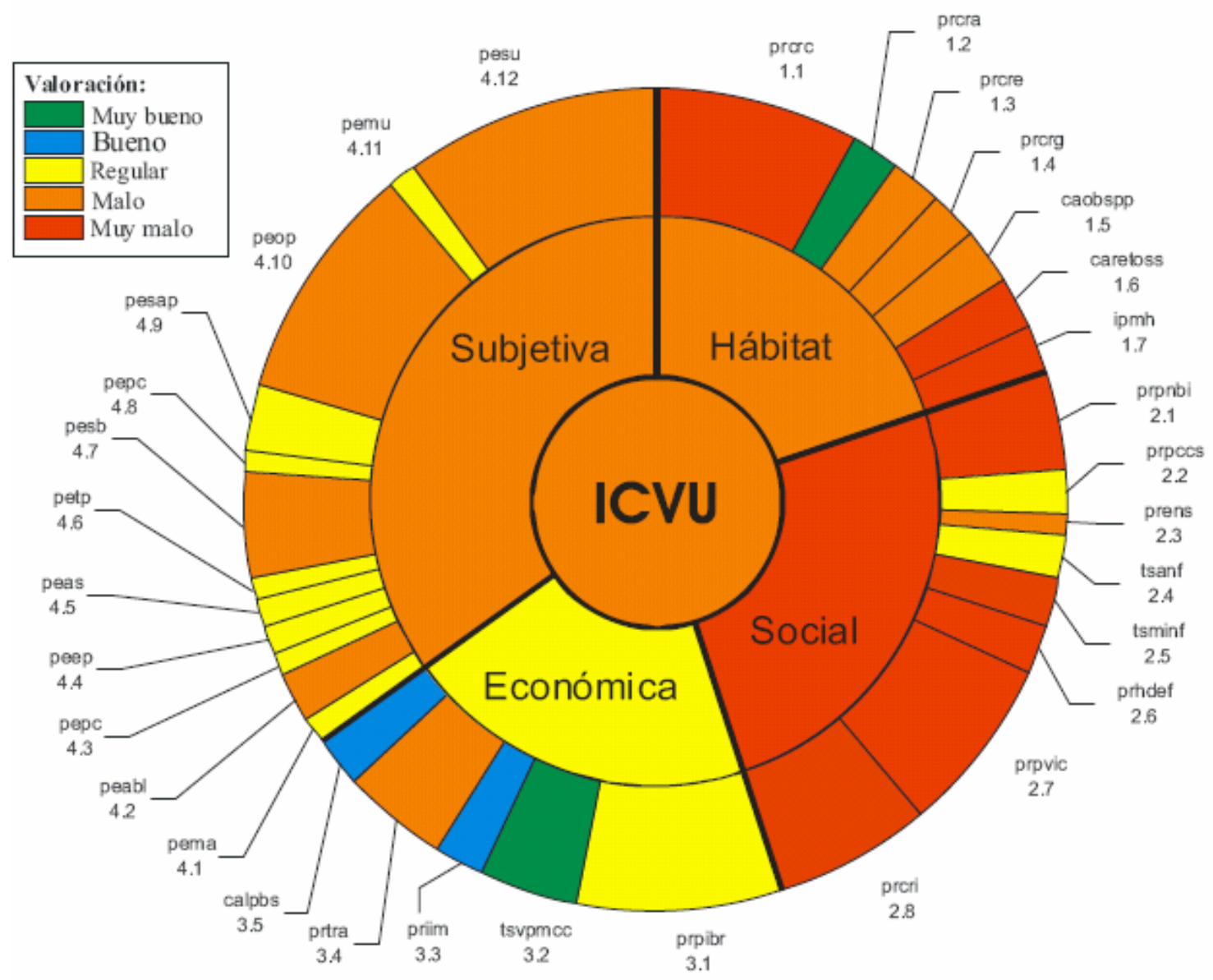

Figura 5.24. Resultados obtenidos al evaluar la ciudad de Quilmes. Fuente: Leva 2005 op cit.

A partir de la tabla anterior, la representación del modelo de Leva usando el framework propuesta es muy simple. En primer lugar se declaran los 32 indicadores con sus respectivos nombres. Luego se declara el índice, llamado icvu, y se le agregan los indicadores anteriores. Posteriormente se carga la expresión matemática que calcula el índice de calidad de vida para la ciudad.

Una vez concluída esta tarea, cualquier cambio en alguno de los indicadores hará que automáticamente se recalcule el valor del índice, evitando la tarea de tener que hacerlo manualmente. Puede consultarse el código fuente completo de este ejemplo, usando el framework propuesto, en el Apéndice I, inciso 3.1. 


\section{Capítulo 6}

\section{Aportes del trabajo y conclusiones}

\subsection{Aportes del trabajo}

El trabajo desarrollado comprendió el estudio y análisis exhaustivo de modelos de calidad de vida basados en índices e indicadores cuantitativos. Los índices e indicadores cuantitativos suelen dividirse en tradicionales (cuando no hay o es mínima la incertidumbre respecto del valor señalado por el índice o indicador) y borrosos (cuando existe un grado de incertidumbre significativo acerca del valor tomado por el índice o indicador). Estos últimos se subdividen a su vez en 2 clases: los modelizados mediante sistemas de inferencia borroso y los modelizados usando operaciones de agregación de conjuntos borrosos. Por lo tanto, hay en total 3 posibles formas de representación de índices e indicadores cuantitativos $\mathrm{y}$, por ende, tres formas de construir modelos sistémicos basados en ellos:

$>$ Modelos sistémicos basados en índices e indicadores tradicionales.

$>$ Modelos sistémicos basados en índices e indicadores representados mediante un sistema de inferencia borroso (SIB).

> Modelos sistémicos basados en índices e indicadores representados mediante operaciones de agregación de conjuntos borrosos.

El aporte principal de este trabajo es el desarrollo de 3 soluciones genéricas (frameworks), una para cada una de las clases de modelos sistémicos antes enumerados. Cada solución, dado su carácter general, sirve como molde para poder ser instanciada con diferentes modelos sistémicos. Estas soluciones genéricas pueden ser aplicadas incluso a otros dominios diferentes al de la calidad de vida en los cuales sea válido la evaluación a través de índices e indicadores cuantitativos.

Otros aportes, ya de carácter más específico, son los relativos a las mejoras sustanciales que cada solución propuesta tiene respecto de las soluciones existentes hoy en día.

Por ejemplo, para los modelos sistémicos basados en índices e indicadores tradicionales se desarrolló un framework que permite la actualización automática de modelos basados en índices e indicadores interdependientes. Esto supone una notable ventaja en términos del tiempo que se ahorra en comparación al requerido cuando la actualización y el cálculo se hacen de forma manual. El mecanismo de actualización permite mantener la consistencia en las relaciones de interdependencia, incluso en aquellas de carácter cíclico.

Otro tema que se analizó fue el manejo de modelos basados en índices e indicadores cuando éstos últimos presentan cierto grado de incertidumbre. Cuando esto ocurre, el uso 
de la matemática tradicional no es adecuado. En su lugar, aparece como herramienta alternativa la lógica borrosa. La lógica borrosa puede ser empleada de 2 maneras para tratar el tema: mediante sistemas de inferencia borrosos o mediante operaciones de agregación de conjuntos borrosos. Para la primer alternativa que contempla el uso de lógica borrosa se desarrolló un framework que permite el desarrollo de sistemas de inferencia borrosos flexibles.

Hemos visto que los programas comerciales existentes presentan ciertas limitaciones a la hora de construir sistemas de inferencia borrosos como por ejemplo:

> El mismo método (ej.: prod) asociado a un operador (ej.: and) se aplica cada vez que aparece el mencionado operador, es decir, no es posible asignar distintos métodos a un mismo operador.

$>$ No es posible elegir el método de implicación para una regla en particular sino que el método que se elija será el que se aplique a todas las reglas.

$>$ El método de agregación que se elige se aplica a cada una de las variables de salida.

Dl método de defuzificación elegido se aplica a cada una de las variables lingüísticas de salida.

El framework propuesto para el desarrollo de SIB flexibles ha superado tales limitaciones ya que:

$>$ Es posible asociar distintos métodos (ej.: prod, min) a las distintas instancias de un mismo operador.

> Cada regla puede tener su propio método de implicación (eventualmente diferente al de otras reglas).

$>$ Cada variable lingüística de salida puede contar con un método de agregación eventualmente diferente al de otras variables lingüísticas de salida.

> Similarmente, cada variable lingüística de salida podrá tener un método de defuzificación diferente quizás al de otras variables lingüísticas de salida.

En síntesis, la solución presentada en esta tesis para el diseño de sistemas de inferencia borrosos (SIB) flexibles supera las limitaciones antes enumeradas permitiendo el uso de distintos tipos de operadores lógicos, métodos de implicación, métodos de agregación y de defuzificación en un mismo SIB en caso de ser necesario. Estos aportes se traducen en un mayor grado de flexibilidad a la hora de construir un sistema de inferencia borroso.

Para la segunda alternativa que contempla el uso de lógica borrosa, y para completar el análisis exhaustivo de modelos basados en índices e indicadores cuantitativos, se presentó un framework para el desarrollo de modelos basados en operaciones de agregación de conjuntos borrosos. A diferencia de otros trabajos como el desarrollado por el Wolfram 
Research (Wolfram Research 2007), el framework presenta un mecanismo de actualización automática. Este mecanismo es necesario dada la interdependencia inherente existente entre índices e indicadores en modelos sistémicos.

\subsection{Conclusiones y trabajo futuro}

El uso de SIG para modelar complejas aplicaciones tendientes a estimar la calidad de vida urbana a menudo se lleva a cabo por medio de modelos basados en índices e indicadores cuantitativos que describen la interrelación existente entre las variables de interés.

Para cada uno de los 3 tipos de modelos sistémicos mencionados en el inciso anterior se elaboró un framework utilizando el paradigma de la programación orientación a objetos, combinando de manera coherente diferentes patrones de diseño, con el fin de lograr soluciones generales que luego puedan ser aplicadas a modelos específicos. Si bien este trabajo tiene como objeto de estudio el análisis de la calidad de vida, cada framework puede ser usado también en otros dominios en los que el desarrollo de modelos basados en índices e indicadores cuantitativos sea una alternativa válida.

Uno de los trabajos más tediosos una vez implantado un SIG es el de la actualización de datos y el recálculo de los indicadores. Esta última parte puede ser resuelta de manera automática si tenemos una clara idea de las influencias que existen entre las variables del modelo sistémico.

En tal caso, como hemos visto, se elaboró un framework que permite representar interdependencia entre índices e indicadores tradicionales, e incluso relaciones cíclicas entre ellos, manteniendo la consistencia de los datos ante cambios en los valores de los índices 0 indicadores.

El framework para el desarrollo de sistemas de inferencia borrosos flexibles permitió descomponer el proceso de inferencia en las etapas de las que consta, posibilitando así una mayor libertad en cuanto a la elección de los métodos que participarán en cada una, pudiendo incluso contar con diferentes métodos para una misma etapa.

El framework para el desarrollo de modelos sistémicos basados en operaciones de agregación de conjuntos borrosos cuenta con el agregado de un mecanismo que permite su actualización automática. El citado mecanismo es necesario debido a la naturaleza sistémica de los modelos de calidad de vida.

Es interesante observar que cuando los datos poseen cierto grado de incertidumbre y se decide utilizar una solución basada en la lógica borrosa, en realidad, no estamos trabajando solamente con datos cuantitativos ya que cuando se realiza la fuzificación de los valores de entrada de un modelo se obtienen valores en el rango [0..1] perteneciente a valores lingüísticos como "aceptable", "óptima”, etc.. Estas últimas son "etiquetas" que denotan claramente datos cualitativos. 
Es importante destacar también el hecho de que el presente trabajo, además de presentar aportes en el campo de la informática, tales aportes no podrían haberse llevado a cabo sin las contribuciones de otras disciplinas como la arquitectura (y más específicamente, el planeamiento urbano), la ecología, las ciencias del ambiente, y algunas más evidentes como las matemáticas, entre otras. Esto se debe a que la "calidad de vida" incorpora aspectos que requieren un análisis multidisciplinario.

Se ha demostrado que es posible implementar los frameworks propuestos usando un lenguaje basado en el paradigma de la programación orientada a objetos de modo que resulta de esperar el hecho de que aquellos SIG que cuenten con lenguajes orientados a objetos para el desarrollo de aplicaciones puedan asimismo incorporar estas soluciones que, sumada a la capacidad de los SIG para manejar datos georreferenciados de una región puedan estimar la calidad de vida del sector bajo estudio al mismo tiempo que se visualiza su estado en la interfase gráfica del SIG. Esto permitiría observar los valores de índices, indicadores y sus dimensiones y tomar nota para iniciar acciones para revertir tempranamente los problemas que se encuentren.

Como trabajo futuro se plantea el hecho de integrar los frameworks propuestos a un SIG comercial para su uso en el análisis de la calidad de vida planteado en un proyecto de reciente acreditación. También se pretende que los frameworks puedan ejecutarse en ambientes independientes de los SIG e independientes de la plataforma, motivo por el cual se planea convertir el código actual en código Java. 


\subsection{Framework para el desarrollo de modelos basados en el uso de índices e indicadores tradicionales}

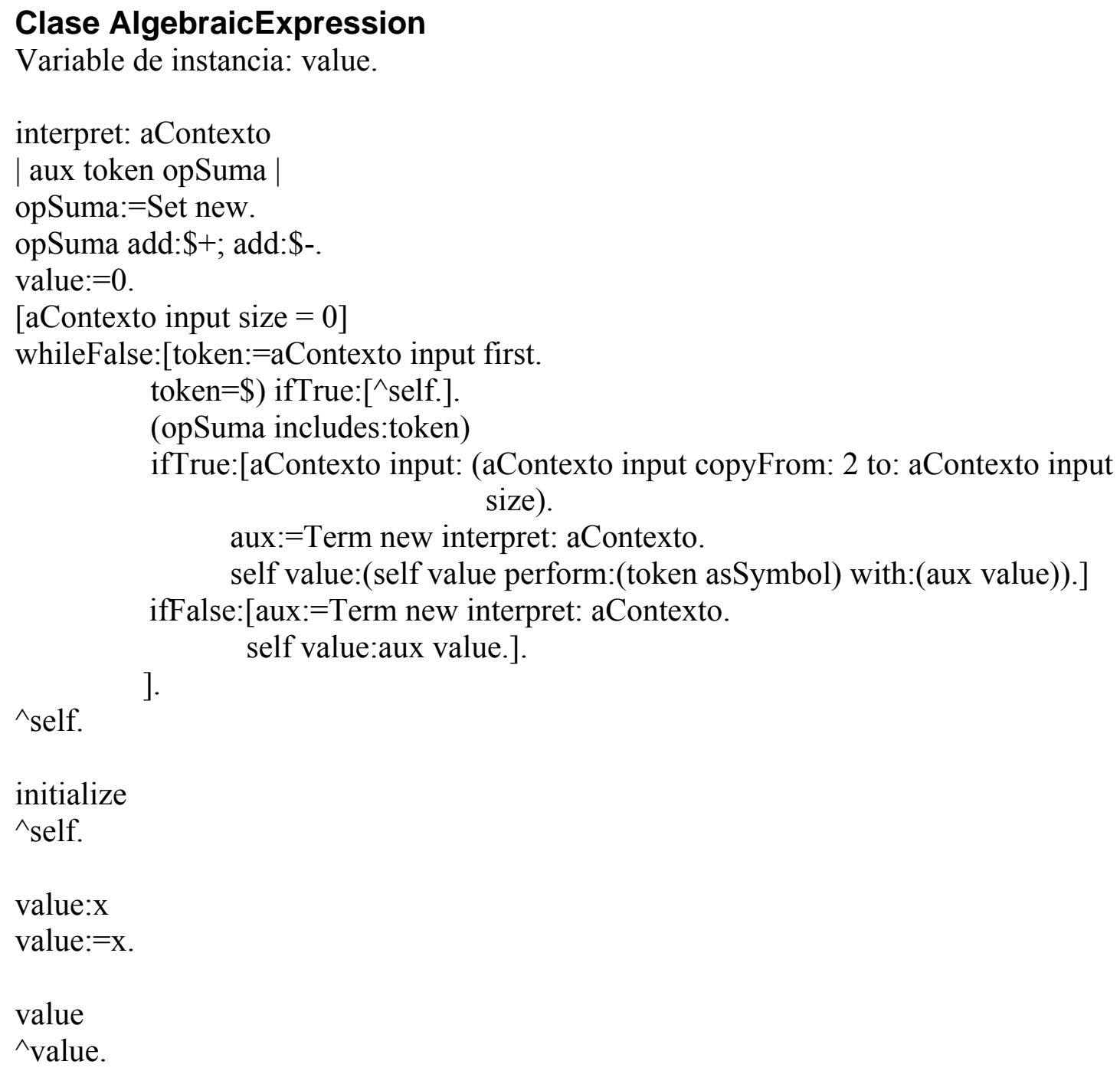

\section{Clase Term}

Variable de instancia: -.

interpret: aContexto

| aux opMult token |

opMult:=Set new. 
opMult add:\$*; add:\$/; add:'div'; add:'mod'.

aux:=Factor new interpret:aContexto.

self value:aux value.

(aContexto input size $>0$ )

ifTrue:[token:=aContexto input first.

[opMult includes:token] whileTrue:[ aContexto input:(aContexto input copyFrom: 2

to:aContexto input size).

aux:=Factor new interpret:aContexto.

(token='div') ifTrue:[token:='//'. ].

(token='mod') ifTrue:[token:='\'.].

self value:(self value perform:

(token asSymbol) with:(aux

(aContexto input size $>0$ )

value)).

ifTrue:[token: $=$ aContexto input first.]

ifFalse:[token:=". ].

].

$\wedge$ self.

asAlgebraicExpression

$\wedge$ AlgebraicExpression new value: self value.

initialize

super initialize.

$\wedge$ self.

\section{Clase Factor}

Variable de instancia: -.

interpret: aContexto

| aux token|

token: $=$ aContexto input first.

(UnaryOperator new isUnaryOperator:token)

ifTrue:[ aux:=UnaryOperator new interpret:aContexto.]

ifFalse: $[$ token $=\$($

ifTrue:[ aContexto input: (aContexto input copyFrom:2 to: aContexto input size).

aux:=AlgebraicExpression new interpret:aContexto.

aContexto input:(aContexto input copyFrom:2 to: aContexto input size) ]

ifFalse:[ aux:=Identifier new interpret:aContexto.]. 
].

self value:aux value.

$\wedge$ self.

initialize

super initialize.

$\wedge$ self.

asTerm

${ }^{\wedge}$ Term new value:self value.

asAlgebraicExpression

${ }^{\wedge}$ self asTerm asAlgebraicExpression.

\section{Clase Identifier}

Variable de instancia: -.

interpret: aContexto

self value:(aContexto input first asNumber).

aContexto input: (aContexto input copyFrom:2 to:aContexto input size).

$\wedge$ self.

initialize

super initialize.

$\wedge$ self.

asTerm

${ }^{\wedge}$ self asFactor asTerm.

asFactor

${ }^{\wedge}$ Factor new value:self value.

asAlgebraicExpression

${ }^{\wedge}$ self asTerm asAlgebraicExpression.

\section{Clase UnaryOperator}

Variables de instancia: operatorName.

interpret: aContexto

| aux |

self operatorName:(aContexto input first). 
aContexto input: (aContexto input copyFrom:3 to:aContexto input size). aux:=AlgebraicExpression new interpret:aContexto.

aContexto input: (aContexto input copyFrom:2 to:aContexto input size). self value:((aux value) perform:(operatorName asSymbol)).

$\wedge$ self.

initialize

super initialize.

$\wedge$ self.

isUnaryOperator:aString

| operatorsList |

operatorsList: $=$ Set new.

operatorsList add:'truncated';

add:'tan'; add:'sqrt';

add:'sin'; add:'cos';

add:'tan';add:'arcTan';

add:'rounded';

add:'arcSin';add:'arcCos';

add:'log';add:'In';

add:'floor';add:'ceiling';

add:'abs'.

^operatorsList includes:aString.

operatorName:x

operatorName: $=\mathrm{x}$.

Las unidades de los indicadores se implementaron usando las clases Unidad y . Así, una unidad como Metro3/persona se implementaría usando 2 objetos de la clase Unit. El primero con su variable de instancia name igual a "Metro" y la variable exponente igual a 3.

El segundo objeto tendrá, en su variable de instancia exponent, el valor -1 y el valor de la variable name será "persona". Generalizando, las unidades que aparezcan dividiendo se escribirán como productos con exponentes negativos. De este modo, el código de las operaciones * y / de la clase CompositeUnit quedan como se observa a continuación.

\section{Clase Unit}

Variables de instancia: name, exponent.

exponent

^exponent. 


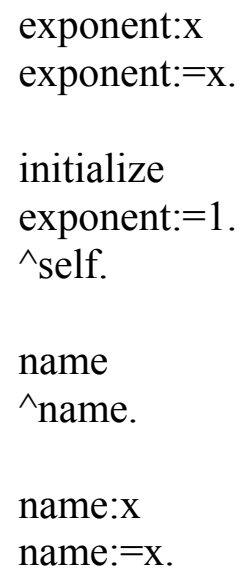

\section{Clase CompoundUnit}

Variable de instancia: units.

initialize

$\wedge$ self.

* anotherUnit

units addAllLast:anotherUnit.

1 to:((units size)-1) do:[:x $\mid(x+1)$ to:(units size) do:[:y | (units at:x) name $=$ (units at:y) name ifTrue:[ (units at:x) exponent: ((units at:x) exponent + (units at:y) exponent). (units at:y) exponent:0.]. ].

units:=units select:[:x $\mid \mathrm{x}$ exponent $\sim=0]$.

].

/ anotherUnit

anotherUnit do:[:x $\mid \mathrm{x}$ exponent:((x exponent)*(-1))].

self * anotherUnit.

addUnit: $x$

units isNil ifTrue:[units:=OrderedCollection new.].

units add:x.

\section{Clase NormalizationMethod}


Variables de instancia: min, max.

initialize

$\wedge$ self.

$\max$

${ }^{\wedge} \max$.

$\min$

$\wedge_{\mathrm{min}}$.

$\min : x$ max:y

$\min :=\mathrm{x}$.

$\max :=\mathrm{y}$.

\section{Clase HighlsBetter}

(Subclase de NormalizationMethod)

initialize

super initialize.

$\wedge$ self.

normalizedValue: $\mathrm{x}$

$\wedge(x-\min ) /(\max -\min )$.

\section{Clase LowlsBetter}

(Subclase de NormalizationMethod)

initialize

super initialize.

$\wedge$ self.

normalizedValue:x

$\wedge(\max -x) /(\max -\min )$.

\section{Clase LexicographicAnalyzer}


Variable de instancia: -.

initialize

$\wedge$ self.

analyse: aByteString withDelimiters: setOfDelimiters symbolsTable: aDictionary reservedWords: setOfReservedWords

"Se han considerado solamente delimitadores de longitud uno"

| palabra tokens conjunto cadena error |

tokens := OrderedCollection new.

cadena $:=$ aByteString.

setOfDelimiters add: Character space.

palabra :=".

1 to: cadena size

do:

[:index |

(setOfDelimiters includes: (cadena at: index) asCharacter)

ifTrue:

[palabra $\sim="$

ifTrue:

[tokens add: palabra.

palabra :="].

(cadena at: index) asCharacter $=$ Character space

ifFalse: [tokens add: (cadena at: index)]]

ifFalse:

[palabra := palabra , (cadena at: index) asSymbol.

index $=$ cadena size ifTrue: [tokens add: palabra]]].

conjunto := Set new.

aDictionary associations do: [:each | conjunto add: each key].

1 to: tokens size

do:

[:index |

(conjunto includes: (tokens at: index))

ifTrue: [tokens at: index put: (aDictionary at: (tokens at: index))].

(setOfReservedWords includes: (tokens at: index))

ifTrue: [self youCanNotUseAReservedWordAsVariableError.]].

$\wedge$ tokens.

youCanNotUseAReservedWordAsVariableError

Transcript show:'You can not use a reserved word as a variable.'.

\section{Clase Contexto}


Variables de instancia: input, output.

initialize

output: $=0$.

$\wedge$ self.

input

input.

input: $\mathrm{x}$

input: $=\mathrm{x}$.

output

^output.

output: aNumber

output:= aNumber asNumber.

\section{Clase DynamicMonitoringSystem}

Variable de instancia: descriptors.

initialize

descriptors: $=$ OrderedCollection new.

$\wedge$ self.

addDescriptor: $\mathrm{x}$

descriptors add:x.

descriptors

$\wedge$ descriptors.

\section{Clase Descriptor}

Variables de instancia: name, buffer, value, minValue, maxValue, threshold, unit, normalizationMethod, description.

value: $\mathrm{x}$

value: $=\mathrm{x}$.

self dependents isNil

ifFalse:[ self dependents do:[:each $\mid($ each $==$ self $)$ 


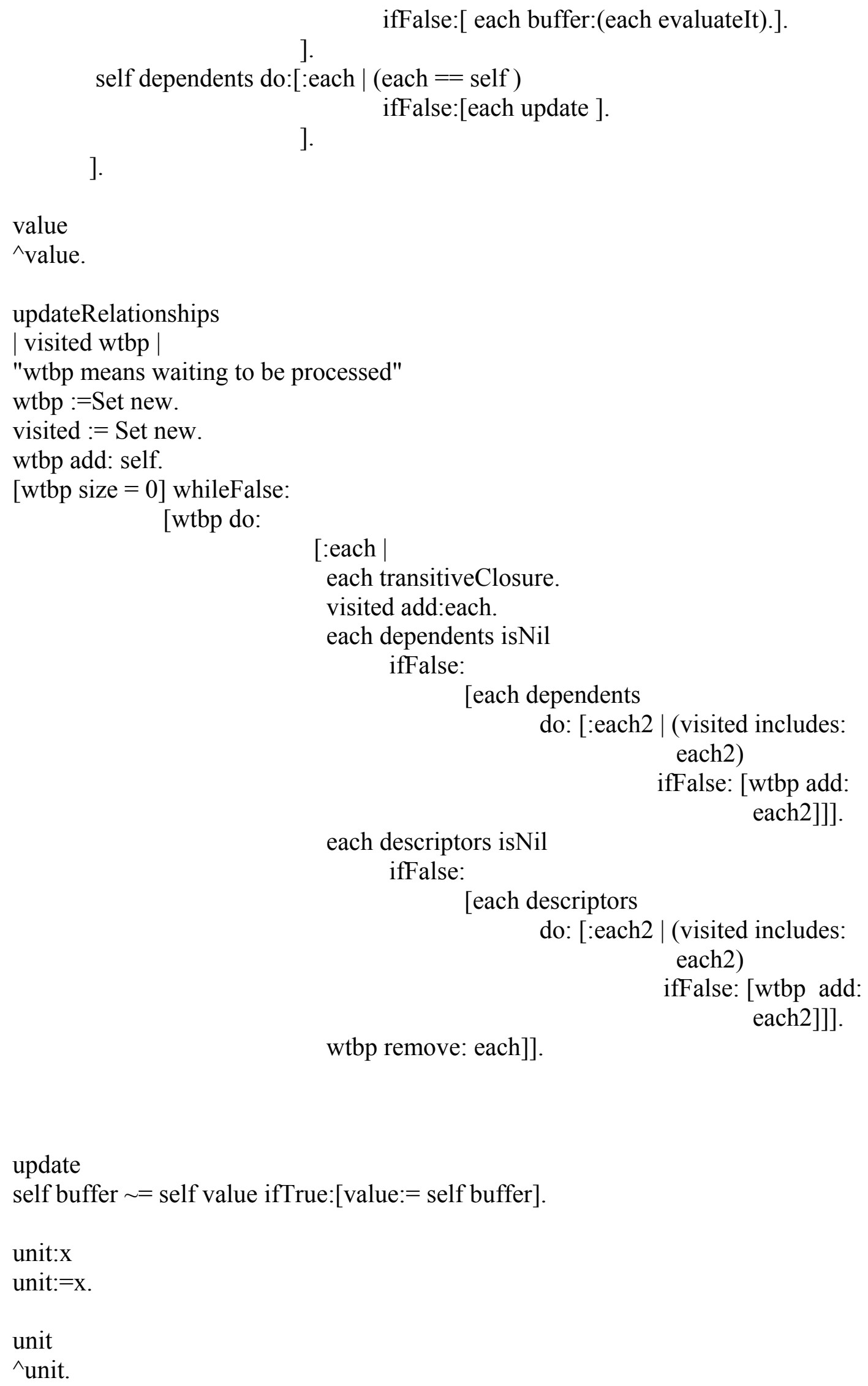




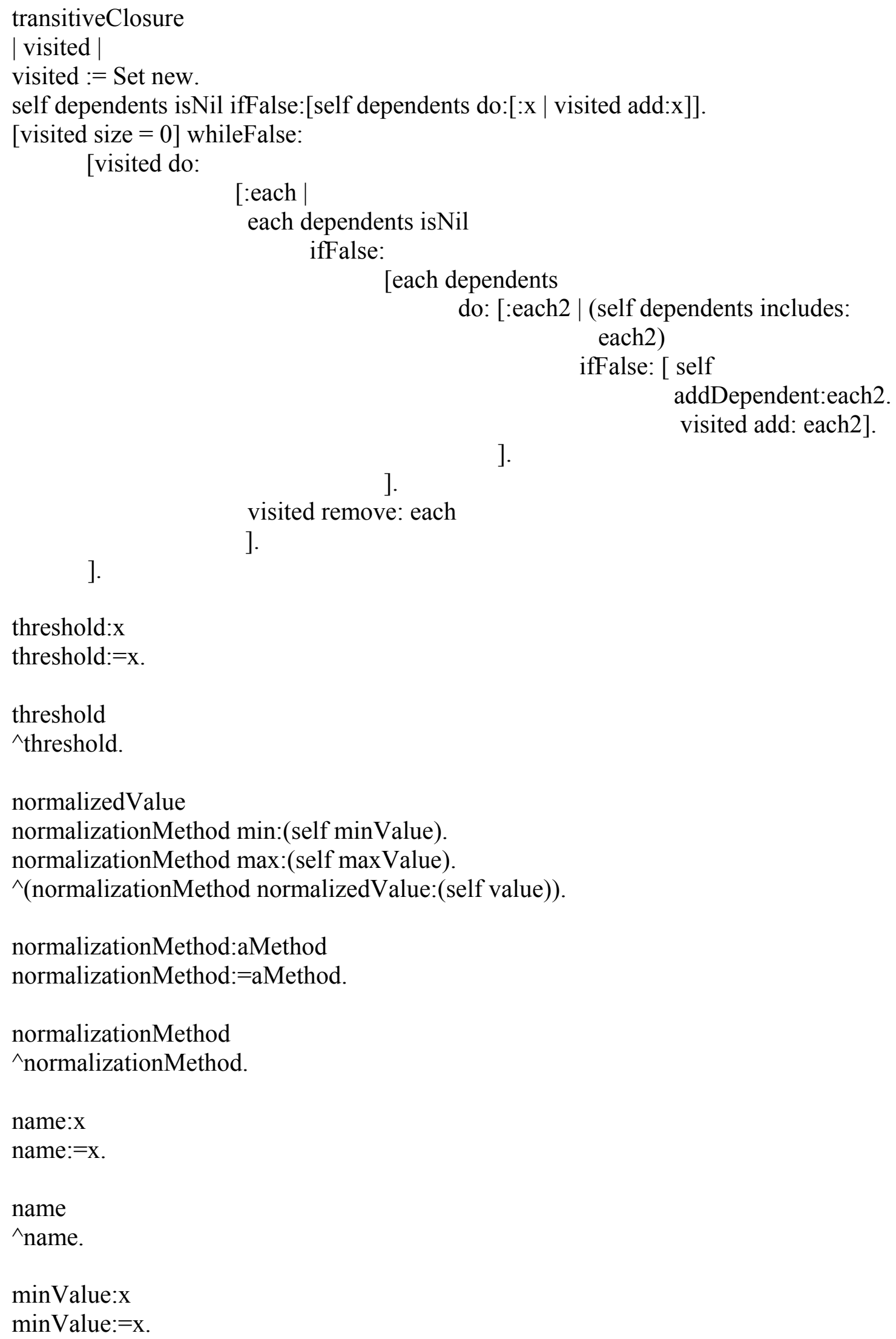




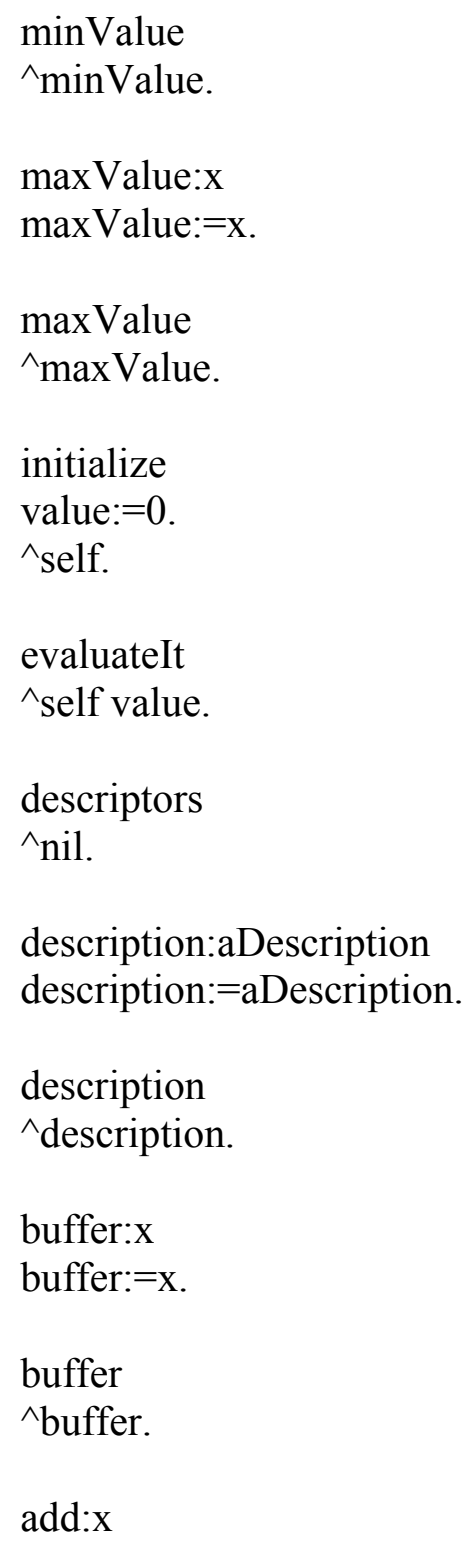

Cada vez que ocurre una modificación en un índice o indicador, aquellos otros índices que dependan de ese cambio deberán actualizarse convenientemente para mantener la consistencia. La idea es que cada vez que ocurre un cambio en un indicador, se verifica quienes están relacionados de manera directa o indirecta (exceptuando el que sufrió el cambio) y se los actualiza convenientemente. Este proceso se realiza en 2 pasos con la ayuda de las variables value y buffer :

1) Para cada objeto relacionado directamente o indirectamente con el que acaba de sufrir un cambio (excepto el que cambió) se calcula el nuevo valor que debería tomar y se almacena en la variable buffer. 
2) Una vez que todos los objetos relacionados anteriores han terminado el paso 1) se actualiza el valor de la variable value con el que se encuentra almacenado en la variable buffer.

\section{Clase Index}

Variable de instancia: expression, aContexto, anExpressionInterpreter, aLexicographicAnalyzer, descriptorsWithKey, descriptors.

add: $x$

descriptors add: $x$.

$\mathrm{x}$ addDependent:self.

self updateRelationships.

descriptors

$\wedge$ descriptors.

evaluateIt

| delimiters tokens |

descriptors do:[:each | descriptorsWithKey at: (each name) put: (each value

printString).].

delimiters:=Set new.

delimiters add:\$(; add:\$); add:\$+; add:\$-; add:\$*; add:\$/.

tokens:=aLexicographicAnalyzer analyse:(self expression) withDelimiters:delimiters

symbolsTable:descriptorsWithKey reservedWords:(Set new).

aContexto input:tokens.

anExpressionInterpreter interpret:aContexto.

$\wedge$ anExpressionInterpreter value.

expression

^expression.

expression: $\mathrm{x}$

expression: $=\mathrm{x}$.

initialize

super initialize.

descriptors:=OrderedCollection new.

descriptorsWithKey:=Dictionary new.

aLexicographicAnalyzer:=LexicographicAnalyzer new.

aContexto:=Contexto new.

anExpressionInterpreter:=AlgebraicExpression new.

$\wedge$ self. 
Clase Indicator

initialize

super initialize.

$\wedge$ self.

3.1 Ejemplo de uso del framework para el desarrollo de modelos basados en el uso de índices e indicadores tradicionales 
prcrc:=Indicator new.

prcrc description: '\% cobertura red de cloacas'; name:'prcrc'; value: 1.

prcra:=Indicator new.

prcra description: '\% cobertura red de agua'; name:'prcra'; value:1.

prcre:=Indicator new.

prcre description: '\% cobertura red de electricidad'; name:'prcre'; value:1.

prcrg:=Indicator new.

prcrg description: '\% cobertura red de gas'; name:'prcrg'; value:1.

caobspp:=Indicator new.

caobspp description: 'Obstáculos promedio al peatón'; name:'caobspp'; value:1.

caretoss:=Indicator new.

caretoss description: 'Reclamos ingresados en ETOSS'; name:'caretoss'; value:1.

ipmh:=Indicator new.

ipmh description: 'Indice de privación material de hogares'; name:'ipmh'; value:1.

prpnbi:=Indicator new.

prpnbi description: '\% población NBI'; name:'prpnbi' ;value:1.

prpccs:=Indicator new.

prpccs description: '\% población con cobertura social'; name:'prpccs' ;value:1.

prens:=Indicator new.

prens description: '\% población 18-29 en nivel superior de educación'; name:'prens'

;value:1.

tsanf:=Indicator new.

tsanf description: 'Tasa de analfabetismo'; name:'tsanf'; value:1.

tsminf:=Indicator new.

tsminf description: ' Tasa de mortalidad infantil cada 1000 habitantes'; name:'tsminf';

value: 1 .

prhdef:=Indicator new.

prhdef description: '\% de hogares deficitarios'; name:'prhdef'; value:1.

prpvic:=Indicator new.

prpvic description: '\% población victimizada'; name:'prpvic'; value:1.

prcri:=Indicator new.

prcri description: '\% crímenes de zona sur'; name:'prcri'; value:1.

prpibr:=Indicator new.

prpibr description: ' \% PIB Regional bienes y servicios'; name:'prpibr'; value:1.

tsvpmcc:=Indicator new.

tsvpmcc description: 'Tasa de variación del precio del metro cuadrado construido';

name:'tsvpmcc'; value: 1 .

priim:=Indicator new.

priim description: '\% importancia de la industria manufacturera'; name:'priim'; value:1.

prtra:=Indicator new.

prtra description: '\% transferencias de provincia'; name:'prtra'; value:1.

calpbs:=Indicator new.

calpbs description: 'cantidad de locales productores de bienes y servicios'; name:'calpbs';

value: 1 .

pema:=Indicator new.

pema description: 'Percepción sobre el medio ambiente'; name:'pema'; value:1.

peabl:=Indicator new. 
peabl description: 'Percepción sobre ABL'; name:'peabl'; value:1. pepc: $=$ Indicator new. pepc description: 'Percepción sobre la participación ciudadana'; name:'pepc'; value:1. peep:=Indicator new. peep description: 'Percepción sobre el estado de los espacios públicos'; name:'peep'; value: 1 . peas:=Indicator new. peas description: 'Percepción sobre la asistencia social'; name:'peas'; value:1. petp:=Indicator new. petp description: 'Percepción sobre la eficiencia del transporte público'; name:'petp'; value: 1 . pesb:=Indicator new. pesb description: 'Percepción sobre las soluciones al barrio'; name:'pesb'; value:1. pepcrep:=Indicator new. pepcrep description: 'Percepción sobre la política cultural'; name:'pepcrep'; value:1. pesap:=Indicator new. pesap description: 'Percepción sobre la salud pública'; name:'pesap'; value:1. peop:=Indicator new. peop description: 'Percepción sobre la obra pública'; name:'peop'; value:1. pemu:=Indicator new. pemu description: 'Percepción sobre la movilidad urbana'; name:'pemu'; value:1. pesu:=Indicator new. pesu description: 'Percepción sobre la seguridad urbana'; name:'pesu'; value:1. icvu:=Index new. icvu description:'Indice de calidad de vida urbana'; name:'icvu'. icvu add:prcrc; add:prera; add:prcre; add:prcrg; add:caobspp; add:caretoss; add:ipmh. icvu add:ipmh; add:prpnbi; add:prpccs; add:prens; add:tsanf; add:tsminf; add:prhdef; add:prpvic;add:preri.

icvu add:prpibr;add:tsvpmcc;add:priim;add:prtra;add:calpbs. icvu add:pema;add:peabl;add:pepc;add:peep;add:peas;add:petp;add:pesb;add:pepcrep; add:pesap;add:peop;add:pemu;add:pesu.

icvu expression:

'prcre* $0.08+$ prcra $* 0.02+$ prcre $* 0.02+$ prcrg $* 0.02+$ caobspp $* 0.02+$ caretoss $* 0.02+$ ipmh $* 0.02+$ prpnbi $* 0.04+$ prpccs $* 0.015+$ prens $* 0.01+$ tsanf $* 0.015+$ tsminf $* 0.02+$ prhdef $* 0.02+$ prpvic $* 0.0$ $7+$ prcri $* 0.06+$ prpibr $* 0.08+$ tsvpmcc $* 0.04+$ priim $* 0.02+$ prtra $* 0.04+$ calpbs $* 0.02+$ pema $* 0.01$ + peabl*0.02+pepc $* 0.01+$ peep $* 0.01+$ peas $* 0.01+$ petp $* 0.01+$ pesb $* 0.04+$ pepcrep $* 0.01+$ pesa p*0.025+ peop* $^{*} 0.095+$ pemu*0.01+pesu*0.1'.

result:=icvu evaluateIt.

result inspect.

"Aquí el índice vale 1" decisionSupportSystem:=DynamicMonitoringSystem new. decisionSupportSystem addDescriptor:icvu. prpibr value:0.2. decisionSupportSystem inspect. "Ahora el índice vale 0.936. " 
Nota: Se han omitido para abreviar las unidades de los indicadores y se ha asignado a cada uno el valor ficticio 1 para que el índice icvu tome asimismo el valor 1. Luego se observa que el cambio en el valor de un indicador (prpibr en este caso) produce también que se modifique el valor del índice. 


\subsection{Framework para el desarrollo de modelos basados en el uso de índices e indicadores tradicionales}

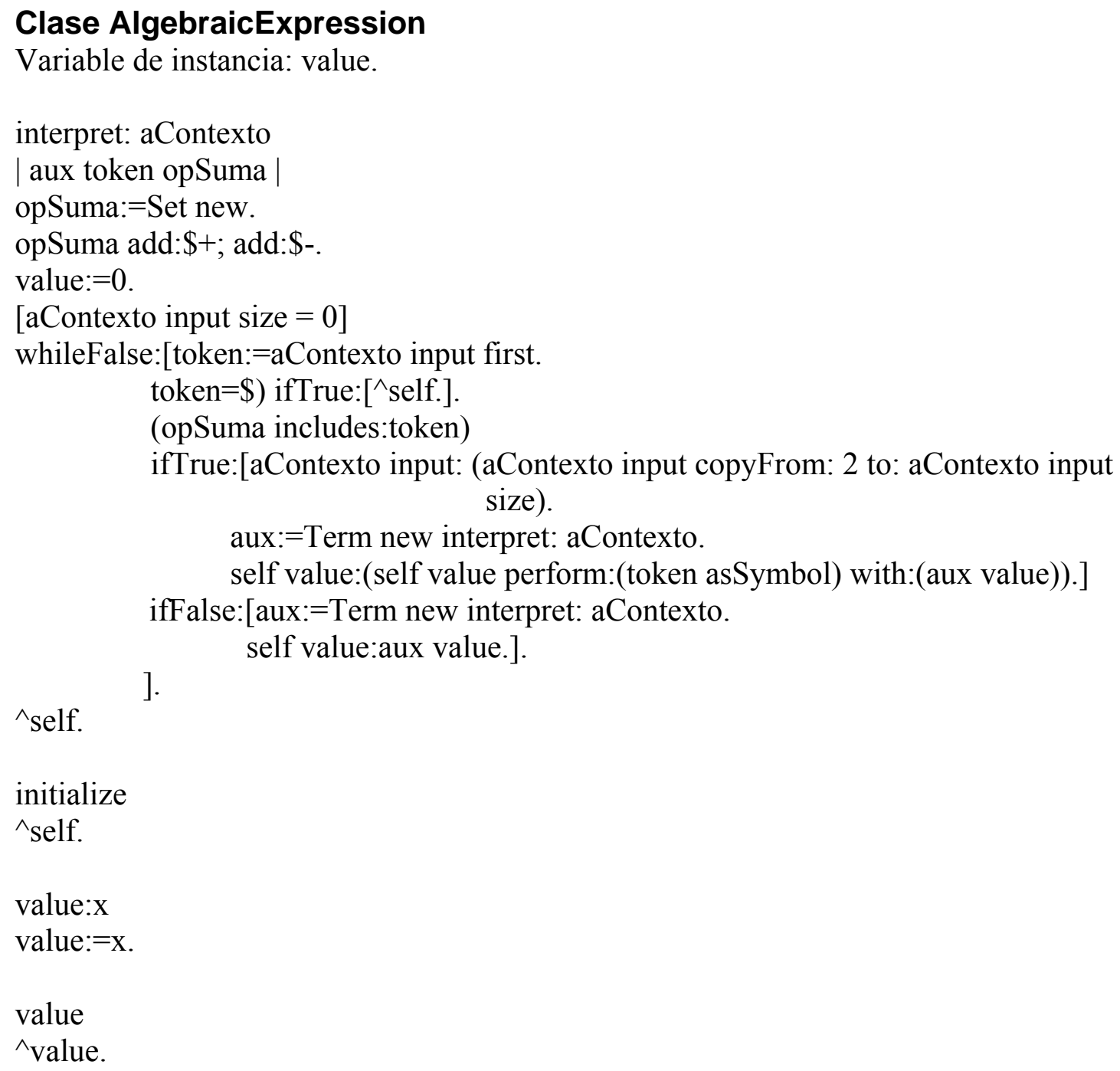

\section{Clase Term}

Variable de instancia: -.

interpret: aContexto

| aux opMult token |

opMult:=Set new. 
opMult add:\$*; add:\$/; add:'div'; add:'mod'.

aux:=Factor new interpret:aContexto.

self value:aux value.

(aContexto input size $>0$ )

ifTrue:[token:=aContexto input first.

[opMult includes:token] whileTrue:[ aContexto input:(aContexto input copyFrom: 2

to:aContexto input size).

aux:=Factor new interpret:aContexto.

(token='div') ifTrue:[token:='//'. ].

(token='mod') ifTrue:[token:='\'.].

self value:(self value perform:

(token asSymbol) with:(aux

(aContexto input size $>0$ )

value)).

ifTrue:[token: $=$ aContexto input first.]

ifFalse:[token:=". ].

].

$\wedge$ self.

asAlgebraicExpression

$\wedge$ AlgebraicExpression new value: self value.

initialize

super initialize.

$\wedge$ self.

\section{Clase Factor}

Variable de instancia: -.

interpret: aContexto

| aux token|

token: $=$ aContexto input first.

(UnaryOperator new isUnaryOperator:token)

ifTrue:[ aux:=UnaryOperator new interpret:aContexto.]

ifFalse: $[$ token $=\$($

ifTrue:[ aContexto input: (aContexto input copyFrom:2 to: aContexto input size).

aux:=AlgebraicExpression new interpret:aContexto.

aContexto input:(aContexto input copyFrom:2 to: aContexto input size) ]

ifFalse:[ aux:=Identifier new interpret:aContexto.]. 
].

self value:aux value.

$\wedge$ self.

initialize

super initialize.

$\wedge$ self.

asTerm

${ }^{\wedge}$ Term new value:self value.

asAlgebraicExpression

${ }^{\wedge}$ self asTerm asAlgebraicExpression.

\section{Clase Identifier}

Variable de instancia: -.

interpret: aContexto

self value:(aContexto input first asNumber).

aContexto input: (aContexto input copyFrom:2 to:aContexto input size).

$\wedge$ self.

initialize

super initialize.

$\wedge$ self.

asTerm

${ }^{\wedge}$ self asFactor asTerm.

asFactor

${ }^{\wedge}$ Factor new value:self value.

asAlgebraicExpression

${ }^{\wedge}$ self asTerm asAlgebraicExpression.

\section{Clase UnaryOperator}

Variables de instancia: operatorName.

interpret: aContexto

| aux |

self operatorName:(aContexto input first). 
aContexto input: (aContexto input copyFrom:3 to:aContexto input size). aux:=AlgebraicExpression new interpret:aContexto.

aContexto input: (aContexto input copyFrom:2 to:aContexto input size). self value:((aux value) perform:(operatorName asSymbol)).

$\wedge$ self.

initialize

super initialize.

$\wedge$ self.

isUnaryOperator:aString

| operatorsList |

operatorsList: $=$ Set new.

operatorsList add:'truncated';

add:'tan'; add:'sqrt';

add:'sin'; add:'cos';

add:'tan';add:'arcTan';

add:'rounded';

add:'arcSin';add:'arcCos';

add:'log';add:'In';

add:'floor';add:'ceiling';

add:'abs'.

^operatorsList includes:aString.

operatorName:x

operatorName: $=\mathrm{x}$.

Las unidades de los indicadores se implementaron usando las clases Unidad y . Así, una unidad como Metro3/persona se implementaría usando 2 objetos de la clase Unit. El primero con su variable de instancia name igual a "Metro" y la variable exponente igual a 3.

El segundo objeto tendrá, en su variable de instancia exponent, el valor -1 y el valor de la variable name será "persona". Generalizando, las unidades que aparezcan dividiendo se escribirán como productos con exponentes negativos. De este modo, el código de las operaciones * y / de la clase CompositeUnit quedan como se observa a continuación.

\section{Clase Unit}

Variables de instancia: name, exponent.

exponent

^exponent. 


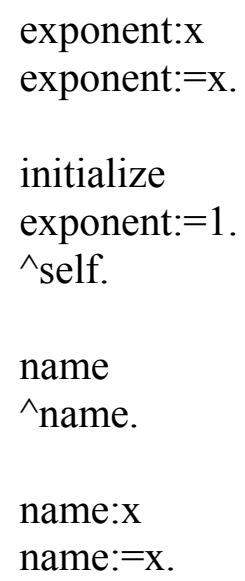

\section{Clase CompoundUnit}

Variable de instancia: units.

initialize

$\wedge$ self.

* anotherUnit

units addAllLast:anotherUnit.

1 to:((units size)-1) do:[:x| $(\mathrm{x}+1)$ to:(units size) do:[:y $\mid$ (units at:x) name= (units at:y) name ifTrue:[ (units at:x) exponent: ((units at:x) exponent + (units at:y) exponent). (units at:y) exponent:0.]. ].

units:=units select:[:x $\mid \mathrm{x}$ exponent $\sim=0]$.

].

/ anotherUnit

anotherUnit do:[:x | x exponent:((x exponent)*(-1))].

self $*$ anotherUnit.

addUnit:x

units isNil ifTrue:[units:=OrderedCollection new.].

units add:x.

\section{Clase NormalizationMethod}


Variables de instancia: min, max.

initialize

$\wedge$ self.

$\max$

${ }^{\wedge} \max$.

$\min$

$\wedge_{\mathrm{min}}$.

$\min : x$ max:y

$\min :=\mathrm{x}$.

$\max :=\mathrm{y}$.

\section{Clase HighlsBetter}

(Subclase de NormalizationMethod)

initialize

super initialize.

$\wedge$ self.

normalizedValue: $\mathrm{x}$

$\wedge(x-\min ) /(\max -\min )$.

\section{Clase LowlsBetter}

(Subclase de NormalizationMethod)

initialize

super initialize.

$\wedge$ self.

normalizedValue:x

$\wedge(\max -x) /(\max -\min )$.

\section{Clase LexicographicAnalyzer}


Variable de instancia: -.

initialize

$\wedge$ self.

analyse: aByteString withDelimiters: setOfDelimiters symbolsTable: aDictionary reservedWords: setOfReservedWords

"Se han considerado solamente delimitadores de longitud uno"

| palabra tokens conjunto cadena error |

tokens := OrderedCollection new.

cadena $:=$ aByteString.

setOfDelimiters add: Character space.

palabra :=".

1 to: cadena size

do:

[:index |

(setOfDelimiters includes: (cadena at: index) asCharacter)

ifTrue:

[palabra $\sim="$

ifTrue:

[tokens add: palabra.

palabra :="].

(cadena at: index) asCharacter $=$ Character space

ifFalse: [tokens add: (cadena at: index)]]

ifFalse:

[palabra := palabra , (cadena at: index) asSymbol.

index $=$ cadena size ifTrue: [tokens add: palabra]]].

conjunto := Set new.

aDictionary associations do: [:each | conjunto add: each key].

1 to: tokens size

do:

[:index |

(conjunto includes: (tokens at: index))

ifTrue: [tokens at: index put: (aDictionary at: (tokens at: index))].

(setOfReservedWords includes: (tokens at: index))

ifTrue: [self youCanNotUseAReservedWordAsVariableError.]].

$\wedge$ tokens.

youCanNotUseAReservedWordAsVariableError

Transcript show:'You can not use a reserved word as a variable.'.

\section{Clase Contexto}


Variables de instancia: input, output.

initialize

output: $=0$.

$\wedge$ self.

input

input.

input: $\mathrm{x}$

input: $=\mathrm{x}$.

output

^output.

output: aNumber

output:= aNumber asNumber.

\section{Clase DynamicMonitoringSystem}

Variable de instancia: descriptors.

initialize

descriptors: $=$ OrderedCollection new.

$\wedge$ self.

addDescriptor: $\mathrm{x}$

descriptors add:x.

descriptors

$\wedge$ descriptors.

\section{Clase Descriptor}

Variables de instancia: name, buffer, value, minValue, maxValue, threshold, unit, normalizationMethod, description.

value: $\mathrm{x}$

value: $=\mathrm{x}$.

self dependents isNil

ifFalse:[ self dependents do:[:each $\mid($ each $==$ self $)$ 


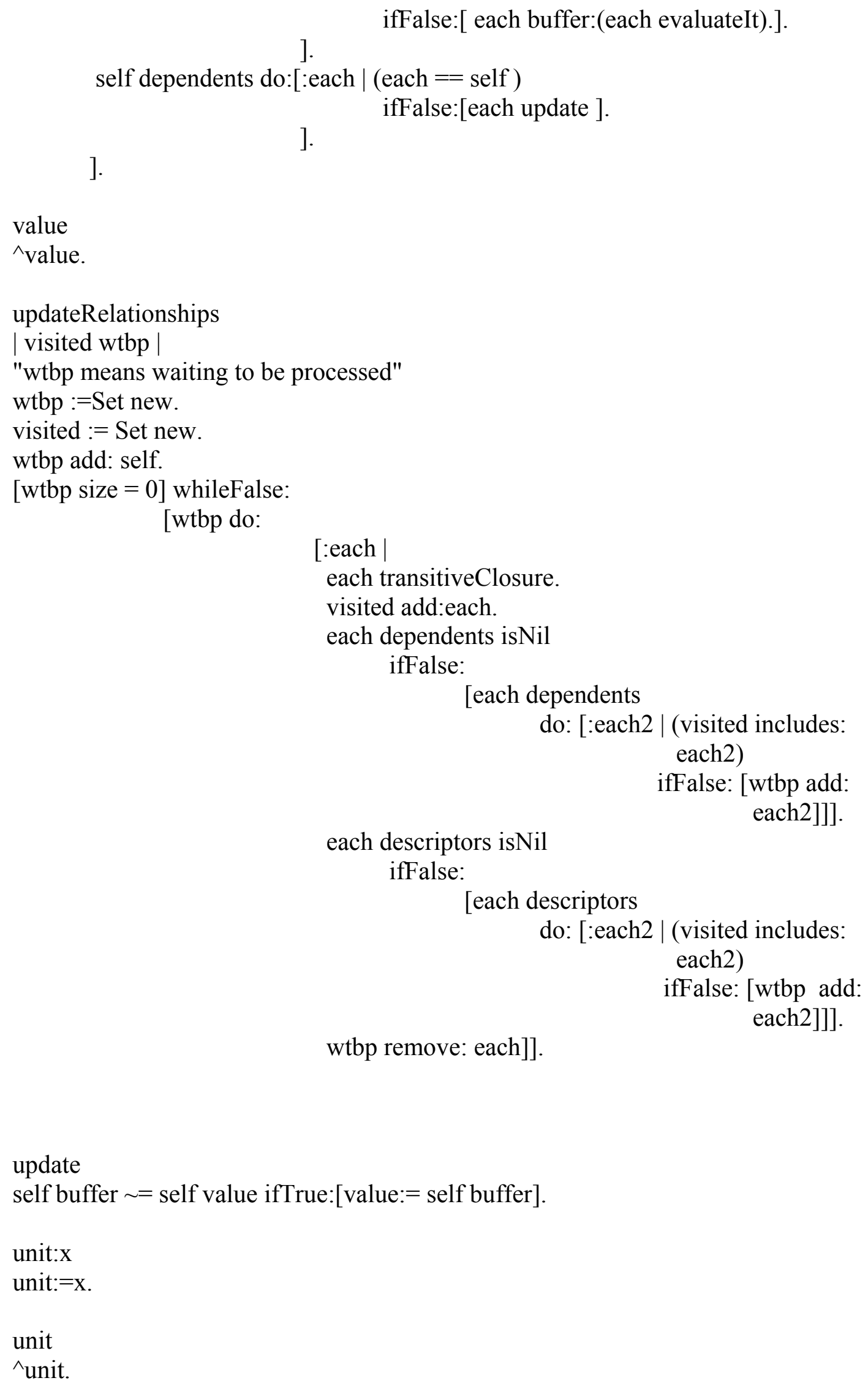




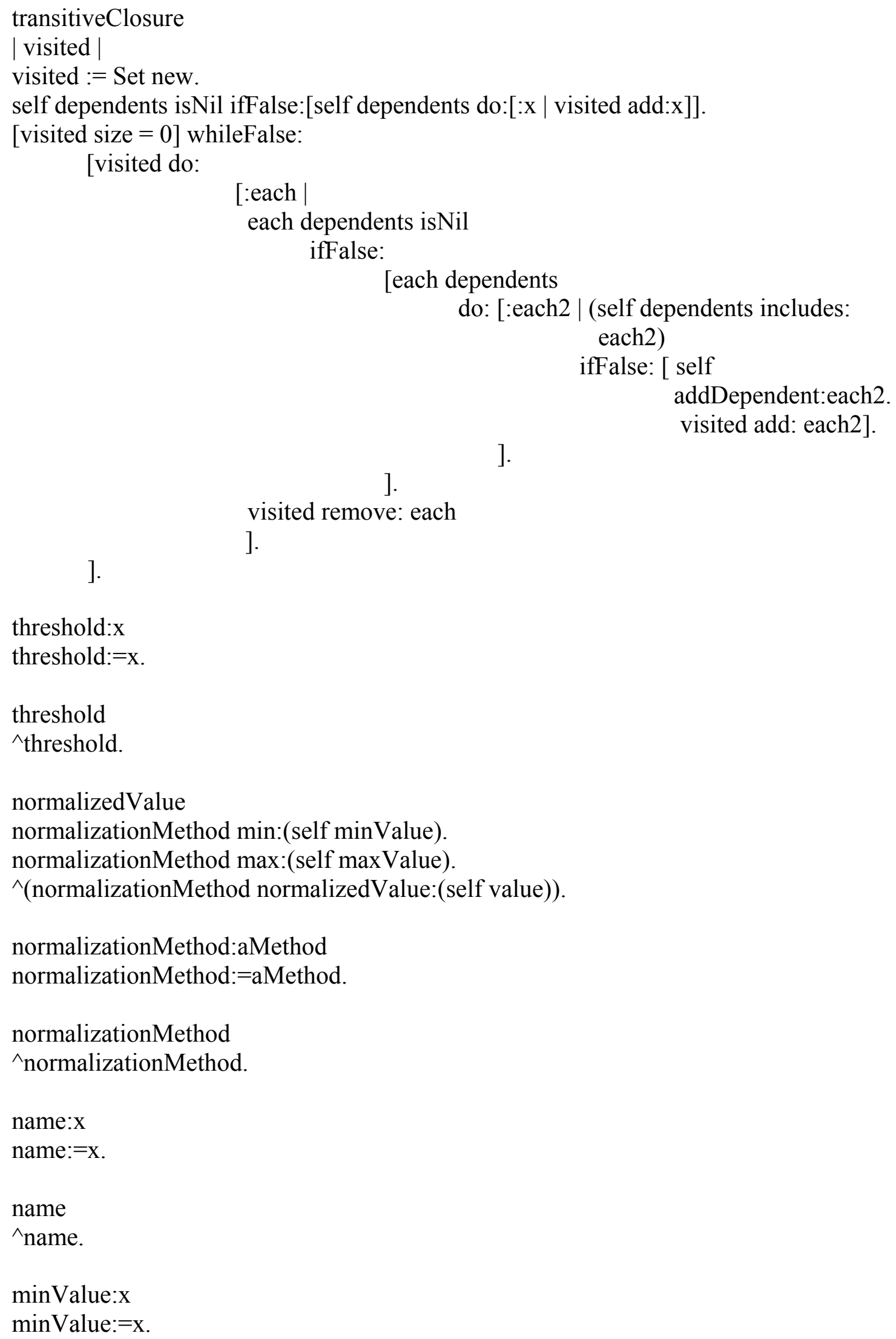




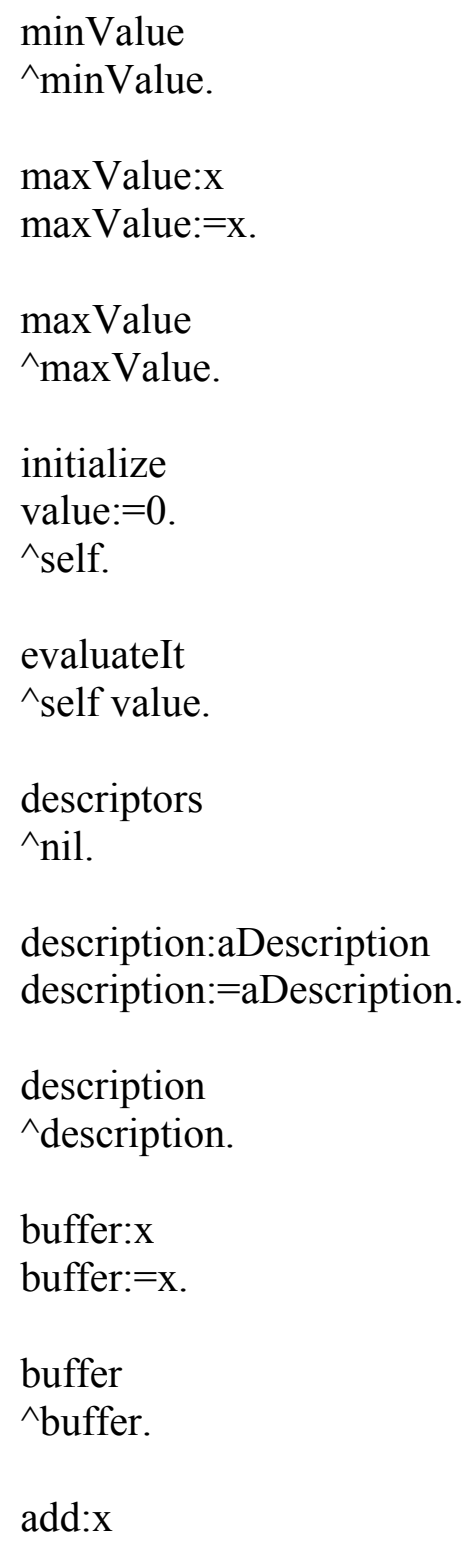

Cada vez que ocurre una modificación en un índice o indicador, aquellos otros índices que dependan de ese cambio deberán actualizarse convenientemente para mantener la consistencia. La idea es que cada vez que ocurre un cambio en un indicador, se verifica quienes están relacionados de manera directa o indirecta (exceptuando el que sufrió el cambio) y se los actualiza convenientemente. Este proceso se realiza en 2 pasos con la ayuda de las variables value y buffer :

1) Para cada objeto relacionado directamente o indirectamente con el que acaba de sufrir un cambio (excepto el que cambió) se calcula el nuevo valor que debería tomar y se almacena en la variable buffer. 
2) Una vez que todos los objetos relacionados anteriores han terminado el paso 1) se actualiza el valor de la variable value con el que se encuentra almacenado en la variable buffer.

\section{Clase Index}

Variable de instancia: expression, aContexto, anExpressionInterpreter, aLexicographicAnalyzer, descriptorsWithKey, descriptors.

add: $x$

descriptors add: $x$.

$\mathrm{x}$ addDependent:self.

self updateRelationships.

descriptors

$\wedge$ descriptors.

evaluateIt

| delimiters tokens |

descriptors do:[:each | descriptorsWithKey at: (each name) put: (each value

printString).].

delimiters:=Set new.

delimiters add:\$(; add:\$); add:\$+; add:\$-; add:\$*; add:\$/.

tokens:=aLexicographicAnalyzer analyse:(self expression) withDelimiters:delimiters

symbolsTable:descriptorsWithKey reservedWords:(Set new).

aContexto input:tokens.

anExpressionInterpreter interpret:aContexto.

$\wedge$ anExpressionInterpreter value.

expression

$\wedge$ expression.

expression: $\mathrm{x}$

expression: $=\mathrm{x}$.

initialize

super initialize.

descriptors:=OrderedCollection new.

descriptorsWithKey:=Dictionary new.

aLexicographicAnalyzer:=LexicographicAnalyzer new.

aContexto:=Contexto new.

anExpressionInterpreter:=AlgebraicExpression new.

$\wedge$ self. 
Clase Indicator

initialize

super initialize.

$\wedge$ self.

3.1 Ejemplo de uso del framework para el desarrollo de modelos basados en el uso de índices e indicadores tradicionales 
prcrc:=Indicator new.

prcrc description: '\% cobertura red de cloacas'; name:'prcrc'; value: 1.

prcra:=Indicator new.

prcra description: '\% cobertura red de agua'; name:'prcra'; value:1.

prcre:=Indicator new.

prcre description: '\% cobertura red de electricidad'; name:'prcre'; value:1.

prcrg:=Indicator new.

prcrg description: '\% cobertura red de gas'; name:'prcrg'; value:1.

caobspp:=Indicator new.

caobspp description: 'Obstáculos promedio al peatón'; name:'caobspp'; value:1.

caretoss:=Indicator new.

caretoss description: 'Reclamos ingresados en ETOSS'; name:'caretoss'; value:1.

ipmh:=Indicator new.

ipmh description: 'Indice de privación material de hogares'; name:'ipmh'; value:1.

prpnbi:=Indicator new.

prpnbi description: '\% población NBI'; name:'prpnbi' ;value:1.

prpccs:=Indicator new.

prpccs description: '\% población con cobertura social'; name:'prpccs' ;value:1.

prens:=Indicator new.

prens description: '\% población 18-29 en nivel superior de educación'; name:'prens'

;value:1.

tsanf:=Indicator new.

tsanf description: 'Tasa de analfabetismo'; name:'tsanf'; value:1.

tsminf:=Indicator new.

tsminf description: ' Tasa de mortalidad infantil cada 1000 habitantes'; name:'tsminf';

value: 1 .

prhdef:=Indicator new.

prhdef description: '\% de hogares deficitarios'; name:'prhdef'; value:1.

prpvic:=Indicator new.

prpvic description: '\% población victimizada'; name:'prpvic'; value:1.

prcri:=Indicator new.

prcri description: '\% crímenes de zona sur'; name:'prcri'; value:1.

prpibr:=Indicator new.

prpibr description: ' \% PIB Regional bienes y servicios'; name:'prpibr'; value:1.

tsvpmcc:=Indicator new.

tsvpmcc description: 'Tasa de variación del precio del metro cuadrado construido';

name:'tsvpmcc'; value: 1 .

priim:=Indicator new.

priim description: '\% importancia de la industria manufacturera'; name:'priim'; value:1.

prtra:=Indicator new.

prtra description: '\% transferencias de provincia'; name:'prtra'; value:1.

calpbs:=Indicator new.

calpbs description: 'cantidad de locales productores de bienes y servicios'; name:'calpbs';

value: 1 .

pema:=Indicator new.

pema description: 'Percepción sobre el medio ambiente'; name:'pema'; value:1.

peabl:=Indicator new. 
peabl description: 'Percepción sobre ABL'; name:'peabl'; value:1. pepc: $=$ Indicator new. pepc description: 'Percepción sobre la participación ciudadana'; name:'pepc'; value:1. peep:=Indicator new. peep description: 'Percepción sobre el estado de los espacios públicos'; name:'peep'; value: 1 . peas:=Indicator new. peas description: 'Percepción sobre la asistencia social'; name:'peas'; value:1. petp:=Indicator new. petp description: 'Percepción sobre la eficiencia del transporte público'; name:'petp'; value: 1 . pesb:=Indicator new. pesb description: 'Percepción sobre las soluciones al barrio'; name:'pesb'; value:1. pepcrep:=Indicator new. pepcrep description: 'Percepción sobre la política cultural'; name:'pepcrep'; value:1. pesap:=Indicator new. pesap description: 'Percepción sobre la salud pública'; name:'pesap'; value:1. peop:=Indicator new. peop description: 'Percepción sobre la obra pública'; name:'peop'; value:1. pemu:=Indicator new. pemu description: 'Percepción sobre la movilidad urbana'; name:'pemu'; value:1. pesu:=Indicator new. pesu description: 'Percepción sobre la seguridad urbana'; name:'pesu'; value:1. icvu:=Index new. icvu description:'Indice de calidad de vida urbana'; name:'icvu'. icvu add:prcrc; add:prera; add:prcre; add:prcrg; add:caobspp; add:caretoss; add:ipmh. icvu add:ipmh; add:prpnbi; add:prpccs; add:prens; add:tsanf; add:tsminf; add:prhdef; add:prpvic;add:preri.

icvu add:prpibr;add:tsvpmcc;add:priim;add:prtra;add:calpbs. icvu add:pema;add:peabl;add:pepc;add:peep;add:peas;add:petp;add:pesb;add:pepcrep; add:pesap;add:peop;add:pemu;add:pesu.

icvu expression:

'prcre* $0.08+$ prcra $* 0.02+$ prcre $* 0.02+$ prcrg $* 0.02+$ caobspp $* 0.02+$ caretoss $* 0.02+$ ipmh $* 0.02+$ prpnbi $* 0.04+$ prpccs $* 0.015+$ prens $* 0.01+$ tsanf $* 0.015+$ tsminf $* 0.02+$ prhdef $* 0.02+$ prpvic $* 0.0$ $7+$ prcri $* 0.06+$ prpibr $* 0.08+$ tsvpmcc $* 0.04+$ priim $* 0.02+$ prtra $* 0.04+$ calpbs $* 0.02+$ pema $* 0.01$ + peabl*0.02+pepc $* 0.01+$ peep $* 0.01+$ peas $* 0.01+$ petp $* 0.01+$ pesb $* 0.04+$ pepcrep $* 0.01+$ pesa p*0.025+ peop* $^{*} 0.095+$ pemu*0.01+pesu*0.1'.

result:=icvu evaluateIt.

result inspect.

"Aquí el índice vale 1" decisionSupportSystem:=DynamicMonitoringSystem new. decisionSupportSystem addDescriptor:icvu. prpibr value:0.2. decisionSupportSystem inspect. "Ahora el índice vale 0.936. " 
Nota: Se han omitido para abreviar las unidades de los indicadores y se ha asignado a cada uno el valor ficticio 1 para que el índice icvu tome asimismo el valor 1. Luego se observa que el cambio en el valor de un indicador (prpibr en este caso) produce también que se modifique el valor del índice. 


\section{Referencias}

Aho, Alfred. Sethi, Ravi. Ullman, Jeffrey D. "Compiladores: Principios, técnicas y herramientas". Addison-Wesley Iberoamericana. 1990.

Andriantiatsaholiniaina, L. A. Kouikoglou, V. S. Phillis, Y. A. Evaluating strategies for sustainable development: fuzzy logic reasoning and sensitivity analysis. Ecological Economics 48, 149-172. 2004a.

Andriantiatsaholiniaina, L. A. Phillis, Y. A. "S.A.F.E: Sustainability Assessment by Fuzzy Evaluation". European Association of Environmental and Resource Economists (EAERE). 2004b.

ANPCyT. Proyecto "URE-AM 2. Políticas de uso racional de la energía en áreas metropolitanas y sus efectos en la dimensión ambiental”. PICT N 13-04116. 1998.

ANPCyT. Proyecto "Sistema de diagnóstico de necesidades básicas en infraestructura, servicios y calidad ambiental en la escala urbano-regional". PICT 13-14509. 2003.

Aracil, Javier. Gordillo, Francisco. “Dinámica de sistemas”. Editorial Alianza. 1997.

Barbero, D. Discoli, C. Rosenfeld, E. Revista Avances en Energías Renovables y Medio Ambiente. "Monitoreo dinámico de indicadores de calidad de vida urbana usando sistemas de información geográficos". 2005.

Barbero, D. Discoli, C. Rosenfeld, E. Congreso Nacional de Arquitectura y Urbanismo. Estado de Situación y Nuevas Perspectivas en el Siglo XXI. "Aplicación de modelos dinámicos en el ámbito urbano utilizando sistemas de información geográficos". 2005.

Barredo Cano, José I. Gómez Delgado, M. "Sistemas de información geográfica y evaluación multicriterio en la ordenación del territorio". 2da edición. Editorial AlfaomegaRa-Ma. 2006.

Belmonte, S. Franco, J. Núñez, V. Viramonte, J. "Evaluación multicriterio de energías renovables en proyectos de ordenación territorial". Avances en energías Renovables y Medio Ambiente. Vol. 10. ISSN 0329-5184. 2006.

Bettini, Virginio. "Elementos de ecología urbana". Editorial Trotta. 1998.

Bone, Christopher. Dragicevic, Suzana. "Modelling forest insect infestations with GIS-based cellular automata and fuzzy sets". 8th International Conference on GeoComputation University of Michigan, Eastern Michigan University, USA,1 - 3 August, 2005. 
Bosque, J. Escobar, F. J. Ernesto García. María Jesús Salado. Sistemas de Información: Prácticas con PC ARC/INFO e IDRISI. Addison-Wesley Iberoamericana / RA-MA. 1994.

Breckling, Broder. Middelhoff, Ulrike. Reuter, Hauke. Individual based models as tools for ecological theory and application: Understanding the emergence of organisational properties in ecological systems. Ecological Modelling, pp. 102-113. 2006.

Brenner, Asher. Shacham, Mordechai. Cutlip, Michael B. Applications of mathematical software packages for modelling and simulations in environmental engineering education. Environmental Modelling \& Software 20. pp 1307-1313. 2005.

Briassoulis, H. "Analysis of land use change. Theoretical and modeling approaches". In The Web Book of Regional Science (www.rri.wvu.edu/regscweb.htm). ed., Scott Loveridge. Morgantown, WV: Regional Research Institute, West Virginia University. 2000 .

Cassiraga, Eduardo F. "Curso de postgrado: geoestadística aplicada". Facultad de Ingeniería. UNLP. La Plata, 17 al 21 de junio de 2002.

Castellar-Busó, H. Historia de los modelos globales. http://www.redcientifica.com/doc/doc200111240003.html

Castelar-Busó, Vincent. "Un modelo sistémico de evolución social sostenible". Tesis doctoral. Departamento de Matemática Aplicada, Universidad de Valencia. 1997.

Calkins, H. W. Tomlinson, R. F. "Geographic Information Systems: Methods and equipment for land use planning”. International Geographic Union Commission on Geographical Data Sensing and Processing. Resource and Land Investigations(RALI) Program, U.S. Geological Survey, Reston, Virginia. 1977.

Carello, Gi. Gratti, P. Mai, V. "Calidad de vida en la ciudad de Buenos Aires: una propuesta de configuración de espacios homogéneos". Población de Buenos Aires Nro. 3, Año 3, abril de 2006. ISSN 1668-5458.

Ceccaroni, Luigi. Cortés, Ulises. Sánchez-Marré, Miquel. OntoWEDSS: augmenting environmental decision-support systems with ontologies. Environmental Modelling \& Software. Vol 19. pp 785-797. 2004.

Centro Internacional de Agricultura Tropical (CIAT), Banco Mundial, Programa de las Naciones Unidas para el Medio Ambiente (PNUMA). Desarrollo de Indicadores: Lecciones Aprendidas de América Central. 2000. URL:

http://www.estrucplan.com.ar/Producciones/Produccion.asp?IDproduccion=189.

Choi, Dae-Young. A new aggregation method in a fuzzy environment. Decision Support Systems 25 (1999) 39-51. 
CIRAD. "Cormas tutorial 1". 2003. Web-site: http://cormas.cirad.fr/pdf/CormasTutoriall.pdf . Accesed: June 16, 2006.

CIRAD. "Building a Cormas model from the scratch". 2002. Web-site: http://cormas.cirad.fr/pdf/CormasTutorial2.pdf. Accesed: June 16, 2006.

Coello Coello, C. A. Curso: Introducción a la optimización multiobjetivo usando metaheurísticas. CACIC 2003. IX Congreso Argentino de Ciencias de la Computación. La Plata, Argentina. 2003.

Colom, A. J. Desarrollo sostenible y educación para el desarrollo. Ed. Octaedro. 2000.

Córcoles Tendero, José Eduardo. Integración de recursos espaciales y no-espaciales en la Web: un acercamiento a la web semántica geoespacial. Tesis doctoral. Universidad de Castilla-La Mancha. Albacete, 2005.

Cornelissen, A. M. G. van den Berg, J. Koops, W. J. Grossman, M. Udo, H. M. J. "Assessment of the contribution of sustainability indicators to sustainable development: a novel approach using fuzzy set theory". Agriculture, Ecosystems and Environment 86 (2000) 173-185.

\section{Costanza, R. Cumberland, J. Daly, H. Goodland, R. Norgaard, R. Una introducción a la economía ecológica. CECSA. 1999.}

\section{Chacón, Rosa M. "La calidad de vida y la planificación urbana". Departamento de Planificación Urbana, Universidad Simón Bolívar, Caracas. 2004.}

Choi, Dae-Young. A new aggregation method in a fuzzy environment. Decision Support Systems 25 (1999) 39-51.

Daly, Herman. "Hacia algunos principios operativos de desarrollo sostenible". Ecological Economics, 2: 1-6. 1990.

Daly, Herman. "Steady state economics". Island Press. Washington. 1991.

de Kok, Jean-Luc. Titus, M. Wind, H. G. "Application of fuzzy sets and cognitive maps to incorporate social science scenarios in integrated assessment models. A case study of urbanization in Ujung Pandang, Indonesia". Integrated Assessment. Vol 1,Number 3, pp. 177-188. July, 2000.

de Paz, José Miguel. Sánchez, Juan. Visconti, Fernando. "Combined use of GIS and environmental indicators for assessment of chemical, physical and biological soil degradation in a Spanish Mediterranean region". Journal of Environmental Management. Vol 79. Issue 2. pp 150-162. 2006.

Denzer, Ralf. Generic integration of environmental decision support systems - state-of-theart. Environmental Modelling \& Software. Vol 20. pp 1217-1223. 2005. 
Diputación de Barcelona. "Sistema municipal de indicadores de sostenibilidad”. 2000.

\section{Dirección general de la vivienda, la arquitectura y el urbanismo. Institut Cerdá. IDEA. "Guía de la edificación sostenible. Calidad energética y medioambiental en edificación". Madrid, España. 1999.}

Doran, Jim. "Agent-based modelling of ecosystems for sustainable resource management". ACAI-01 Summer school. Prague. July, 2001.

Dreyfus-León, Michel. "Modelling cooperation between fishermen with a cellular automaton". A framework for fishing effort spatial dynamics. Ecological Informatics. Pp 101-105. Vol 1. 2006.

Dubois, D., Prade, H., 1985. A review of fuzzy set aggregation connectives. Inform. Sci. $36,85-121$.

Dubois, D., Prade, H., 1988. Possibility Theory. An approach to Computerized Processing of Uncertainty. Plenum Press, New York.

Ducey, M. J. Larson, B. C. A fuzzy set approach to the problem of sustainability. Forest Ecology and Management 115 (1999) 29-40.

Echenique, M.(compilador). Modelos matemáticos de la estructura espacial urbana: aplicaciones en América Latina. Ediciones SIAP. 1975.

European Commision. "Sustainable urban development in the European Union: A framework for action". 1998.

European Communities. "The urban audit. Towards the benchmarking of quality of life in 58 european cities". Volume I: The yearbook (Overview. Comparative section). Volume II: The yearbook (Summary results for each city) . Volume III: The urban audit manual. 2000. URL: http://www.inforegio.cec.int/urban/audit/.

Fernández Güell, J. M. Planificación estratégica de ciudades. Editorial Gustavo Gili. 2da edición. 2000.

Ferraro, D. O. La sustentabilidad en la Pampa Interior (Argentina): desarrollo y evaluación de indicadores de impacto ambiental del uso de pesticidas y labranzas usando lógica difusa. Tesis Doctoral. Facultad de Agronomía, UBA, 2005.

Ferraro, Diego O. Ghersa, C. M. Sznaider, Gustavo A. "Evaluation of environmental impact indicators using fuzzy logic to assess the mixed cropping systems of the Inland Pampa, Argentina". Agriculture Ecosystems \& Environment 96(2003)1-18.

Forrester, Jay W. “Urban dynamics”. M.I.T. Press. 1969. 
Fundación Bariloche / Amílcar O. Herrera, Hugo D. Scolnik, Graciela Chichilnisky, Gilberto C. Gallopin, Jorge E. Hardoy, Diana Mosovich, Enrique Oteiza, Gilda L. De Romero Brest, Carlos E. Suárez, Luis Talavera. “Catástrofe o nueva sociedad ?”. Modelo mundial latinoamericano. 1977.

Gamma, Erich. Helm, Richard. Johnson, Ralph. Vlissides, John. "Design patterns: Elements of reusable object-oriented software". Addison-Wesley. 1995.

García Espuche, A. Rueda, S. La ciutat sostenible. Centre de Cultura Contemporània de Barcelona. ISBN 84-88811-50-0. Barcelona, 1999.

Gómez Orea, D. "Evaluación de impacto ambiental. Un instrumento preventivo para la gestión ambiental”. Ediciones Mundi-Prensa. ISBN 84-8476-084-7. 2003.

Gómez Orea, D. Ordenación Territorial. Ediciones Mundi-Prensa. Editorial Agrícola Española, S. A. 2002.

Gianella, A. E. Introducción a la epistemología y a la metodología de la ciencia. Editorial Universidad Nacional de La Plata. 2000.

González Manteiga, María Teresa. "Modelos matemáticos discretos en las ciencias de la naturaleza. Teoría y problemas”. Editorial Diaz de Santos. 2003.

Gordillo, Silvia. "Modelización de Campos Continuos en Sistemas de Información Geográfica“. Tesis de magister en Ingeniería de Software. Facultad de Informática. UNLP. 1998.

Gordillo, S. Balaguer, F. Mostaccio, C. Das Neves, F. Developing GIS applications with objects: a design pattern approach. GeoInformatica 3:1, 7-32. Kluwer Academic Publishers, Boston. 1999.

Gronewold, A. Sonnenschein, M. "Event-based modelling of ecological systems with asynchronous cellular automata”. Ecological modelling, 108, pp 37-52. 1998.

Hamman, Yasser. Moore, Antoni. Whigham, Peter. Freeman, Claire. "A vector-agent paradigm for dynamic urban modelling". In: The 15th Annual Colloquium of the Spatial Information Research Centre, 1-3 December 2003a, Dunedin, New Zealand.

Hamman, Yasser. Moore, Tony. Whigham, Peter. Freeman, Claire. "Towards the modelling of sustainable cities with multi-reactive agents". Proceedings of the 7th International Conference on GeoComputation, University of Southampton, United Kingdom. 8 - 10 September, 2003b.

Hardi, P. and Pinter, L. "Models and methods of measuring sustainable development performance: revised draft discussion report prepared for the Sustainable Development Coordination Unit, Executive Council, Government of Manitoba”. International Institute for Sustainable Development; IISD. Winnipeg: IISD, 1995. 35 p. 1995. 


\section{Hilera, J. R. Martínez,V. J. Redes neuronales artificiales. Fundamentos, modelos y aplicaciones. Editorial RA-MA. 1995.}

Hill, Michael J. Braaten, Robert. Veitch, Simon M. Lees, Brian G. Sharma, Sunil. Multicriteria decision analysis in spatial decision support: the ASSESS analytic hierarchy process and the role of quantitative methods and spatially explicit analysis. Environmental Modelling \& Software. Vol. 20. pp 955-976. 2005.

Hillier, Frederick S. Lieberman, Gerald J. "Introducción a la investigación de operaciones". McGraw Hill. 1997.

Huang, Bo. Web-based dynamic and interactive environmental visualization. Computers, Environment and Urban Systems 27(2003) 623-636.

Jiménez Herrero, Luis M. "Desarrollo sostenible y economía ecológica”. Editorial Síntesis. 1997.

Kaufmann, Arnold. Gil Aluja, Jaume. "Nuevas técnicas para la dirección estratégica". Universitat de Barcelona Publicacions. 1991.

Kliksberg, B. "Hacia una economía con rostro humano". Fondo de cultura económica de Argentina S.A. 2002.

Kocabas, V. Dragicevic, S. "Sensitivity analysis of a gis-based cellular automata model". ISPRS 2004. Istambul, Turkey. 2004.

Kurtz, J. C. Jackson, L. E. Fisher, W. S. "Strategies for evaluating indicators based on guidelines from the Environmental Protection Agency's Office of Research and Development". Ecological Indicators 1 (2000) 49-60.

Lamas, Alvaro. Curso: indicadores ambientales. Facultad de agronomía. Universidad de Buenos Aires. URL: http://www.agro.uba.ar/ced/tem_amb.htm. Accedido: 28-7-2006.

Lavalle, C. McCormick, N. Kasanko, M. Demicheli, J. Barredo, J. Turchini, M. Monitoring, planning and forecasting dynamics in European areas - The territorial approach as key to implement European policies. CORP 2001.

Le Page, Christophe. Martin, Manuel. "MagmaS: plate-forme de simulation couplant les niveaux individuel et collectif de gestion des effluents d'élevage". F. Guerrin, J.-M. Paillat (éditeurs scientifiques), 2003. Modélisation des flux de biomasse et des transferts de fertilité - cas de la gestion des effluents d'élevage à l'île de la Réunion. Restitution des travaux de l'Atp 60/99. Actes du séminaire des 19-20 juin 2002, Montpellier, France. Cirad, Colloques, Cédérom.

Lek, S., Guégan, J.F. "Artificial neural networks as a tool in ecological modelling, an introduction”. Ecological Modelling 120, 65-73. 1999. 
Lenz, R. J. M. Beuttler, A. "Experiences with GIS-based planning tool for spatial ecobalances". Environmental Modelling \& Software. Vol. 18. pp 581-585. 2003.

Lemmi, Achille; Betti, Gianni (Eds.). Fuzzy Set Approach to Multidimensional Poverty Measurement. Series: Economic Studies in Inequality, Social Exclusion and Well-Being. Vol. 3. .ISBN: 978-0-387-34249-8. 2006.

Leva, Germán. "Indicadores de calidad de vida urbana. Teoría y metodología”. Universidad Nacional de Quilmes. 2005.

\section{Lim, Ling L. Hughes, Susan J. Hellawell, Emma E. Integrated decision support system for urban air quality assessment. Environmental Modelling \& Software. Vol. 20. pp 947-954. 2005.}

Lindenmayer, D. B. Future directions for biodiversity conservation in managed forests: indicators species, impact studies and monitoring programs. Forest ecology and management 115, 277-287. 1999.

Liu, K. F. R. Evaluating environmental sustainability: an integration of multiple-criteria decision-making and fuzzy logic. Environmental Management 39: 721-736. 2007.

Liu, Y. Phinn, S. R. Modelling urban development with cellular automata incorporating fuzzy-set approaches. Computers, Environment and Urban Systems 27 (2003) 637-658.

Mamdani, E.H. Assilian, S. "An experiment in linguistic synthesis with a fuzzy logic controller", International Journal of Man-Machine Studies, Vol. 7, No. 1, pp. 1-13, 1975.

Martin, Manuel. Piquet, Eric. Guerrin, François. "MagmaS: a multi-agents system based on dynamical models coupling; application to animal wastes management". ESS2001. 2001.

Martínez, Silvio. Requena, Alberto. “Dinámica de sistemas. Vol. 2: Modelos”. Alianza Editorial. 1986.

Mas, J. F. Puig, H. Palacio, J. L. Sosa-López, A. "Modelling deforestation using GIS and artificial neural networks". Environmental Modelling \& Software. Vol 19. pp 461-471. 2004.

Meadows, Donella H. Meadow, Dennis L. Randers, Jørgen. "Más allá de los límites del crecimiento". Ed. El País-Aguilar. 1992.

Mendoza, G. A. Prabhu, R. Multiple criteria decision making approaches to assessing forest sustainability using criteria and indicators: a case study. Forest Ecology and Management 131 (2000) 107-126. 
Moffatt, I. Hanley, N. "Modelling sustainable development: systems dynamic and inputoutput approaches". Environmental Modelling \& Software. Vol. 16. pp 545-557. 2001.

Moldes, F. J. “Tecnología de los sistemas de información geográfica”. Ed. RA-MA. 1995.

Momo, F. R. Capurro, A. F. Ecología matemática. Principios y aplicaciones. Ediciones Cooperativas. ISBN 987-1246-20-X. 2006.

Moriani, Gianni. “Manuale di ecocompatibilità". Marsilio Editori. 2001.

NCGIA. Core curriculum. 3 Volumes. I. Introduction to GIS. II. Technical issues in GIS. III. Application issues in GIS. Santa Barbara, California. National Center for Geographic Information and Analysis/University of California. 1990.

\section{Nussbaum, Martha C. Sen, Amartya.(compiladores). "La calidad de vida". Fondo de cultura económica. México. 1996.}

Odum, E. P. Ecología. 3ra. Edición. Ed. Internamericana. Mexico, D.F.. 1972.

\section{OECD. “Children's environmental health indicators: a survey". 2005.}

OECD. "Core set of indicators for environmental performance reviews. A synthesis report by the Group on the State of the Environment". Environment monographs N 83. 1993.

Orallo, J. H. Quintana, M. J. R. Ramírez, C. F. "Introducción a la minería de datos". Pearson Prentice Hall. 2004. Madrid, España.

Özesmi, Uygar. Özesmi, Stacy. "A participatory approach to ecosystem conservation: Fuzzy cognitive maps and stakeholder group analysis in Uluabat lake, Turkey". Environmental Management. Vol. 31. No4, pp. 518-531. 2003.

Pahl-Wostl, Claudia. "Agent based simulation in integrated assessment and resources management". In Rizzoli, A. E. and Jakeman, A. J., (eds.), Integrated Assessment and Decision Support, Proceedings of the First Biennial Meeting of the International Environmental Modelling and Software Society, Volume 1, pp. 334- 339. iEMSs, 2002.

Papadimitriou, F. "Modelling indicators and indices of landscape complexity: an approach usign G.I.S.”. Ecological Indicators 2 (2002) 17-25.

Papajorgji, Petraq. "A plug and play approach for developing environmental models". Environmental Modelling \& Software 20. pp 1353-1357. 2005.

Parker, P. Letcher, R. Jakeman, A. Beck, M. B. Harris, G. Argent, R. M. Hare, M. PahlWostl, C. Voinov, A. Janssen, M. Sullivar, P. Scoccimarro, M. Friend, A. Sonnenshein, M. Barker, D. Matejicek, L. Odulaja, D. Deadman, P. Lim, K. Larocque, G. Tarikhi, P. Fletcher, C. Put, A. Maxwell, T. Charles, A. Breeze, H. Nakatani, N. Mugdal, S. Naito, W. Osidele, O. Eriksson, I. Kautsky, U. Kautsky, E. Naeslund, B. Kumblad, L. Park, R. 
Maltagliati, S. Girardin, P. Rizzoli, A. Mauriello, D. Hoch, R. Pelletier, D. Reilly, J. Olafsdottir, R. Bin, S. Progress in integrated assessment and modelling. Environmental Modelling \& Software. Vol 17. pp 209-217. 2002.

Phillis, Y. A. Andriantiatsaholiniaina, L. A. Sustainability: an ill-defined concept and its assessment using fuzzy logic. Ecological Economics 37 (2001) 435-456.

Pirozzi, Maria A. Zicarelli, Maria. Environmental modeling on masively parallel computers. Environmental Modelling \& Software. Vol 15. pp 489-496. 2000.

Poch, Manel. Comas, Joaquim. Rodríguez-Roda, Ignasi. Sànchez-Marrè, Miquel. Cortés, Ulises. Designing and building real environmental decision support systems. Environmental Modelling \& Software. Vol 19. pp 857-873. 2004.

Popp, J. Hoag, D. Hyatt, D. E. "Sustainability indices with multiple objectives”. Ecological Indicators 1 (2001) 37-47.

Pijanowski, B.C., Brown, D.G., Shellito, B.A., Manik, G.A. "Using neural networks and GIS to forescast land use changes: a land transformation model". Computers, Environment and Urban Systems 26 (6), 553-575. 2002.

Pirozzi, Maria A. Zicarelli, Maria. Environmental modeling on masively parallel computers. Environmental Modelling \& Software. Vol 15. pp 489-496. 2000.

Pullar, D. "Simumap: a computational system for spatial modelling". Environmental Modelling \& Software 19. pp 235-243. 2004.

Purvis, M. Cranefield, S. Ward, R. Nowostawski, M. Carter, D. Bush, G. "A multiagent system for the integration of distributed environmental information". Environmental Modelling \& Software 18, pp 565-572. 2003.

Quaddus, M. A. Siddique, M. A. B. Modelling sustainable development planning: A multicriteria decision conferencing approach. Environmental International 27 (2001) 89-95.

Rabinovich, Jorge. Curso de postgrado: "La evaluación de impactos ambientales (orientado a la ingeniería)". Facultad de Ciencias Agrarias y Forestales. UNLP. 2005.

Rapaport, A. Terreaux, J. P. Doyen, L. Viability analysis for the sustainable management of renewable resources. Mathematical and Computer Modelling 43, pp 466-484. 2006.

\section{Ravella, Olga. "La planificación urbana regional. Orígenes, presente y futuro". Editorial de la Universidad Nacional de La Plata. 2001.}

Recknagel, Friedrich. Ecological informatics. "Understanding ecology by biologicallyinspired computation”. Springer. 2003. 
Rees, W. "La huella ecológica: Población y riqueza. Indicadores territoriales de sustentabilidad". Ecología Política no 12. 1996.

Robertshaw, J. E. Mecca, S. J. Rerick, M. N. Problem solving: a systems approach. ISBN 0-89433-075-6.

Rosenfeld, E. Discoli, C. San Juan, G. Martini, I. Hoses, S. Barbero, D. Domínguez, M. C. Estudio del comportamiento de malla de redes e infraestructura y servicios de la aglomeración del gran Buenos Aires-La Plata. Evaluación de eficiencia energética y calidad de vida urbana. Revista Avances en Energías Renovables y Medio Ambiente. Vol. 5, pp. 61-66. ISSN 0329-5184. 2001.

Rosenfed, E. Discoli, C. San Juan, G. Martini, I. Hoses, S. Barbero, D. Domínguez, M. C. Modelo de calidad de vida urbana. Determinación de índices y espacialización de áreas homogéneas. Revista Avances en Energías Renovables y Medio Ambiente. Vol. 6, $\mathrm{N}^{\circ}$., pp. 41-46. ISSN 0329-5184. 2002.

\section{Rosenfeld, E. San Juan, G. Discoli, C. Indice de calidad de vida urbana para una gestión territorial sustentable. Avances en energías renovables y medio ambiente. Volumen 4. Nro. 1. pp. 1.35-1.38. ISSN 0329-5184. 2000.}

Rueda, Salvador. Modelos de ordenación del territorio más sostenibles. Barcelona, 2002. URL: geobuzon.fcs.ucr.ac.cr/modelosurbanos.pdf.

Rueda, Salvador. Departament de Medi Ambient de la Generalitat de Catalunya. "Modelos e indicadores para ciudades más sostenibles". 1999. URL: www.forumambiental.org.

Russell, Stuart. Norvig, Peter. “Artificial intelligence: A modern approach”. Prentice-Hall. 2003.

Salles, Paulo. Bredeweg, Bert. Modelling population and community dynamics with qualitative reasoning. $3^{\text {rd }}$ Conference of the International Society for Ecological Informatics. Grottaferrata, Italy. 26-30/8/2002.

Schreider, S. Y. Mostovaia, A. D. "Model sustainability in DSS design and scenario formulatio. What are the right scenarios?". Environment International 27(2001)97-102.

Senge, Peter. "La quinta disciplina”. Editorial Granica. 2004.

Seppelt, Ralf. “Computer-Based environmental management”. WILEY-VCH. 2003.

Seppelt, R. Richter, O. "It was an artefact not the result": A note on systems dynamic model development tools. Environmental Modelling \& Software 20. pp 1543-1548. 2005.

Silvert, W. Ecological impact classification with fuzzy sets. Ecological Modelling 96 (1997) 1-10. 
Silvert, W. "Fuzzy indices of environmental conditions". Ecological Modelling 130 (2000) 111-119.

Star, Jeffrey. Estes, John. "Geographic Information Systems. An introduction". Prentice Hall. 1990.

Stelting, Stephen. Maassen, Olav. "Patrones de diseño aplicados a Java". Pearson-Prentice Hall. 2003.

\section{Sutter II, Glenn W. "Applicability of indicator monitoring to ecological risk assessment”. Ecological Indicators 1(2001). Pp 101-112.}

System Dynamic Group. "Road Maps: A guide to learning dynamic systems”. MIT, 1992. URL: http://sysdyn.mit.edu/road-maps/rm-toc.html.

The MathWorks, Inc. Fuzzy Logic Toolbox 2. User's guide. 2007. URL: www.mathworks.com/access/helpdesk/help/toolbox/fuzzy/fp754.html Acceded: 23-82007.

Troyer, Michael E. A spatial approach for integrating and analyzing indicators of ecological and human condition. Ecological indicators 2, 211-220. 2002.

Tuma, A. "Energy and material management based on a fuzzy-petri net approach". Int. J. Environment and Sustainable Development, 2002, I, (2), 160-170.

United Nations Centre for Human Settlements (UNCHS)- United Nations Environment Programme (UNEP). "Sustainable cities programme (SCP)". Volume I: Preparing the environmental profile. Volume II: Organising, conducting and reporting a city consultation. Volume 3: Establishing and supporting the working group process. Volume 4: Formulating issue-specific strategies and action plans. Volume 5: Institutionalising the EPM process. Volume 6: Urban air quality management handbook. Volume 7: Building environmental management information systems. Volume 8: Integrating gender responsiveness in EPM. Volume 9: Measuring progress in EPM. 1999. Web-site: http://www.unchs.org/scp .

Urciuolo, Adriana. "Sistemas de hidroinformática. Técnicas orientadas a objetos apropiadas para aplicaciones de modelación de simulación hidrológica". Tesis de magister en Ingeniería de Software. Facultad de Informática. UNLP. 2003.

Valentin, A. Spangenberg, J. H. "A guide to community sustainability indicators". Environmental Impact Assessment Review 20 (2000) 381-392. (leí abstract)

Vasseur, P. Cossu-Leguille, C. Biomarkers and community indices as complementary tools for environmental safety. Environment International 28, 711-717. 2003.

Venetoulis, Jason. Talberth, John. "Ecological footprint of nations 2005 update". URL: http://www.ecologicalfootprint.org/pdf/Footprint\%20of\%20Nations\%202005.pdf 
Vera Rebollo, J. F. Ivars Baidal, J. A. "Indicadores de sostenibilidad para destinos maduros. Creando estructuras para la investigación y la educación en política turística y gestión de destinos". Madrid, 2-3 de junio de 2004. Organización Mundial de Turismo.

Vergara, F. Sala Espiell, G. Willis, E. Gulino, E. Dottori, C. Curso de postgrado: Dinámica de sistemas aplicada a PyMEs. Facultad de Ingeniería, UNLP. 2002.

Wackernagel, M. Rees,W. “Our Ecological Footprint”. The New Catalyst, bioregional series. Canada. 1996.

Wang, F. "The use of artificial neural networks in a geographical information systems for agricultural land suitability assessment”. Environment and Planning A 26, 265-284. 1994.

WCED, World Commission on Environmental and Development. "Our common future". Oxford University Press. 1987.

\section{Wenderholm, Elaine. Eclpss: a Java-based framework for parallel ecosystem simulation and modeling. Environmental Modelling \& Software. Vol 20. pp 1081- 1100. 2005.}

Witten, I. H. Frank, E. "Data mining: Practical machine learning tools and techniques with Java implementations”. Morgan Kaufmann Publishers, 2000.

Wolfram Research. Mathematica Fuzzy Logic. The most flexible environment for exploring fuzzy systems. URL: http://media.wolfram.com/documents/FuzzyLogicDocumentation.pdf . 2007.

Wooldridge, Michael. “An Introduction to Multiagent Systems”. John Wiley \& Sons. 2002.

Yao, Xiaobai. "Research issues in spatio-temporal data mining". University consortium for geographic information science (UCGIS), Workshop on geospatial visualization and knowledge discovery. Lansdowne, Virginia, Nov. 18-20. 2003.

Yeh, Anthony Gar-On. Li, Xia. "Uncertainties in urban simulation using cellular automata and GIS". Proceedings of the 7th International Conference on GeoComputation, University of Southampton, United Kingdom, 8 - 10 September 2003.

Yu, Chang-Ching. Quinn, John T. Dufournaud, Christian M. Harrington, Joseph J. Rogers, Peter P. Lohani, Bindu N. Effective dimensionality of environmental indicators: a principal component analysis with bootstrap confidence intervals. Journal of environmental management 53, 101-109, 1998.

Yu, Po-Lung. Multiple-Criteria Decision Making. Concepts, techniques, and extensions. Plenum Press, New York, 1985. 
Yuan, May. McIntosh, John. "GIS representation for visualizing and mining geographic dynamics". University Consortium for Geographic Information Science (UCGIS) Workshop on Geospatial Visualization and Knowledge Discovery (Lansdowne, VA) November, 2003.

Zadeh, L. A. "Fuzzy sets”. Information and Control, Vol. 8. pp 338-353.1965.

Zimmerman, Kiana Marie. "A spatial model for Markov chain analysis of grasshopper population dynamics in Wyoming". Master thesis in Computer Science. University of Wyoming. 1999. 